Florida International University

FIU Digital Commons

$3-5-2020$

\title{
Advanced Oxidation Processes for the Remediation of Problematic Organophosphorus Compounds and Perfluoroalkyl Substances
}

\author{
A M Abdullah \\ Department of Chemistry and Biochemistry, Florida International University, aabdu040@fiu.edu
}

Follow this and additional works at: https://digitalcommons.fiu.edu/etd

Part of the Analytical Chemistry Commons, and the Environmental Chemistry Commons

\section{Recommended Citation}

Abdullah, A M, "Advanced Oxidation Processes for the Remediation of Problematic Organophosphorus Compounds and Perfluoroalkyl Substances" (2020). FIU Electronic Theses and Dissertations. 4442.

https://digitalcommons.fiu.edu/etd/4442

This work is brought to you for free and open access by the University Graduate School at FIU Digital Commons. It has been accepted for inclusion in FIU Electronic Theses and Dissertations by an authorized administrator of FIU Digital Commons. For more information, please contact dcc@fiu.edu. 


\section{FLORIDA INTERNATIONAL UNIVERSITY}

Miami, Florida

\section{ADVANCED OXIDATION PROCESSES FOR THE REMEDIATION OF PROBLEMATIC ORGANOPHOSPHORUS COMPOUNDS AND PERFLUOROALKYL SUBSTANCES}

A dissertation submitted in partial fulfillment of the requirements for the degree of DOCTOR OF PHILOSOPHY

in CHEMISTRY by

A. M. Abdullah 
To: Dean Michael R. Heithaus

College of Arts, Sciences, and Education

This dissertation, written by A. M. Abdullah, and entitled Advanced Oxidation Processes for the Remediation of Problematic Organophosphorus Compounds and Perfluoroalkyl Substances having been approved in respect to style and intellectual content, is referred to you for judgment.

We have read this dissertation and recommend that it be approved.

$\begin{array}{r}\hline \text { Jeffrey Joens } \\ \hline \text { Krishnaswamy Jayachandran } \\ \hline \text { Stanislaw Wnuk } \\ \hline \text { Kevin O'Shea, Major Professor }\end{array}$

Date of Defense: March 05, 2020

The dissertation of A. M. Abdullah here is approved.

Dean Michael R. Heithaus

College of Arts, Sciences, and Education

Andrés G. Gil

Vice President for Research and Economic Development and Dean of the University Graduate School

Florida International University, 2020 
(C) Copyright 2020 by A. M. Abdullah

All rights reserved. 


\title{
DEDICATION
}

\author{
I dedicate this dissertation to
}

my parents, Md. Maiz Uddin \& Mst. Afroza Akter,

and

my wife, Fahmida Akter Ruma

for their love, support, and encouragement throughout my Ph.D. journey. 


\section{ACKNOWLEDGMENTS}

My sincere gratitude and many thanks go to my mentor, Professor Dr. Kevin O'Shea, for his guidance, support, and especially patience \& the examples he set for me throughout my Ph.D. program. I am appreciative of the opportunity to work with him, and I will always admire him for his mentorship. May God bless him!

I would like to extend my sincere thanks to my committee members, Dr. Stanislaw Wnuk, Dr. Raphael Raptis, Dr. Jeffrey Joens, and Dr. Krishnaswamy Jayachandran for their invaluable time, feedback and suggestions from different organic, inorganic, physical, and environmental chemistry perspectives that help me to improve the quality of my research work and dissertation. Acknowledgments are extended to my collaborators Dr. Piero Gardinali, and Dr. Natalia Quinete of FIU, for their generous help, training, and guidance with the LC-MS analysis. I am also thankful to Dr. Miguel Pinilla of Universidad Autónoma de Nuevo León, Mexico, and Dr. Suresh Pillai of the Institute of Technology, Ireland, for their collaboration on the modified titanium dioxide project. My special thanks to Dr. Dani Cui for her cooperation on the PFAS projects.

I also want to thank all the previous and current group members in Dr. O'Shea's research group for being helpful and friendly. Special thanks to Mr. Ya Li Hsu for his help with the GC-NPD, IC, and NMR analyses.

Finally, I would like to acknowledge the Department of Chemistry and University Graduate School of FIU for supporting me financially, including the Dissertation Year Fellowship (DYF), and the Bangladesh Council of Scientific and Industrial Research (BCSIR) for helping me to pursue my Ph.D. studies. 


\author{
ABSTRACT OF THE DISSERTATION \\ ADVANCED OXIDATION PROCESSES FOR THE REMEDIATION OF \\ PROBLEMATIC ORGANOPHOSPHORUS COMPOUNDS AND \\ PERFLUOROALKYL SUBSTANCES \\ by
}

A. M. Abdullah

Florida International University, 2020

Miami, Florida

Professor Kevin O’Shea, Major Professor

The presence of persistent organic pollutants, including organophosphorus esters (OPEs) and perfluoroalkyl substances (PFASs) in drinking water sources, is a serious threat to the environment and human health. Advanced oxidation processes (AOPs), specifically $\mathrm{TiO}_{2}$ photocatalysis and sonolysis, were evaluated to degrade these pollutants in water.

The $\mathrm{UV} / \mathrm{TiO}_{2}$ photocatalysis can effectively degrade tris (2-chloroethyl) phosphate (TCEP) to innocuous materials. The degradation follows pseudo-first-order kinetics and consistent with the Langmuir-Hinshelwood model. Intermediate products identified by ${ }^{31} \mathrm{P}-$ NMR show sequential oxidation of alkyl chains, ultimately leading to phosphate. Scavenger studies indicate hydroxyl radical $(\bullet \mathrm{OH})$ is the primary species responsible for the degradation.

One of the primary drawbacks of $\mathrm{TiO}_{2}$ photocatalysis is the costly $\mathrm{UV}$ required for $\mathrm{TiO}_{2}$ activation. We, therefore, synthesized doped $\mathrm{NFP}-\mathrm{TiO}_{2}$ photocatalysts and demonstrated visible light activation yields $\bullet \mathrm{OH}$, keys for the photocatalysis of organic 
toxins. Prepared $\mathrm{TiO}_{2}$ was characterized by $\mathrm{X}$-ray and spectroscopic techniques, and $\bullet \mathrm{OH}$ generation was quantitated using coumarin trap under UV and visible light.

Ultrasonic irradiation, an AOP, does not require any catalysts to treat organic pollutants in water. We demonstrated the ultrasonic degradation of TCEP at $640 \mathrm{kHz}$. Hydroxyl radical scavengers added into the reaction solution before treatment indicate the degradation of TCEP proceeds through both pyrolysis and hydroxyl-mediated oxidation. Ultrasonic treatment of TCEP leads to three primary products, including the diester and monoester of TCEP confirmed by UHPLC-Orbitrap-MS studies.

Naled, a highly toxic organophosphate pesticide, was sprayed extensively aerially to exterminate mosquitos harboring the Zika virus. Little is known about the fate and degradation of Naled. Our results demonstrated that Naled can persist in the environment significantly upon condition. Ultrasonic irradiation at $640 \mathrm{kHz}$ dramatically enhances the degradation of Naled, leading to the byproducts, including dimethylphosphate identified by FT-ICR-MS.

Effective degradation of a variety of emerging PFAS has been demonstrated by ultrasonic irradiation. A detailed kinetic investigation on the problematic PFAS GenX revealed that the degradation proceeds primarily by pyrolysis, and hydroxyl radicalmediated degradation is insignificant. UHPLC-Orbitrap-MS was used to identify the PFAS primary intermediates. We proposed that PFAS partition to the gas-liquid interfacial region and undergo extensive pyrolysis, leading to the conversion of fluorides. 


\section{TABLE OF CONTENTS}

CHAPTER

PAGE

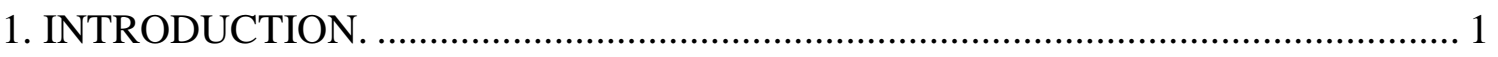

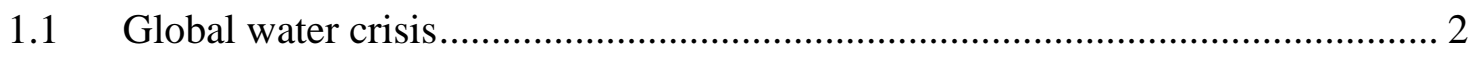

1.2 Water contamination by organophosphorus compounds ................................. 3

1.3 Water contamination by perfluoroalkyl substances (PFASs) ........................... 5

1.4 Advanced oxidation processes (AOPs) ................................................... 7

1.5 Objectives of the dissertation .................................................................. 15

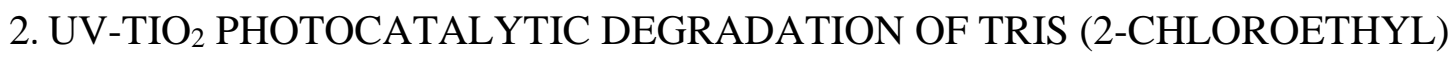

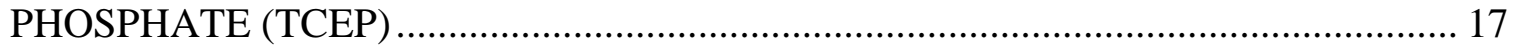

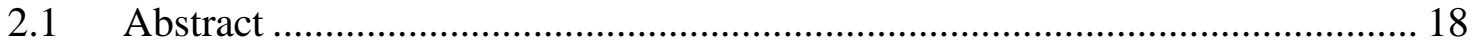

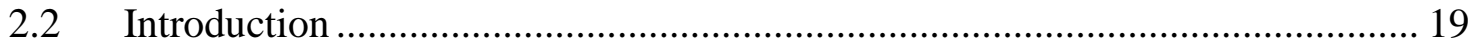

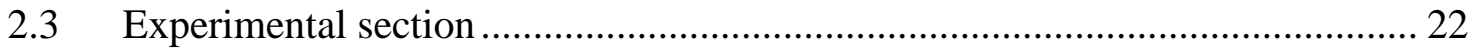

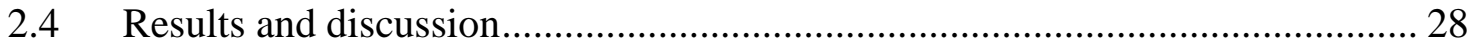

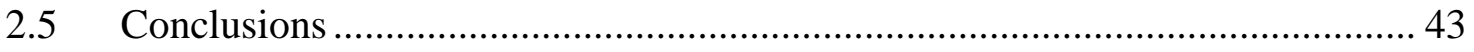

3. DEVELOPMENT OF VISIBLE LIGHT-ACTIVATED TITANIUM DIOXIDE

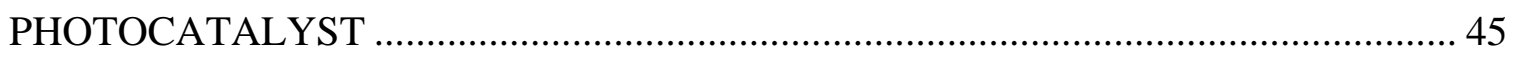

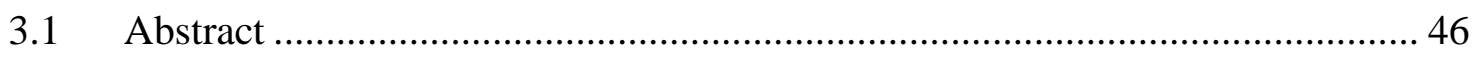

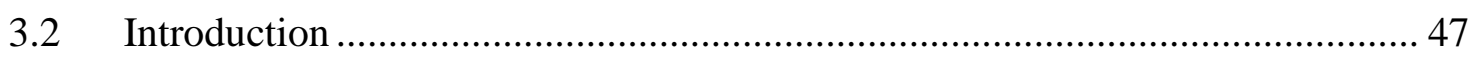

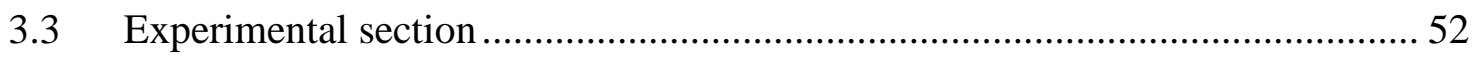

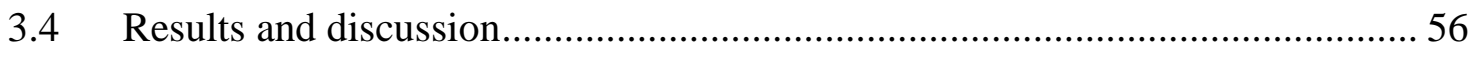

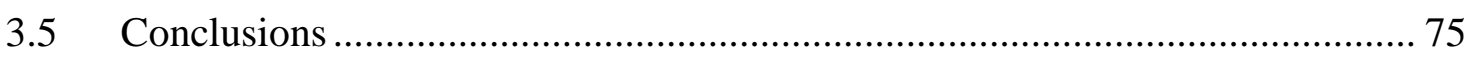

4. KINETICS AND MECHANISTIC INVESTIGATION OF ULTRASONIC INDUCED DEGRADATION OF TRIS (2-CHLOROETHYL) PHOSPHATE

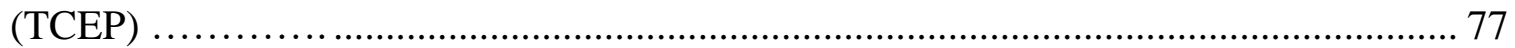

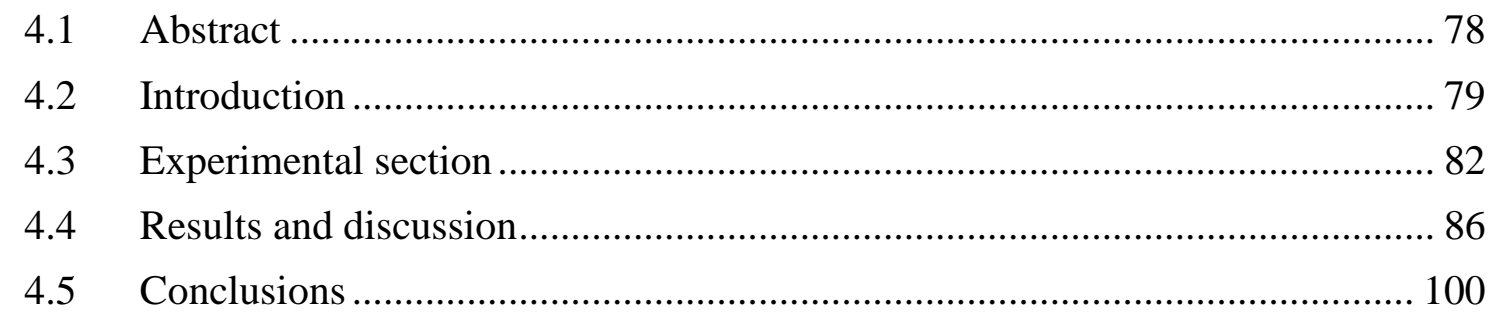




\section{HYDROLYSIS AND ULTRASONIC INDUCED DEGRADATION OF THE}

NALED: KINETICS, PRODUCTS AND MECHANISTIC INVESTIGATION

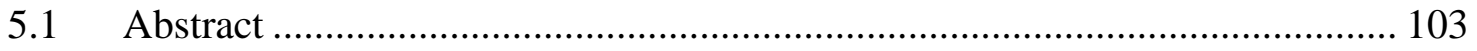

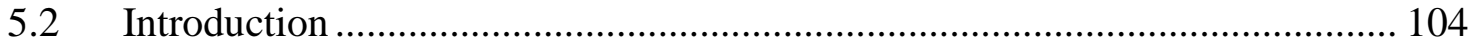

5.3 Hydrolysis of Naled: Products studies and mechanistic investigation............. 108

5.3.1 Experimental section....................................................................... 108

5.3.2 Results and discussion ................................................................... 110

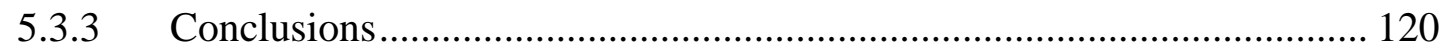

5.4 Ultrasonic induced degradation of Naled: Kinetics and mechanistic

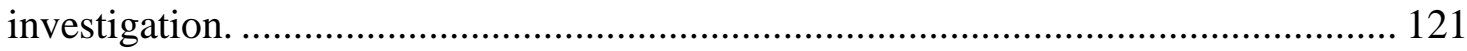

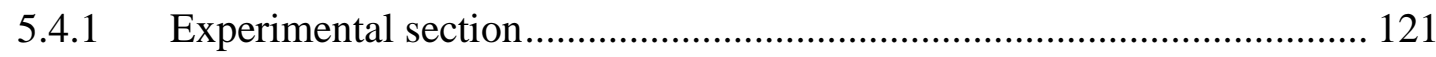

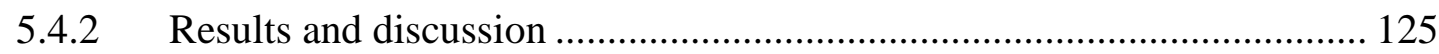

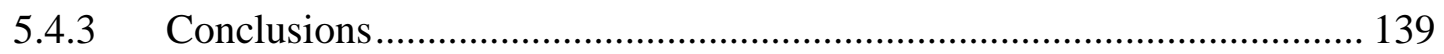

6. ULTRASONIC REMEDIATION OF EMERGING PERFLUOROALKYL

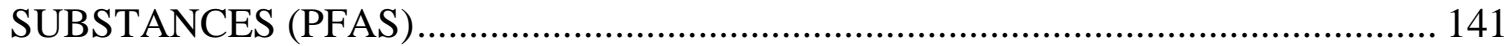

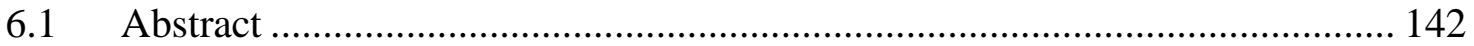

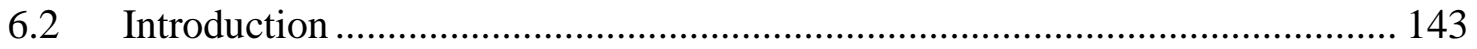

6.3 Experimental section ....................................................................... 148

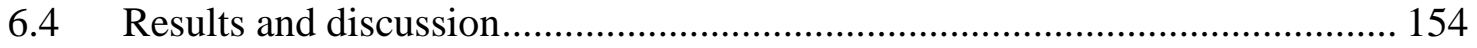

6.5 Conclusions ........................................................................................ 175

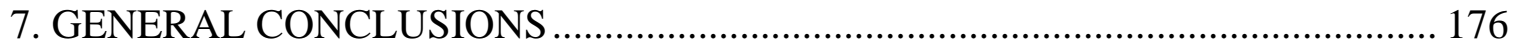

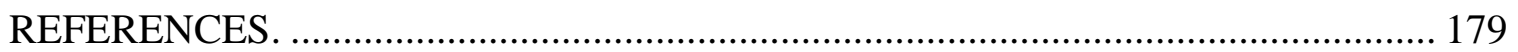

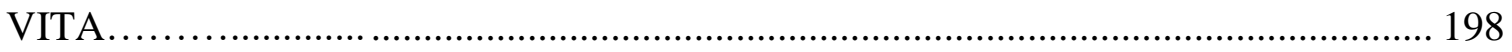




\section{LIST OF TABLES}

TABLE

PAGE

1. General structural comparison of different organophosphorus compounds 4

2. List of a number of selected legacy and emerging PFASs with chemical structures ..... 6

3. Initial degradation rates and their corresponding pseudo-first-order rate constant of TCEP as a function of concentration by $\mathrm{TiO}_{2}$ photocatalytic oxidation in $\mathrm{O}_{2}$-saturated aqueous solution

4. The prepared $\mathrm{TiO}_{2}$ materials as a function of reduction time with $\mathrm{NaBH}_{4}$ along with their thicknesses of the amorphous layer.

5. Band gap of $\mathrm{NaBH}_{4}$ treated $\mathrm{P} 25 \mathrm{TiO}_{2}, \mathrm{NF}-\mathrm{TiO}_{2}$, and $\mathrm{NFP}-\mathrm{TiO}_{2}$ series and their corresponding photo-excited absorption wavelength

6. Raman band position of synthesized materials

7. Calculated $\mathrm{OH}-\mathrm{index}$ of prepared $\mathrm{TiO}_{2}$ materials

8. Kinetic parameters for the ultrasonic oxidation of TCEP at $640 \mathrm{kHz}$ in $\mathrm{O}_{2}$-saturated aqueous solution......

9. Likely degradation pathways of ultrasonic treatment of TCEP in the presence of different hydroxyl radical scavengers

10. By-products/intermediates generated during the ultrasonic treatment of TCEP with their exact mass and mass/charge $(\mathrm{m} / \mathrm{z})$ ratio in positive ionization mode

11. Summary table of NMR data for the products generated during the hydrolysis of Naled

12. Kinetic parameters for the ultrasonic degradation of Naled at $640 \mathrm{kHz}$ in

$\mathrm{O}_{2}$-saturated aqueous solution.

13. Likely degradation pathways of ultrasonic treatment of Naled in the presence of different hydroxyl radical scavengers

14. Identified by-products/intermediates generated during the ultrasonic treatment of Naled with their exact mass and mass/charge $(\mathrm{m} / \mathrm{z})$ ratio in negative ionization mode..137

15. Name and structure of a number of select perfluoroalkyl substances (PFASs)....... 144

16. Initial degradation rates of GenX as a function of GenX concentration in argonsaturated solution 
17. Pseudo-first-order rate constant $(\mathrm{k})$ of the sonolytic degradation of GenX in the

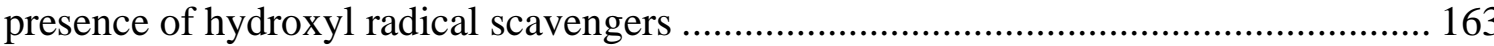

18. Defluorination of select PFASs upon ultrasonic treatment.................................... 166 


\section{LIST OF FIGURES}

FIGURE

PAGE

1. Mechanisms for the production of reactive oxygen species and the subsequent oxidations of organic contaminants by $\mathrm{TiO}_{2}$ photocatalysis...................................... 10

2. Graphical representation of the acoustic cavitation process. ..................................... 13

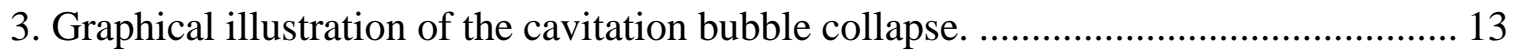

4. GC-NPD calibration curve for the determination of TCEP concentration using

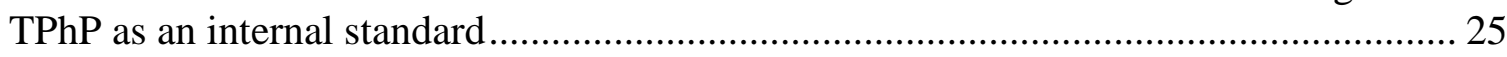

5. Ion chromatographic calibration curve for the determination of the concentration of

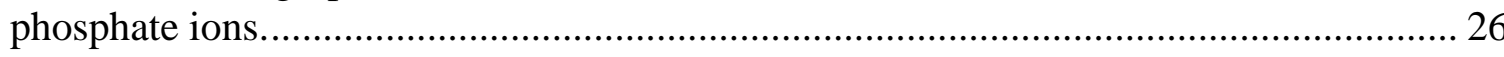

6. Ion chromatographic calibration curve for the determination of chloride ions. ........... 27

7. $\mathrm{TiO}_{2}$ photocatalysis of TCEP at $350 \mathrm{~nm}$ in $\mathrm{O}_{2}$-saturated suspension. ........................ 28

8. Degradation kinetics of TCEP $\left([\mathrm{TCEP}]_{0}=18-270 \mu \mathrm{M}\right)$ upon irradiation at $350 \mathrm{~nm}$ at $\mathrm{O}_{2}$-saturated $\mathrm{TiO}_{2}(0.10 \mathrm{~g} / \mathrm{L})$ aqueous suspension................................................ 29

9. Pseudo-first-order kinetics plots of TCEP degradation upon irradiation at $350 \mathrm{~nm}$

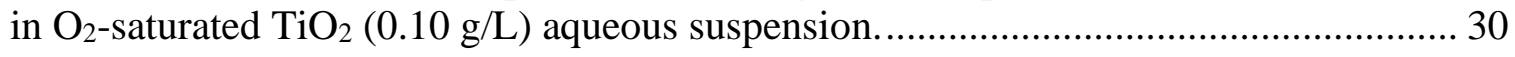

10. Langmuir-Hinshelwood plot of the degradation of TCEP $\left([\text { TCEP }]_{0}=18-270 \mu \mathrm{M}\right)$ upon irradiation at $350 \mathrm{~nm}$ at $\mathrm{O}_{2}$-saturated $\mathrm{TiO}_{2}(0.10 \mathrm{~g} / \mathrm{L})$ aqueous suspension. ........... 32

11. Evolution of $\mathrm{PO}_{4}{ }^{3-}$ and $\mathrm{Cl}^{-}$ion upon irradiation at $350 \mathrm{~nm}$ in $\mathrm{O}_{2}$-saturated $\mathrm{TiO}_{2}$

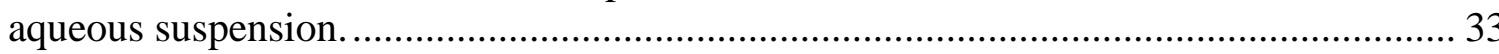

12. Reduction of total organic carbon (TOC) as a function of irradiation time of $\mathrm{TiO}_{2}$

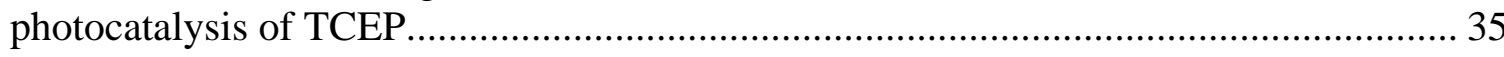

13. $\mathrm{TiO}_{2}$ photocatalytic degradation of TCEP in $\mathrm{O}_{2}$-saturated aqueous suspension at

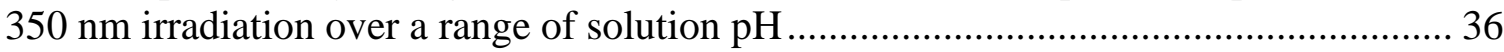

14. Effect of coumarin on the $\mathrm{TiO}_{2}$ photocatalytic degradation of TCEP at $350 \mathrm{~nm}$ in

$\mathrm{O}_{2}$-saturated suspension.

15. ${ }^{31} \mathrm{P}-\mathrm{NMR}$ spectra of $\mathrm{TiO}_{2}$ photocatalytic reaction mixture of TCEP $\left([\mathrm{TCEP}]_{0}=\right.$ $15.06 \mathrm{mM})$. 40

16. Phosphorus-containing product distribution during $\mathrm{TiO}_{2}$ photocatalysis of TCEP $\left([\mathrm{TCEP}]_{0}=15.06 \mathrm{mM}\right)$ in the $\mathrm{D}_{2} \mathrm{O}$ solution monitored by ${ }^{31} \mathrm{P}-\mathrm{NMR}$. 
17. Proposed mechanism for the hydroxyl radical-mediated photocatalytic degradation of TCEP.

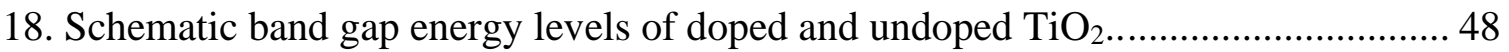

19. The reaction of $\mathrm{COU}$ and $\bullet \mathrm{OH}$ for the production of highly florescent $7 \mathrm{HC} \ldots \ldots \ldots . . . . .51$

20. Spectrofluorometer calibration curve for the measuring of 7HC. .............................. 56

21. Color photographs of reduced $\mathrm{TiO}_{2}$ synthesized by thermal treatment with $\mathrm{NaBH}_{4} .57$

22. Comparison of XRD patterns among $\mathrm{P} 25 \mathrm{TiO}_{2}$ and reduced forms of $\mathrm{P} 25 \mathrm{TiO}_{2}$

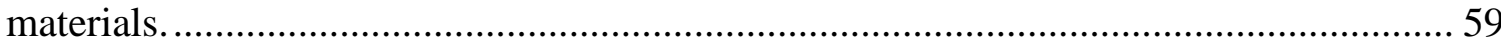

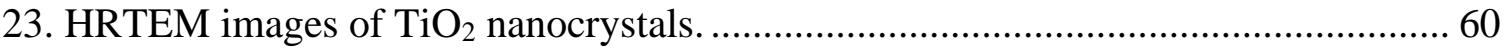

24. HRTEM images of $\mathrm{N}$, and $\mathrm{F}$ co-doped $\mathrm{TiO}_{2}$ nanocrystals. ............................................ 61

25. HRTEM images of N, F, and $\mathrm{P}$ co-doped $\mathrm{TiO}_{2}$ nanocrystals..................................... 62

26. EDXRF spectrum of $\mathrm{N}$, and $\mathrm{F}$ co-doped $\mathrm{TiO}_{2}\left(\mathrm{NF}-\mathrm{TiO}_{2}\right)$......................................... 63

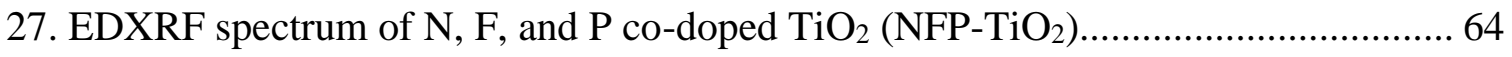

28. UV-Visible diffuse reflectance spectra of synthesized $\mathrm{TiO}_{2}$ materials...................... 65

29. Raman spectrum of $\mathrm{P} 25 \mathrm{TiO}_{2}$ series showing a shift toward the visible region as a

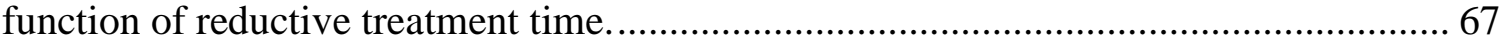

30. Change of fluorescence intensity observed at $455 \mathrm{~nm}$ during the irradiation of P25 $\mathrm{TiO}_{2}$ suspended in a $125 \mu \mathrm{M} \mathrm{COU}$ aqueous solution.

31. Production of $7 \mathrm{HC}$ by reduced $\mathrm{P} 25 \mathrm{TiO}_{2}$ photocatalysts under $350 \mathrm{~nm}$ irradiation... 70

32. Production of $7 \mathrm{HC}$ by $\mathrm{NFP}^{-\mathrm{TiO}_{2}}$ photocatalyst under $350 \mathrm{~nm}$ irradiation. ............... 70

33. Production of $7 \mathrm{HC}$ by $\mathrm{P} 25 \mathrm{TiO}_{2}$ and the $\mathrm{NFP}-\mathrm{TiO}_{2}$ series upon irradiation with

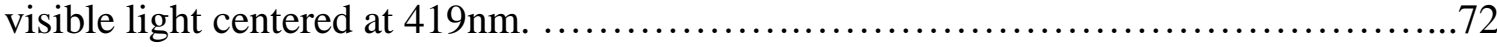

34. Production of $7 \mathrm{HC}$ by $\mathrm{P} 25 \mathrm{TiO}_{2}$ and $\mathrm{NF}-\mathrm{TiO}_{2}$ series upon irradiation at visible light at $450 \mathrm{~nm}$

35. Relative comparison of $\mathrm{OH}-\mathrm{index}$ of various $\mathrm{TiO}_{2}$ based photocatalysts at visible

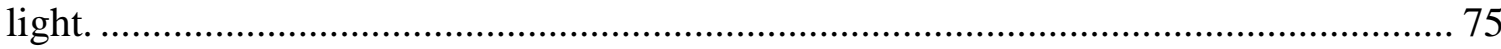

36. GC-NPD calibration curve for the determination of TCEP concentration in aqueous solution. 
37. Ion chromatographic calibration curve for chloride and phosphate ions. 85

38. Ultrasonic induced degradation of TCEP at $640 \mathrm{kHz}$ in $\mathrm{O}_{2}$-saturated aqueous solution. 87

39. Degradation of TCEP as a function of treatment time over the initial concentrations of 3.1-84 $\mu \mathrm{M}$ at $640 \mathrm{kHz}$ in the $\mathrm{O}_{2}$-saturated aqueous solution. 88

40. Pseudo-first-order kinetics plots of TCEP over a range of initial concentration $3.1-84 \mu \mathrm{M}$ upon ultrasonic treatment at $640 \mathrm{kHz}$ in $\mathrm{O}_{2}$-saturated aqueous solution..... 89

41. Partitioning of TCEP molecules in the hot spot, gas-liquid interface, and bulk liquid phase.

42. Langmuir-Hinshelwood kinetic plots for the ultrasonic degradation of TCEP at $640 \mathrm{kHz}$ in $\mathrm{O}_{2}$ saturated aqueous solution of TCEP $\left([\mathrm{TCEP}]_{0}=3.1 \mu \mathrm{M}-84 \mu \mathrm{M}\right)$.

43. Effect of hydroxyl radical scavengers on the sonochemical degradation of TCEP at $640 \mathrm{kHz}$ in oxygenated aqueous solution.

44. Evolution of $\mathrm{PO}_{4}{ }^{3-}$ and $\mathrm{Cl}^{-}$ion upon ultrasonic treatment at $640 \mathrm{kHz}$ in $\mathrm{O}_{2}$-saturated aqueous solution of TCEP $\left([\mathrm{TCEP}]_{0}=93.5 \mu \mathrm{M}\right)$. 96

45. Relative abundance of intermediate products during ultrasonic treatment of TCEP $\left([\mathrm{TCEP}]_{0}=7.0 \mu \mathrm{M}\right)$ in oxygenated aqueous solution.

46. Proposed hydroxyl radical-mediated degradation of TCEP via $\beta-\mathrm{H}$ abstraction mechanism. 99

47. Proposed hydroxyl radical-mediated degradation of TCEP via $\alpha-\mathrm{H}$ abstraction mechanism.

48. ${ }^{31} \mathrm{P}\{\mathrm{H}\}$-NMR spectra during the degradation reaction mixture of Naled in $\mathrm{H}_{2} \mathrm{O} / \mathrm{D}_{2} \mathrm{O}$ solution with starting $\mathrm{pH} 6.4$ and concentration of Naled $3.2 \mu \mathrm{M}$.

49. ${ }^{31} \mathrm{P}-\mathrm{NMR}$ and $31 \mathrm{P}\{\mathrm{H}\}-\mathrm{NMR}$ spectra of the Naled hydrolysis in $\mathrm{H}_{2} \mathrm{O} / \mathrm{D}_{2} \mathrm{O}$ solution after 170 hours.

50. Water suppressed ${ }^{1} \mathrm{H}$ NMR spectrum of Naled hydrolysis in $\mathrm{H}_{2} \mathrm{O} / \mathrm{D}_{2} \mathrm{O}$ solution. ... 112

51. Reaction profile of starting material and products for the hydrolysis of Naled in $\mathrm{H}_{2} \mathrm{O} / \mathrm{D}_{2} \mathrm{O}$ solution at ambient temperature.

52. Pseudo-first-order kinetic plot of the hydrolysis of Naled in $\mathrm{H}_{2} \mathrm{O} / \mathrm{D}_{2} \mathrm{O}$ solution at ambient temperature 
53. Hydrolysis of Naled as a function of temperature in non-buffered $\mathrm{H}_{2} \mathrm{O} / \mathrm{D}_{2} \mathrm{O}$ solution.

54. Arrhenius plot of the hydrolysis of Naled over a range of the temperature 40 $80{ }^{\circ} \mathrm{C}$ at $\mathrm{D}_{2} \mathrm{O} / \mathrm{H}_{2} \mathrm{O}$ solution.

55. Effect of initial solution $\mathrm{pH}$ on the hydrolysis of Naled in buffered $\mathrm{H}_{2} \mathrm{O} / \mathrm{D}_{2} \mathrm{O}$ aqueous solution

56. Effect of initial solution $\mathrm{pH}$ on the half-lives of Naled in buffered $\mathrm{H}_{2} \mathrm{O} / \mathrm{D}_{2} \mathrm{O}$ solution.

57. Hydrolysis of trimethyl phosphate.

58. Debromination of Naled by nucleophilic debromination mechanism. 118

59. Proposed nucleophilic addition-elimination reaction during the hydrolysis of Naled.

60. Nucleophilic substitution at ethyl carbon center of Naled leading to dimethyl phosphate.

61. Proposed secondary nucleophilic addition/elimination pathways at the $\mathrm{P}$ atom of the Naled diester product.

62. Schematic diagram of the experimental ultrasound setup.

63. GC-NPD calibration curve for the determination of Naled using TCEP as an internal standard..

64. Ion chromatographic calibration curve for the determination of bromide, chloride, dimethyl phosphate, and phosphate ions in aqueous solution.

65. Ultrasonic induced degradation of Naled at $640 \mathrm{kHz}$ in $\mathrm{O}_{2}$-saturated aqueous solution.

66. Degradation of Naled as a function of treatment time over the initial concentration of $39-309 \mu \mathrm{M}$ at $640 \mathrm{kHz}$ in the $\mathrm{O}_{2}$-saturated aqueous solution.

67. Pseudo-first-order kinetic plots of Naled over a range of initial concentration of $39-309 \mu \mathrm{M}$ upon ultrasonic treatment at $640 \mathrm{kHz}$ in $\mathrm{O}_{2}$-saturated aqueous solution... 128

68. Partitioning of Naled molecules in the hot spot, gas-liquid interface, and bulk liquid phase.

69. Langmuir-Hinshelwood kinetic plots of the ultrasound-assisted degradation of Naled at $640 \mathrm{kHz}$ over a range of the initial concentration of $39 \mu \mathrm{M}-309 \mu \mathrm{M}$. 
70. Effect of hydroxyl radical scavengers on the sonochemical degradation of Naled at $640 \mathrm{kHz}$ in oxygenated aqueous solution.

71. Ion chromatogram of the ultrasonic treated solution of Naled at $240 \mathrm{~min}$.

72. Evolution of $\mathrm{Br}^{-}, \mathrm{Cl}^{-}, \mathrm{DMP}$, Formate, and $\mathrm{PO}_{4}{ }^{3-}$ as a function of treatment time during the ultrasonic irradiation of Naled at $640 \mathrm{kHz}$ in oxygenated aqueous solution..135

73. Proposed hydroxyl radical-mediated degradation via hydrogen abstraction mechanism.

74. LC-MS calibration curve for the determination of GenX in aqueous solution 150

75. LC-MS calibration curve for the determination of PFBA concentration in aqueous solution.

76. LC-MS calibration curve for the quantification of PFPA concentration in aqueous solution

77. LC-MS Calibration curve for the quantification of PFHpA in aqueous solution..... 152

78. Potentiometric calibration curve for the determination fluoride ion PFAS aqueous solutions treated with ultrasonic irradiation.

79. Ion chromatographic calibration curve for the determination of fluoride ions in ultrasonically treated PFAS solutions.

80. Ultrasonic treatment of emerging PFASs at $640 \mathrm{kHz}$ in argon saturated aqueous solution.

81. Degradation kinetics of GenX $\left([\mathrm{GenX}]_{0}=3-60 \mu \mathrm{M}\right)$ upon ultrasonic irradiation at $640 \mathrm{kHz}$ in Ar-saturated aqueous solution.

82. Pseudo-first-order kinetics plots of ultrasonic degradation of GenX over a range of initial concentration of 3-60 $\mu \mathrm{M}$ at $640 \mathrm{kHz}$ in Ar-saturated aqueous solution. 158

83. Partitioning of GenX molecules in the hot spot, gas-liquid interface, and bulk liquid phase.

84. Langmuir-Hinshelwood kinetic plot of the ultrasound-assisted degradation of GenX over a range of initial concentration.

85. Evolution of fluoride ions upon ultrasonic treatment of a variety of emerging PFASs $\left([\mathrm{PFAS}]_{0}=2000 \mathrm{ppb}\right)$ at $640 \mathrm{kHz}$ in Ar-saturated aqueous solution.

86. Ultrasonic degradation of GenX $\left([\mathrm{GenX}]_{0}=6.1 \mu \mathrm{M}\right)$ and evolution of fluoride at $640 \mathrm{kHz}$ in Ar-saturated aqueous solution. 166 
87. Evolution of fluoride ions in sonolytic degradation of GenX in the presence of

-OH scavengers.

88. Ion chromatographic analysis of small molecular ions during the ultrasonic treatment of $\mathrm{GenX}\left([\mathrm{GenX}]_{0}=60.6 \mu \mathrm{M}\right)$ at $640 \mathrm{kHz}$ in Ar-saturated aqueous solution.169

89. UHPLC-Orbitrap-HRMS chromatogram of the identified ultrasonic degradation products of GenX $\left([\mathrm{GenX}]_{0}=60.6 \mu \mathrm{M}\right)$ over treatment time.

90. Time profile relative abundance of intermediate products during ultrasonic treatment of GenX $\left([\mathrm{GenX}]_{0}=60.6 \mu \mathrm{M}\right)$ at $640 \mathrm{kHz}$ in Ar-saturated aqueous solution.171

91. Molecular structure of GenX 172

92. Reductive defluorination mechanism of GenX. 173

93. A secondary transformation via oxidative defluorination of GenX products

94. $\beta$-pyrolysis mechanism of GenX.

95. Hydrolysis of acetyl chloride to the formation of fluoride ions 174 


\section{LIST OF ABBREVIATIONS AND SYMBOLS}

\begin{tabular}{|c|c|}
\hline AOP & - Advanced oxidation process \\
\hline $\mathrm{COU}$ & - Coumarin \\
\hline DCM & - Dichloromethane \\
\hline DDEMP & -1,2-dibromo-2,2-dichloroethyl methyl phosphate \\
\hline DEMP & - Diethyl methylphosphonate \\
\hline DMMP & - Dimethyl methylphosphonate \\
\hline DMP & - Dimethyl phosphate \\
\hline EDXRF & - Energy dispersive X-ray fluorescence \\
\hline EPA & - Environmental Protection Agency \\
\hline FT-ICR-MS & - Fourier transform ion cyclotron mass spectrometry \\
\hline GAC & - Granular activated carbon \\
\hline $\mathrm{GC}$ & - Gas chromatography \\
\hline GenX & - Perfluoro 2-methyl-3-oxahexanoic acid \\
\hline $\mathrm{H}_{2} \mathrm{O}_{2}$ & - Hydrogen peroxide \\
\hline $\mathrm{HO} \bullet$ & - Hydroxyl radical \\
\hline HRTEM & - High-resolution transmission electron microscope \\
\hline IC & - Ion chromatography \\
\hline $\mathrm{k}$ & - Rate constant \\
\hline $\mathrm{K}_{\mathrm{LH}}$ & - Apparent equilibrium constant \\
\hline $\mathrm{k}_{\mathrm{rxn}-\mathrm{LH}}$ & - Reactivity constant \\
\hline MMP & - Monomethyl phosphate \\
\hline
\end{tabular}




\begin{tabular}{|c|c|}
\hline MPA & - Methyl phosphonic acid \\
\hline MS & - Mass spectrometry \\
\hline MTBE & - Methyl tert-butyl ether \\
\hline $\mathrm{NaBH}_{4}$ & - Sodium borohydride \\
\hline Naled & - 1,2-dibromo-2,2-dichloro dimethyl phosphate \\
\hline $\mathrm{NFP}_{-\mathrm{TiO}}$ & - Nitrogen, fluorine, and phosphorus co-doped titanium dioxide \\
\hline $\mathrm{NF}-\mathrm{TiO}_{2}$ & - Nitrogen and fluorine co-doped titanium dioxide \\
\hline NPD & - Nitrogen phosphorus detector \\
\hline $\mathrm{O}_{2}^{\cdot-}$ & - Superoxide anions \\
\hline $\mathrm{O}_{3}$ & - Ozone \\
\hline OPE & - Organophosphate ester \\
\hline $\mathrm{P}_{2} \mathrm{O}_{5}$ & - Phosphorus pentoxide \\
\hline PFAS & - Poly- and perfluoroalkyl substance \\
\hline PFBA & - Perfluorobutanoic acid \\
\hline PFCA & - Perfluoro carboxylic acid \\
\hline PFDCA & - Polyfluorodicarboxylic acid \\
\hline PFECA & - Perfluoroether carboxylic acid \\
\hline PFHpA & - Perfluoroheptanoic acid \\
\hline PFMeoBA & - Perfluoro-5-oxahexanoic acid \\
\hline PFOA & - Perfluorooctanoic acid \\
\hline PFOS & - Perfluorooctanesulfonic acid \\
\hline PFPA & - Perfluoropentanoic acid \\
\hline
\end{tabular}




$\begin{array}{ll}\text { ROS } & - \text { Reactive oxygen species } \\ \text { TBA } & - \text { t-Butanol } \\ \text { TCEP } & - \text { Tris (2-chloroethyl) phosphate } \\ \text { TCPP } & - \text { Tris (1-chloro-2-propyl) phosphate } \\ \text { TDCPP } & - \text { Tris (1,3-dichloro-2-propyl) phosphate } \\ \text { TFA } & - \text { Trifluoroacetic acid } \\ \text { TiO } 2 & - \text { Titanium dioxide } \\ \text { TOC } & - \text { Total organic carbon } \\ \text { TPA } & - \text { Terephthalic acid } \\ \text { TPhP } & - \text { Triphenyl phosphate } \\ { }^{31} \mathrm{H}-\mathrm{NHC} & - \text { Proton nuclear magnetic resonance } \\ \text { UHPL-Orbitrap-HRMS - Ultrahigh performance liquid chromatography orbitrap high- } & \\ & \end{array}$




\section{CHAPTER 1 INTRODUCTION}




\subsection{Global water crisis}

The water crisis is among the most serious global challenges. In 2019, UNESCO reported more than two billion people do not have access to safe drinking water [1]. At least 17 countries are in threat or suffering from extreme stress caused by the lack of clean water supplies [2]. Nearly 2000 children are dying daily because of waterborne diseases [3]. The global demand for clean water increases by $1 \%$ annually because of population growth, economic development, and urbanization [4].

In contrast, the availability and supplies of freshwater resources are shrinking in response to heavy industrial contamination, residual run-off, and untreated wastewater $[5,6]$. In addition to the vast number of inorganic contaminants and harmful algal blooms, the presence of organic pollutants including pharmaceuticals and hormones, poly- and perfluoroalkyl substances, benzotriazoles, brominated and emerging flame retardants, organophosphorus compounds, and personal care products has led to widespread pollution of global drinking water resources [7]. The growing demands of clean water and the diminishing supplies of fresh water and pose a serious threat to human health and the planet. Therefore, the identification of sustainable, safe, and cost-effective water treatment technologies is very critical to address the urgent need for clean water. My dissertation focuses on the exploration of fundamental studies on advanced oxidation processes for identifying, understanding, and assessment of water treatment methods for the decontamination of the emerging problematic organic pollutants, including organophosphate ester (OPE) and poly- and perfluoroalkyl substance (PFAS). In the following sections, we will specifically discuss a brief introduction and occurrence of 
organophosphate esters and perfluoroalkyl substances in the environment and will also highlight the background of advanced oxidation processes for their potential remediation in water.

\subsection{Water contamination by organophosphorus compounds}

Organophosphorus compounds have been extensively used as a pesticide, chemical warfare agents, flame retardants, plasticizers in agriculture, industry, and medicine $[8,9]$. Recently, however, organophosphate esters (OPEs), used as a flame retardant in a wide range of commercial products including furniture, plastics, automobiles, polyurethane foam, electronic equipment, and cable have attracted particular attention because of their widespread presence in the air, water, and sediments $[9,10]$. The worldwide demand for the OPE flame retardants is rising; the global annual consumption of flame retardants was $\sim$ 100,000 tons in 1992 and increased by three fold to $~ 300,000$ tons in 2004 [9]. The total flame-retardant used in Western Europe in 2006 was 465,000 tons, of which $20 \%$ (91,000 tons) came from the organophosphate esters [9]. The OPEs are triesters of phosphoric acid, whereby the hydrogen atoms of each hydroxy groups are replaced by an aliphatic or organic substrate. Commonly used chlorinated organophosphate esters are tris (2-chloroethyl) phosphate (TCEP), tris (1-chloro-2-propyl) phosphate (TCPP), and tris (1,3-dichloro-2propyl) phosphate (TDCPP). Unlike other organophosphorus compounds used as pesticides and chemical warfare agents, organophosphate esters (OPEs) are less reactive and resistant to degradation because of the less reactive nature of the phosphorus-oxygen single bond compared to the phosphorus-fluorine and phosphorus-sulfur bonds associated 
with chemical warfare agents and pesticides [11]. The structural comparison among these organophosphorus compounds is also presented in Table $\mathbf{1 .}$

Table 1. General structural comparison of different organophosphorus compounds

\begin{tabular}{|c|c|c|}
\hline $\begin{array}{l}\text { Organophosphorus } \\
\text { compound }\end{array}$ & General structure & Specific example \\
\hline Pesticide & 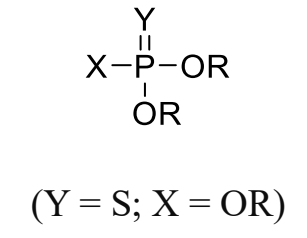 & ion \\
\hline $\begin{array}{c}\text { Chemical warfare } \\
\text { agent }\end{array}$ & 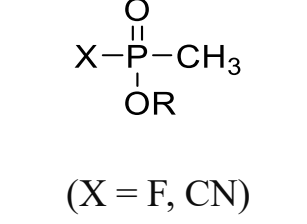 & Sarin \\
\hline Flame retardant & $\begin{array}{c}\mathrm{O} \\
\mathrm{R}_{2} \mathrm{O}-\stackrel{\mathrm{P}}{\mathrm{P}}-\mathrm{OR}_{1} \\
\mathrm{O} \mathrm{O}_{3}\end{array}$ & 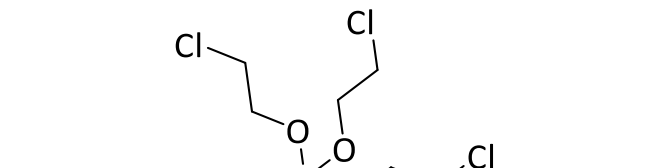 \\
\hline & $\begin{array}{l}\mathrm{R}=\text { alkyl or } \\
\text { aryl substituent }\end{array}$ & Tris (2-chloroethyl) phosphate (TCEP) \\
\hline
\end{tabular}

The OPE compounds are mixed with the host materials as an additive; these can, therefore, leach out into the environment when host materials break down during the aging process. The detection of OPEs in different environmental matrices, including air, water, sediment, and biota from ppt to sub-ppm level is well documented [10,12-15]. One study showed that a significant amount of the organophosphate flame retardant TDCPP in polyester garments was extracted by water during washing, suggesting that chlorinated 
phosphate flame retardants are appreciably mobile in the polyester media with probability to release in water during standard laundry practice [16]. These compounds have a relatively long persistence in aquatic environments, and the diester-metabolites are also highly resistive to further hydrolysis $[9,17]$. Organophosphate esters are bio-accumulative and toxic because of strong interactions with cholinesterase, an essential enzyme for the proper functioning of the nervous system [18-20]. Multiple studies reported OPE exposure in biological systems is connected with a range of disorders from acute to chronic neurological issues, endocrine disruption, hepatotoxicity, reproductive toxicity, and development toxicity $[9,18,21]$.

\subsection{Water contamination by perfluoroalkyl substances (PFASs)}

Perfluoroalkyl substances (PFASs) are a class of anthropogenic chemicals used for a wide variety of applications such as protective coating of metals, water-proofing of materials, fire-fighting foams for electrical fires, semiconductor etching, fluoropolymer synthesis, and other purposes for decades [22,23]. These compounds ultimately are released into the environment primarily as a result of improper disposal of manufacturing waste, leaching from landfills, and uses in the military exercise. Table 2 shows a number of selected legacy and emerging PFASs. Each PFAS molecule has a hydrophilic head and a lipophilic tail containing extremely strong carbon-fluorine bonds in their carbon-carbon backbone. All these properties make PFASs incredibly persistent in aquatic environments and give the 'forever chemical' moniker $[23,24]$. The presence of PFAS in our aquatic 
environment is well documented [25-29]. It is also estimated that more than $98 \%$ of Americans have PFASs in their bodies [30,31].

Table 2. List of a number of selected legacy and emerging PFASs with chemical structures

\begin{tabular}{|c|c|c|}
\hline PFAS name & Formula & PFAS structure \\
\hline Trifluoroacetic acid & TFA & $\mathrm{F}_{3} \mathrm{C}$ \\
\hline Perfluorobutanoic acid & PFBA & $\mathrm{F}_{3} \mathrm{C}$ \\
\hline Perfluoropentanoic acid & PFPA & $\mathrm{F}_{3} \mathrm{C}^{-\mathrm{C}}$ \\
\hline Perfluorohexanoic acid & PFHxA & \\
\hline Perfluoroheptanoic acid & PFHpA & $\mathrm{F}_{3} \mathrm{C}^{-}$ \\
\hline Perfluorooctanoic acid & PFOA & \\
\hline Perfluorooctanesulfonic acid & PFOS & 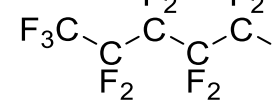 \\
\hline Perfluoro-5-oxahexanoic acid & PFMeoBA & $\mathrm{F}_{3} \mathrm{C}$ \\
\hline $\begin{array}{l}\text { Perfluoro 2-methyl-3-oxahexanoic } \\
\text { acid }\end{array}$ & GenX & $\mathrm{F}_{3} \mathrm{C}^{-}$ \\
\hline Octafluoroadipic acid & - & 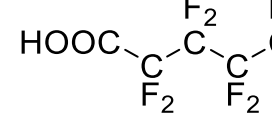 \\
\hline
\end{tabular}

Unfortunately, exposure of PFAS causes adverse health effects in liver, kidneys, blood, thyroid, and the immune system [32-35]. Given the potent negative health 
consequence of PFASs, the US-EPA has placed a restriction on the manufacture and commercial application of perfluorooctanoic acid (PFOA) and perfluorooctanoic sulfonic acid (PFOS), the two most widely used PFASs in 2002 [7]. However, there are a number of smaller chain PFASs still in use. DuPont introduced a different class of PFASs called perfluoroether carboxylic acid (PFECA) that contains carbon-oxygen $(\mathrm{C}-\mathrm{O})$ bonds in their backbone, in addition to the carbon-carbon bond typically associated with the legacy PFASs [27]. Perfluoro (2-methyl-3-oxahexanoic) acid, known as GenX, is one example of PFECAs that was introduced in 2009 as a substitute for PFOA [27,36]. Given the ether functionality and decreasing hydrophobicity, it was forecasted that GenX would be less persistent than legacy PFASs. Unfortunately, this new generation emerging PFAS GenX was detected in the Cape Fear river, a drinking water sources of North Carolina [27], and demonstrated resistance to bio-degradation similar to PFOA. Although there are limited toxicological studies for GenX on human health, lab experiments on rats revealed that GenX is also toxic and causes hepatotoxicity [37,38]. There are a number of water remediation technologies, including granular activated carbon (GAC) based adsorption, membrane filtration, ion exchange resin, as well as chemical treatments and advanced oxidation processes. Next, we will focus on the advanced oxidation processes, their mechanisms and applications for the treatment of organic pollutants in water.

\subsection{Advanced oxidation processes (AOPs)}

Advanced oxidation processes have been shown to be very effective for the destruction of a wide range of naturally occurring toxins, pesticides, contaminants of 
emerging concern, and organic pollutants [6,39-42]. These processes employ the hydroxyl radical $(\cdot \mathrm{OH})$, which is an extremely strong reactive oxygen species with a redox potential in between $+2.8 \mathrm{eV}$ and $1.95 \mathrm{eV}$ depending on the $\mathrm{pH}[43,44]$. The hydroxyl radical is very non-selective and rapidly reacts with most of the organic compounds with a rate constant on the order of $10^{8}-10^{10} \mathrm{M}^{-1} \mathrm{~s}^{-1}$ and eventually mineralizes them into innocuous species, ideally $\mathrm{CO}_{2}$, water, and mineral acid, shown in Scheme 1 [42].

Organic pollutants/toxins

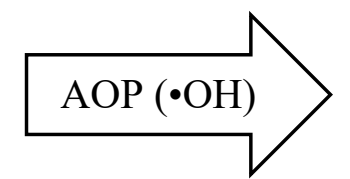

$\mathrm{H}_{2} \mathrm{O}+\mathrm{CO}_{2}+\mathrm{HX}$ (Innocuous products)

Scheme 1 Conversion of organic pollutants/toxins into innocuous materials via advanced oxidation technologies involving hydroxyl radicals

The hydroxyl radical reacts with most of the organic compounds primarily by the addition (Equation 1) or hydrogen abstraction reaction pathways (Equation 2) [6,42]. Less common is electron transfer pathway, which may occur with exceedingly electronrich systems (Equation 3). The addition of $\cdot \mathrm{OH}$ to the unsaturated $\pi$ systems is often diffusion-controlled $\left(\sim 10^{-9} \mathrm{M}^{-1} \mathrm{~s}^{-1}\right)$, while the hydrogen abstraction pathway with a C-H bond is $\sim 10^{-8} \mathrm{M}^{-1} \mathrm{~s}^{-1}$. Regardless of addition and abstraction by $\bullet \mathrm{OH}$ radicals, both pathways yield carbon-centered free radicals. The resulting carbon-centered free radical readily reacts with dissolved molecular oxygen to form organoperoxyl radicals. Subsequent free radical chain oxidation processes can ultimately lead to the mineralization.

$$
\begin{aligned}
& \mathrm{H}_{2} \mathrm{C}=\mathrm{CH}_{2}+\cdot \mathrm{OH} \rightarrow \cdot \mathrm{CH}_{2}-\mathrm{CH}_{2}(\mathrm{OH}) \\
& \mathrm{CH}_{3} \mathrm{OH}+\cdot \mathrm{OH} \rightarrow \mathrm{H}_{2} \mathrm{O}+\cdot \mathrm{CH}_{2} \mathrm{OH}
\end{aligned}
$$




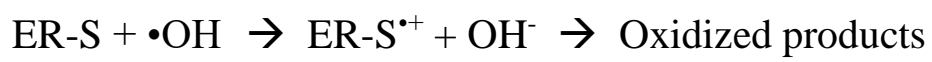

Hydroxyl radicals can be produced by a variety of advanced oxidation processes including, $\mathrm{UV} / \mathrm{H}_{2} \mathrm{O}_{2}, \mathrm{UV} / \mathrm{O}_{3}, \mathrm{H}_{2} \mathrm{O}_{2} / \mathrm{O}_{3}$, Fenton $\left(\mathrm{H}_{2} \mathrm{O}_{2} / \mathrm{Fe}^{2+}\right)$, photo-Fenton, nonthermal plasmas, sonolysis, photocatalysis, radiolysis, and supercritical water oxidation processes. My dissertation only focuses on the exploration of the $\mathrm{TiO}_{2}$ photocatalysis and sonolysis for the remediation of OPEs and PFASs in water. The following section will be highlighted with two specific advanced oxidation processes, specifically $\mathrm{TiO}_{2}$ photocatalysis, and sonolysis.

\subsubsection{Titanium dioxide $\left(\mathrm{TiO}_{2}\right)$ photocatalysis}

Semiconductor photocatalysis, an advanced oxidation technology, can produce reactive oxygen species (ROS) upon excitation by appropriate energy [45]. Titanium dioxide $\left(\mathrm{TiO}_{2}\right)$ is a widely used semiconductor material for photocatalysis studies because of its high photo-activity, low cost, low toxicity, and excellent thermal and chemical stability [46-48]. The $\mathrm{TiO}_{2}$ photocatalysis can lead to the transformation of a wide variety of organic pollutants and toxins into less toxic materials [49]. Since the breakthrough study reported in 1972 by Fujihima and Honda, $\mathrm{TiO}_{2}$ photocatalysis has been extensively investigated for the destruction of a large number of hazardous contaminants, such as pesticides, halocarbons, and aromatic compounds in water [45,50,51]. In 2019, ScienceDirect published approximately 5,000 articles on $\mathrm{TiO}_{2}$ regarding their modification, analysis, and on a range of applications, including photocatalysis [52]. The 
overall process of $\mathrm{TiO}_{2}$ photocatalysis induced degradation of organic pollutants is illustrated in Figure 1.

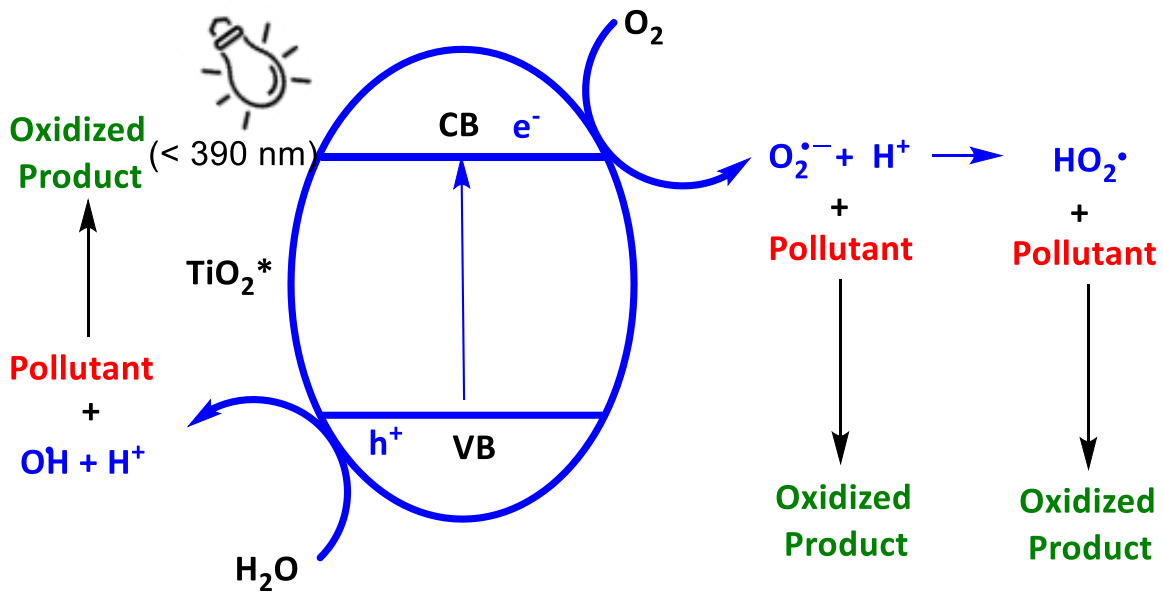

Figure 1. Mechanisms for the production of reactive oxygen species and the subsequent oxidations of organic contaminants by $\mathrm{TiO}_{2}$ photocatalysis.

The band gap of $\mathrm{TiO}_{2}$ (anatase) is $3.2 \mathrm{eV}$; thus, it requires light in the $\mathrm{UV}$ range for excitation [46]. Titanium dioxide absorbs photons of appropriate wavelength $(\lambda<390 \mathrm{~nm})$ and generates electron $\left(\mathrm{e}^{-} \mathrm{CB}\right) /$ hole $\left(\mathrm{h}^{+} \mathrm{vB}\right)$ pairs. The electron/hole pairs can recombine or migrate to the surface of $\mathrm{TiO}_{2}$ and form a number of reactive oxygen species, including hydroxyl radicals $(\bullet \mathrm{OH})$ and superoxide anions $\left(\mathrm{O}_{2}{ }^{\bullet-}\right)$ in the presence of water and oxygen $[45,46,53]$. Among these ROS, the hydroxyl radical is considered to the primary species leading to the degradation of organic compounds. While direct oxidation and reduction of organic molecules by the electron/hole pair can be envisioned, such direct transformation is generally not competitive in aqueous solution. $\mathrm{The}^{\mathrm{TiO}} 2$ photocatalytic water treatment has advantages over a number of AOPs. Activated $\mathrm{TiO}_{2}{ }^{*}$ photocatalysis does not require the continuous supply of other oxidants, such as $\mathrm{O}_{3}$ and $\mathrm{H}_{2} \mathrm{O}_{2}$. The cost of the production 
and handling of $\mathrm{O}_{3}$ and $\mathrm{H}_{2} \mathrm{O}_{2}$ can be prohibitive. Titanium dioxide is highly stable and can be reused without significant loss of photocatalytic properties. Therefore, $\mathrm{TiO}_{2}$ can be used in photocatalysis processes either as a suspension in solution or as a thin film on the supporting material [54]. The powdered $\mathrm{TiO}_{2}$ can increase the catalytic efficiency because of the high surface area, in addition to the low costs and easy preparation [46]. The possible formation of a dark catalytic sludge of powder $\mathrm{TiO}_{2}$ can lead to a decrease in the UV irradiation efficiency under very specific conditions [45,50]. Even though the high stability and activity of the catalyst are required when the $\mathrm{TiO}_{2}$ thin film is applied, the elimination of the removal of the $\mathrm{TiO}_{2}$ particles after the reaction is a great advantage [55].

\subsubsection{Ultrasound induced advanced oxidation process (sonolysis)}

Ultrasound (US) is a kind of acoustic energy having frequencies higher than the maximum audible limit of human hearing (> $20 \mathrm{kHz}$ ). While US is extensively used in a variety of industrial applications, including in electronics, navigation, security, medical imaging, the use of ultrasound in chemical processing or for the remediation of toxic/persistent compounds in water has seen only limited commercial application. [56,57]. The application of ultrasonic irradiation for water treatment was first reported in 1970 [58] and has been widely investigated for the decontamination of a wide variety of hazardous organic pollutants and toxins from water over the past couple of decades $[57,59,60]$. The use of US in water treatment has several unique advantages over other commonly used methods. Granular activated carbon (GAC) based adsorption has limited options for the remediation of organic pollutants [61-67]. These methods are only effective for a limited 
number of compounds and often are cost-prohibitive because of their regular maintenance and regeneration [67]. Traditional $\mathrm{UV} / \mathrm{H}_{2} \mathrm{O}_{2}$ techniques are cost-prohibitive because of the continuous supply of oxidants. Ultrasonic treatment requires no chemical additives and effectively works in a turbid, color solution, and sludge [68]. Although energy conversion from electrical to acoustic is relatively low, proper optimization of energy efficiency or dynamics of the reaction system can improve its application efficiency $[57,69,70]$.

The chemical effects of ultrasonic irradiation do not come from direct interaction or absorption of ultrasonic wavelength with the target compounds; the effects derive principally from a physical process called acoustic cavitation [71]. When an ultrasonic wave travels through liquids, a phenomenon involving the formation, growth, and violent collapse of bubbles in water can occur and is known as acoustic cavitation [72]. As sound waves pass through the liquid, alternating low-pressure rarefaction and high-pressure compression cycles are propagated. In the rarefaction cycle, there is a formation of microbubbles from gas nuclei already present the liquid. In the compression cycle, the volume of gas bubbles dramatically decreases because of increasing pressure in the surrounding area. Thus, the gas bubble grows and shrinks during the alternation of the pressure sequence of the ultrasonic wave, and after multiple cycles, bubbles collapse violently as a result of the pressure differential within and outside of the gas bubble. The phenomenon of the generation, growth, and the implosion of bubbles in liquid during the exposure of ultrasound is known as acoustic cavitation. The graphical summary of the cavitation process is illustrated in Figure 2. The creation of extreme temperatures (around $5000 \mathrm{~K}$ ) and pressures (nearly $500 \mathrm{~atm}$ ) because of the violent collapse at cavitational site, leading to thermal homolysis of water into $\mathrm{H} \bullet$ and $\bullet \mathrm{OH}$ radicals (Equation 4). The 
generation of $\bullet \mathrm{OH}$ during the ultrasonic treatment is characteristic of advanced oxidation process [71]. The acoustic cavitation is often broken into three distinct zones (Figure 3), a sonochemical hot spot (red), a gas-liquid interface (yellow), and bulk liquid (blue). The hot spot presents an extremely high temperature (> $5000 \mathrm{~K}$ ) and pressure (> 500 atm) $[71,73]$. The gas-liquid interface with a high temperature and pressure (> $2000 \mathrm{~K}$ and $>200 \mathrm{~atm}$ ) satisfies the condition of supercritical water; thus, this region becomes hydrophobic rather than hydrophilic [59]. The bulk solution remains at near ambient temperature.

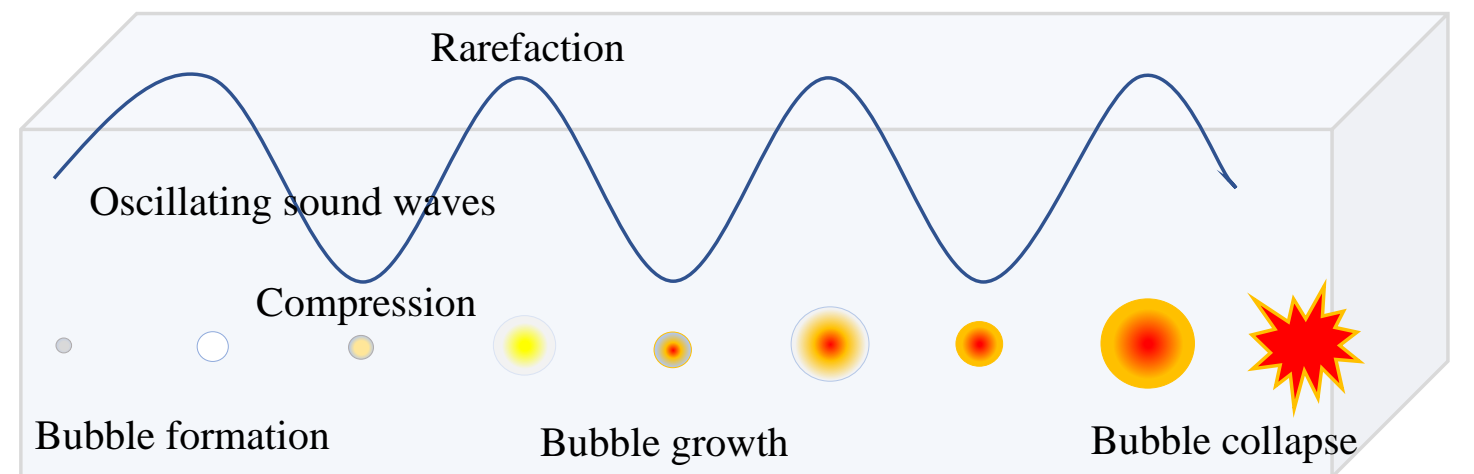

Figure 2. Graphical representation of the acoustic cavitation process.

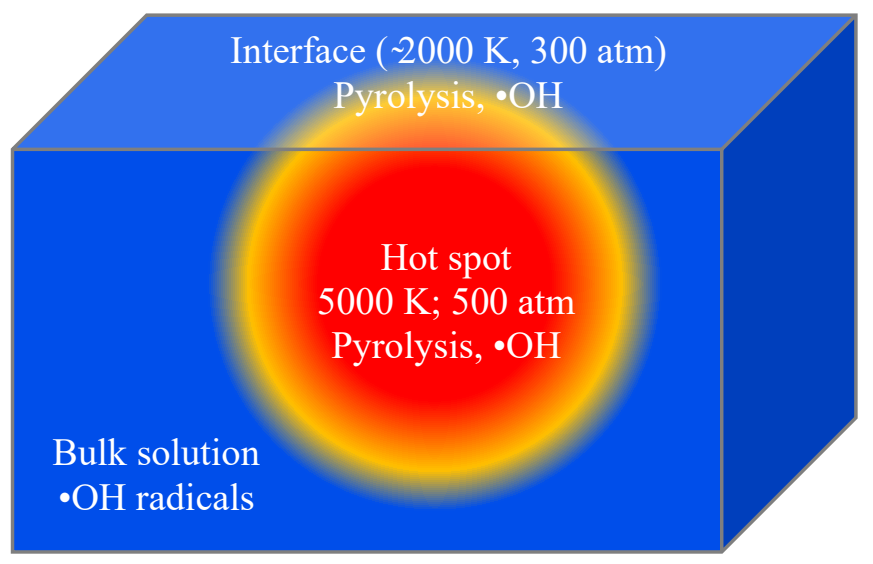

Figure 3. Graphical illustration of the cavitation bubble collapse. 
The most salient feature of ultrasonic irradiation is that it can work by both direct pyrolysis and hydroxyl radical-mediated oxidation [59]. Acoustic cavitation leads to increased chemical reactivity in the solution through the formation of a number of primary and secondary reactive species (Equations 4 - 7) [57,59]. In addition to the generation of hydroxyl radicals, US leads to the generation of the secondary reactive species, such as hydrogen peroxide, from the addition of two hydroxyl radicals following the dissociation of water vapor within collapsing bubbles. Sonochemical hot-spot and the gas-liquid interface have a unique reaction environment caused by the formation of hydroxyl radicals by the pyrolysis of water molecules $[71,72]$. Volatile compounds can diffuse to the hotspot and be pyrolyzed directly under the extreme temperatures. The $\bullet \mathrm{OH}$ formed at the hotspot and gas-liquid can diffuse to the bulk solution and react with the compounds dissolved in the bulk solution. The hydroxyl radicals at the gas-liquid interface are localized and can react with the target compound. The pollutants can also undergo thermal processes. Therefore, the combination of pyrolysis and oxidation of the target makes ultrasoundinduced remediation of the contaminants an attractive water treatment method.

$$
\begin{aligned}
& \left.\left.\left.\mathrm{H}_{2} \mathrm{O}+()\right)\right)\right) \rightarrow \mathrm{H} \bullet+\mathrm{HO} \bullet \\
& \left.\left.\left.\mathrm{O}_{2}+()\right)\right)\right) \rightarrow 2 \mathrm{O} \bullet \\
& \mathrm{O}_{2}+\mathrm{H} \bullet \rightarrow \mathrm{HO}_{2} \bullet \\
& \mathrm{H}_{2} \mathrm{O}+\mathrm{O} \bullet \rightarrow 2 \mathrm{HO} \bullet
\end{aligned}
$$

The ultrasound-induced degradation of target pollutants is highly dependent on the properties of the target compounds, such as the octanol-water partition coefficient, Henry's law constant, rate constant with $\bullet \mathrm{OH}$, and diffusivity [74]. The compounds possessing high 
hydrophobicity with low diffusivity, or vice versa, tend to have additional time to partition the gas-liquid interface. Volatile compounds tend to diffuse to the hot-spot and thus can be readily pyrolyzed by the extreme temperatures in the region. Ultrasonic irradiation was proved to be one of the most useful methods to remediate methyl tert-butyl ether (MTBE) in water, while granular activated carbon adsorption is not effective for the removal of MTBE [75]. Cyanobacteria blooms, responsible for the production of toxic microcystins, have become a severe issue in freshwater or coastal areas. However, ultrasonic irradiation can degrade the structure of microcystins, leading to a decrease in activity and bio-toxicity of microcystins [76]. Interestingly, ultrasonic irradiation can effectively mineralize the extremely persistent perfluoroalkyl substances (PFASs) in water [77-79]. Recent studies show that emerging perfluoroalkyl substances, including GenX and other smaller chain PFASs, can be converted into fluoride ions by ultrasonic pyrolysis [80].

\subsection{Objectives of the dissertation}

The research focus of the current dissertation explores the fundamental understanding of advanced oxidation processes specifically $\mathrm{TiO}_{2}$ photocatalysis and sonolysis for the remediation of a number of targeted organic pollutants including tris (2chloroethyl) phosphate (TCEP), a model halogenated organophosphate flame retardants; Naled (1,2-dibromo-2,2-dichloro dimethyl phosphate), an organophosphate insecticide commonly used for controlling adult mosquitoes; and a number of perfluoroalkyl substances (PFASs) with the detailed kinetic and mechanistic understanding of GenX (perfluoro 2-methyl-3-oxahexanoic acid). Another important focus of the dissertation is to 
develop the visible light active titanium oxide by a simple solid-state reduction reaction. The dissertation also investigated the fundamental insight of the ultrasonic degradation of TCEP and investigated the hydrolysis of Naled to understand their environmental fate with the identification of metabolites during the hydrolysis. These studies will provide in-depth knowledge about $\mathrm{TiO}_{2}$ photocatalysis and ultrasonic irradiation for the remediation of emerging halogenated organophosphate compounds and highly persistent emerging perfluoroalkyl substances. 
CHAPTER 2 UV-TIO 2 PHOTOCATALYTIC DEGRADATION OF TRIS (2CHLOROETHYL) PHOSPHATE (TCEP) 


\subsection{Abstract}

The presence of halogenated organophosphate flame retardants in natural water systems is a widespread concern because of their potential threat to the environment and human health. The $\mathrm{TiO}_{2}$ photocatalysis at $350 \mathrm{~nm}$ leads to rapid degradation of tris (2chloroethyl) phosphate (TCEP). The observed degradation follows pseudo-first-order kinetics at a specific concentration. The apparent rate constants varied from 0.28 to 0.03 $\min ^{-1}$ depending on the initial concentrations over the range of $18-270 \mu \mathrm{M}$, indicating the heterogeneous degradation process is likely controlled by mass transfer (adsorption< - >desorption) at the surface of $\mathrm{TiO}_{2}$. The degradation kinetics also fit the LangmuirHinshelwood model with apparent kinetic parameters of $0.03 \mu \mathrm{M}^{-1}$ and $13.1 \mu \mathrm{M} \mathrm{min}{ }^{-1}$ for the apparent equilibrium constant $\left(\mathrm{K}_{\mathrm{LH}}\right)$ and the reactivity constant $\left(\mathrm{k}_{\mathrm{rxn}-\mathrm{LH}}\right)$, respectively. Studies of ${ }^{1} \mathrm{H}$ - and ${ }^{31} \mathrm{P}-\mathrm{NMR}$ indicate sequential oxidation of the alkyl ester chains (alkyl phosphate), initially leading to the diester product, followed by the formation of the monoester and ultimately producing phosphate. Under strongly alkaline conditions the degradation is enhanced, from $\mathrm{pH} 4$ to 9 the degradation is relatively constant, while under highly acidic conditions the degradation is inhibited. Effective mineralization is achieved as demonstrated by excellent chloride (98\%) and phosphate (94\%) mass balances, as well as the loss of total organic carbon (TOC) $>95 \%$. The addition of an equal molar amount of the hydroxyl radical scavenger, coumarin, leads to a pronounced reduction in degradation, indicating hydroxyl radicals mediate the degradation process. These results demonstrate $\mathrm{TiO}_{2}$ photocatalytic oxidation has promise for the treatment of aqueous solutions contaminated with organophosphate flame retardants. 


\subsection{Introduction}

Organophosphorus compounds have been extensively used as pesticides, chemical warfare agents, flame retardants, and plasticizers [8,9]. Organophosphate esters (OPEs), used as flame retardants in a wide range of commercial products including furniture, plastics, automobile, polyurethane foam, and electronic equipment and cable, have attracted significant attention because of their widespread presence in air, water, and sediments $[9,10]$. These compounds are highly toxic and potential carcinogens from lowlevel species to high-level vertebrates [18-21]. The growing concerns over human health issues and the adverse effects of OPEs on ecosystems lead to their inclusion in the Toxic Substance Control Act (TSCA) from US-EPA [81]. The OPEs are additives, not chemically bonded to the host materials, and thus often leach into the surrounding environment [9]. A number of studies detected OPEs in wastewater, drinking water sources, air, dust, and even in biological systems $[10,12,15,82,83]$. Because of their widespread environmental occurrences and documented harmful impacts on human health, treatment of the OPEs has become critical to drinking water providers. Conventional water treatment methods, including activated carbon, membrane filtration, and reverse osmosis, are unable to effectively remove OPEs, particularly halogenated organophosphate esters [13,84-86]. The phosphorus-oxygen (P-O) bonds present in the OPEs are generally much more stable to hydrolysis than the phosphorus-sulfur (P-S) and phosphorus-fluorine (P-F) bonds present in most pesticides and chemical warfare agents [11]. The stability of the P-O contributes to the relatively long environmental persistence of OPEs. 
The $\mathrm{TiO}_{2}$ photocatalytic degradation of organic compounds has been demonstrated for the destruction of an extensive number of hazardous contaminants in aqueous systems $[49,87]$. Upon absorbtion of photons at appropriate wavelengths $(\lambda<390 \mathrm{~nm}) \mathrm{TiO}_{2}$ generates electron $\left(\mathrm{e}^{-} \mathrm{CB}\right) /$ hole $\left(\mathrm{h}^{+}{ }_{\mathrm{VB}}\right)$ pairs, initiating a series of competing processes represented below in Equations 8 - 12. The electron/hole pairs can recombine or migrate to the surface of $\mathrm{TiO}_{2}$ and form reactive oxygen species (ROS) in the presence of water and oxygen $[45,46]$. Although a number of ROS are generated during $\mathrm{TiO}_{2}$ photocatalysis and can lead to the mineralization of the organic compounds, hydroxyl radicals $(\bullet \mathrm{OH})$ are considered the primary species leading to the degradation of organic compounds $[47,88]$. In general, $\bullet \mathrm{OH}$ reacts with nearly all organic molecules, except per-halogenated or strongly electron-deficient compounds. The primary reaction pathways of $\bullet \mathrm{OH}$ radical include the abstraction of hydrogen atom and the addition to an unsaturated $\pi$ system to yield carbon-centered free radicals. Although less common, electron transfer can also occur from electron-rich substrates to $\bullet \mathrm{OH}$. The resulting carbon-centered radicals readily react with dissolved molecular oxygen to form organoperoxyl radicals. Subsequent radical chain oxidation processes can ultimately lead to mineralization [89].

$$
\begin{aligned}
& \mathrm{TiO}_{2}+h v \rightarrow \mathrm{h}^{+} \mathrm{vB}^{-} \mathrm{e}_{\mathrm{CB}}^{-} \\
& \mathrm{H}_{2} \mathrm{O}+\mathrm{h}^{+}{ }_{\mathrm{vB}} \rightarrow \mathrm{H}^{+}+\mathrm{HO} \bullet \\
& \mathrm{O}_{2}+\mathrm{e}_{\mathrm{CB}}^{-} \rightarrow \mathrm{O}_{2}^{\cdot-} \\
& \text { Pollutant }+\mathrm{HO} \bullet \rightarrow \text { Pollutant }_{\mathrm{ox}} \\
& \text { Pollutant }+\mathrm{h}^{+}{ }_{\mathrm{vB}} \rightarrow \text { Pollutant }
\end{aligned}
$$


A number of reports have appeared on the $\mathrm{TiO}_{2}$ photocatalysis of organophosphorus compounds [13,90-96]. O'Shea et al. [91] demonstrated rapid $\mathrm{TiO}_{2}$ photocatalysis of dimethyl methylphosphonate (DMMP) and diethyl methylphosphonate (DEMP). The initial intermediate product resulting from oxidation of alkyl ester chain is a mono-ester, which is subsequently converted to methyl phosphonic acid (MPA) and, ultimately, phosphate upon continued irradiation. While a number of reaction mechanisms can be envisioned for these transformations, detailed radiolysis studies demonstrated that hydroxyl radical initiated hydrogen abstraction from $\alpha$-hydrogen on the ester chain is the primary step in the transformations [97]. There are very few reports on the $\mathrm{TiO}_{2}$ photocatalytic degradation of halogenated organophosphorus flame retardants. In a recent paper, Antonopoulou et al. [93] reported the $\mathrm{TiO}_{2}$ photocatalytic degradation of tris (1chloro-2-propyl) phosphate (TCPP) over the range of $25-500 \mu \mathrm{g} / \mathrm{L}$ in ultrapure and real water under simulated solar irradiation. While detailed product studies of the TCPP were not conducted, the diester of TCPP was proposed as an intermediate in route to mineralization. The $\mathrm{TiO}_{2}$ photocatalysis of TCEP has yet to be reported; however, Ruan et al. demonstrated the degradation of TCEP by $\mathrm{UV} / \mathrm{H}_{2} \mathrm{O}_{2}$ oxidation and proposed its mineralization into $\mathrm{Cl}^{-}, \mathrm{PO}_{4}{ }^{3-}, \mathrm{CO}_{2}$, and $\mathrm{H}_{2} \mathrm{O}$ showing the diester as an intermediate [94]. Cristale et al. [13] reported $\mathrm{O}_{3} / \mathrm{UV} / \mathrm{H}_{2} \mathrm{O}_{2}$ treatment leads to slow degradation and incomplete removal of several halogenated organophosphorus flame retardants from the water. The $\mathrm{UV} / \mathrm{H}_{2} \mathrm{O}_{2}, \mathrm{UV} / \mathrm{H}_{2} \mathrm{O}_{2} / \mathrm{O}_{3}$, and $\mathrm{UV} / \mathrm{O}_{3}$, mediated degradations of an $\mathrm{OPE}[95,96]$, have been reported; however, degradation was dramatically affected by water quality. While advanced oxidation of halogenated OPEs has the potential to produce low molecular weight halogenated aldehydes, ketones, and carboxylic acids, analogous to disinfection by- 
products, detailed product, and mechanistic studies have yet to be reported. We report herein detailed kinetic and product studies for the $\mathrm{TiO}_{2}$ photocatalysis of TCEP as a model compound of the organophosphate flame retardants.

\subsection{Experimental section}

\subsubsection{Materials}

Tris (2-chloroethyl) phosphate (TCEP), 2-chloroethanol, and triphenyl phosphate (TPhP) were purchased from Aldrich Chemical Company. High purity GC grade dichloromethane (DCM) was obtained from Fisher Scientific. Sodium chloride, sodium hydroxide, nitric acid, sodium carbonate, sodium hydrogen carbonate, potassium dihydrogen phosphate, phosphorus pentoxide, and orthophosphoric acid were also purchased from Fisher Scientific. The catalyst $\mathrm{P}_{25} \mathrm{TiO}_{2}$ particles [CAS no. 13463-67-7] were supplied by Degussa. Coumarin was purchased from MP Biomedicals, LLC. The oxygen from Trigas was the highest purity available. Millipore water $(18 \mathrm{M} \Omega \cdot \mathrm{cm})$ and volumetric glassware were used for the preparation of all of the aqueous solutions.

Di-(2-chloroethyl) hydrogen phosphate (diester adduct) was synthesized by an alkaline hydrolysis process reported by Barnard et al. [98]. A solution of TCEP (0.21 moles) in $25 \mathrm{~mL}$ of $10 \% \mathrm{NaOH}$ solution was refluxed for 20 hours. The reaction mixture was cooled to room temperature, acidified with concentrated hydrochloric acid, and the product collected by liquid-liquid solvent extraction with dichloromethane. The yield of the product was $\sim 60 \%$. The product was characterized by ${ }^{31} \mathrm{P}-\&{ }^{1} \mathrm{H}-\mathrm{NMR}$ spectroscopy; 
${ }^{31} \mathrm{P}-\mathrm{NMR}\left(\mathrm{D}_{2} \mathrm{O}, 400 \mathrm{MHz}\right) \delta-0.2\left(1 \mathrm{H}, \mathrm{q},{ }^{3} \mathrm{~J}_{\mathrm{P}-\mathrm{H}}=6.9 \mathrm{~Hz}\right),{ }^{1} \mathrm{H}-\mathrm{NMR}\left(\mathrm{D}_{2} \mathrm{O}, 400 \mathrm{MHz}\right) \delta$

$4.1\left(2 \mathrm{H}, \mathrm{dt},{ }^{3} \mathrm{~J}_{\mathrm{P}-\mathrm{H}}=6.8 \mathrm{~Hz},{ }^{3} \mathrm{~J}_{\mathrm{H}-\mathrm{H}}=5.1 \mathrm{~Hz}\right), \delta 3.8\left(2 \mathrm{H}, \mathrm{t},{ }^{3} \mathrm{~J}_{\mathrm{H}-\mathrm{H}}=5.1 \mathrm{~Hz}\right)$.

The 2-chloroethyl dihydrogen phosphate (monoester adduct) was prepared by the procedure reported by Via et al. [99]. First, 2-chloroethanol (12.4 mmoles) was added to phosphorus pentoxide $\mathrm{P}_{2} \mathrm{O}_{5}(6.0$ mmoles $)$ and then heated for 3 hours at nearly $70{ }^{\circ} \mathrm{C}$ in the presence of 3.3 mmoles of water. After 3 hours, the mixture was cooled to room temperature. The yield of monoester measured by ${ }^{31} \mathrm{P}-\mathrm{NMR}$ was $65 \%$. The NMR details are ${ }^{31} \mathrm{P}-\mathrm{NMR}\left(\mathrm{D}_{2} \mathrm{O}, 400 \mathrm{MHz}\right) \delta-0.52\left(1 \mathrm{P}, \mathrm{t},{ }^{3} \mathrm{~J}_{\mathrm{P}-\mathrm{H}}=7.0 \mathrm{~Hz}\right) ;{ }^{1} \mathrm{H}-\mathrm{NMR}\left(\mathrm{D}_{2} \mathrm{O}, 400 \mathrm{MHz}\right) \delta$ $3.35\left(2 \mathrm{H}, \mathrm{dt},{ }^{3} \mathrm{~J}_{\mathrm{P}-\mathrm{H}}=7.0 \mathrm{~Hz},{ }^{3} \mathrm{~J}_{\mathrm{H}-\mathrm{H}}=5.4 \mathrm{~Hz}\right), 2.92\left(2 \mathrm{H}, \mathrm{t},{ }^{3} \mathrm{~J}_{\mathrm{H}-\mathrm{H}}=5.4 \mathrm{~Hz}\right)$.

\subsubsection{Photocatalytic experiment}

A Rayonet photochemical reactor equipped with a cooling fan and fourteen phosphor-coated $(350 \mathrm{~nm})$ low-pressure black lights in a merry-go-around arrangement was used for all photocatalytic experiments (The details of the photochemical reactor is available at Southern New England Ultra-Violet Company, www.rayonet.org, model RPR100). The light flux was determined using potassium ferrioxalate actinometry and agreed to within $10 \%$ of the manufacturer's specifications $\left(1.6 \times 10^{16}\right.$ photons $\left./ \mathrm{sec} / \mathrm{cm}^{3}\right)$. A Pyrex glass cylinder vessel with Teflon stopper was used as a reaction vessel $(\mathrm{L}=30 \mathrm{~cm}, \mathrm{D}=2.5$ cm). In a typical experiment, a $\mathrm{TiO}_{2}$ suspension was prepared by adding $10 \mathrm{mg}$ of $\mathrm{TiO}_{2}$ particles to $100 \mathrm{~mL}$ of TCEP aqueous solution. The initial TCEP concentration was varied from 10 to $300 \mu \mathrm{M}$ for kinetic studies. High concentration of TCEP were used for product 
studies. The $\mathrm{TiO}_{2}$ suspensions were sonicated in an ultrasonic cleaning bath for 5 mins to ensure uniform suspension. The suspension was purged with oxygen gently for 10 minutes prior to irradiation. The aqueous suspension was magnetically stirred and irradiated in the photochemical reactor. The reaction vessel was removed from the reactor at desired time intervals, rigorously shaken for 30 seconds, then a $5.0 \mathrm{~mL}$ aliquot of $\mathrm{TiO}_{2}$ suspension withdrawn and immediately passed through a $0.45 \mu \mathrm{m}$ PTFE filter. The filter was rinsed with another $5.0 \mathrm{~mL}$ of deionized water and combined with the original filtrate to make the total volume of $10 \mathrm{~mL}$. To investigate the role of solution $\mathrm{pH}$ on the $\mathrm{TiO}_{2}$ photocatalytic degradation of TCEP, $\mathrm{NaOH}$ and $\mathrm{HNO}_{3}$ were added to adjust the corresponding initial $\mathrm{pH}$ of aqueous TCEP solution. The $\mathrm{pH}$ measurements were conducted on Mettler Toledo $\mathrm{pH}$ meter. For evaluating the contribution of hydroxyl radicals involved in the degradation process, we added coumarin as hydroxyl radical scavenger in TCEP photocatalytic degradation.

\subsubsection{Gas chromatographic (GC) analysis of TCEP}

The concentration of TCEP was monitored by GC (Hewlett-Packard 6890) equipped with a nitrogen phosphorus detector (NPD). The TCEP was extracted from the filtered aqueous solution with dichloromethane (DCM) for analyses. The extraction was carried out in a $40 \mathrm{~mL}$ glass extraction vial by adding $5 \mathrm{~mL}$ of DCM into $10 \mathrm{~mL}$ of the aqueous solution. Another $0.075 \mathrm{~mL}$ of DCM containing $4000 \mathrm{ppm}$ triphenyl phosphate as an internal standard was added to each sample. The extraction vial was agitated in an Orbit Shaker (Lab-Line) for 10 minutes at $300 \mathrm{rpm}$, before transferring one $\mathrm{mL}$ of the $\mathrm{DCM}$ 
phase to a $2.0 \mathrm{~mL}$ sample vial for GC analysis. The same extraction procedure was employed in the preparation of calibration standards for the GC-NPD. Chromatographic separation was carried out on a DB-5 fused silica capillary column [82]. The sample was injected manually in splitless mode. The injector temperature was set to $250{ }^{\circ} \mathrm{C}$ and the detector temperature at $300{ }^{\circ} \mathrm{C}$. The initial GC temperature was held at $40{ }^{\circ} \mathrm{C}$ for 4 mins and increased to $190{ }^{\circ} \mathrm{C}$ at $15^{\circ} \mathrm{C} / \mathrm{min}$ and then $10^{\circ} \mathrm{C} / \mathrm{min}$ to the final temperature of $310{ }^{\circ} \mathrm{C}$ which was maintained for 4 mins. Helium was used as a carrier gas. The concentration of TCEP was determined using the characteristic retention time, reference standard, careful calibration of NPD, and quantification using an internal standard. The detector response was calibrated against a series of TCEP aqueous solution ranging from $5-300 \mu \mathrm{M}$ with the internal standard yielding a correlation coefficient $\left(\mathrm{R}^{2}\right) \geq 0.99$ (Figure 4). Standards were run periodically to ensure accurate calibration of GC.

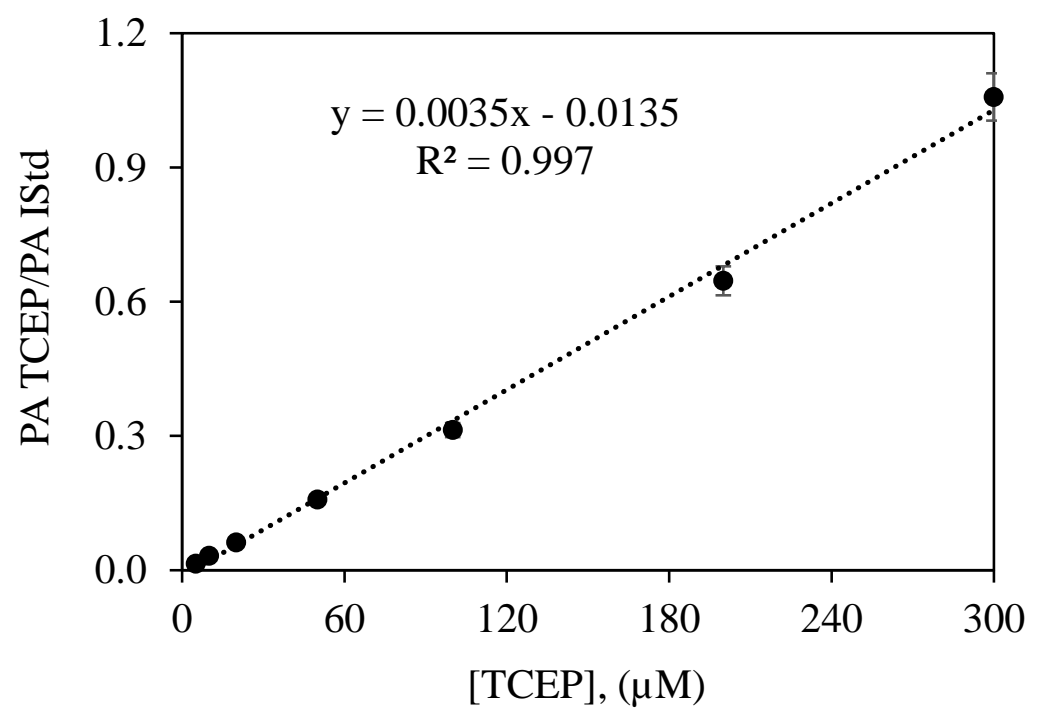

Figure 4. GC-NPD calibration curve for the determination of TCEP concentration using $\mathrm{TPhP}$ as an internal standard. (Data were reproducible within $\pm 5 \%$ on the basis of triplicate runs). 


\subsubsection{Analysis of mineralization products}

Ion chromatography (IC) was used to monitor phosphate $\left(\mathrm{PO}_{4}{ }^{3-}\right)$ and chloride $\left(\mathrm{Cl}^{-}\right)$ as mineralization products of TCEP. A 761 Compact IC Metrohm equipped with a Metrosep A Supp 5 column and conductivity detector was employed using the manufacturer's protocol. A mixture of $3.2 \mathrm{mM}$ sodium carbonate and $1.0 \mathrm{mM}$ sodium hydrogen carbonate aqueous solution was used as a buffer with a flow rate of $0.7 \mathrm{~mL} / \mathrm{min}$. The column was regenerated using a $0.125 \mathrm{M}$ solution of sulfuric acid with a flow rate of $2.0 \mathrm{~mL} / \mathrm{min}$. The detector response was calibrated, and a standardization curve developed using carefully prepared phosphate from 0.01 to $0.32 \mathrm{mM}$ (Figure 5), and chloride from 0.02 to $0.85 \mathrm{mM}$ standard solutions yields correlation coefficients $\geq 0.99$ (Figure 6).

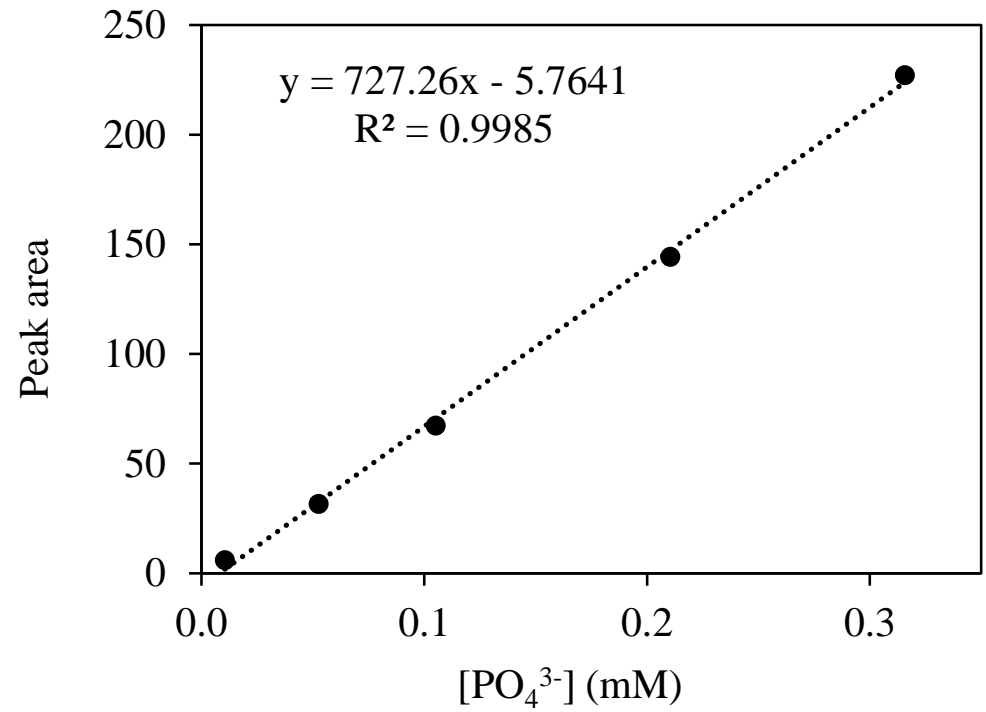

Figure 5. Ion chromatographic calibration curve for the determination of the concentration of phosphate ions. 


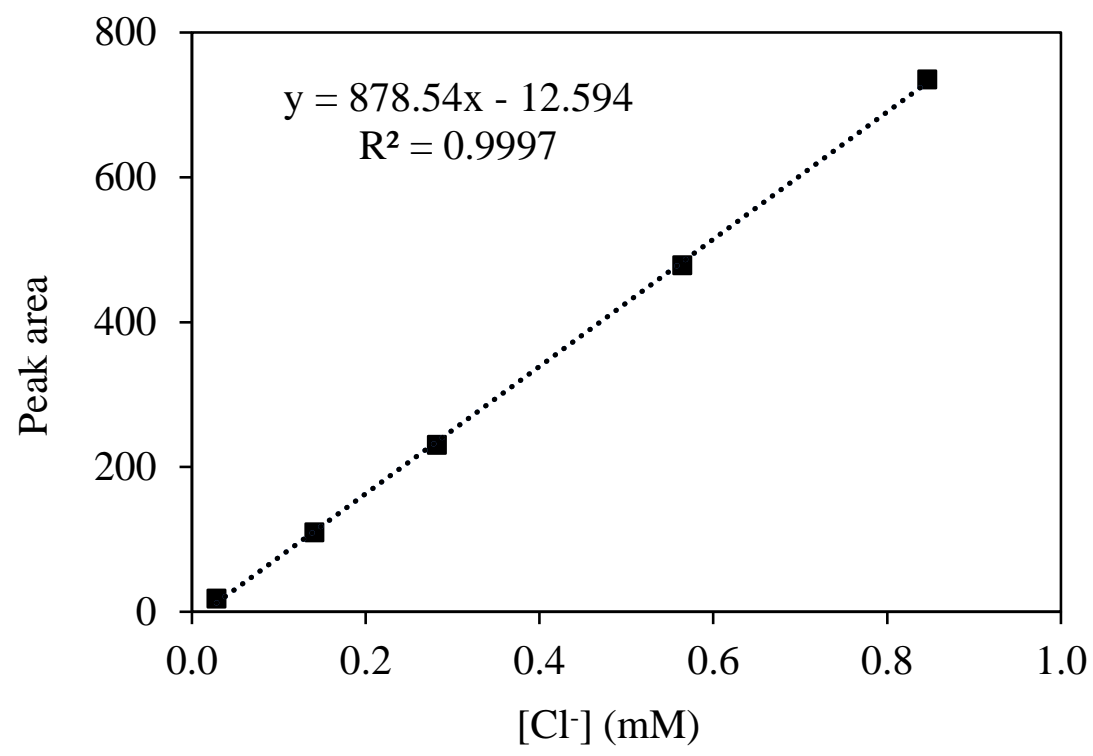

Figure 6. Ion chromatographic calibration curve for the determination of chloride ions.

\subsubsection{Analysis of intermediates and byproducts}

An NMR spectrometer (Bruker-Spectrospin 400 Ultrashield) was used to record the ${ }^{31} \mathrm{P}-\mathrm{NMR}(162 \mathrm{MHz})$ and ${ }^{1} \mathrm{H}-\mathrm{NMR}(400 \mathrm{MHz})$ spectra of starting materials and to monitor intermediate and final products during the $\mathrm{TiO}_{2}$ photocatalysis of TCEP [100]. The

${ }^{31} \mathrm{P}-\mathrm{NMR}$ chemical shifts were reported in ppm with respect to the resonance peak of $85 \%$ $\mathrm{H}_{3} \mathrm{PO}_{4}$ used as an external chemical shift reference. For the NMR product studies, the initial concentration of TCEP was $15.06 \mathrm{mM}$. 


\subsection{Results and discussion}

\subsubsection{Photocatalytic degradation}

Photocatalysis of TCEP $(109 \mu \mathrm{M})$ at $350 \mathrm{~nm}$ in an $\mathrm{O}_{2}$-saturated aqueous suspension of $\mathrm{TiO}_{2}$ leads to rapid degradation, is shown in Figure 7. Control experiments run in the absence of $\mathrm{TiO}_{2}$ or light demonstrated that direct photolysis and hydrolysis and/or adsorption of TCEP were insignificant. However, under photocatalytic conditions $\left(\mathrm{TiO}_{2} / \mathrm{hv} / \mathrm{O}_{2}\right)$, more than $50 \%$ of TCEP was eliminated within 10 minutes of irradiation. The observed rate of TCEP degradation decreased with the time of irradiation. The reduction in the rate of degradation as a function of treatment time is attributed to lower TCEP concentrations and the increase of by-product concentrations competing with TCEP for active sites at the surface of $\mathrm{TiO}_{2}[91,93]$. Complete degradation of TCEP was observed within 60 mins of irradiation.

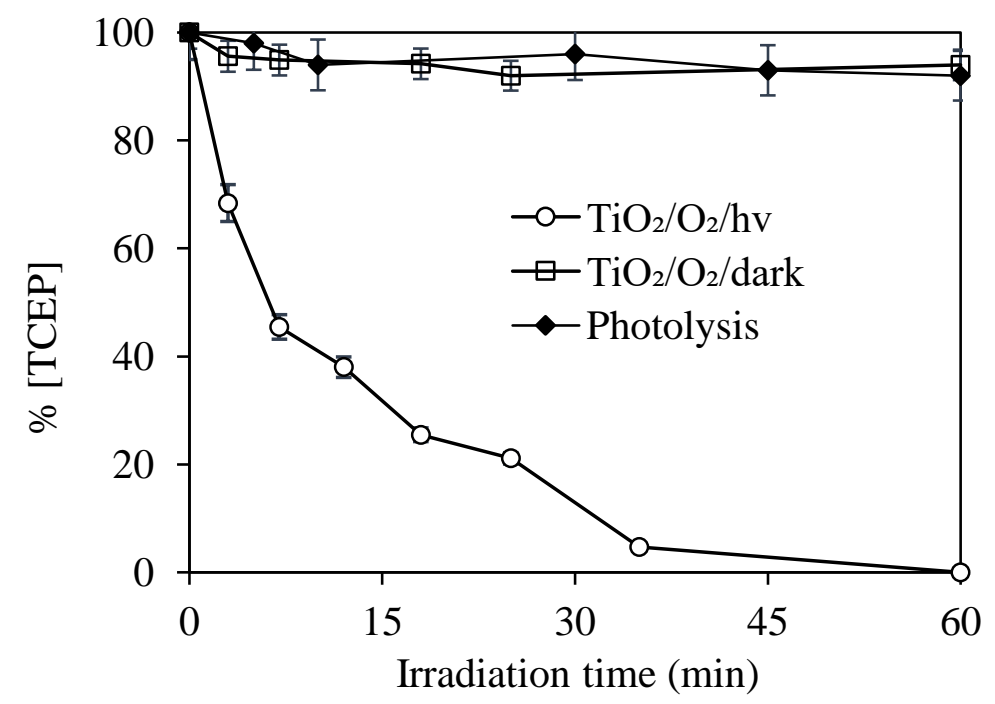

Figure 7. $\mathrm{TiO}_{2}$ photocatalysis of TCEP at $350 \mathrm{~nm}$ in $\mathrm{O}_{2}$-saturated suspension. $[\mathrm{TCEP}]_{0}=$ $109 \mu \mathrm{M},\left[\mathrm{TiO}_{2}\right]=0.10 \mathrm{~g} / \mathrm{L}$, and $\mathrm{pH}=6.5$. The reproducibility was within $5 \%$ on the basis of representative triplicate runs. 
The degradation kinetics of TCEP were studied over a range of initial concentrations from $18-270 \mu \mathrm{M}$, shown in Figure 8. The initial degradation rates of TCEP as a function of starting substrate concentration were determined from the first $15-20 \%$ disappearance of the TCEP to minimize the effect of products on the initial kinetic parameters and summarized in Table 3. With increasing initial TCEP concentration, the observed degradation rate decreases. The observation is rationalized on the basis of the finite number of reactive sites on the $\mathrm{TiO}_{2}$ surface or adsorbed $\bullet \mathrm{OH}$ thus, as the initial TCEP concentration increases, the portion of adsorbed target compounds on the $\mathrm{TiO}_{2}$ surface compared to those in solution decreases reducing the observed rate. In addition, the by-products of TCEP may slow down the degradation because of competition for adsorption sites and hydroxyl radicals [93].

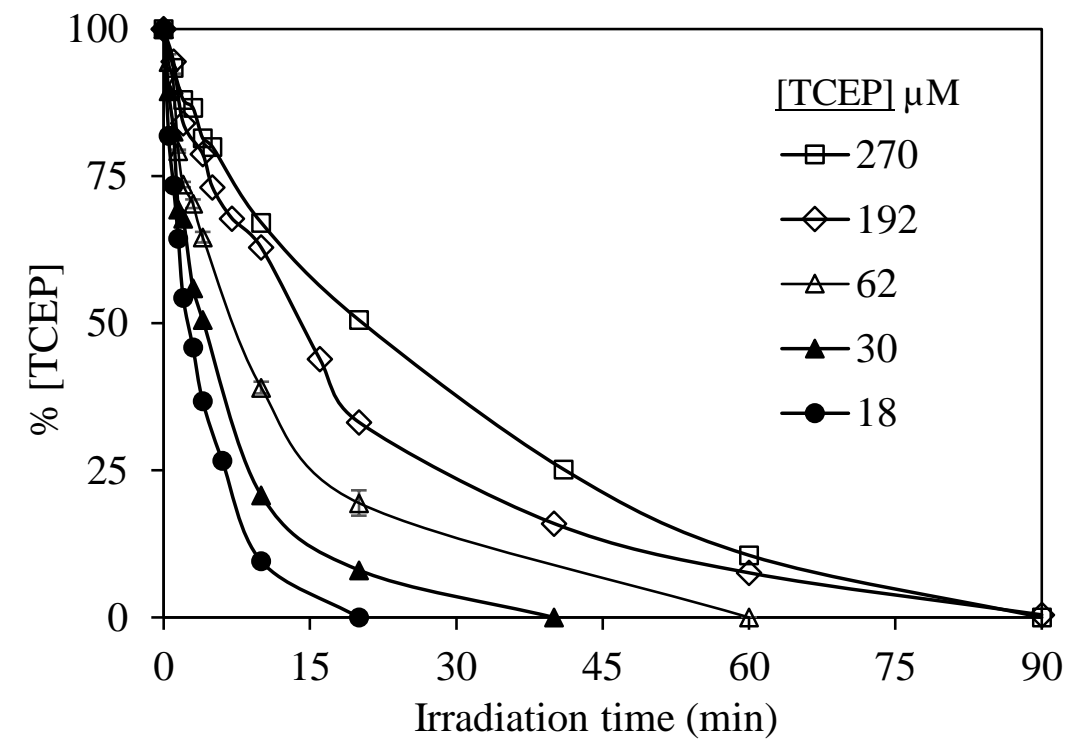

Figure 8. Degradation kinetics of TCEP $\left([\mathrm{TCEP}]_{0}=18-270 \mu \mathrm{M}\right)$ upon irradiation at 350 $\mathrm{nm}$ at $\mathrm{O}_{2}$-saturated $\mathrm{TiO}_{2}(0.10 \mathrm{~g} / \mathrm{L})$ aqueous suspension. 
Plots of pseudo-first-order kinetics for the $\mathrm{TiO}_{2}$ photocatalytic degradation of TCEP are presented in Figure 9. The rate constants (k) were calculated from the slope of the linear pseudo-first-order equation, $\left[\operatorname{lnC}_{t} / C_{0}=-k t\right]$, where $C_{t}$ and $C_{0}$ are the concentrations of TCEP at time $t$ and at the start of the reaction. The results are summarized in Table 3. While the results for a given concentration of TCEP are consistent with pseudofirst-order kinetics, by the virtue of the linear relationship of $\ln \left(\mathrm{C}_{\mathrm{t}} / \mathrm{C}_{0}\right)$ as a function of time, the change in the rate constant as a function of initial concentration suggests that the reaction kinetics are more complex than a simple pseudo-first-order reaction. The observed rate constant increases by order of magnitude when the substrate concentration is decreased by nearly 15 fold. Similarly, a reduction of the reaction order as a function of substrate concentration in the $\mathrm{TiO}_{2}$ photocatalysis has been reported by Sabin et al. [101]. The change in the rate constant can be the result of mass transfer limitations (adsorption $<->$ desorption) at the surface of $\mathrm{TiO}_{2}$.

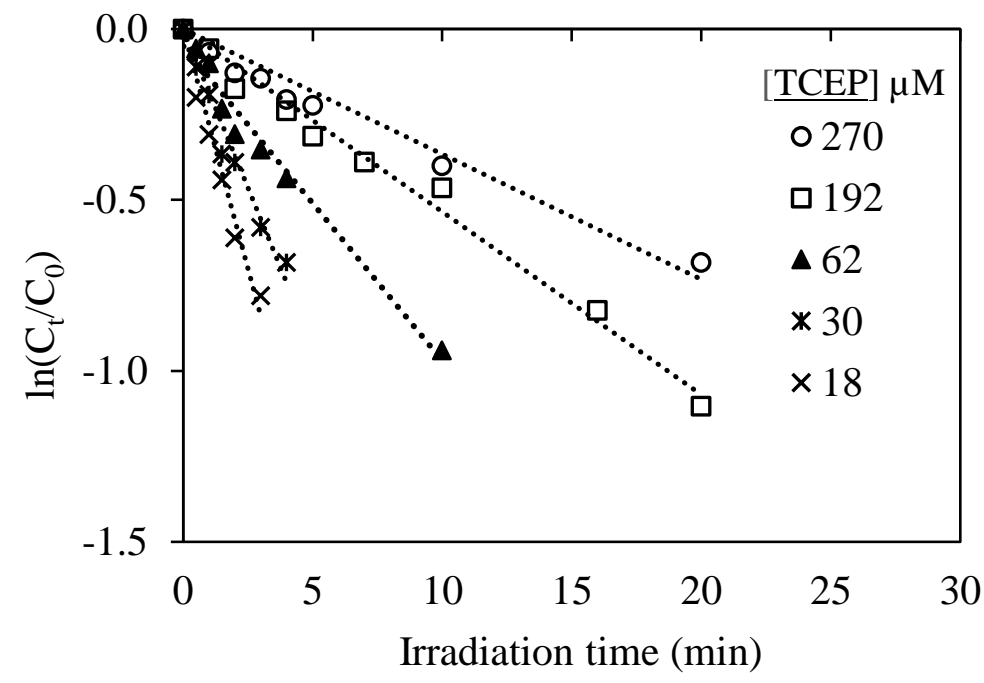

Figure 9. Pseudo-first-order kinetics plots of TCEP degradation upon irradiation at 350 $\mathrm{nm}$ in $\mathrm{O}_{2}$-saturated $\mathrm{TiO}_{2}(0.10 \mathrm{~g} / \mathrm{L})$ aqueous suspension. 
Table 3. Initial degradation rates and their corresponding pseudo-first-order rate constant of TCEP as a function of concentration by $\mathrm{TiO}_{2}$ photocatalytic oxidation in $\mathrm{O}_{2}$-saturated aqueous solution

\begin{tabular}{ccccc}
\hline $\begin{array}{c}{[\text { TCEP }]} \\
(\mu \mathrm{M})\end{array}$ & $\begin{array}{c}\text { Initial rate } \\
\left(\mu \mathrm{Mmin}^{-1}\right)\end{array}$ & $\begin{array}{c}\mathrm{R}^{2} \text { value for } \\
\text { initial rate }\end{array}$ & $\begin{array}{c}\text { Pseudo-first-order rate } \\
\text { constant }\left(\mathrm{min}^{-1}\right)\end{array}$ & $\begin{array}{c}\mathrm{R}^{2} \text { value for } \\
\text { rate constant }\end{array}$ \\
\hline 18 & 4.4 & 0.96 & 0.28 & 0.96 \\
30 & 5.9 & 0.95 & 0.19 & 0.97 \\
62 & 8.0 & 0.96 & 0.12 & 0.95 \\
192 & 10.6 & 0.95 & 0.05 & 0.98 \\
270 & 12.2 & 0.93 & 0.03 & 0.99 \\
\hline
\end{tabular}

The $\mathrm{TiO}_{2}$ photocatalysis is a heterogeneous process requiring adsorption and reaction at or near the surface of $\mathrm{TiO}_{2}[45,102,103]$. The Langmuir-Hinshelwood $(\mathrm{L}-\mathrm{H})$ kinetic model has been effectively employed in the modeling of $\mathrm{TiO}_{2}$ photocatalytic transformation to an extensive number of organics by plotting the initial degradation rates as a function of concentration $[48,49,104]$. The L-H equation is represented in Equation 13, where $r_{0}$ is the initial degradation rate of target materials, $\mathrm{C}_{0}$ is the initial concentration of substrate, $\mathrm{k}_{\mathrm{rxn}-\mathrm{LH}}$ is the reactivity constant, and $\mathrm{K}_{\mathrm{LH}}$ is the apparent equilibrium constant.

Langmuir-Hinshelwood equation: $1 / \mathrm{r}_{0}=1 / \mathrm{k}_{\mathrm{rxn}-\mathrm{LH}} \mathrm{K}_{\mathrm{LH}} \mathrm{C}_{0}+1 / \mathrm{k}_{\mathrm{rxn}-\mathrm{LH}}$

The L-H experiment was conducted over a range of initial concentrations $(18-270 \mu \mathrm{M})$ at constant $\mathrm{TiO}_{2}$ concentration under uniform light intensity. Using the value of the leastsquare fit correlation coefficient $\left(\mathrm{R}^{2} \geq 0.988\right)$ of the L-H plot (Figure 10), the degradation kinetics of TCEP are in good agreement with the L-H mechanism. The L-H kinetic parameters determined from the slope and intercept of the L-H plot are $\mathrm{K}_{\mathrm{LH}}=0.03 \mu \mathrm{M}^{-1}$ and $\mathrm{k}_{\mathrm{rxn}-\mathrm{LH}}=13.1 \mu \mathrm{M} \min ^{-1}$. The L-H kinetic parameters are often referred to as apparent 
kinetic parameters, which may not correlate to their original intended kinetic parameters [105]. However, the L-H kinetic parameters are valuable for predicting degradation rates and for making comparisons among different compounds over a range of reaction conditions [106]. The equilibrium constant, $\mathrm{K}_{\mathrm{LH}}$, is theoretically associated with the partitioning of TCEP at the surface of $\mathrm{TiO}_{2}$, and $\mathrm{k}_{\mathrm{rxn}-\mathrm{LH}}$ is a coefficient related to the reactivity of the target compounds (susceptibility of TCEP to degradation). The $\mathrm{TiO}_{2}$ photocatalytic induced degradation of TCEP adheres to pseudo-first-order and the L-H kinetic models despite the complex interplay among the production of hydroxyl radicals at the surface and the surface adsorption<->desorption of target compounds leading to the degradation.

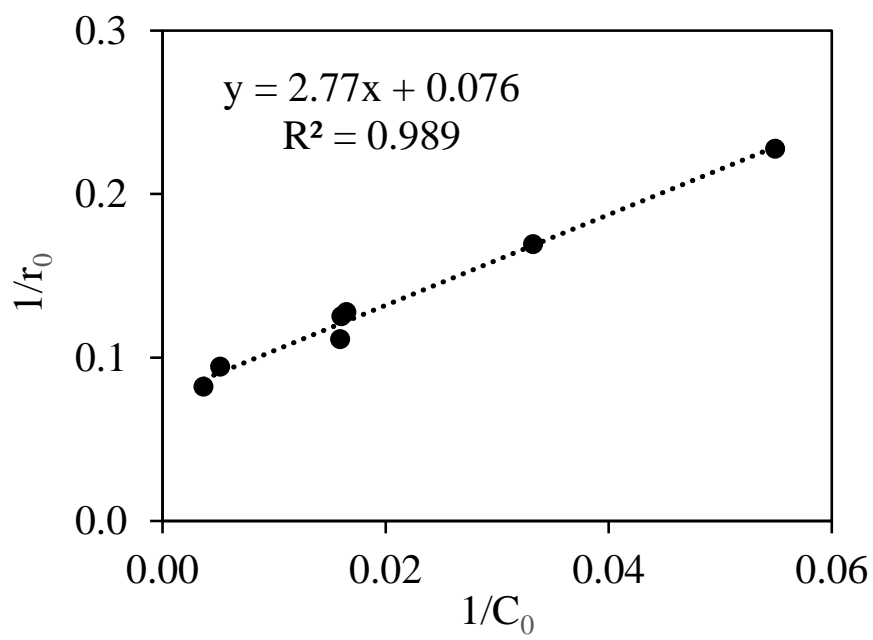

Figure 10. Langmuir-Hinshelwood plot of the degradation of TCEP $\left([\text { TCEP }]_{0}=18-270\right.$ $\mu \mathrm{M})$ upon irradiation at $350 \mathrm{~nm}$ at $\mathrm{O}_{2}$-saturated $\mathrm{TiO}_{2}(0.10 \mathrm{~g} / \mathrm{L})$ aqueous suspension.

\subsubsection{Mineralization of TCEP}

The $\mathrm{TiO}_{2}$ photocatalytic mineralization of TCEP was assessed by measuring the production of $\mathrm{PO}_{4}^{3-}$ and $\mathrm{Cl}^{-}$, Figure 11, as well as the total organic carbon (TOC) present 
in solution, Figure 12, as a function of irradiation time. Excellent phosphate and chloride mass balances were observed upon extended irradiation. Tris (2-chloroethyl) phosphate contains one phosphorus atom and three chlorine atoms.

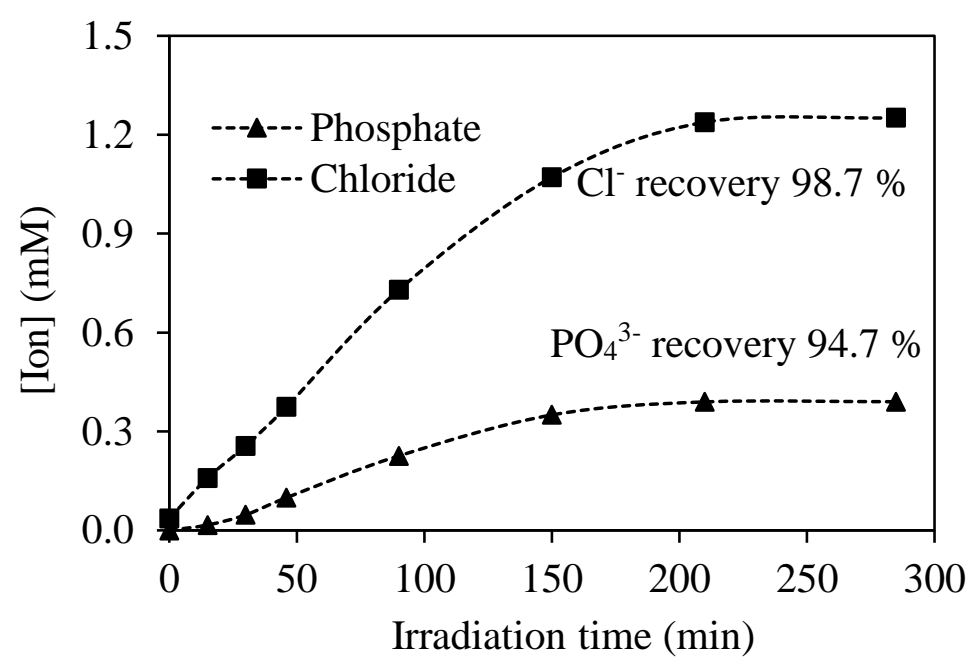

Figure 11. Evolution of $\mathrm{PO}_{4}{ }^{3-}$ and $\mathrm{Cl}^{-}$ion upon irradiation at $350 \mathrm{~nm}$ in $\mathrm{O}_{2}$-saturated $\mathrm{TiO}_{2}$ aqueous suspension. $[\mathrm{TCEP}]_{0}=0.422 \mathrm{mM},\left[\mathrm{TiO}_{2}\right]=0.10 \mathrm{~g} / \mathrm{l}$, and data were reproducible $\pm 5 \%$ on the basis of a representative triplicate runs.

From an initial concentration of $0.422 \mathrm{mM}$ of TCEP, $0.40 \mathrm{mM}$ of phosphate (94.7\%) and $1.25 \mathrm{mM}$ of chloride (98.7\%) ions were measured by IC. While Antonopoulou et al. reported an almost complete mass balance of chloride ions, a phosphorus mass balance of only $60 \%$ was reported during the $\mathrm{TiO}_{2}$ photocatalytic degradation of TCPP [93]. We observed $\mathrm{TiO}_{2}$ photocatalysis of TCEP was complete within an hour; however, to achieve the extensive transformation of TCEP and by-products to phosphate required extended irradiation. The delay in phosphate mass balance indicates the involvement of intermediate products $[107,108]$. The starting material, TCEP, is degraded within 50 mins, at which time the mass balances for chloride is $35 \%$ and for phosphate $25 \%$. Once the TCEP is fully 
degraded, the formation of chloride and phosphate continues for another $\sim 2$ hours of treatment. After $\sim 3$ hours of irradiation, mineralization to chloride and phosphate is $\geq$ $95 \%$. The delay in the formation of mineralization products relative to the disappearance of TCEP indicates the presence of chlorinated organic by-products with and without phosphorus at longer treatment times.

Mineralization of TCEP by $\mathrm{TiO}_{2}$ photocatalytic irradiation is further supported by the monitoring of the level of total organic carbon (TOC) in the reaction solution. TOC of irradiated TCEP solution was determined by a TOC-VCSH analyzer (Shimadzu, Japan) using a high-temperature platinum combustion method [109]. An aliquot of twenty mL of irradiated TCEP solution was filtered, then acidified to $\mathrm{pH}<2$ with $3 \mathrm{~N} \mathrm{HCl}$ and sparged with $\mathrm{CO}_{2}$-free compressed air before injection. The combustion derived $\mathrm{CO}_{2}$ was carried by ultra-zero grade compressed air and detected by a non-dispersive infrared $\mathrm{CO}_{2}$ detector. The initial [TCEP] was $110 \mu \mathrm{M}$ for TOC measurements in an aqueous solution irradiated over $\mathrm{TiO}_{2}$ photocatalyst. Results demonstrate (Figure 12) that $50 \%$ of TOC was removed from the reaction solution within one hour. Over the 2 hours of irradiation, more than $95 \%$ TOC removal indicating near complete mineralization.

\subsubsection{Effect of solution $\mathrm{pH}$ on $\mathrm{TiO}_{2}$ photocatalytic degradation of TCEP}

Solution $\mathrm{pH}$ can have a pronounced effect on the $\mathrm{TiO}_{2}$ photocatalytic degradation of organophosphorus compounds $[11,110]$. The effect of solution $\mathrm{pH}$ on photocatalytic 
degradation of TCEP was evaluated by varying the solution $\mathrm{pH}$ from highly acidic ( $\mathrm{pH} 2.0)$ to highly alkaline (pH 11.8) conditions, illustrated in Figure 13.

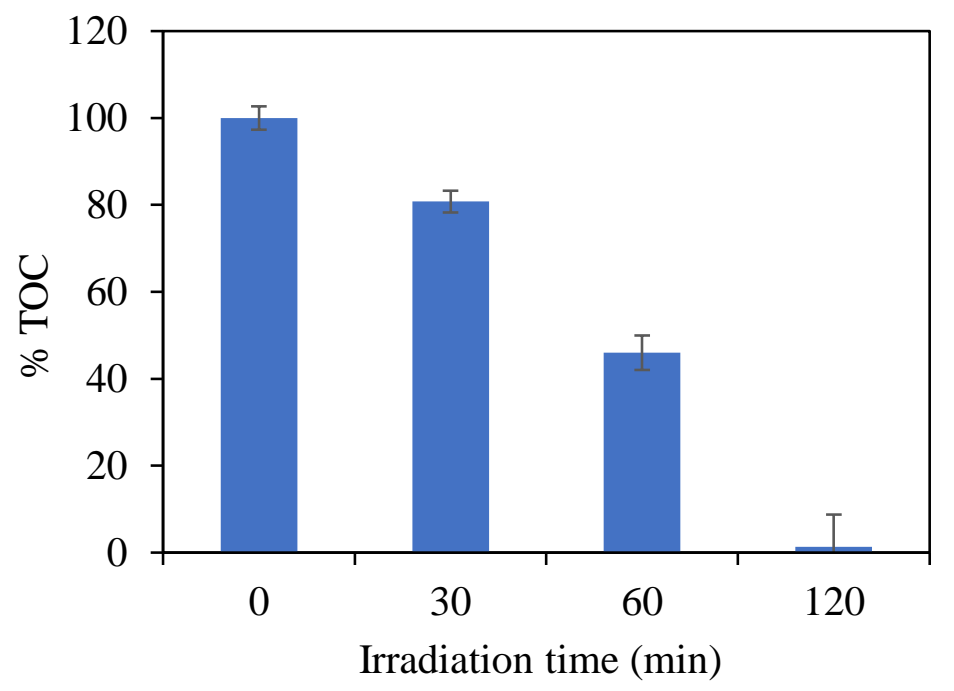

Figure 12. Reduction of total organic carbon (TOC) as a function of irradiation time of $\mathrm{TiO}_{2}$ photocatalysis of TCEP. $[\mathrm{TCEP}]_{0}=110 \mu \mathrm{M},\left[\mathrm{TiO}_{2}\right]=0.10 \mathrm{~g} / \mathrm{L}$, and standard deviation was $\pm 5 \%$.

At modestly acidic to basic conditions ( $\mathrm{pH} 4-9)$, the rates of degradation are relatively constant. However, under highly acidic $\mathrm{pH}$, the rate of TCEP degradation decreases while under highly basic $\mathrm{pH}$, the rate of degradation increases significantly. Since the phosphate ester functional group can undergo base hydrolysis, a dark control experiment at the highly alkaline $\mathrm{pH}$ was carried out. However, no significant loss of TCEP was observed under highly alkaline conditions in the dark. A number of factors can contribute to the enhanced photocatalytic degradation at alkaline conditions. The surface of $\mathrm{TiO}_{2}$ under alkaline conditions has negative charges, which can lead to reduced 
agglomeration compared to neutral conditions. Reduced agglomeration can contribute to the higher surface area, higher adsorption, and faster degradation rates [111]. In addition, at high $\mathrm{pH}$, the surface of $\mathrm{TiO}_{2}$ is negative, and thus the probability of adsorption of anionic by-products and phosphate decreases, leading to the faster degradation of a neutral target compound. The $\mathrm{pKa}$ of the hydroxyl radical is 11.5 . Thus at $\mathrm{pH} 11.8$, hydroxyl radical is converted to an oxygen atom radical anion $\left(\cdot \mathrm{OH} \rightleftharpoons \mathrm{O}^{-}+\mathrm{H}^{+}\right)$, which may have higher reactivity [112].

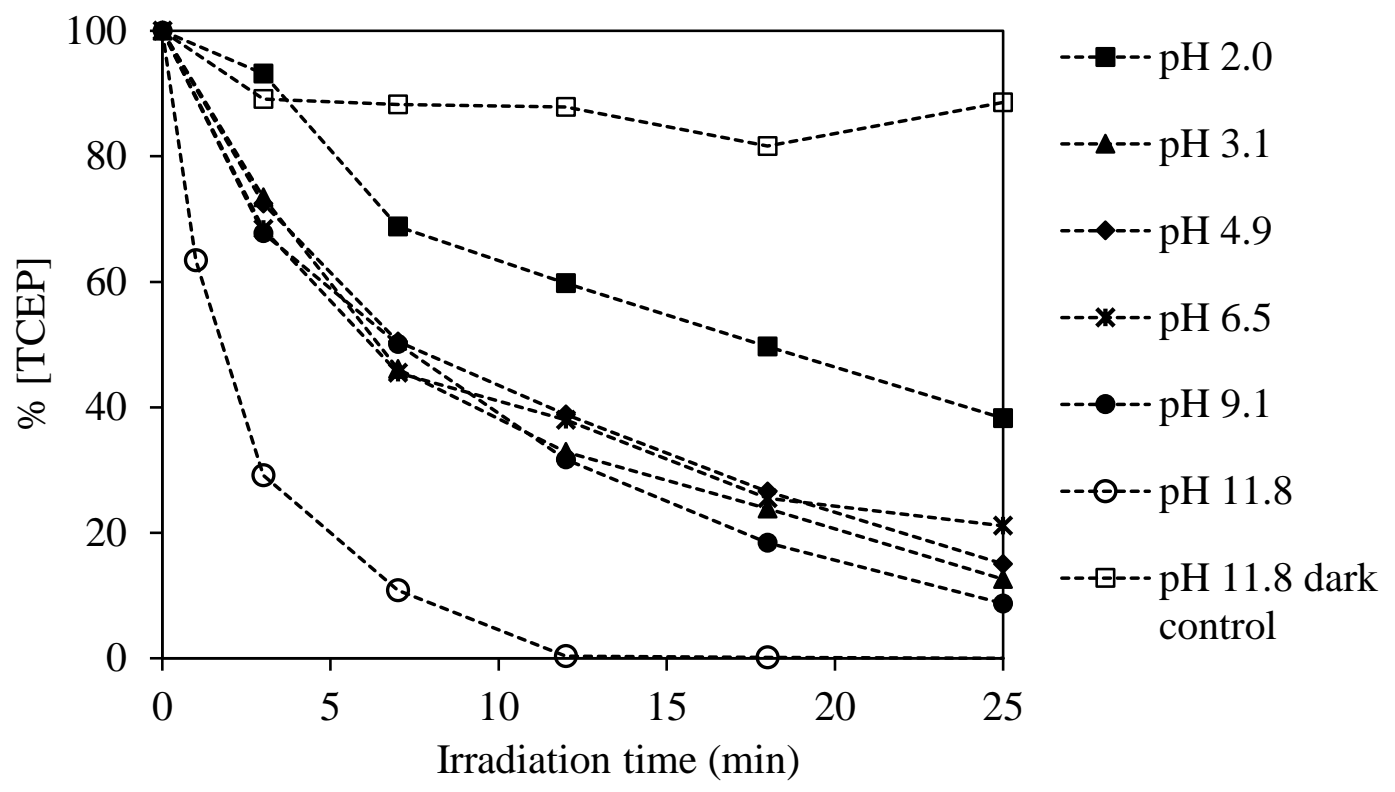

Figure 13. $\mathrm{TiO}_{2}$ photocatalytic degradation of TCEP in $\mathrm{O}_{2}$-saturated aqueous suspension at $350 \mathrm{~nm}$ irradiation over a range of solution $\mathrm{pH}$. [TCEP] $]_{0}=109 \mu \mathrm{M},\left[\mathrm{TiO}_{2}\right]=0.10 \mathrm{~g} / \mathrm{L}$.

\subsubsection{Scavenging studies to assess the contribution of hydroxyl radicals}

While hydroxyl radicals are often considered the predominant species initiating the degradation processes during $\mathrm{TiO}_{2}$ photocatalysis, other species can also contribute to the 
degradation. The reactions of hydroxyl radicals with organic compounds is a bimolecular process $[95,113,114]$. To probe the role of the hydroxyl radical in degradation kinetics, coumarin, a well-known hydroxyl radical trap, was added to the reaction solution [115]. Upon the addition of an equimolar amount of coumarin, the degradation decreases by $\sim 70$ $\%$, which indicates hydroxyl radicals are the main species participating in the degradation process of TCEP, as illustrated in Figure 14.

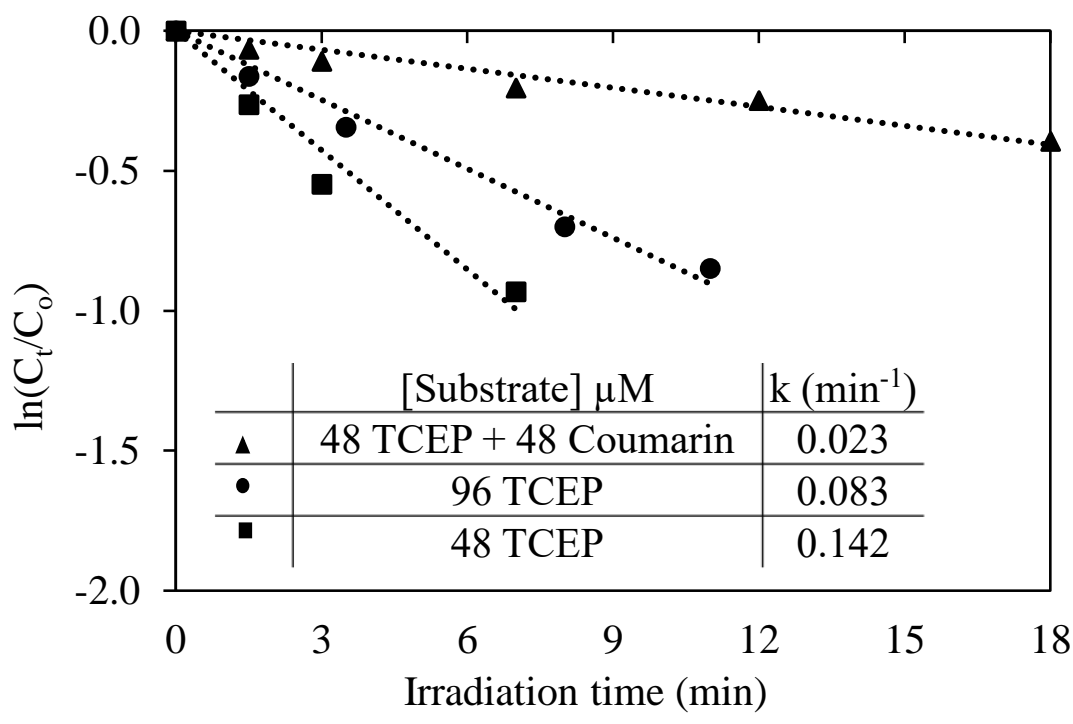

Figure 14. Effect of coumarin on the $\mathrm{TiO}_{2}$ photocatalytic degradation of TCEP at $350 \mathrm{~nm}$ in $\mathrm{O}_{2}$ saturated suspension.

The second-order rate constant $(\mathrm{k})$ of hydroxyl radical for coumarin is $\mathrm{k} \cdot \mathrm{OH}+\mathrm{COU}=2.9 \times 10^{9}$ $\mathrm{M}^{-1} \mathrm{~s}^{-1}$ and for TCEP is $\mathrm{k} \cdot \mathrm{OH}+\mathrm{TCEP}=5.6 \times 10^{8} \mathrm{M}^{-1} \mathrm{~s}^{-1}[95]$, the $\sim 70-75 \%$ reduction of TCEP degradation with the addition of coumarin is nicely correlated to competition kinetics for hydroxyl radical. The observed rate for TCEP degradation decreases 70-75 \% from 0.083 to $0.023 \mathrm{~min}^{-1}$ upon the addition of an equimolar amount of scavenger. A 50\% decrease in the reaction rate for TCEP degradation would be expected if the rate constants were 
equal. The $75 \%$ decrease observed reflects the faster bimolecular rate constant for coumarin being almost double the rate constant, $(2.9 / 5.6 \sim 52 \%)$ for the reaction of TCEP with $\bullet \mathrm{OH}$. Thus, diluting the relative concentration of TCEP by $50 \%$ decreases rate by 50 $\%$, and since the bimolecular hydroxyl radical rate constant for TCEP is $52 \%$ of the rate constant for coumarin, the overall theoretical rate decreases to $0.50 \times 0.52=0.26$ or $26 \%$. Normalization of the original observed rate for the dilution and difference in reactivity gives a theoretical rate $0.083 \mathrm{~min}^{-1} \times 0.26=0.22 \mathrm{~min}^{-1}$, which is within the experimental error of the observed rate $0.23 \mathrm{~min}^{-1}$ indicating that hydroxyl radical is the predominant species leading to the degradation of TCEP under our experimental conditions.

\subsubsection{Products studies}

Product studies are critical to establish the course of degradation and to determine the formation and fate of intermediates during the $\mathrm{TiO}_{2}$ photocatalytic degradation. The halogenated organophosphate esters are composed of carbon, hydrogen, oxygen, phosphorus, and halogen atoms. The final mineralized degradation products of TCEP are $\mathrm{CO}_{2}, \mathrm{H}_{2} \mathrm{O}$, phosphate $\left(\mathrm{PO}_{4}{ }^{3-}\right)$, and chloride $\left(\mathrm{Cl}^{-}\right)$ions. As discussed earlier, the $\mathrm{TiO}_{2}$ photocatalytic degradation of TCEP yields near the stoichiometric amount of chloride and phosphate ions as mineralization products, but intermediates products have yet to be reported. On the basis of previous studies of organophosphorus compounds, oxidation of alkyl phosphate ester groups can be achieved by $\mathrm{TiO}_{2}$ photocatalysis; thus, subsequent conversion of TCEP to the diester adduct, TCEP-diester subsequently to the TCEPmonoester is proposed as shown in Scheme 2 [11]. Mass spectrometry (MS) is a powerful 
tool and has been extensively used for identifying oxidative products in $\mathrm{TiO}_{2}$ photocatalysis. The MS identification relies primarily on molecular weight and often cannot distinguish among constitutional and geometric isomers. In addition, an elevated capillary temperature is used in MS during the ionization, which may lead to a potential transformation of products generated during photocatalytic oxidation. With above information in mind, NMR spectrometry allows for detailed characterization of the products at room temperature during $\mathrm{TiO}_{2}$ photocatalysis of TCEP. To identify the phosphorus-containing intermediate products during photocatalysis, the ${ }^{31} \mathrm{P}-\mathrm{NMR}$ spectra of TCEP reaction mixtures were recorded as a function of treatment time, illustrated in

Figure 15.

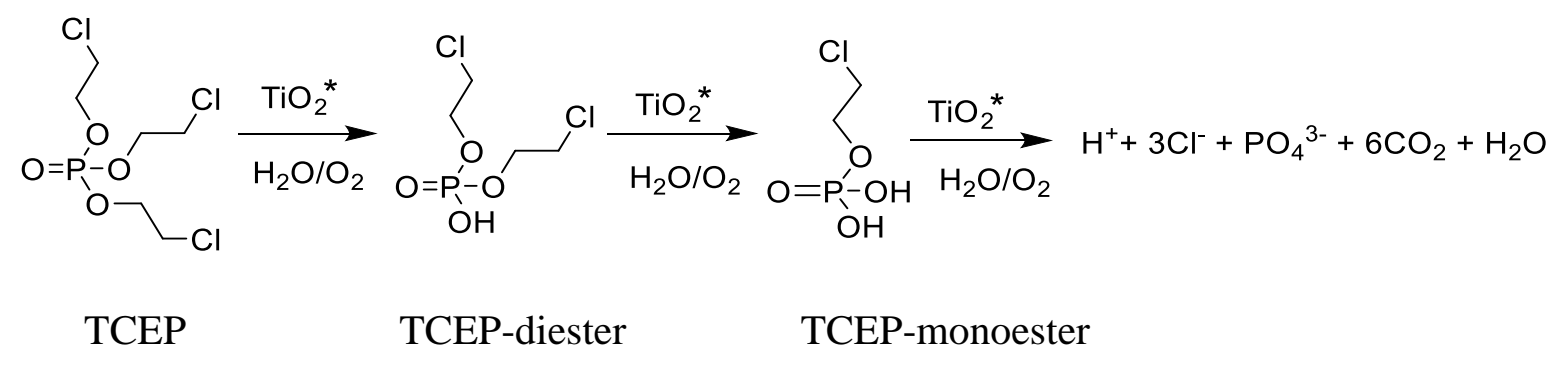

Scheme 2 Reaction pathways for $\mathrm{TiO}_{2}$ photocatalytic degradation of TCEP to mineralization products $\left(\mathrm{TiO}_{2} *\right.$ indicates photo activation).

We identified di (2-chloroethyl) hydrogen phosphate (TCEP-diester) as the main phosphorus-containing intermediate during the photocatalysis. The identity of the intermediate was confirmed by ${ }^{31} \mathrm{P}-\mathrm{NMR}$ and ${ }^{1} \mathrm{H}-\mathrm{NMR}$ via comparison with our prepared authentic samples. Complete mineralization of TCEP into phosphate ions was also confirmed by NMR studies comparing the signal of the ${ }^{31} \mathrm{P}-\mathrm{NMR}$ spectrum of phosphoric acid. 


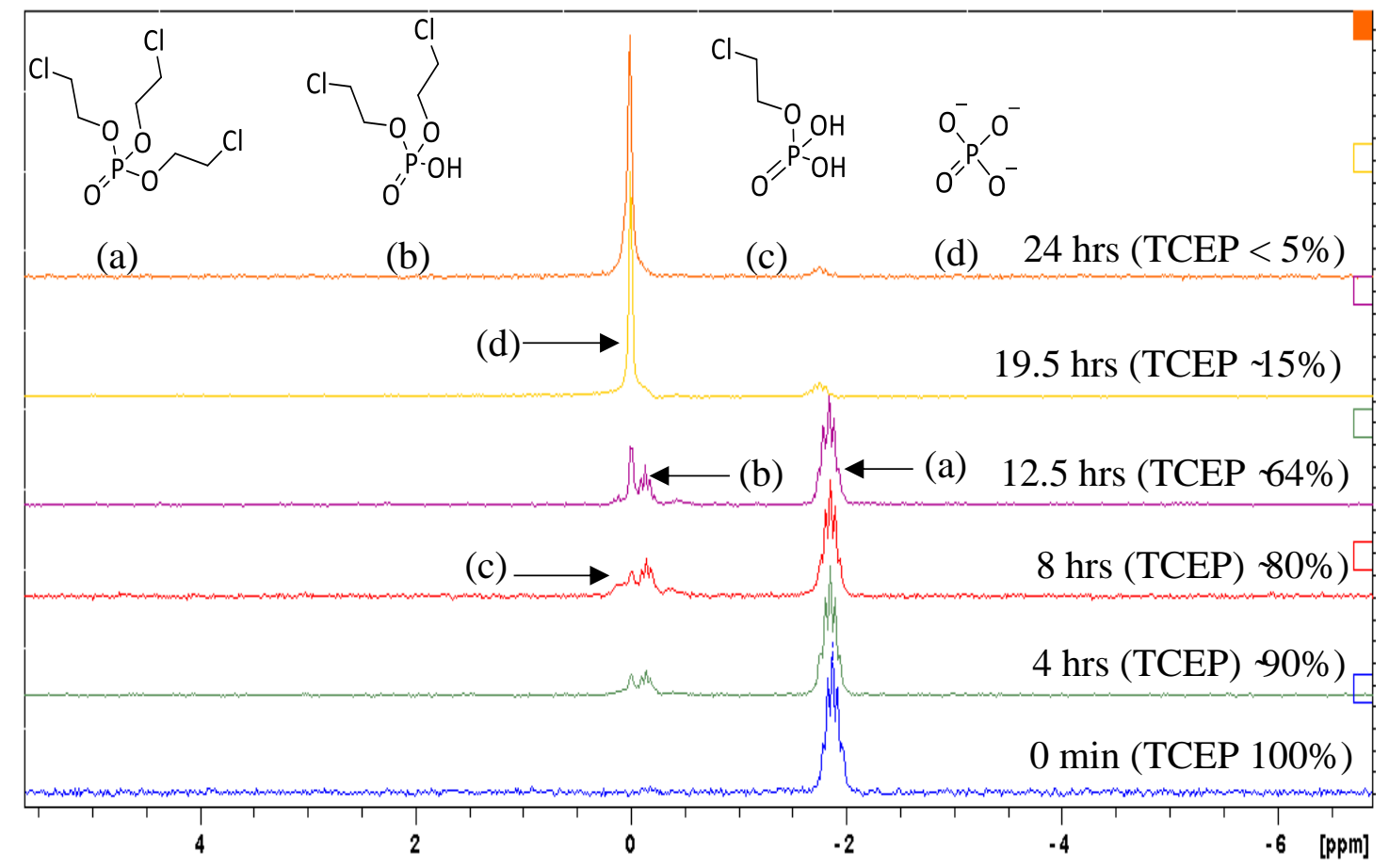

Figure 15. ${ }^{31} \mathrm{P}-\mathrm{NMR}$ spectra of $\mathrm{TiO}_{2}$ photocatalytic reaction mixture of TCEP $\left([\mathrm{TCEP}]_{0}=\right.$ $15.06 \mathrm{mM})$.

Previous reports established that phosphonates are transformed from diester to monoester via oxidation of ester side chain and finally mineralized to phosphates [11], and in the present study, monoester of TCEP, 2-chloroethyl dihydrogen phosphate (TCEPmonoester), was also identified. The ${ }^{1} \mathrm{H}-\mathrm{NMR}$ characterization of the reaction solutions did not indicate the presence of detectable amounts of chloroacetic acid, chloroacetaldehyde, 2- chloroethanol. The production and lifetime of low molecular weight organochlorine compounds appear to be short given the excellent $\mathrm{Cl}^{-}$mass balance upon continued irradiation. Ruan et al. [94] proposed ester-type intermediates in the degradation of TCEP by $\mathrm{UV} / \mathrm{H}_{2} \mathrm{O}_{2}$. However, they only identified small organic molecules like formic acid, 
acetic acid, and phosphate in $\mathrm{PO}_{4}{ }^{3-}$ without reporting any organophosphorus or organochlorine by-products. The time profile for the disappearance of TCEP and the formation of diester, monoester, and phosphate products during the photocatalysis is illustrated in Figure 16.

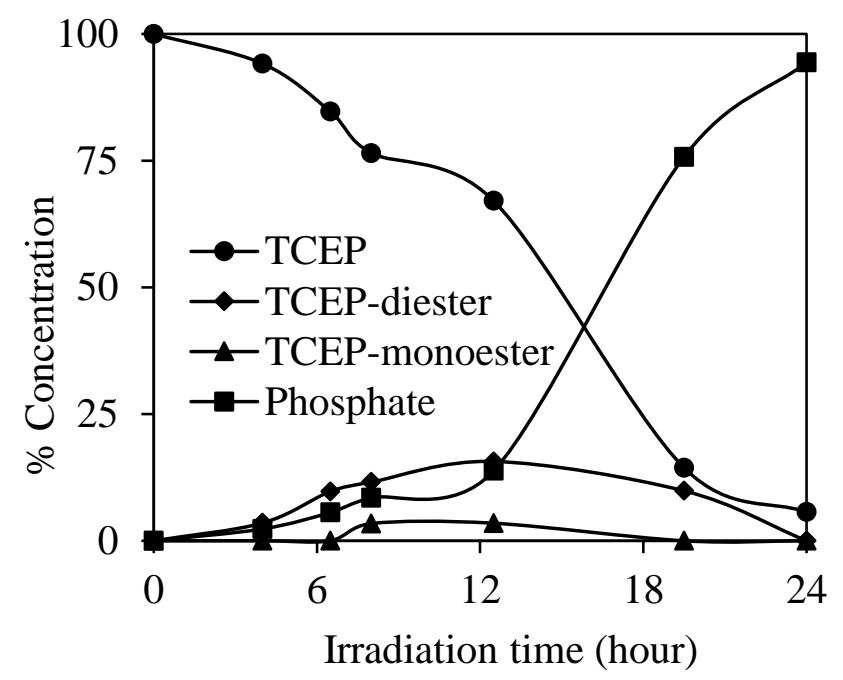

Figure 16. Phosphorus-containing product distribution during $\mathrm{TiO}_{2}$ photocatalysis of TCEP $\left([T C E P]_{0}=15.06 \mathrm{mM}\right)$ in the $\mathrm{D}_{2} \mathrm{O}$ solution monitored by ${ }^{31} \mathrm{P}-\mathrm{NMR}$.

\subsubsection{Mechanistic consideration}

A number of reaction mechanisms can be envisioned to explain the formation of major diester type compounds of TCEP. The hydroxyl radical $(\bullet \mathrm{OH})$ reacts with an organic molecule via one of the three different mechanisms: hydrogen atom abstraction, electrophilic addition to the double bond, and electron transfer from an organic molecule. Following these insights and detailed mechanistic studies of related organophosphates, probable mechanisms for the hydroxyl radical-mediated conversion of TCEP into its diester, monoesters, and finally to mineralization are shown in Figure 17 involving 
hydrogen abstraction mechanism. In the abstraction mechanism, a hydrogen atom is abstracted from ethyl ester carbon leading to the formation of a carbon-centered radical. The hydrogens alpha to the oxygen atom and chlorine atom will be activated towards abstraction by electronic effects, but the more reactive position should be alpha to the oxygen atom. The resulting carbon-centered radical can undergo further oxidation leading to the formation of an acetal, either by direct reaction with another hydroxyl radical, which in aqueous solution will be converted to the partially hydrolyzed ester or by the addition of oxygen to form a peroxyl radical. The dimerization of two peroxyl radicals, followed by extrusion of $\mathrm{O}_{2}$ via a Russell mechanism, can also be used to explain the observed products [11]. Oxidation of the remaining 2-chloroethoxy group yields 2-chloroethyl dihydrogen phosphate. Subsequent hydroxyl radical-mediated oxidation can convert the diester adduct to monoester adduct and subsequently to phosphate. The formation of di (2-chloroethyl) hydrogen phosphate and 2-chloroethyl dihydrogen phosphates are consistent with the hydroxyl radical-mediated pathways, even though the 2-chloroethyl dihydrogen phosphate disappears quickly. This may be caused by the hydroxyl radicals readily oxidizing the 2chloroethyl-dihydrogen phosphate at the surface of the photocatalyst and finally mineralization to phosphate ion. 

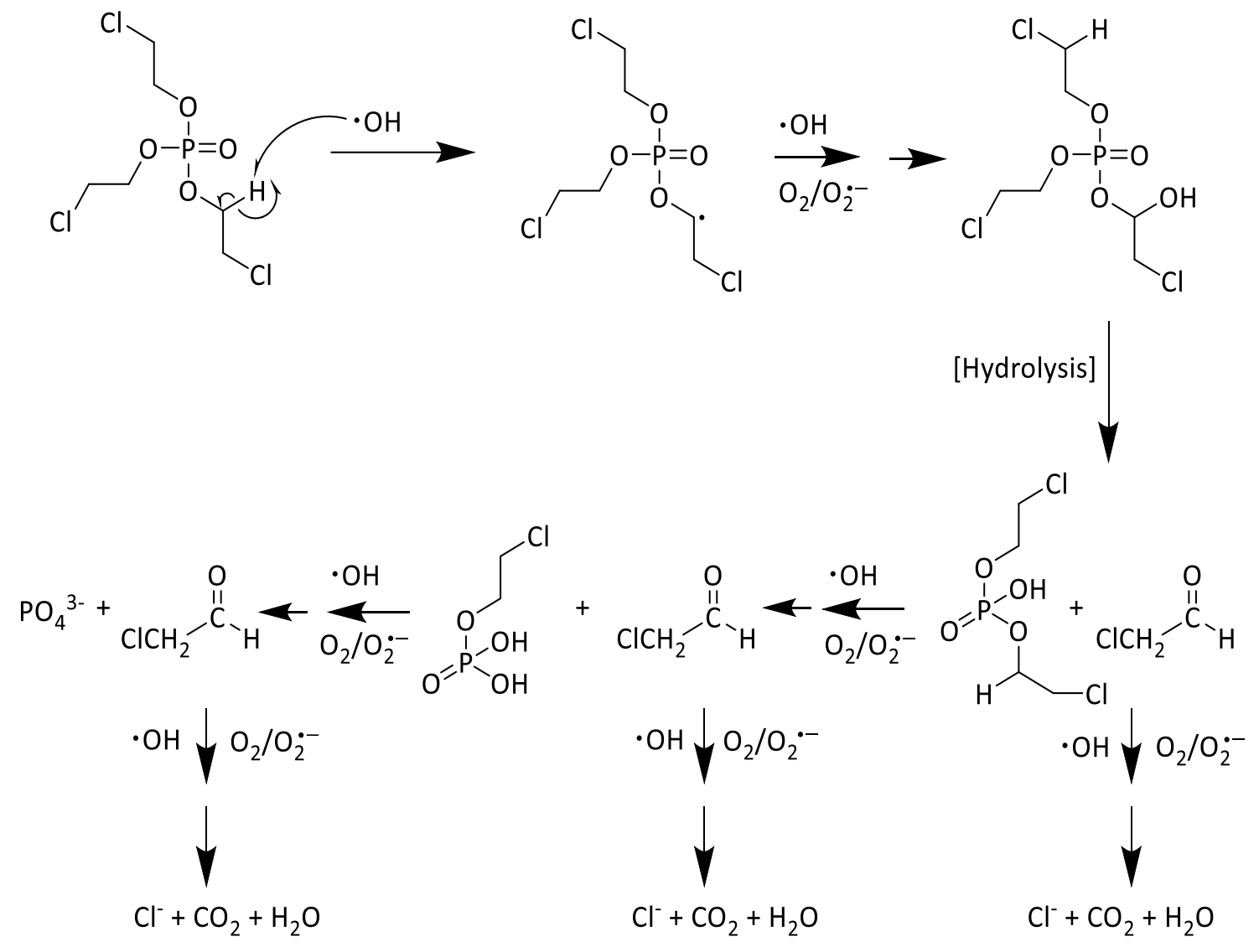

Figure 17. Proposed mechanism for the hydroxyl radical-mediated photocatalytic degradation of TCEP.

\subsection{Conclusions}

We have shown the $\mathrm{TiO}_{2}$ photocatalytic degradation of the organophosphate flame retardant, tris (2-chloroethyl) phosphate (TCEP), is effective upon the irradiation at 350 $\mathrm{nm}$ in oxygen-saturated aqueous suspension. The degradation follows pseudo-first-order kinetics with varying rate constant depending on the initial concentration of TCEP and fits the Langmuir-Hinshelwood model. The apparent kinetic parameters obtained from the application of these models can be used for predictive purposes and to address treatment 
objectives. Intermediate products included the di- and mono-esters adducts, which were conclusively identified by comparison with authentic samples using ${ }^{1} \mathrm{H}-$ and ${ }^{31} \mathrm{P}-\mathrm{NMR}$. Final products from extended irradiation demonstrate nearly complete mineralization can be obtained upon extended treatment. Mechanistic consideration indicates the degradation proceeds via hydroxyl radical-mediated pathways. These results suggest that $\mathrm{TiO}_{2}$ photocatalytic oxidation will be useful for the decontamination of aqueous solutions contaminated with the recalcitrant organophosphate compounds. 
CHAPTER 3 DEVELOPMENT OF VISIBLE LIGHT-ACTIVATED

TITANIUM DIOXIDE PHOTOCATALYST 


\subsection{Abstract}

The photocatalytic activities of reduced titanium dioxide $\left(\mathrm{TiO}_{2}\right)$ materials have been investigated by measuring their ability to produce hydroxyl radical upon UV and visible light irradiation. Degussa $\mathrm{P} 25 \mathrm{TiO}_{2}$ was doped with nitrogen $(\mathrm{N})$, fluorine $(\mathrm{F})$, and/or phosphorus (P) and then subjected to surface modification employing a thermophysicochemical process in the presence of a reducing agent, sodium borohydride $\left(\mathrm{NaBH}_{4}\right)$. The reduced $\mathrm{TiO}_{2}$ materials were characterized by XRD, HRTEM, EDXRF, UVVisible, and Raman spectrometry. Surface doping of $\mathrm{TiO}_{2}$ was employed to modulate the band gap energies into the visible wavelength region for better overlap with the solar spectrum. Hydroxyl radical generation, central to $\mathrm{TiO}_{2}$ photocatalytic water purification applications, was quantitated using coumarin as a trap under UV and visible light irradiation of the reduced $\mathrm{TiO}_{2}$ materials. At $350 \mathrm{~nm}$ irradiation, the yield of hydroxyl radicals generated by the reduced forms of $\mathrm{TiO}_{2}$ was nearly $90 \%$ of hydroxyl radicals generated by the Degussa $\mathrm{P} 25 \mathrm{TiO}_{2}$. Hydroxyl radical generation by these reduced forms of $\mathrm{TiO}_{2}$ was also observed under visible light irradiation (419 and $450 \mathrm{~nm}$ ). These results demonstrated a simple surface modification of doped $\mathrm{TiO}_{2}$ can lead to visible light activity, which is important for more economical solar driven applications of $\mathrm{TiO}_{2}$ photocatalysis. 


\subsection{Introduction}

While titanium dioxide $\left(\mathrm{TiO}_{2}\right)$ has attracted remarkable attention as a photocatalyst over the past few decades for the treatment of wastewater and the degradation of hazardous chemicals, significant industrial applications and commercial benefits have yet to be realized $[46,116,117]$. The $\mathrm{TiO}_{2}$ photocatalysis requires absorption of a photon typically in the UV region $(\lambda<400 \mathrm{~nm})$ to generate an electron $\left(\mathrm{e}_{\mathrm{CB}}^{-}\right) / \mathrm{hole}\left(\mathrm{h}^{+} \mathrm{vB}\right)$ pair, Equation 14, which can initiate degradation through the production of reactive oxygen species (ROS) as outlined below in Equations 14-18. The recombination of the electron/hole pair is often a dominant process that eliminates the potential for the formation of ROS. In competition with recombination, the electron/hole pairs can migrate to the surface of $\mathrm{TiO}_{2}$ and form ROS in the presence of water and oxygen [45,118-120]. While direct oxidation and reduction of target substrates by electron/hole pair can also be envisioned, such direct transformations are generally not competitive in aqueous solution. The primary processes leading to degradation of target pollutants usually involve the formation of ROS, hydroxyl radical $(\bullet \mathrm{OH})$, Equations 15 and 18, superoxide anion radical $\left(\mathrm{O}_{2}{ }^{-}\right)$, Equation 16, and hydrogen peroxide $\left(\mathrm{H}_{2} \mathrm{O}_{2}\right)$, Equation 17. Although a number of ROS are generated in a $\mathrm{TiO}_{2}$ photo-oxidation process and can lead to the mineralization of organic pollutants, $\bullet \mathrm{OH}$ is considered the primary species leading to degradation $[49,51,121]$.

$$
\begin{aligned}
& \mathrm{TiO}_{2}+h v \rightarrow \mathrm{h}^{+} \mathrm{VB}^{-} \mathrm{e}_{\mathrm{CB}}^{-} \\
& \mathrm{H}_{2} \mathrm{O}+\mathrm{h}^{+} \mathrm{VB} \rightarrow \mathrm{H}^{+}+\cdot \mathrm{OH} \\
& \mathrm{O}_{2}+\mathrm{e}^{-} \mathrm{CB} \rightarrow \mathrm{O}_{2}^{\cdot-} \\
& 2 \mathrm{H}_{2} \mathrm{O}+\mathrm{O}_{2}^{\cdot-} \rightarrow \mathrm{H}_{2} \mathrm{O}_{2}+2 \mathrm{HO} \bullet+\mathrm{O}_{2}
\end{aligned}
$$




$$
\mathrm{H}_{2} \mathrm{O}_{2}+\mathrm{e}_{\mathrm{CB}}^{-} \rightarrow 2 \mathrm{HO} \bullet
$$

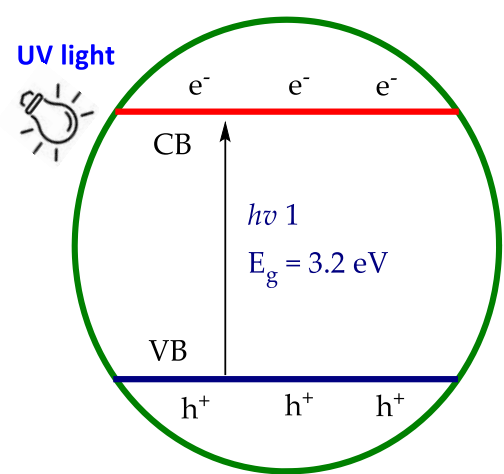

Undoped $\mathrm{TiO}_{2}$

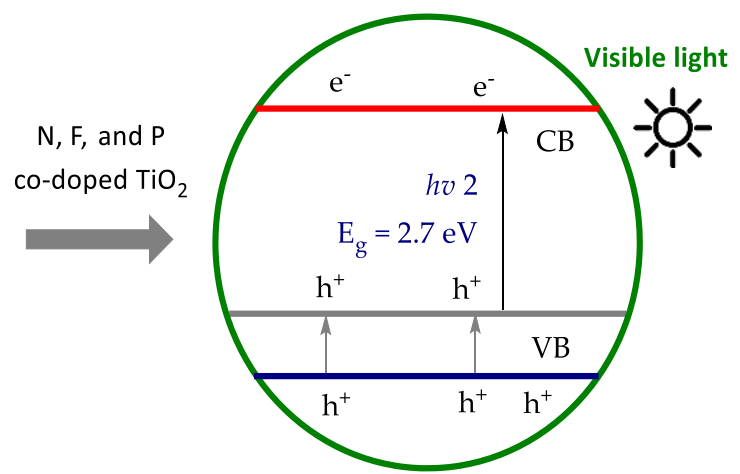

$\mathrm{N}, \mathrm{F}$, and $\mathrm{P}$ co-doped $\mathrm{TiO}_{2}$

Figure 18. Schematic band gap energy levels of doped and undoped $\mathrm{TiO}_{2}$. $\mathrm{E}_{\mathrm{g}}$ stands for the band energy gap between the valance band (VB) and conduction band (CB).

The $\mathrm{TiO}_{2}$ is readily available, inexpensive, and chemically stable; however, there are two major drawbacks to $\mathrm{TiO}_{2}$ photocatalysis [46,122]. Firstly, the photoexcitation of unmodified $\mathrm{TiO}_{2}$ requires UV light. Secondly, the quantum yield for photochemical production of ROS is low because of the rapid recombination of electron/hole pairs $[88,120]$. The solar spectrum is predominately in the visible region, with only $\sim 5 \%$ of the total irradiation in the UV region. A major challenge in $\mathrm{TiO}_{2}$ photocatalysis is to utilize the visible region of the solar spectrum. Extension of the $\mathrm{TiO}_{2}$ light absorption profile into the visible light region offers significantly improved economic viability compared to those requiring UV activation. A number of techniques including non-metal doping with nitrogen $(\mathrm{N})$, sulfur (S), carbon (C), fluorine (F), iodine (I), boron (B), non-metals co-doping, metal deposition, dye sensitization, semiconductor coupling, and enriching the oxygen content of $\mathrm{TiO}_{2}$ have led to a variety visible light-activated (VLA) $\mathrm{TiO}_{2}$ materials over the last 
decade $[46,116,123-128]$. A number of metal doping materials have been previously explored; however, metal doping often produces undesirable metal titanates at high processing temperatures [129-132]. Non-metal doping or co-doping into the $\mathrm{TiO}_{2}$ modifies the valence band level of $\mathrm{TiO}_{2}$, reducing the effective band gap energy, as shown in Figure 18, and modulating the light absorption into the visible light region [133-138]. Although the incorporation of dopant elements can result in the advantage of narrowing band gap energies, dopants can influence charge carrier recombination processes, and the limited solubility of dopants into the bulk materials as well as thermal instability have limited photocatalytic applications of doped $\mathrm{TiO}_{2}$ materials[139-143].

Simple reduction of $\mathrm{Ti}$ within the $\mathrm{TiO}_{2}$ matrix leads to stable colored $\mathrm{TiO}_{2}$ with visible light-absorbing properties, and these materials have attracted extensive attention because of enhanced photocatalytic activity [144-147]. Notably, black $\mathrm{TiO}_{2}$ prepared from the hydrogenation of $\mathrm{TiO}_{2}$ nanocrystals at high-pressure exhibits relatively low band gap energy and enhanced photocatalytic activity for water splitting and dye degradation [144]. A number of approaches, including high pressure, high temperature, plasma-assisted hydrogenation, and high-temperature aluminum vapor reduction, have been explored for the preparation of $\mathrm{VLA} \mathrm{TiO}_{2}$ materials [145-148]. High-pressure and/or high-temperature protocols are often experimentally challenging and/or expensive. Recently, Tan et al. developed a fast and simple chemical reduction method for the production of colored $\mathrm{TiO}_{2}$ through a controllable solid-state reaction of $\mathrm{NaBH}_{4}$ and crystalline $\mathrm{TiO}_{2}$ at moderate temperature $\left(<300{ }^{\circ} \mathrm{C}\right)[149]$. The resulting reduced $\mathrm{TiO}_{2}$ material possessed a narrow band gap with a crystalline core/amorphous shell structure $\left(\mathrm{TiO}_{2} @ \mathrm{TiO}_{2-\mathrm{x}}\right)$ containing 
oxygen vacancies at the surface of $\mathrm{TiO}_{2}$ promoting the separation of charge carriers and leading to improved VLA photocatalytic performance. Herein, we synthesized reduced codoped $\mathrm{P} 25 \mathrm{TiO}_{2}$ through thermal treatment in the presence of $\mathrm{NaBH}_{4}$ in an attempt to extend the $\mathrm{TiO}_{2}$ photocatalytic function into the visible light region. Although reduction and co-doping of $\mathrm{TiO}_{2}$ can narrow band gap energies appropriate for the absorption of visible light, enhanced visible-light photocatalytic activity is not ensured [46]. The photocatalytic activity is generally associated with a redox reaction initiated by the photogenerated charge carriers. Assessment and comparisons of the photocatalytic activity of different $\mathrm{TiO}_{2}$ materials are challenging because of the variation of experimental conditions, equipment design, flux intensity, loading, band gap, surface area, and crystal lattice and composition. While the application of $\mathrm{TiO}_{2}$ photocatalysis for remediation of pollutants and toxins in aqueous media has been studied extensively, assessing the specific effectiveness of the photocatalyst is still not standardized [150-155]. Since $\bullet O H$ is generally the primary species initiating the degradation of target pollutants during $\mathrm{TiO}_{2}$ photocatalysis, monitoring $\bullet \mathrm{OH}$ production during $\mathrm{TiO}_{2}$ photocatalysis is an effective way to evaluate $\mathrm{TiO}_{2}$ photocatalytic activity. Noteworthy, Xiang et al. reported an $\mathrm{OH}$-index parameter, as expressed in Equation 19, to assess the activity of a photocatalyst [155].

$$
\mathrm{OH} \text {-index }=\left(\mathrm{r} / \mathrm{r}_{0}\right) \times 100
$$

where $\mathrm{r}$ and $\mathrm{r}_{0}$ are the formation rate of $\bullet \mathrm{OH}$ on the irradiated photocatalyst and reference photocatalyst $\mathrm{P} 25 \mathrm{TiO}_{2}$ respectively. The $\mathrm{P} 25 \mathrm{TiO}_{2}$ was taken as the reference standard for the production of $\bullet \mathrm{OH}$ under UV irradiation as one of the most extensively investigated and most active commercial photocatalyst [154]. 
Direct measurement of $\bullet \mathrm{OH}$ is difficult because its short wavelength $(<230 \mathrm{~nm})$ absorbance makes it challenging to monitor, and its high reactivity results in an extremely short lifetime (often $10^{-9} \mathrm{~s}$ ) [121]. Given these limitations, indirect methods have been established to trap hydroxyl radicals with the formation of stable hydroxyl radical adducts. Among hydroxyl radical traps, coumarin (COU) forms a hydroxyl radical adduct that can be readily quantitated using fluorescence spectroscopy. We have employed coumarin, which yields 7-hydroxycoumarin (7HC) upon trapping of hydroxyl radical, as shown in Figure 19. The concentration of $7 \mathrm{HC}$ measured by fluorescence is proportional to the production of hydroxyl radicals by $\mathrm{TiO}_{2}$ materials under $\mathrm{UV}$ and visible light [115].

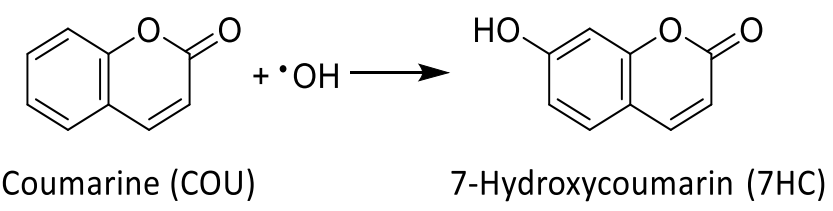

Figure 19. The reaction of $\mathrm{COU}$ and $\bullet \mathrm{OH}$ for the production of highly florescent $7 \mathrm{HC}$.

One of the purposes of the study was to develop visible light active forms of $\mathrm{TiO}_{2}$ through a simple reduction process. We prepared the $\mathrm{VLA} \mathrm{TiO}_{2}$ materials using a controllable solid-state thermal physicochemical process. Detailed physical and chemical characterization of the prepared materials, along with their optical properties, is reported herein. Hydroxyl radical production is reported as a measure of the viability of these $\mathrm{TiO}_{2}$ materials for the destruction of environmental contaminants in potential water treatment applications. The study also compares the relative photocatalytic efficiency of prepared $\mathrm{TiO}_{2}$ materials using $\mathrm{OH}$-index. Our results provide insight into the development of visible light-activated photocatalysts for the destruction of organic pollutants in water. 


\subsection{Experimental section}

\subsubsection{Materials}

The P25 $\mathrm{TiO}_{2}$ donated by Degussa was employed as a starting material. $\mathrm{N}$ and $\mathrm{F}$ co-doped $\mathrm{TiO}_{2}\left(\mathrm{NF}-\mathrm{TiO}_{2}\right)$ and $\mathrm{N}, \mathrm{F}$, and $\mathrm{P}$ co-doped $\mathrm{TiO}_{2}\left(\mathrm{NFP}-\mathrm{TiO}_{2}\right)$ were prepared by using titanium tetraisopropoxide (97.0 \%), isopropanol (99.0 \%), ammonium hexafluorophosphate (NFP) $(\geq 95.0 \%)$, urea (N) $(\geq 98.0 \%)$, trifluoroacetic acid (TFA) $(99.0 \%)$ and phosphoric acid (PA) (85 wt. \%). A detailed experimental procedure to prepare these samples is provided in Ref [122]. Sodium borohydride $\left(\mathrm{NaBH}_{4}\right)$ obtained from Acros Organics was $98 \%$ pure and used without further purification. Coumarin was purchased from MP Biomedicals, LLC. 7-Hydroxycoumarin (7HC) was $99 \%$ pure and purchased from Acros Organics. The air used to purge samples were from Trigas of the highest available purity. Millipore water $(18 \mathrm{M} \Omega \cdot \mathrm{cm})$ was used for the preparation of all aqueous solutions.

\subsubsection{Preparation of reduced $\mathrm{TiO}_{2}$ materials}

In a typical procedure, $4.0 \mathrm{~g}$ of $\mathrm{P} 25 \mathrm{TiO}_{2}$ was mixed with $1.5 \mathrm{~g}$ of $\mathrm{NaBH}_{4}$ in an agate mortar and thoroughly ground with a pestle for $30 \mathrm{~min}$ at room temperature. The resulting mixture was transferred to a porcelain boat and placed in a tubular furnace. Gradient heat was applied at a rate of $10{ }^{\circ} \mathrm{C} \mathrm{min}^{-1}$ from room temperature to $300{ }^{\circ} \mathrm{C}$ under an argon atmosphere and baked for an additional $30-70 \mathrm{~min}$ at $300{ }^{\circ} \mathrm{C}$. The sample was removed from the furnace and allowed to naturally cool to room temperature. The resulting 
colored $\mathrm{TiO}_{2}$ was washed with deionized water and ethanol several times to eliminate unreacted $\mathrm{NaBH}_{4}$ and undesired by-products. The washed sample was stored for characterization after drying at $70{ }^{\circ} \mathrm{C}$ for one hour. A series of reduced forms of $\mathrm{NF}^{-\mathrm{TiO}_{2}}$ $\left(\mathrm{NF}-\mathrm{TiO}_{2}{ }^{\text {red }}\right)$ and reduced forms of $\mathrm{NFP}-\mathrm{TiO}_{2}\left(\mathrm{NFP}-\mathrm{TiO}_{2}{ }^{\text {red }}\right)$ were prepared as a function of reduction time.

\subsubsection{Characterization of reduced $\mathrm{TiO}_{2}$ materials}

The X-ray diffraction (XRD) patterns were taken for the reduced $\mathrm{TiO}_{2}$ materials employing a Bruker Advance D8 X-ray diffractometer, with $\mathrm{Cu} \mathrm{K} \alpha(\lambda=1.54056 \AA)$ radiation with continuous scanning in the range of $10^{\circ}<2 \Theta<90^{\circ}$. Structure, surface morphology, and microstructure of prepared materials were characterized by highresolution transmission electron microscope (HRTEM) and STEM imaging studies using FEI TITAN G2 80-300 operated at $300 \mathrm{kV}$. Samples were sonicated and placed onto a carbon-coated copper grid for scanning by microscope. The concentration of N, F, P, and $\mathrm{Ti}$ in doped $\mathrm{TiO}_{2}$ samples was determined using the energy dispersive $\mathrm{X}$-ray fluorescence (EDXRF) analyses. The vibrational spectroscopy of hybrid nanostructure was identified using the Thermo Scientific XDR Raman microscope employing a $532 \mathrm{~nm}$ laser at $5 \mathrm{~mW}$ power. The UV-Visible absorption spectra of the various $\mathrm{TiO}_{2}$ materials were recorded at room temperature on a Varian Cary 100 Bio UV-Visible spectrophotometer in the wavelength range of 220-800 $\mathrm{nm}$. The band gap of the prepared samples was calculated from Kubelka-Munk plots. 


\subsubsection{Photocatalytic experiment}

The illumination of the $\mathrm{TiO}_{2}$ suspension was carried out in a Rayonet Photochemical Reactor equipped with a cooling fan and up to 16 lamps in a merry-goround arrangement (details of the reactor, model RPR-100, are available at Southern New England Ultra Violet Company) [156]. Three sets of lamps provide specific irradiation centered around 350, 419, or $450 \mathrm{~nm}$. Eight lamps equally distributed within the reactor were employed in each experiment. A phosphor coated black light of nearly $350 \mathrm{~nm}$ was used for UV irradiation and white tungsten bulbs of 419 and $450 \mathrm{~nm}$ for visible light irradiations. The intensity of light fluxes for $350 \mathrm{~nm}, 419 \mathrm{~nm}$, and $450 \mathrm{~nm}$ was at $10 \%$ deviation according to manufacturer specifications. Pyrex glass reaction vessels with Teflon stoppers $(\mathrm{L}=30 \mathrm{~cm}, \mathrm{D}=2.5 \mathrm{~cm})$ were employed for all photocatalysis experiments. In a typical experiment, $100 \mathrm{~mL}$ of $125 \mu \mathrm{M}$ COU aqueous solution was loaded with $10 \mathrm{mg}$ of catalyst and sonicated in an ultrasonic cleaning bath for 10 minutes to produce a uniform of suspension. The mixture was gently purged with air for 10 minutes prior to irradiation. The aqueous suspension was magnetically stirred during irradiation in a photochemical reactor. The reaction vessel was removed from the reactor at desired time intervals, vigorously shaken for 30 seconds, and a $5.0 \mathrm{~mL}$ aliquot withdrawn from the reaction solution and immediately passed through a $0.45 \mu \mathrm{m}$ PTFE filter. The filter was rinsed with another $5.0 \mathrm{ml}$ of deionized water combined with filtrate to make the total volume of 10 $\mathrm{ml}$ for future analyses. 


\subsubsection{Measurement of the formation of hydroxyl radicals}

The concentrations of $\bullet \mathrm{OH}$ during irradiation of the aqueous $\mathrm{TiO}_{2}$ suspensions were measured from the concentration of highly fluorescent hydroxyl radical adduct (7HC) produced from the reaction of $\bullet \mathrm{OH}$ with $\mathrm{COU}$. Using the established yield of $7 \mathrm{HC}$ from the $\mathrm{COU}+\bullet \mathrm{OH}$ reaction, the concentration of $\bullet \mathrm{OH}$ production can be determined as a function of irradiation time. The optimal $\mathrm{COU}$ concentration ranges for $\bullet \mathrm{OH}$ production are reported between 100-1000 $\mu \mathrm{M}$ [88]. Czili et al. observed maximum initial yields when the $\mathrm{COU}$ concentration was $100 \mu \mathrm{M}$ [115]. While $\bullet \mathrm{OH}$ generated during $\mathrm{TiO}_{2}$ photocatalysis is primarily formed at the surface, $\bullet \mathrm{OH}_{\text {ads }}$ can diffuse from the $\mathrm{TiO}_{2}$ surface leading free $\bullet \mathrm{OH}$. Previous studies have shown free $\bullet \mathrm{OH}$ and $\bullet \mathrm{OH}_{\text {ads }}$ occur at or near the surface and have similar reactivities. The trapping efficiency of $\bullet \mathrm{OH}$ in $\mathrm{TiO}_{2}$ suspension reported by Zhang et al. is $\sim 6.1 \%$ using $100 \mu \mathrm{M} \mathrm{COU} \mathrm{[157].} \mathrm{Newton} \mathrm{and} \mathrm{Milligan} \mathrm{reported}$ similar trapping efficiency of $4.7 \%$ [158]. The detection and quantification of 7HC were carried out by a Horiba FluoroMax Spectrofluorometer setting with excitation and emission wavelengths at 332 and $455 \mathrm{~nm}$, respectively. The equipment was calibrated against a series of standard $7 \mathrm{HC}$ concentrations ranging from 0.1 to $3.0 \mu \mathrm{M}(0.1,0.5,1.0,1.5,2.0$, and $3.0 \mu \mathrm{M}$ ). The calibration plot, shown in Figure 20, was obtained by plotting the fluorescence intensity measured at $455 \mathrm{~nm}$ as a function of $7 \mathrm{HC}$ concentration. The correlation coefficient of the calibration plot was $\geq 0.99$. 


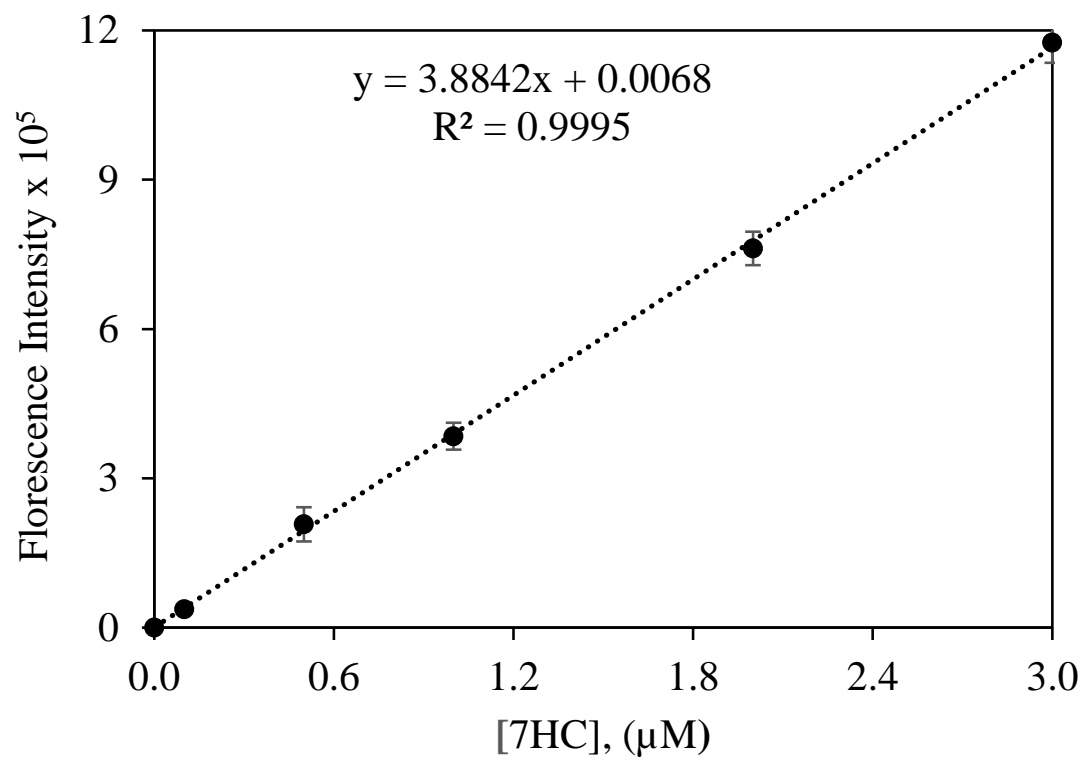

Figure 20. Spectrofluorometer calibration curve for the measuring of 7HC. Standard deviation was $\pm 5 \%$ on the basis of triplicate runs

\subsection{Results and discussion}

A series of the reduced $\mathrm{TiO}_{2}$ materials (identified as $\mathrm{TiO}_{2}{ }^{\text {red }}$ ) for $\mathrm{P} 25 \mathrm{TiO}_{2}$ and $\mathrm{N}, \mathrm{F}$, and/or P co-doped $\mathrm{TiO}_{2}\left(\mathrm{NF}-\mathrm{TiO}_{2}\right.$ and $\left.\mathrm{NFP}-\mathrm{TiO}_{2}\right)$ were synthesized by thermal treatment with $\mathrm{NaBH}_{4}$ for 30, 50, and 70 min following the reported method [149] as detailed in the experimental section. The specific conditions of thermal treatment used in the preparation of reduced $\mathrm{TiO}_{2}$ materials are tabulated in Table 4, and the optical reflectance of representative samples are shown in Figure 21. 
Table 4. The prepared $\mathrm{TiO}_{2}$ materials as a function of reduction time with $\mathrm{NaBH}_{4}$ along with their thicknesses of the amorphous layer

\begin{tabular}{|c|c|c|c|c|c|c|}
\hline \multirow{2}{*}{$\begin{array}{l}\text { Series } \\
\text { name }\end{array}$} & \multicolumn{6}{|c|}{ Thickness over the treatment time with $\mathrm{NaBH}_{4}$ at $300{ }^{\circ} \mathrm{C}$} \\
\hline & $30 \mathrm{~min}$ & $(\mathrm{~nm})$ & $50 \mathrm{~min}$ & $(\mathrm{~nm})$ & $70 \mathrm{~min}$ & $(\mathrm{~nm})$ \\
\hline $\mathrm{P} 25 \mathrm{TiO}_{2}$ & $\mathrm{TiO}_{2}{ }^{\text {red } 30}$ & 1.2 & $\mathrm{TiO}_{2}{ }^{\text {red } 50}$ & 1.5 & $\mathrm{TiO}_{2}{ }^{\text {red } 70}$ & 2.0 \\
\hline $\mathrm{NF}_{-} \mathrm{TiO}_{2}$ & $\mathrm{NF}-\mathrm{TiO}_{2}{ }^{\text {red }} 30$ & 1.3 & $\mathrm{NF}_{-} \mathrm{TiO}_{2}{ }^{\text {red } 50}$ & 2.1 & $\mathrm{NF}_{-} \mathrm{TiO}_{2}{ }^{\text {red }} 70$ & 6.0 \\
\hline $\mathrm{NFP}_{-} \mathrm{TiO}_{2}$ & $\mathrm{NFP}-\mathrm{TiO}_{2}{ }^{\text {red } 30}$ & 1.0 & $\mathrm{NFP}-\mathrm{TiO}_{2}{ }^{\text {red }} 50$ & 1.5 & $\mathrm{NFP}-\mathrm{TiO}_{2}{ }^{\text {red }} 70$ & 2.0 \\
\hline
\end{tabular}

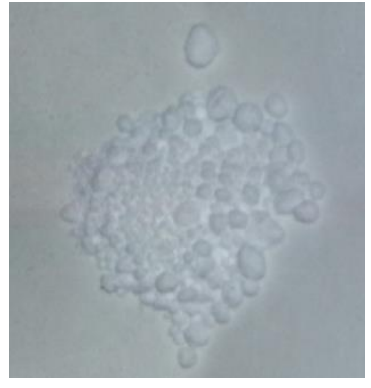

$\left(\mathrm{P} 25 \mathrm{TiO}_{2}\right)$

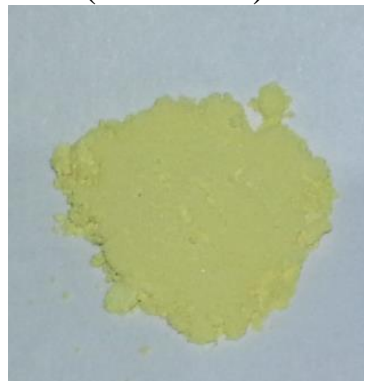

$\left(\mathrm{NF}-\mathrm{TiO}_{2}\right)$

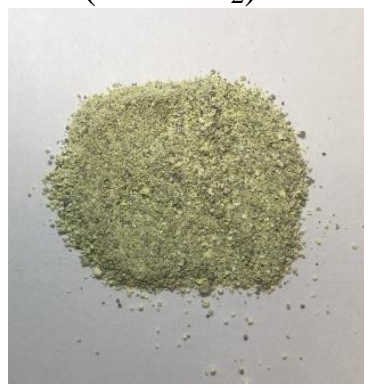

$\left(\mathrm{NFP}_{-} \mathrm{TiO}_{2}\right)$

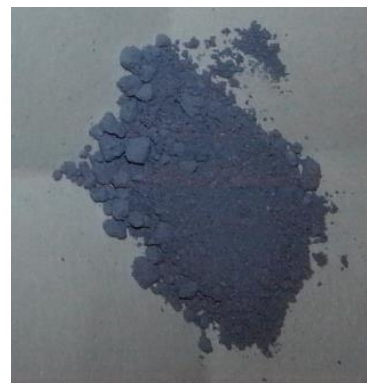

$\left(\mathrm{TiO}_{2}{ }^{\mathrm{red} 30}\right)$

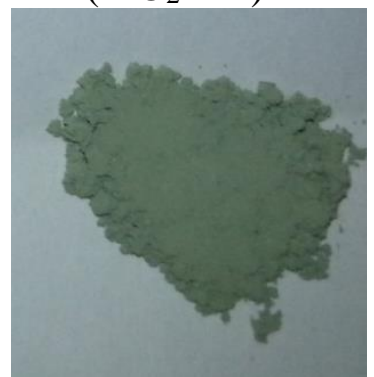

$\left(\mathrm{NF}-\mathrm{TiO}_{2}{ }^{\text {red } 30}\right)$

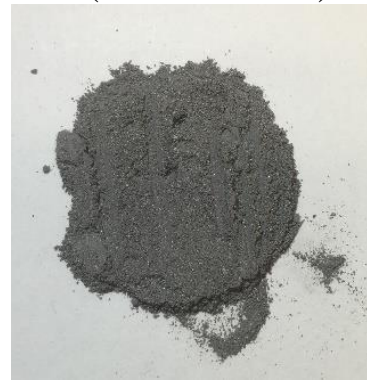

$\left(\mathrm{NFP}-\mathrm{TiO}_{2}{ }^{\text {red } 30}\right)$

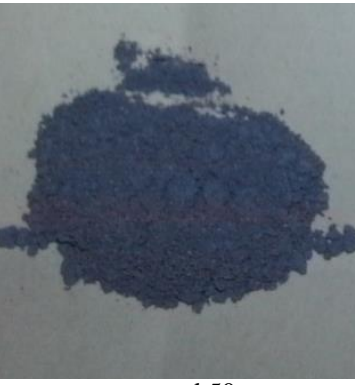

$\left(\mathrm{TiO}_{2}{ }^{\text {red } 50}\right)$

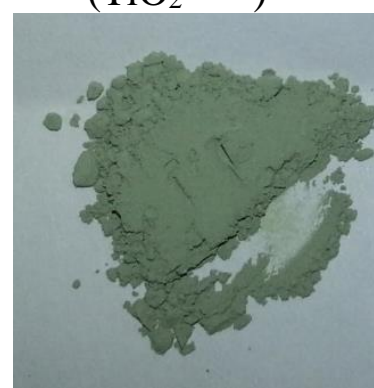

$\left(\mathrm{NF}-\mathrm{TiO}_{2}{ }^{\text {red } 50}\right)$

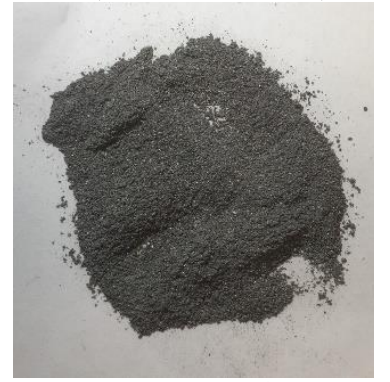

$\left(\mathrm{NFP}-\mathrm{TiO}_{2}{ }^{\text {red 50}}\right)$

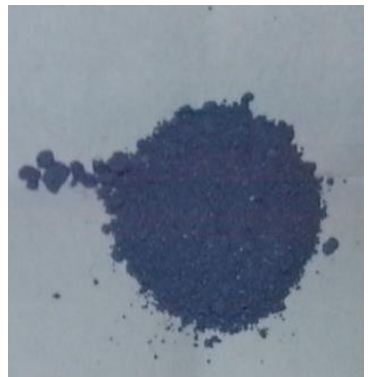

$\left(\mathrm{TiO}_{2}{ }^{\mathrm{red} 70}\right)$

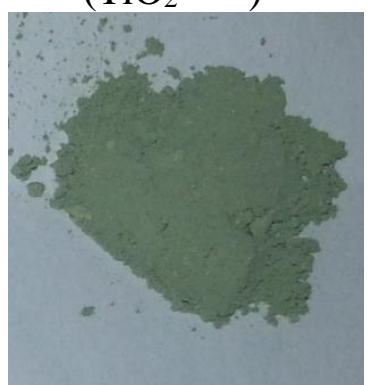

$\left(\mathrm{NF}-\mathrm{TiO}_{2}{ }^{\text {red } 70}\right)$

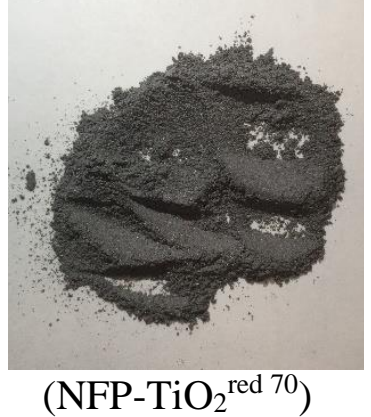

Figure 21. Color photographs of reduced $\mathrm{TiO}_{2}$ synthesized by thermal treatment with $\mathrm{NaBH}_{4}$ 


\subsubsection{Phase structure analysis}

The performance of a photocatalyst is often dependent on the many factors, including the crystal structure, surface area, and composition $[128,130,159]$. The $\mathrm{TiO}_{2}$ can exist as three different forms; anatase, rutile, and brookite [129,159-162]. Anatase is considered the most photo-catalytically active crystal form. The photocatalytic activity of $\mathrm{TiO}_{2}$ can vary dramatically depending on its lattice structure, and thus, XRD patterns were used to analyze the crystalline properties of synthesized $\mathrm{TiO}_{2}$ samples. The XRD data of $\mathrm{P} 25 \mathrm{TiO}_{2}$ and reduced $\mathrm{TiO}_{2}$ are provided in Figure 22. All observed peaks on the XRD patterns of the reference $\mathrm{P} 25 \mathrm{TiO}_{2}$ and the reduced $\mathrm{TiO}_{2}{ }^{\text {red }}$ were indexed to anatase and rutile phases. The intensity of XRD peaks for $\mathrm{TiO}_{2}{ }^{\text {red }} 70$ associated with anatase phase, however, decreased, indicating lower crystallization caused by surface modification at longer treatment times without a significant change of crystallinity. Anatase (tetragonal structure, a \& b) $3.78 \AA$; c) $9.50 \AA$ ) and rutile (tetragonal structure, a \& b) $4.58 \AA$; c) 2.95 $\AA$ ) are the two major forms of crystalline $\mathrm{TiO}_{2}$. Titanium dioxide can also exist in another thermodynamically unstable form called brookite (rhombohedral structure, a) $5.43 \AA$; b) 9.16 $\AA$; c) $5.13 \AA$ ). The brookite phase was not detected in any of the samples in the present study. Previous experiments showed that anatase is kinetically more stable than rutile, while rutile is reported to be more thermodynamically stable than anatase at normal atmospheric pressure and temperature $[122,161]$. It has been found that a crystalline mixture of the two different phases of titanium dioxide, such as anatase and rutile, is more photoactive than $100 \%$ anatase [161-163]. 


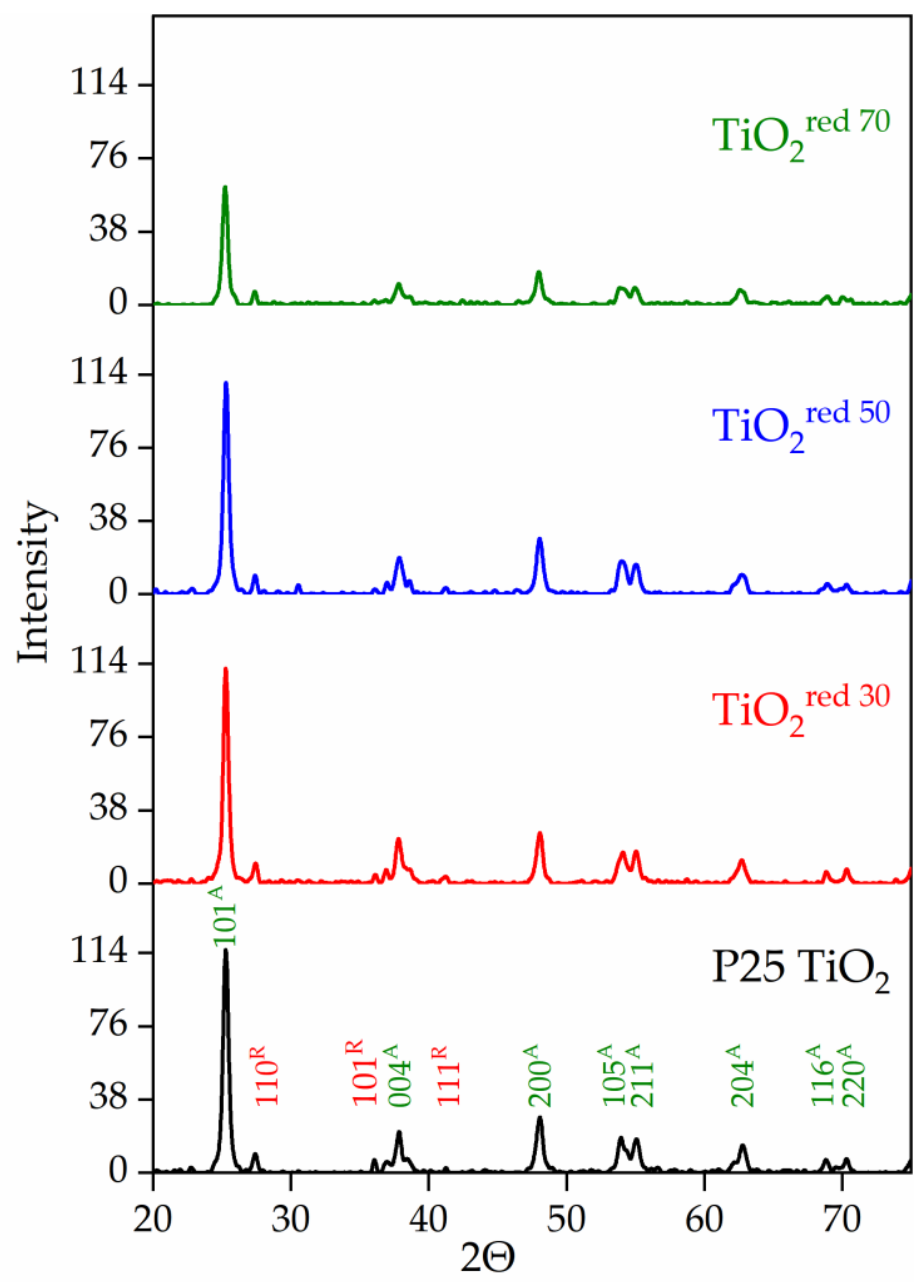

Figure 22. Comparison of XRD patterns among $\mathrm{P} 25 \mathrm{TiO}_{2}$ and reduced forms of $\mathrm{P} 25 \mathrm{TiO}_{2}$ materials. (Superscript $\mathrm{R}$ and A represent the anatase and rutile phases, respectively)

\subsubsection{Microstructural and morphological analysis}

Micrographs of high-resolution transmission microscopy of $\mathrm{P} 25 \mathrm{TiO}_{2}$ materials and the reduced forms of $\mathrm{NF}-\mathrm{TiO}_{2}$ and $\mathrm{NFP}-\mathrm{TiO}_{2}$ are presented in Figure 23-25. The high crystalline order of the $\mathrm{TiO}_{2}$ nanoparticles with the characteristic lattice of anatase possessing indexed planes of (101) and (200) was observed in all samples. A thin amorphous layer was observed at the surface of the reduced $\mathrm{TiO}_{2}$ nanoparticles indicative 
of surface modification. The measured thicknesses of the amorphous layers are tabulated in Table 4. The values of the amorphous layer and the characteristics of the crystalline order of the anatase suggest that we can modulate the amorphous layer by changing the duration of thermal treatment and consequently modulate the band gap energies into the visible light region.

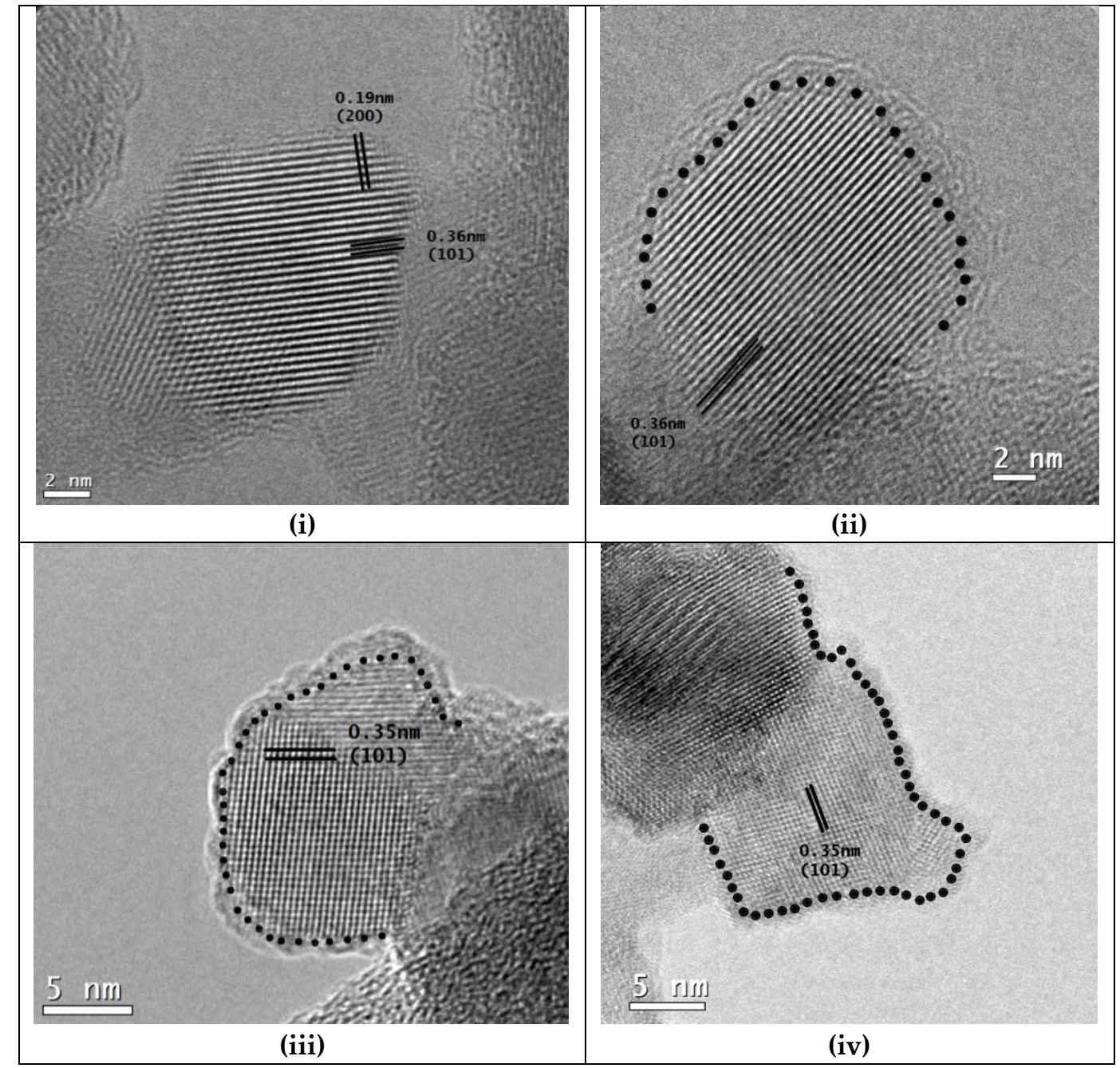

Figure 23. HRTEM images of $\mathrm{TiO}_{2}$ nanocrystals. (i) $\mathrm{P} 25 \mathrm{TiO}_{2}$ before reduction, (ii) $\mathrm{TiO}_{2}{ }^{\text {red }}$ ${ }^{70}$ (2.0 $\mathrm{nm}$ of the amorphous layer), (iii) $\mathrm{TiO}_{2}{ }^{\text {red } 50}$ (1.5 $\mathrm{nm}$ of the amorphous layer), and (iv) $\mathrm{TiO}_{2}{ }^{\text {red } 30}(1.2 \mathrm{~nm}$ of the amorphous layer) 


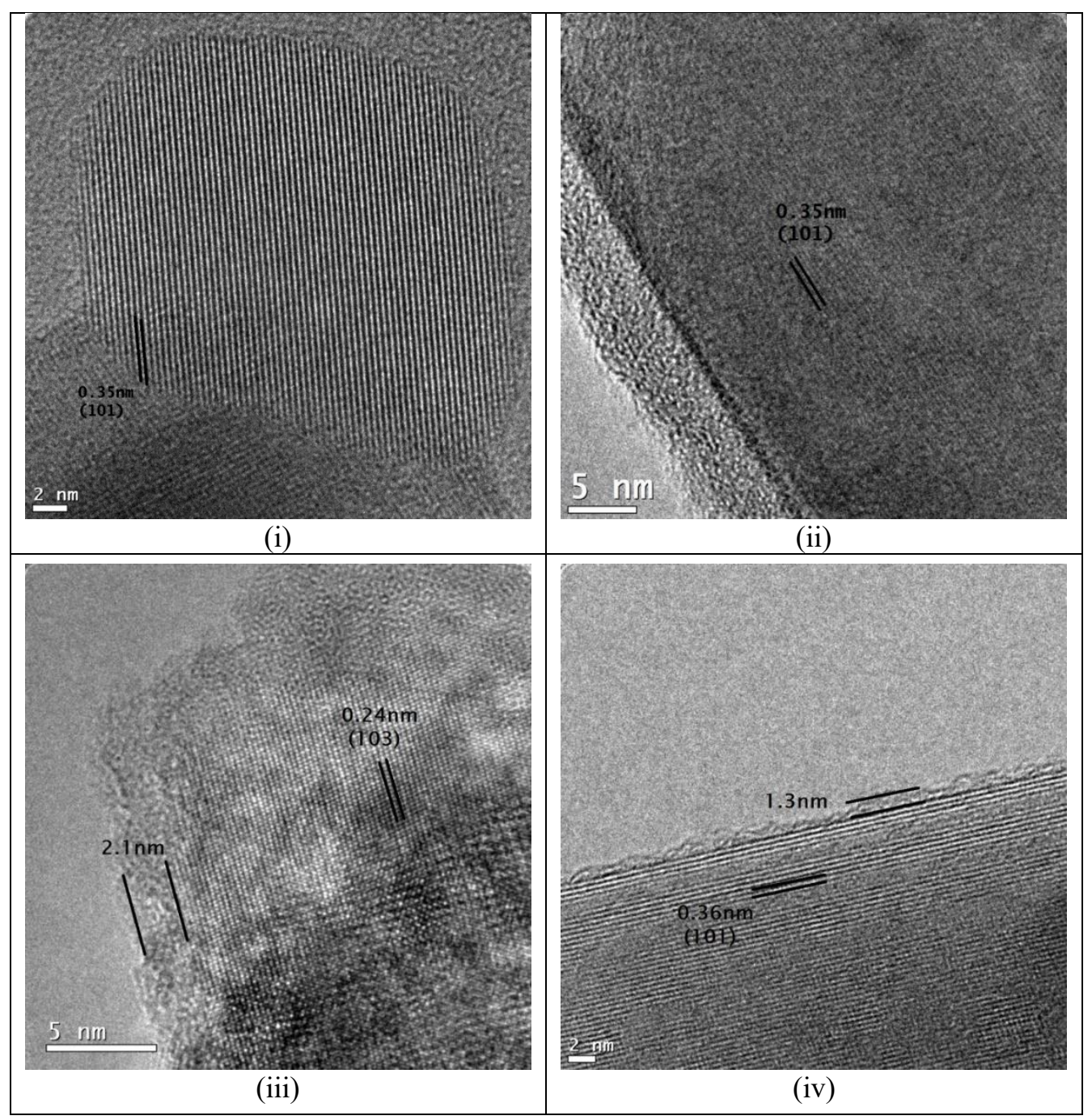

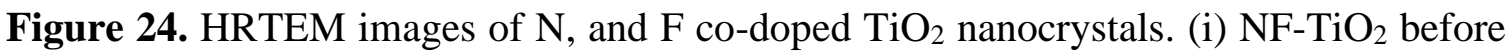

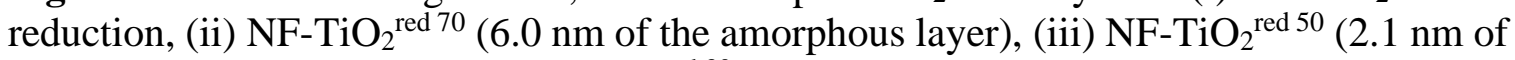
the amorphous layer) and (iv) $\mathrm{NF}-\mathrm{TiO}_{2}{ }^{\text {red } 30}$ (1.3 $\mathrm{nm}$ of the amorphous layer) 


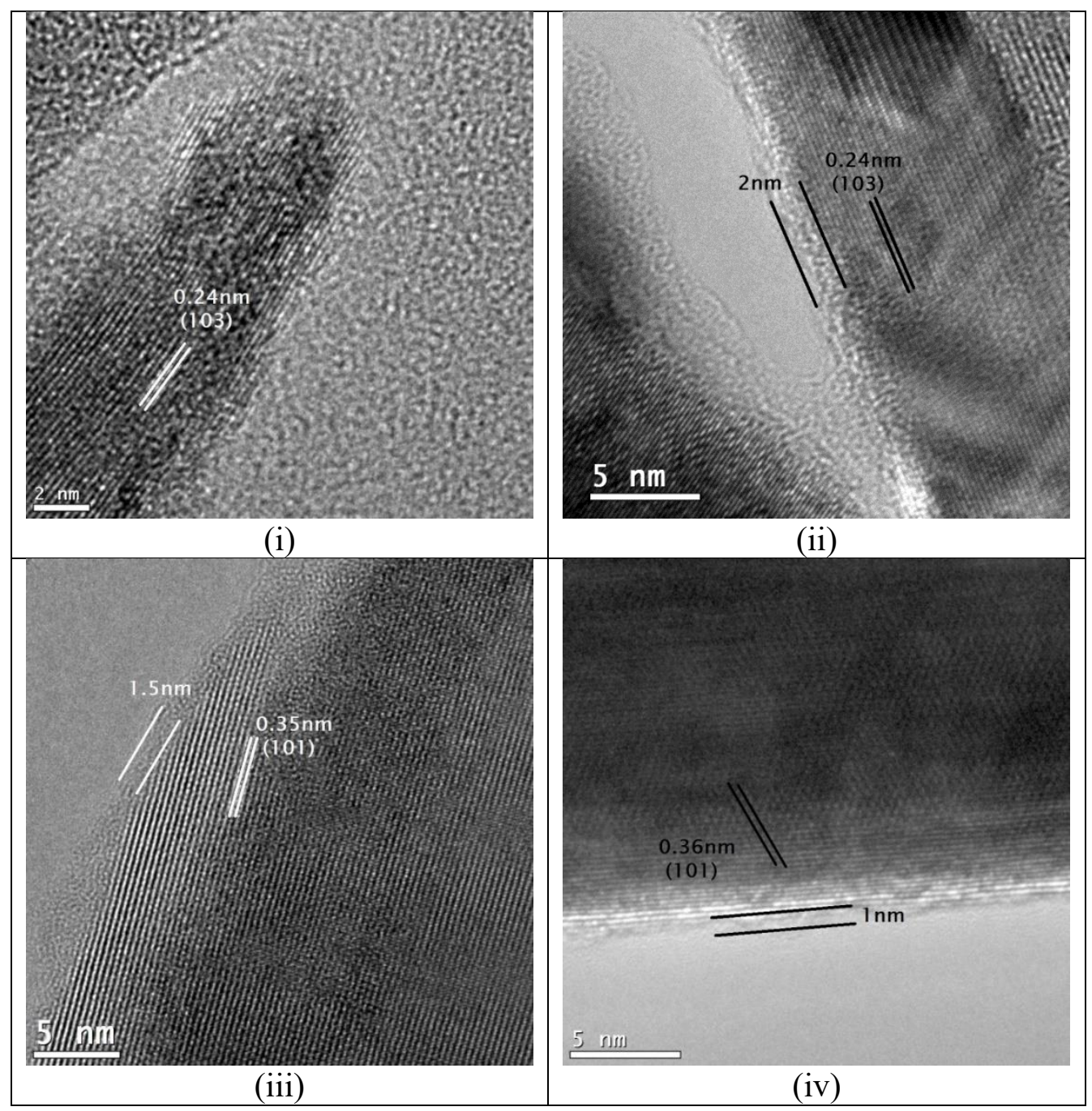

Figure 25. HRTEM images of $\mathrm{N}, \mathrm{F}$, and $\mathrm{P}$ co-doped $\mathrm{TiO}_{2}$ nanocrystals. (i) $\mathrm{NFP}-\mathrm{TiO}_{2}$

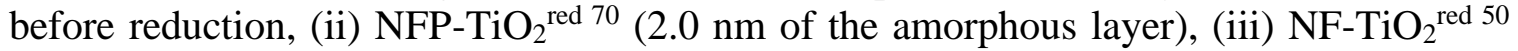
(1.5 nm of the amorphous layer) and (iv) ${\mathrm{NF}-\mathrm{TiO}_{2}}^{\text {red }} 30$ (1.0 $\mathrm{nm}$ of the amorphous layer) 


\subsubsection{EDXRF analysis}

Our results demonstrated effective doping of $\mathrm{TiO}_{2}$ with nonmetals $\mathrm{N}, \mathrm{F}$, and $\mathrm{P}$. Chemical composition as weight percentage for the synthesized catalyst $\mathrm{NF}-\mathrm{TiO}_{2}$ was $\mathrm{N}$ (7.17\%), $\mathrm{O}(42.46 \%), \mathrm{F}(3.40 \%)$ and $\mathrm{Ti}(46.97 \%)$ and for the $\mathrm{NFP}^{-\mathrm{TiO}_{2}}$ the composition was determined as $\mathrm{N}(9.17 \%), \mathrm{O}(37.28 \%), \mathrm{F}(12.56 \%), \mathrm{P}(7.35 \%)$, and $\mathrm{Ti}(33.65 \%)$. The XRF spectrum of doped samples $\mathrm{NF}-\mathrm{TiO}_{2}$ and $\mathrm{NFP}-\mathrm{TiO}_{2}$ are presented in Figure 26 -27. Degussa P25 has an average crystalline size of $21 \mathrm{~nm}$ with a specific surface area of $50 \mathrm{~m}^{2} / \mathrm{g}$ [164]. The particle size of $22.3 \mathrm{~nm}$ was calculated for the NFP samples processed at $600{ }^{\circ} \mathrm{C}$, with a modest increase to $29.5 \mathrm{~nm}$ at $1000{ }^{\circ} \mathrm{C}$ and $40.7 \mathrm{~nm} 1100{ }^{\circ} \mathrm{C}$ reported [122].

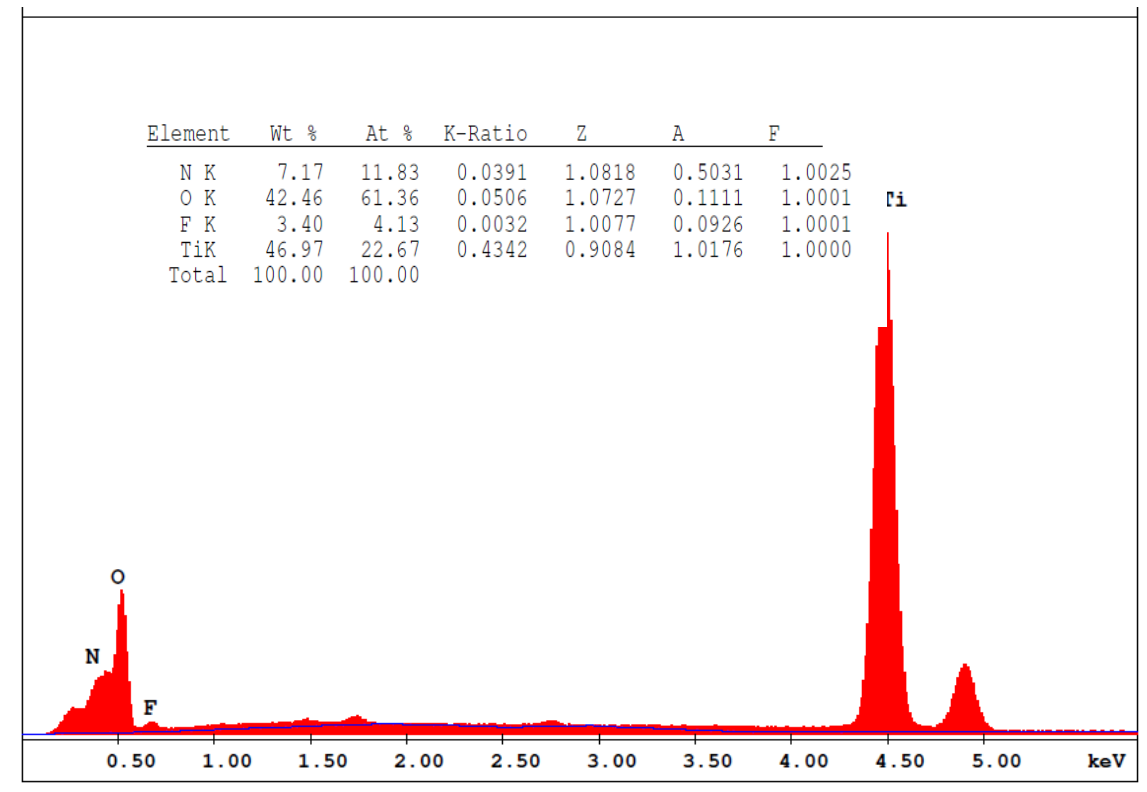

Figure 26. EDXRF spectrum of $\mathrm{N}$, and $\mathrm{F}$ co-doped $\mathrm{TiO}_{2}\left(\mathrm{NF}-\mathrm{TiO}_{2}\right)$. 


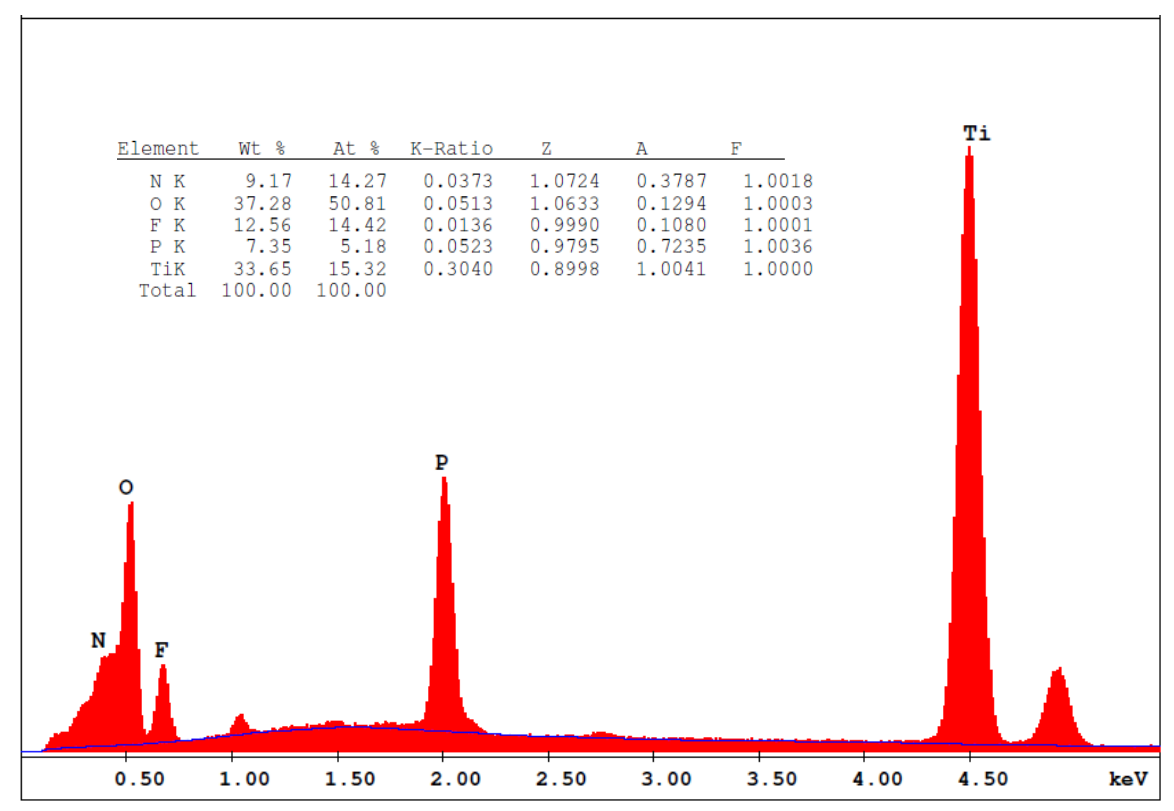

Figure 27. EDXRF spectrum of N, F, and $\mathrm{P}$ co-doped $\mathrm{TiO}_{2}\left(\mathrm{NFP}-\mathrm{TiO}_{2}\right)$.

\subsubsection{UV-Vis and Raman spectroscopy}

The colors of the prepared $\mathrm{TiO}_{2}$, presented in Figure 20, indicate visible light absorption. The UV-visible diffuse reflectance spectra of the reduced $\mathrm{TiO}_{2}$ samples, provided in Figure 28, were used to determine the specific absorption edges and band gap energies. The results demonstrated the band gap energies of doped samples shift to the visible light region compared to the unmodified $\mathrm{P} 25 \mathrm{TiO}_{2}$. A reduction of the band gap energy from $3.1 \mathrm{eV}$ to $2.23 \mathrm{eV}$ was observed for $\mathrm{P} 25 \mathrm{TiO}_{2}$ after treatment of approximately one hour. For $\mathrm{NF}_{-} \mathrm{TiO}_{2}$ particles, the band gap energy dropped by $0.8 \mathrm{eV}$ to $1.30 \mathrm{eV}$. The $\mathrm{NFP}_{-} \mathrm{TiO}_{2}$ particles possess a band gap of $2.7 \mathrm{eV}$, decreasing to $2.35 \mathrm{eV}$ upon reduction. The insertion of $\mathrm{N}$ atom into $\mathrm{TiO}_{2}$ lattices is reported to create a new inter-band state above the valence band of $\mathrm{TiO}_{2}$ leading to the observed absorbance shift into the visible light 
region [165]. Since the absorbance edges of the prepared samples shifted into the visible light region, we assigned surface modification, and the production of an amorphous layer on the $\mathrm{TiO}_{2}$ particle results in changes in the band gap energy and visible light absorption properties. The band gap energies calculated by Kubelka-Munk plots are summarized in Table 5.

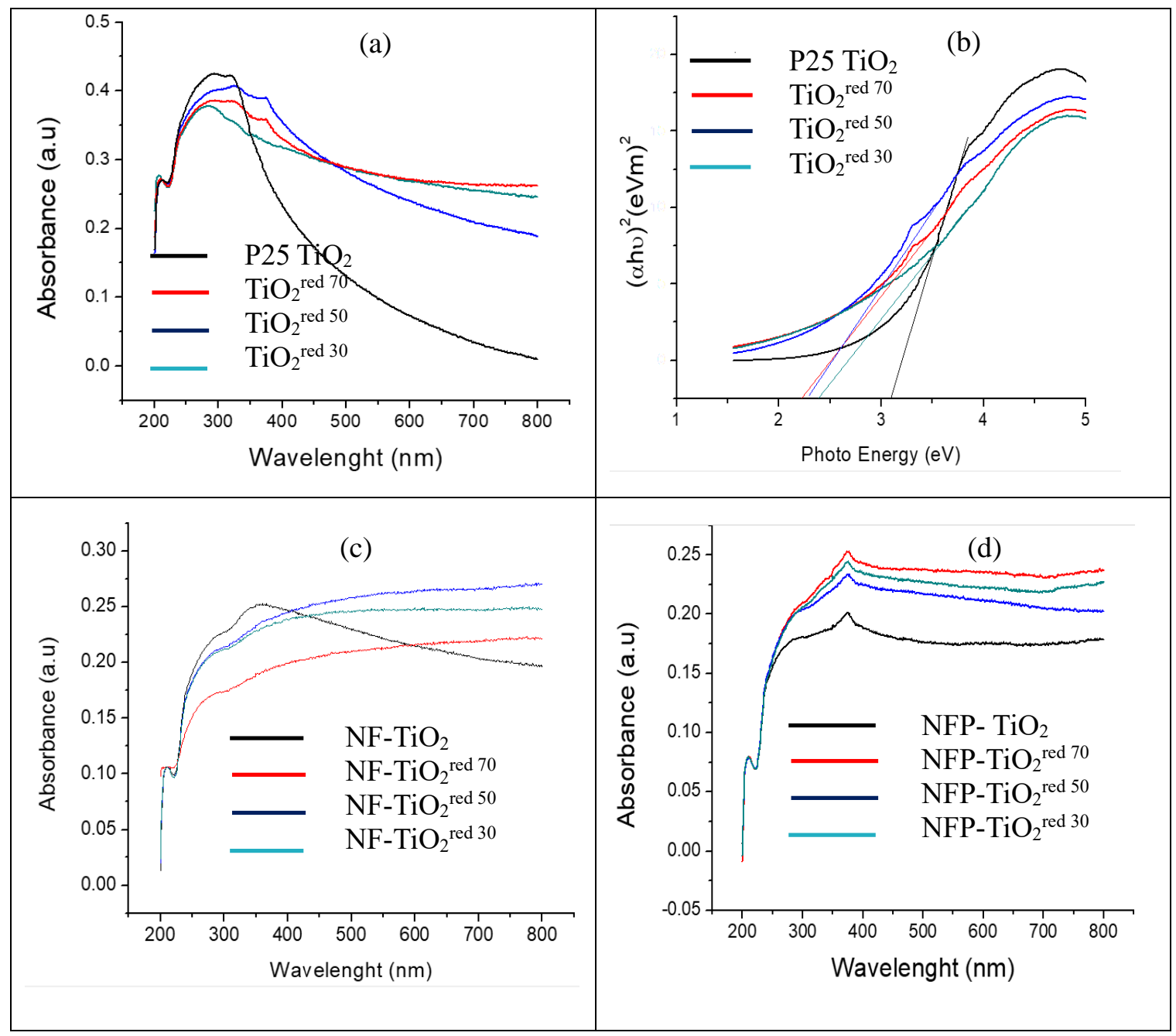

Figure 28. UV-Visible diffuse reflectance spectra of synthesized $\mathrm{TiO}_{2}$ materials. (a) $\mathrm{P} 25$ $\mathrm{TiO}_{2}$ series, (b) Kubelka-Munk plot for $\mathrm{P}_{25} \mathrm{TiO}_{2}$ series, (c) $\mathrm{NF}^{-\mathrm{TiO}_{2}}$ series, and (d) NFP$\mathrm{TiO}_{2}$ series. 
Table 5. Band gap of $\mathrm{NaBH}_{4}$ treated $\mathrm{P} 25 \mathrm{TiO}_{2}, \mathrm{NF}-\mathrm{TiO}_{2}$, and $\mathrm{NFP}-\mathrm{TiO}_{2}$ series and their corresponding photo-excited absorption wavelength

\begin{tabular}{|c|c|c|c|c|c|c|c|c|}
\hline Particles & $\begin{array}{l}\Delta \mathrm{E} \\
(\mathrm{eV})\end{array}$ & $\lambda(\mathrm{nm})$ & Particles & $\begin{array}{l}\Delta \mathrm{E} \\
(\mathrm{eV})\end{array}$ & $\lambda(\mathrm{nm})$ & Particles & $\begin{array}{l}\Delta \mathrm{E} \\
(\mathrm{eV})\end{array}$ & $\lambda(\mathrm{nm})$ \\
\hline $\mathrm{P} 25 \mathrm{TiO}_{2}$ & 3.10 & 400 & $\mathrm{NF}_{-\mathrm{TiO}_{2}}$ & 2.10 & 590 & $\mathrm{NFP}^{-\mathrm{TiO}_{2}}$ & 2.70 & 459 \\
\hline $\mathrm{TiO}_{2}{ }^{\text {red } 30}$ & 2.40 & 516 & $\mathrm{NF}-\mathrm{TiO}_{2}{ }^{\text {red } 30}$ & 1.43 & 867 & NFP-TiO ${ }_{2}^{\text {red } 30}$ & 2.51 & 494 \\
\hline $\mathrm{TiO}_{2}{ }^{\text {red } 50}$ & 2.30 & 540 & NF-TiO ${ }_{2}^{\text {red } 50}$ & 1.35 & 918 & $\mathrm{NFP}-\mathrm{TiO}_{2}{ }^{\text {red }} 50$ & 2.40 & 516 \\
\hline $\mathrm{TiO}_{2}{ }^{\text {red } 70}$ & 2.23 & 556 & $\mathrm{NF}-\mathrm{TiO}_{2}{ }^{\mathrm{red}} 70$ & 1.30 & 953 & $\mathrm{NFP}^{-\mathrm{TiO}_{2}}{ }^{\text {red }} 70$ & 2.35 & 527 \\
\hline
\end{tabular}

Raman spectra of the $\mathrm{TiO}_{2}$ materials exhibited the characteristic bands corresponding to $\mathrm{Eg} 1, \mathrm{Bg} 1, \mathrm{Ag} 1$, and $\mathrm{Eg} 3$ at 146, 396, 516, and $637 \mathrm{~cm}^{-1}$, respectively, data are shown in Table 6, for the vibrational modes of the anatase phase of $\mathrm{TiO}_{2}$ [166]. Small shifts of the vibration mode were observed, as shown in Figure 29. The modest shift is assigned to the surface disorder as a result of the amorphous layer over the $\mathrm{TiO}_{2}$ nanoparticle (possible formation of oxygen vacancies or non-stoichiometry defects). Amorphous surface layers can also lead to peak broadening. Oxygen vacancy promotes the charge carrier separation and can potentially enhance the photocatalytic performance [149]. 
Table 6. Raman band position of synthesized $\mathrm{TiO}_{2}$ materials

\begin{tabular}{|c|c|c|c|c|}
\hline $\mathrm{P} 25 \mathrm{TiO}_{2}\left(\mathrm{~cm}^{-1}\right)$ & $\mathrm{TiO}_{2}{ }^{\mathrm{red} 70}\left(\mathrm{~cm}^{-1}\right)$ & $\mathrm{TiO}_{2}{ }^{\text {red } 50}\left(\mathrm{~cm}^{-1}\right)$ & $\mathrm{TiO}_{2}{ }^{\text {red } 30}\left(\mathrm{~cm}^{-1}\right)$ & Band \\
\hline 143 & 146 & 143 & 145 & Eg1 \\
\hline 396 & 394 & 395 & 397 & $\mathrm{Bg} 1$ \\
\hline 516 & 511 & 511 & 521 & Ag1 \\
\hline 637 & 634 & 634 & 636 & Eg3 \\
\hline $\mathrm{NF}-\mathrm{TiO}_{2}$ & $\mathrm{NF}-\mathrm{TiO}_{2}{ }^{\text {red } 70}$ & $\mathrm{NF}-\mathrm{TiO}_{2}{ }^{\text {red } 50}$ & NF-TiO ${ }_{2}^{\text {red } 30}$ & Band \\
\hline 142 & 144 & 145 & 144 & $\mathrm{Eg}_{1}$ \\
\hline 393 & 393 & 392 & 393 & $\mathrm{Bg}_{1}$ \\
\hline 512 & 511 & 512 & 511 & $\mathrm{Ag}_{1}$ \\
\hline 635 & 634 & 633 & 633 & $\mathrm{Eg}_{3}$ \\
\hline $\mathrm{NFP}^{-\mathrm{TiO}_{2}}$ & NFP-TiO ${ }_{2}^{\text {red } 70}$ & $\mathrm{NFP}_{-\mathrm{TiO}_{2}}^{\text {red } 50}$ & NFP-TiO ${ }_{2}^{\text {red } 30}$ & Band \\
\hline 143 & 148 & 147 & 149 & $\mathrm{Eg}_{1}$ \\
\hline 393 & 390 & 390 & 391 & $\mathrm{Bg}_{1}$ \\
\hline 511 & 506 & 509 & 507 & $\mathrm{Ag}_{1}$ \\
\hline 636 & 630 & 634 & 633 & $\mathrm{Eg}_{3}$ \\
\hline
\end{tabular}

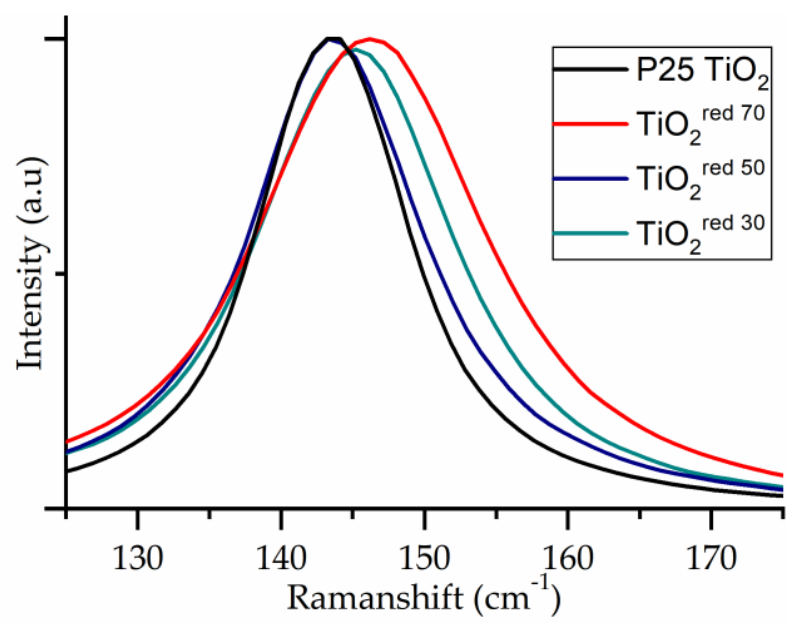

Figure 29. Raman spectrum of $\mathrm{P} 25 \mathrm{TiO}_{2}$ series showing a shift toward the visible region as a function of reductive treatment time. 


\subsubsection{Photocatalytic hydroxyl radicals $(\bullet \mathrm{OH})$ production}

The production of the $\cdot \mathrm{OH}$ adduct, $7 \mathrm{HC}$, was monitored to assess the production of - $\mathrm{OH}$ by the reduced $\mathrm{TiO}_{2}$ materials at different irradiation wavelengths. Figure 30 shows the growth of fluorescence intensity of the hydroxyl radical adduct, $7 \mathrm{HC}$, at $455 \mathrm{~nm}$ as a function of irradiation time under $350 \mathrm{UV}$ light in the presence of $\mathrm{P} 25 \mathrm{TiO}_{2}$, as a reference for comparing different photo-catalysts. Control experiments in the dark and in the absence of $\mathrm{P} 25 \mathrm{TiO}_{2}$ did not yield 7HC. The inset of Figure 30 shows the concentration of $7 \mathrm{HC}$ in $\mathrm{P} 25 \mathrm{TiO}_{2}$ aqueous suspension as a function of irradiation time. Triplicate experiments yield reproducibility to within $95 \%$. The yield of $7 \mathrm{HC}$ increased in a linear fashion initially and reached a maximum at approximately $1.0 \mu \mathrm{M}$ at $20 \mathrm{~min}$ of irradiation. Upon continued irradiation, the production of 7HC gradually decreased because of the likely depletion of coumarin, as well as the simultaneous formation and degradation of $7 \mathrm{HC}$ at higher concentrations. The formation of $7 \mathrm{HC}$ followed pseudo-zero-order kinetics in accordance with previous reports $[154,157]$. An apparent pseudo-zero-order rate constant $\left(\mathrm{k}_{\mathrm{app}}\right)$ of 0.16 $\mu \mathrm{M} \min ^{-1}\left(\mathrm{R}^{2}=0.99\right)$ was determined under our experimental conditions. The observed rate constant was different from the rate constant of $0.023 \mu \mathrm{M} \mathrm{min}{ }^{-1}$ reported by Nagarajan et al. [154] likely a result of differences in experimental conditions including starting concentration, flux intensity, reactor design, etc. The concentration of $7 \mathrm{HC}(1.0 \mu \mathrm{M})$ produced at $20 \mathrm{~min}$ was equivalent to $[\bullet \mathrm{OH}]=16.4 \mu \mathrm{M}$ assuming trapping efficiency $6.1 \%$ of total $\bullet \mathrm{OH}[154,157]$. 


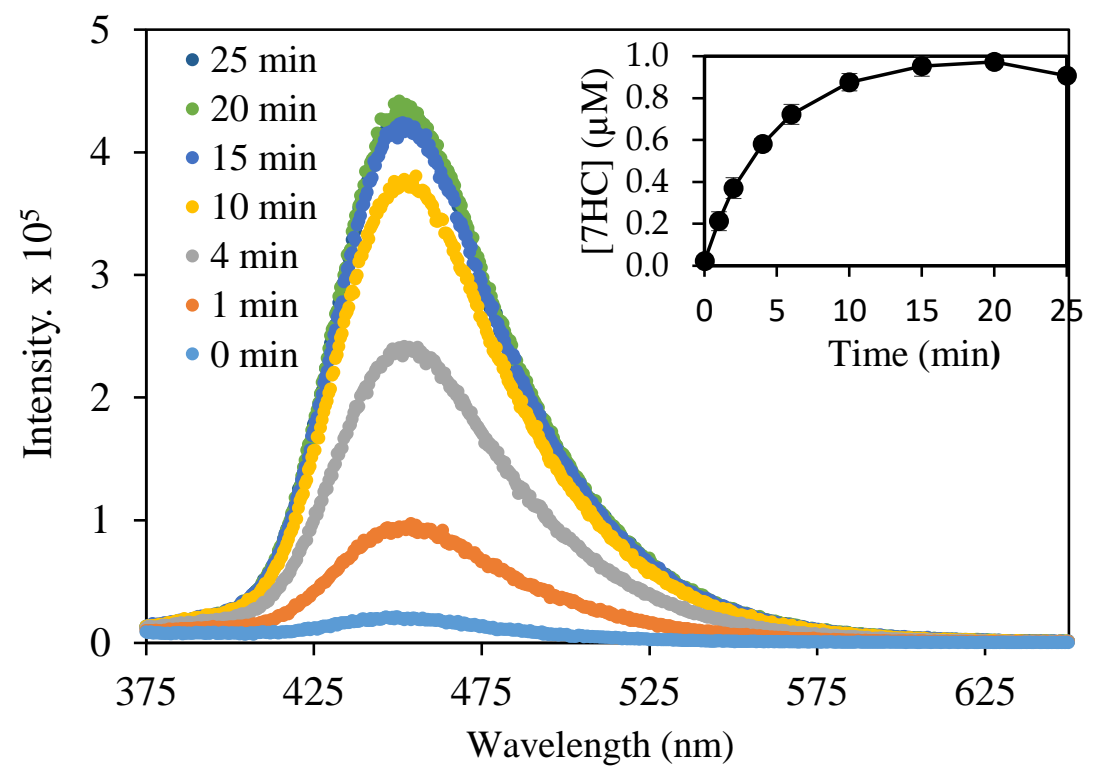

Figure 30. Change of fluorescence intensity observed at $455 \mathrm{~nm}$ during the irradiation of P25 $\mathrm{TiO}_{2}$ suspended in a $125 \mu \mathrm{M}$ COU aqueous solution. The catalyst load was $0.10 \mathrm{~g} / \mathrm{L}$. The plot of $7 \mathrm{HC}$ vs. irradiation time was shown in the inset. The irradiation of $\mathrm{P} 25 \mathrm{TiO}_{2}$ suspension was carried out at $350 \mathrm{~nm}$.

\subsubsection{Evaluation of the photocatalytic performance}

The photocatalytic production of $7 \mathrm{HC}$ of the reduced $\mathrm{TiO}_{2}$ materials was carried out under the same conditions employed for the baseline using $\mathrm{P} 25 \mathrm{TiO}_{2}$ irradiation at $\lambda=$ 350,419 , and $450 \mathrm{~nm}$. Significant amounts of $\bullet \mathrm{OH}$, quantitated on the basis of formation of $7 \mathrm{HC}$, were produced by reduced $\mathrm{P} 25 \mathrm{TiO}_{2}$ under $\mathrm{UV}(350 \mathrm{~nm})$ irradiation shown in Figure 31. The formation of $7 \mathrm{HC}$ by reduced $\mathrm{TiO}_{2}{ }^{\text {red }}$ was slower than the reference $\mathrm{P} 25$ $\mathrm{TiO}_{2}$ and followed the order of $\mathrm{TiO}_{2}{ }^{\text {red }}{ }^{30}>\mathrm{TiO}_{2}{ }^{\text {red }} 70>\mathrm{TiO}_{2}{ }^{\text {red }} 50$. Under $350 \mathrm{~nm}$, the productions of hydroxyl radicals by reduced doped $\mathrm{NF}-\mathrm{TiO}_{2}$ and $\mathrm{NFP}-\mathrm{TiO}_{2}$ were insignificant (Figure 32). No direct correlation was observed with the treatment time by $\mathrm{NaBH}_{4}, \cdot \mathrm{OH}$ production, and the band gap energies. 


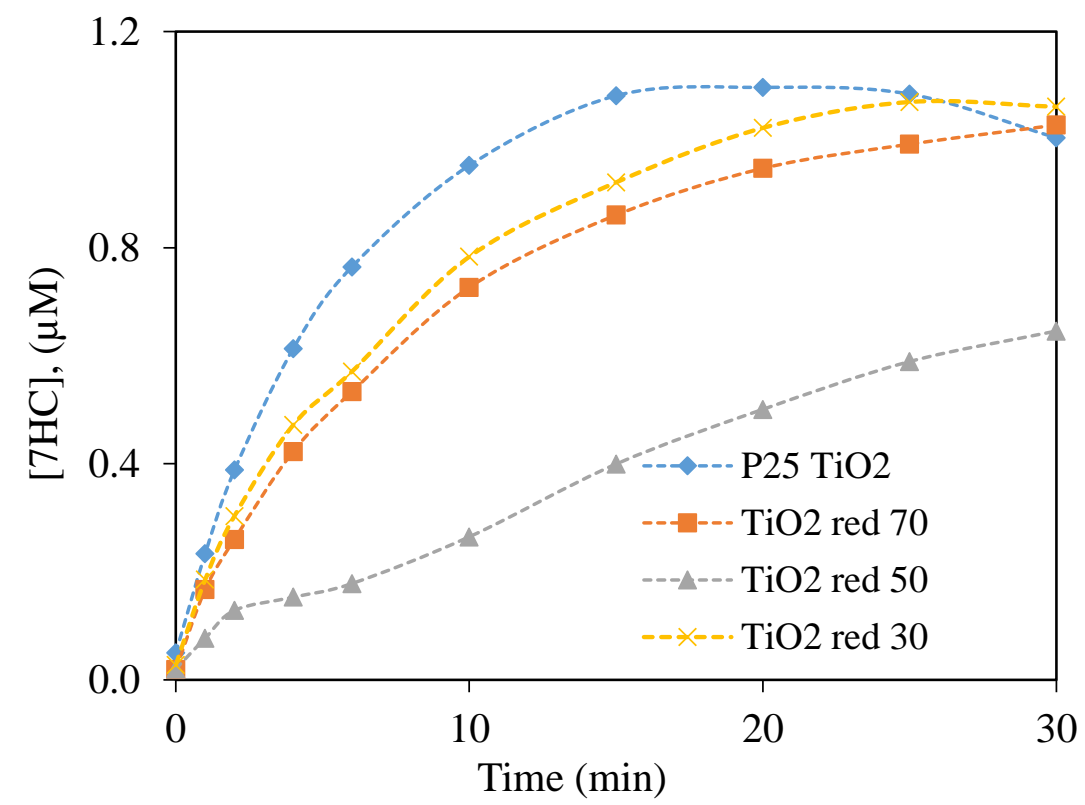

Figure 31. Production of $7 \mathrm{HC}$ by reduced $\mathrm{P} 25 \mathrm{TiO}_{2}$ photocatalysts under $350 \mathrm{~nm}$ irradiation. Catalyst loading was $0.10 \mathrm{~g} / \mathrm{L}$ and $[\mathrm{COU}]_{0}=125 \mu \mathrm{M}$.

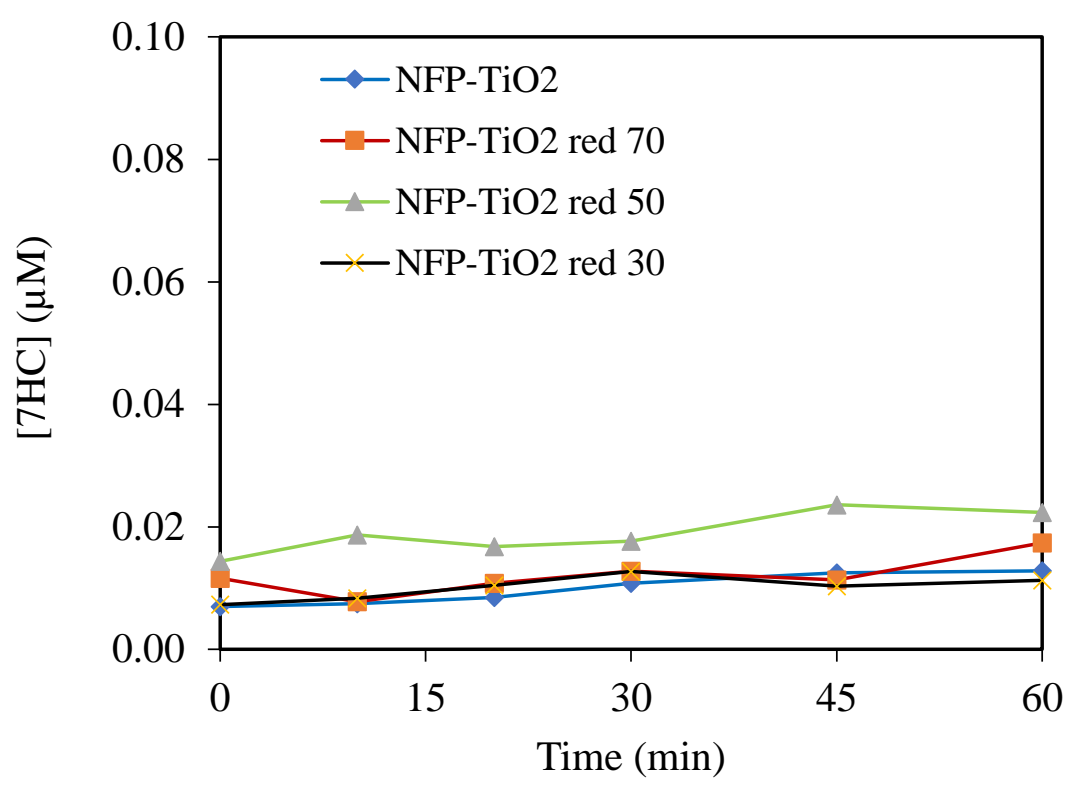

Figure 32. Production of $7 \mathrm{HC}$ by $\mathrm{NFP}-\mathrm{TiO}_{2}$ photocatalyst under $350 \mathrm{~nm}$ irradiation. Catalyst loading was $0.10 \mathrm{~g} / \mathrm{L}$, and $[\mathrm{COU}]_{0}=125 \mu \mathrm{M}$. 
Visible light-activated photocatalysis has been reported to be effective for the degradation of the organic pollutants $[123,124,131,164]$. The band gap of $\mathrm{P}^{2} 5 \mathrm{TiO}_{2}$ is $3.1 \mathrm{eV}$, and upon reduction with $\mathrm{NaBH}_{4}$, the band gap energy decreases to $2.23 \mathrm{eV}$ corresponding to light absorption wavelengths $\sim 556 \mathrm{~nm}$. Using the calculated band gap for $\mathrm{NF}^{-\mathrm{TiO}_{2}}$ and NFP$\mathrm{TiO}_{2}$ series, shown in Table 5, reduced $\mathrm{NF}-\mathrm{TiO}_{2}{ }^{\text {red }}$ and $\mathrm{NFP}-\mathrm{TiO}_{2}{ }^{\text {red }}$ may be active in near IR region and at $\sim 500 \mathrm{~nm}$, respectively. The photocatalytic production of $7 \mathrm{HC}$ in aqueous suspension of the synthesized $\mathrm{TiO}_{2}$ materials under irradiation at 419 and $450 \mathrm{~nm}$ are presented in Figure 33 - 34. For the quantitative estimation of their relative photocatalytic activity, we calculated OH-index for each of the prepared samples using Equation 19 on the basis of formation rate of $7 \mathrm{HC}$ correlated to the production of $\bullet \mathrm{OH}$ for only the initial 10 minutes of reaction to avoid the possible degradation of $7 \mathrm{HC}$. The calculated $\mathrm{OH}-$ indexes are summarized in Table 7 . Though the formation rate of $\bullet \mathrm{OH}$ depends on various factors, including phase structures, particle size, crystallinity, and surface defects, the composition is an important factor in the photolytic activity of $\mathrm{TiO}_{2}$ materials. A graphical comparison production of $\bullet \mathrm{OH}$ at visible light is presented in Figure 35. In general, the larger the OH-index, the higher the photocatalytic activity. The $\mathrm{P} 25 \mathrm{TiO}_{2}$ showed the highest $\mathrm{OH}$-index for $\mathrm{UV}$ activation compared to the reduced $\mathrm{TiO}_{2}$ materials. $\mathrm{P} 25 \mathrm{TiO}_{2}$ is among the most active photocatalysts for the degradation of organic compounds initiated by $\bullet \mathrm{OH}$ radicals under $\mathrm{UV}$ irradiation. However, under the visible light region, $\mathrm{P} 25 \mathrm{TiO}_{2}$ did not show appreciable photoactivity. In the visible range, $\mathrm{NaBH}_{4}$ treated $\mathrm{P} 25 \mathrm{TiO}_{2}$, $\mathrm{TiO}_{2}{ }^{\text {red } 70}, \mathrm{TiO}_{2}{ }^{\text {red } 50}$, and $\mathrm{TiO}_{2}{ }^{\text {red } 30}$ showed enhanced photocatalytic activity compared to reference $\mathrm{P} 25 \mathrm{TiO}_{2}$. Though NFP co-doped $\mathrm{TiO}_{2}$ exhibited limited photocatalytic activity under visible light, $\mathrm{NaBH}_{4}$ treatment did not make a difference in the performance. 

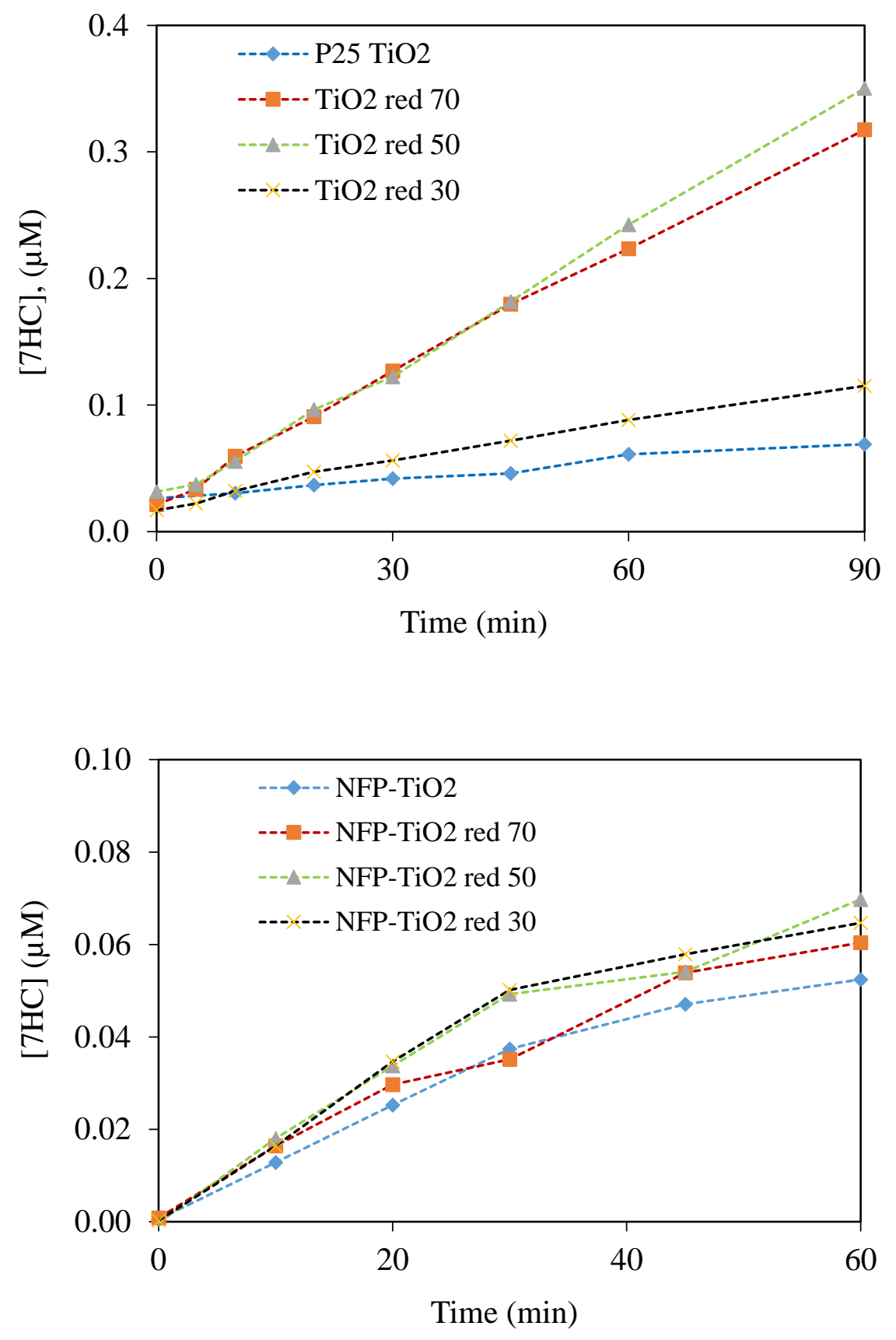

Figure 33. Production of $7 \mathrm{HC}$ by $\mathrm{P} 25 \mathrm{TiO}_{2}$ and the $\mathrm{NFP}-\mathrm{TiO}_{2}$ series upon irradiation with visible light centered at $419 \mathrm{~nm}$. Catalyst loading was $0.10 \mathrm{~g} / \mathrm{L}$ and $[\mathrm{COU}]_{0}=125 \mu \mathrm{M}$. 

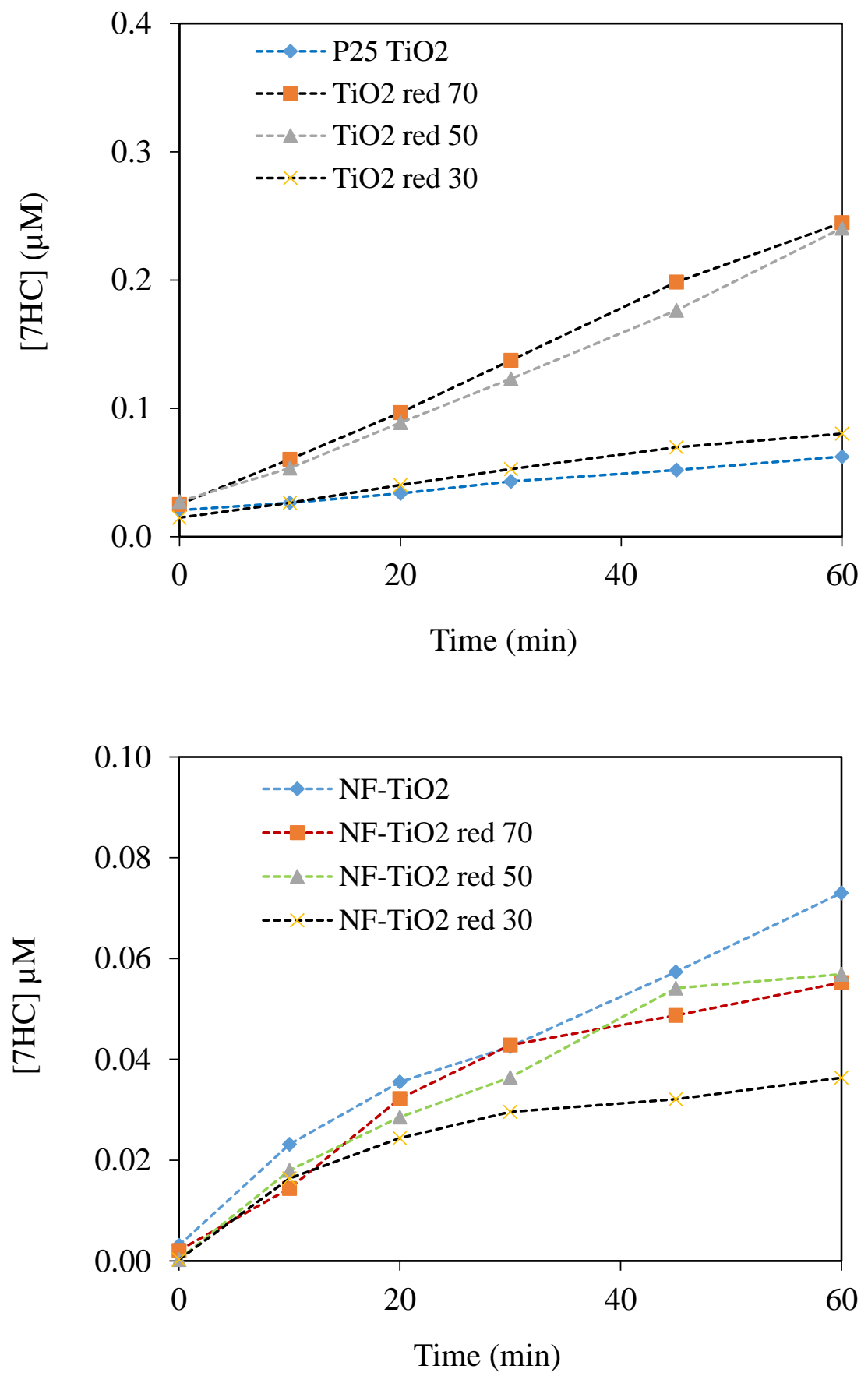

Figure 34. Production of $7 \mathrm{HC}$ by $\mathrm{P} 25 \mathrm{TiO}_{2}$ and $\mathrm{NF}^{-\mathrm{TiO}_{2}}$ series upon irradiation at visible light at $450 \mathrm{~nm}$. Catalyst loading was $0.10 \mathrm{~g} / \mathrm{L}$ and $[\mathrm{COU}]=125 \mu \mathrm{M}$. 
Table 7. Calculated $\mathrm{OH}$-index of prepared $\mathrm{TiO}_{2}$ materials

\begin{tabular}{|c|c|c|c|}
\hline \multirow{2}{*}{ Catalysts } & \multicolumn{3}{|c|}{ OH-index } \\
\hline & $350 \mathrm{~nm}$ & $419 \mathrm{~nm}$ & $450 \mathrm{~nm}$ \\
\hline $\mathrm{P} 25 \mathrm{TiO}_{2}$ & $100^{*}$ & 0.3 & 0.4 \\
\hline $\mathrm{TiO}_{2}{ }^{\text {red }} 70$ & 86 & 2.1 & 2.5 \\
\hline $\mathrm{TiO}_{2}^{\text {red } 30}$ & 75 & 2.2 & 2.4 \\
\hline $\mathrm{TiO}_{2}^{\text {red } 50}$ & 33 & 0.7 & 0.7 \\
\hline $\mathrm{NF}^{-\mathrm{TiO}_{2}}$ & 0.04 & $\mathrm{n} / \mathrm{d}$ & 0.8 \\
\hline $\mathrm{NF}-\mathrm{TiO}_{2}{ }^{\text {red }} 70$ & 0.03 & $\mathrm{n} / \mathrm{d}$ & 0.9 \\
\hline $\mathrm{NF}-\mathrm{TiO}_{2}{ }^{\text {red }} 50$ & 0.06 & $\mathrm{n} / \mathrm{d}$ & 0.7 \\
\hline $\mathrm{NF}-\mathrm{TiO}_{2}{ }^{\text {red } 30}$ & 0.05 & $\mathrm{n} / \mathrm{d}$ & 0.6 \\
\hline $\mathrm{NFP}^{-\mathrm{TiO}_{2}}$ & 0.01 & 0.8 & $\mathrm{n} / \mathrm{d}$ \\
\hline $\mathrm{NFP}-\mathrm{TiO}_{2}{ }^{\text {red }} 70$ & 0.01 & 0.9 & $\mathrm{n} / \mathrm{d}$ \\
\hline $\mathrm{NFP}-\mathrm{TiO}_{2}{ }^{\text {red }} 50$ & 0.01 & 0.8 & $\mathrm{n} / \mathrm{d}$ \\
\hline $\mathrm{NFP}-\mathrm{TiO}_{2}{ }^{\text {red }} 30$ & 0.01 & 1.1 & $\mathrm{n} / \mathrm{d}$ \\
\hline
\end{tabular}

* The data are reproducible with 5\% of error on the basis of some triplicate runs. $\mathrm{n} / \mathrm{d}$ represents no photocatalytic experiment of respective material for this condition was carried out. 


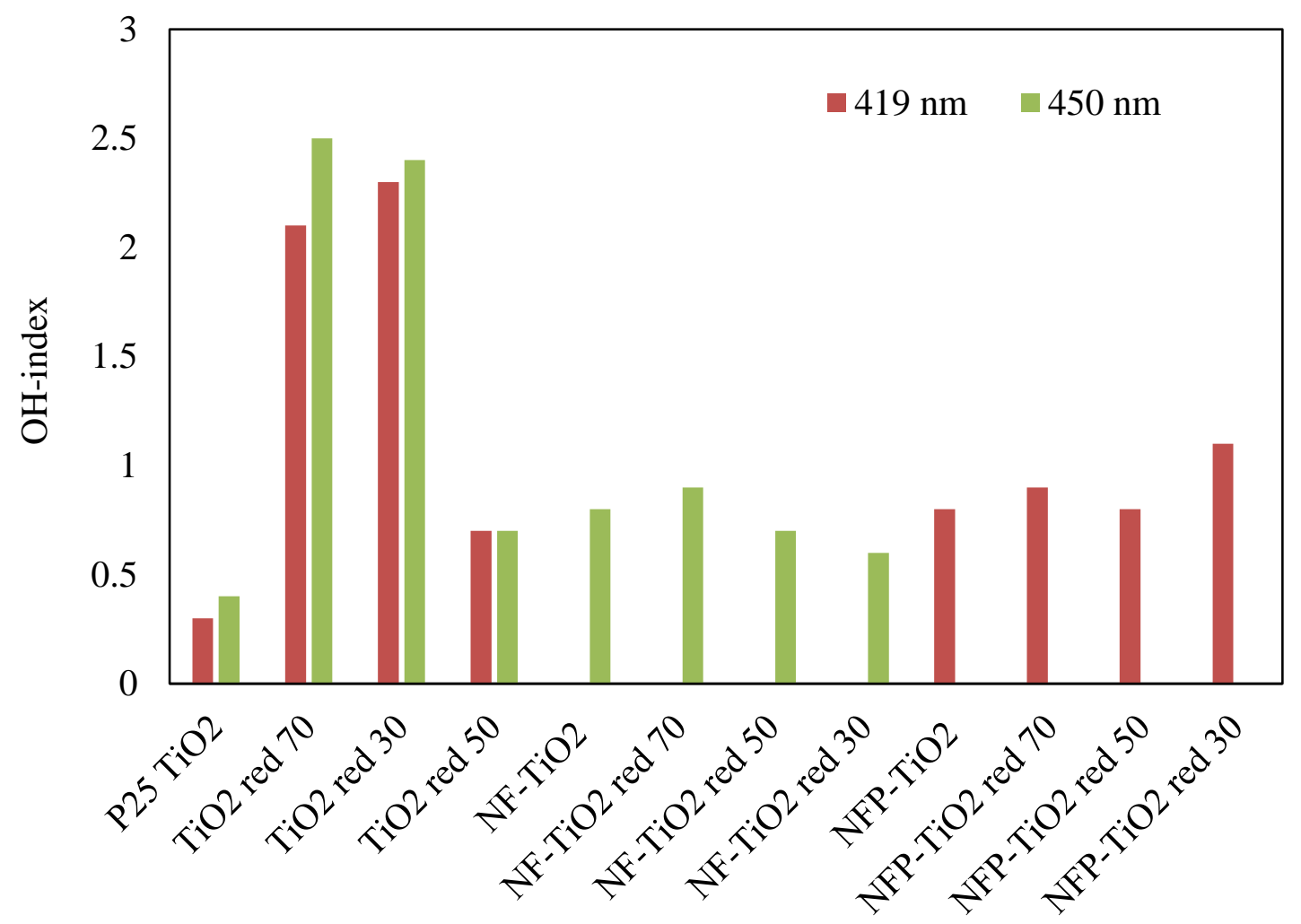

Catalysts

Figure 35. Relative comparison of $\mathrm{OH}$-index of various $\mathrm{TiO}_{2}$ based photocatalysts at visible light. Error was $\pm 5 \%$ on the basis of select triplicate runs.

\subsection{Conclusions}

The visible light-activated reduced forms of $\mathrm{TiO}_{2}$ materials were prepared by a simple solid-state thermo-physicochemical treatment using $\mathrm{NaBH}_{4}$. The materials were subsequently characterized by XRD, HRTEM, EDXRF, UV-Visible, and Raman spectrometry. Optical measurement suggested that physicochemical treatment can modulate the band gap energy suitable properties for efficient photocatalytic activity. Coumarin was used as a fluorescent probe to trap and measure the $\bullet \mathrm{OH}$ generated in 
catalyst suspension under UV and visible light irradiation. The photocatalytic performances of the synthesized reduced $\mathrm{TiO}_{2}$ materials were assessed by quantitative measurement of hydroxyl radical production under the irradiation of UV and visible light. Finally, the $\mathrm{OH}$-index of a photocatalyst using the formation rate of hydroxyl radicals was calculated to compare the relative photocatalytic activity of a photocatalyst. Though P25 $\mathrm{TiO}_{2}$ was found as the most active photocatalyst in the UV region, $\mathrm{NaBH}_{4}$ reduced forms of $\mathrm{TiO}_{2}$ were identified as significantly active photocatalyst under visible irradiation. 
CHAPTER 4 KINETICS AND MECHANISTIC INVESTIGATION OF ULTRASONIC INDUCED DEGRADATION OF TRIS (2CHLOROETHYL) PHOSPHATE (TCEP) 


\subsection{Abstract}

The widespread use of hazardous organophosphate ester (OPE) flame retardants has led to the contamination of groundwater and drinking water sources. Given the negative impact of OPE on environmental and human health, there is a critical need to identify an effective remediation process. We report herein that ultrasonic irradiation leads to degradation of TCEP, a model organophosphate flame retardant, from aqueous solution. Our results demonstrate the degradation of TCEP upon irradiation at $640 \mathrm{kHz}$ in an oxygensaturated aqueous solution. The degradation follows pseudo-first-order kinetics with rate constants varying from 0.09 to $0.02 \mathrm{~min}^{-1}$ depending on the initial concentrations ranging from 3.1- $84 \mu \mathrm{M}$. The rate constant for the degradation decreases with increasing initial TCEP concentration implying the process may be controlled by partitioning at the gasliquid interface during ultrasonic cavitation. The degradation also fits the LangmuirHinshelwood model suggesting the degradation occurs at the gas-liquid interface. Detailed product studies using liquid chromatography orbitrap high-resolution mass spectrometry show the mono and diester adducts of TCEP, specifically 2-chloroethyl dihydrogen phosphate and bis (2-chloroethyl) hydrogen phosphate are the primary degradation products. Mineralization of TCEP to chloride and phosphate was monitored by ion chromatography over the extended irradiation time. Mass balances of $48 \%$ and $32 \%$ were observed for chloride and phosphate, respectively, after six hours of treatment, while TCEP has a half-life of less than one hour under our experimental conditions. Our results suggest that sonolytic oxidation is a rapid and effective method for the degradation of TCEP from aqueous solutions. 


\subsection{Introduction}

Organophosphate esters (OPEs) are used in a wide variety of consumer and industrial products, including plastic, furniture, automobile, electronic cable, and electronic equipment, to enhance their flame resistivity and thermo stability $[9,10]$. OPEs are introduced as additives into finished products without any covalent bonding; thus, a significant portion of OPEs can leach from the product matrix into the environment and contaminate aquatic systems. The presence of organophosphorus esters (OPEs) in drinking water sources, air, sediments, and even in biological matrixes is well documented $[9,10,14,82,167]$. The molecules of OPEs are triesters of phosphoric acid and contain a P$\mathrm{O}$ bond, which is relatively resistive to hydrolysis compared to the P-S and P-F bonds associated with the organophosphorus pesticides and chemical warfare agent. Because of their limited reactivity, OPEs are quite persistent in the environment [91]. Unfortunately, OPEs are often highly toxic and cause a variety of adverse health issues, including acute to chronic neurological disorders, endocrine disruption, reproductive toxicity, developmental delay, and hepatotoxicity [18-21]. The US-EPA included several organophosphorus flame retardants in the list of Toxic Substance Control Act (TSCA) [81]. Recently, substantial interest and effort have been triggered in developing OPEs treatment technologies. Conventional activated sludges treatment is not effective in decontaminating organophosphate esters from water [13]. Although membrane filtration, reverse osmosis, and activated carbon can trap OPEs from water either in a concentrated liquid or in a solid matrix, these techniques require further treatment and often are cost-prohibitive $[13,84-$ 86,168-170]. Degradation of organophosphorus esters has been reported in a couple of 
laboratory-scale studies $[13,90-96]$. Our recent studies on the $\mathrm{TiO}_{2}$ photocatalysis of tris (2-chloroethyl) phosphate (TCEP) showed nearly complete mineralization into carbon dioxide, water, chloride, and phosphate. We identified diester and monoester adducts of TCEP using ${ }^{31} \mathrm{P}-\mathrm{NMR}$ spectroscopy and proposed hydroxyl radical-mediated sequential oxidation of alkyl chains of TCEP [51]. Ruan et al. also reported $\mathrm{UV} / \mathrm{H}_{2} \mathrm{O}_{2}$ treatment of tris (2-chloroethyl) phosphate (TCEP) in aqueous solution and showed its mineralization into $\mathrm{Cl}^{-}, \mathrm{PO}_{4}^{3-}, \mathrm{CO}_{2}$, and $\mathrm{H}_{2} \mathrm{O}$ proposing the diester as an intermediate [94]. However, $\mathrm{UV} / \mathrm{H}_{2} \mathrm{O}_{2}$ treatment of effluent water leads to slow degradation and incomplete removal of several halogenated organophosphorus flame retardants, including TCEP [96].

Ultrasonic irradiation offers a promising application for the decontamination of a wide variety of hazardous organic pollutants and toxins from water and wastewater $[57,59,60]$. The use of ultrasound in water treatment has a number of unique advantages over the $\mathrm{TiO}_{2}$ photocatalysis and $\mathrm{UV} / \mathrm{H}_{2} \mathrm{O}_{2}$. Ultrasonic irradiation can initiate oxidative and pyrolytic degradation processes [59]. Such treatment does not require any chemical additives and can effectively work on turbid and colored solutions as well as sludge. Although the efficiency of conversion from electrical to acoustic energy is relatively low, proper optimization of energy efficiency or dynamics of the reaction system, however, can improve the application efficiency $[57,69,70]$. Exposure of ultrasonic irradiation in water induces acoustic cavitation, a phenomenon involving the generation, growth, and violent collapse of gas bubbles in water [71,72]. Soundwaves propagate through liquid water via cycles of compression and rarefaction. In the rarefaction cycle, there is a formation of microbubbles from the gas nuclei present in the solution. In the compression cycle, the 
volume of bubbles decreases dramatically because of increasing pressure in the surrounding water. Thus, the bubble grows and contracts sequentially until the pressure gradient overcomes the cavitation threshold leading to a violent bubble collapse. The violent bubble collapse results in extreme temperatures $(\sim 5000 \mathrm{~K})$ and pressures $(\sim 500$ atm) at the cavitational site, leading to thermal homolysis of water vapor into $\mathrm{H} \bullet$ and $\mathrm{HO} \bullet$. that is a key to advanced oxidation processes used for the water purification [71]. The acoustic cavitation is often broken into three distinct zones; the hot spot with temperatures reaching $\sim 5000 \mathrm{~K}$ and pressure on the order of $500 \mathrm{~atm}$, an interfacial region with $2000 \mathrm{~K}$ and 300 atm, and bulk solution which can be maintained near ambient conditions $[71,73]$.

A limited number of studies have been reported for the sonolytically induced oxidation of organophosphorus compounds [92,171,172]. O'Shea et al. successfully demonstrated the decomposition of dimethyl methylphosphonate (DMMP) and diethyl methylphosphonate (DEMP) at $640 \mathrm{kHz}$ into acetic acid, formic acid, oxalic acid, methylphosphonic acid, phosphate ions and proposed a hydroxyl radical initiated oxidation mechanism [92]. Although low molecular weight halogenated aldehydes, ketones, and carboxylic acids, analogous to disinfection by-products are generated during the advanced oxidation of halogenated organophosphate compounds, detailed product and mechanistic investigation by ultrasonic irradiation, however, have yet to be reported. Herein, we report the detailed kinetic and mechanistic studies of ultrasonic treatment of a model organophosphate ester flame retardant, tris (2-chloroethyl) phosphate (TCEP). The pyrolysis and hydroxyl radical-mediated oxidation partitioning among the different regions of ultrasonic cavitation also have been discussed to figure out their relative roles on the degradation of TCEP during the ultrasonic irradiation. 


\subsection{Experimental section}

\subsubsection{Materials}

Tris (2-chloroethyl) phosphate (TCEP), and triphenyl phosphate (TPhP) were purchased from Aldrich Chemical Company. High purity GC grade dichloromethane (DCM) was obtained from Fisher Scientific. Coumarin was purchased from MP Biomedicals, LLC. Terephthalic acid was bought from the Alfa Aesar. Sodium carbonate and sodium hydrogen carbonate were purchased from Fisher Scientific. The oxygen was from Trigas of the highest purity available. Millipore water $(18 \mathrm{M} \Omega \cdot \mathrm{cm})$ and volumetric glassware were used for the preparation of all of the aqueous solutions.

\subsubsection{Sonolytic experiment}

An ultrasonic reactor UES 1.5-660 Pulsar (Ultrasonic Energy Systems Inc.) was employed for all the sonolytic reactions. The reactor is equipped with an ultrasound generator, a transducer, and a $550 \mathrm{~mL}$ cylinder-shaped glass vessel. Ultrasonic treatment was carried out in a pulse mode with the frequency $640 \mathrm{kHz}$ under the power amplitude of $650 \mathrm{~W}$. Power density of the sonication was $10.2 \mathrm{~W} / \mathrm{cm}^{2}$ with ultrasonic horn diameter of $9 \mathrm{~cm}$. The ultrasound waves traveled through $5 \mathrm{~cm}$ of water and a $38 \mu \mathrm{m}$ of polyethylene film to reach the $500 \mathrm{~mL}$ solution inside the glass vessel with $9 \mathrm{~cm}$ diameter. In a typical reaction, $500 \mathrm{~mL}$ of TCEP solution was transferred to the glass reaction vessel, the transducer was attached, and the unit submerged in a 10-gallon ice-water bath maintained at $7 \pm 1{ }^{\circ} \mathrm{C}$. All solutions were purged with oxygen gas for $15 \mathrm{~min}$ before exposure to 
ultrasonic irradiation. Samples of $5 \mathrm{~mL}$ of treated solution were withdrawn at specific time intervals for analyses.

\subsubsection{Gas chromatographic (GC) analysis of TCEP}

A gas chromatograph (Hewlett-Packard 6890) equipped with a nitrogenphosphorus detector (NPD) was employed to analyze the TCEP concentration. The detailed extraction procedure and the GC analytical method of TCEP are described elsewhere [51]. The extraction of TCEP from an ultrasonically treated solution was extracted with $5.0 \mathrm{~mL}$ of dichloromethane (DCM) in a $40 \mathrm{~mL}$ extraction vial using triphenyl phosphate (TPhP) as an internal standard. The same extraction procedure was followed in the preparation of calibration standards for the GC-NPD analysis. Samples were injected manually to the GC inlet setting up at $250^{\circ} \mathrm{C}$ in splitless mode [82]. Chromatographic separation was carried out on a DB-5 fused silica capillary column. The initial GC temperature was held at $40{ }^{\circ} \mathrm{C}$ for $4 \mathrm{~min}$ and increased to $190{ }^{\circ} \mathrm{C}$ at $15{ }^{\circ} \mathrm{C} \min ^{-1}$ and then $10{ }^{\circ} \mathrm{C} \min ^{-1}$ to the final temperature of $310^{\circ} \mathrm{C}$ which was maintained for $4 \mathrm{~min}$. Helium was used as a carrier gas. The concentration of TCEP was determined using the characteristic retention time, reference standard, and careful calibration of the NPD. The detector response was calibrated against a series of standard TCEP aqueous solutions ranging from $1-100 \mu \mathrm{M}$ with TPhP internal standard yielding a correlation coefficient $\left(\mathrm{R}^{2}\right) \geq 0.99$ (Figure 36). Standards were run periodically to ensure accurate calibration of GC. 


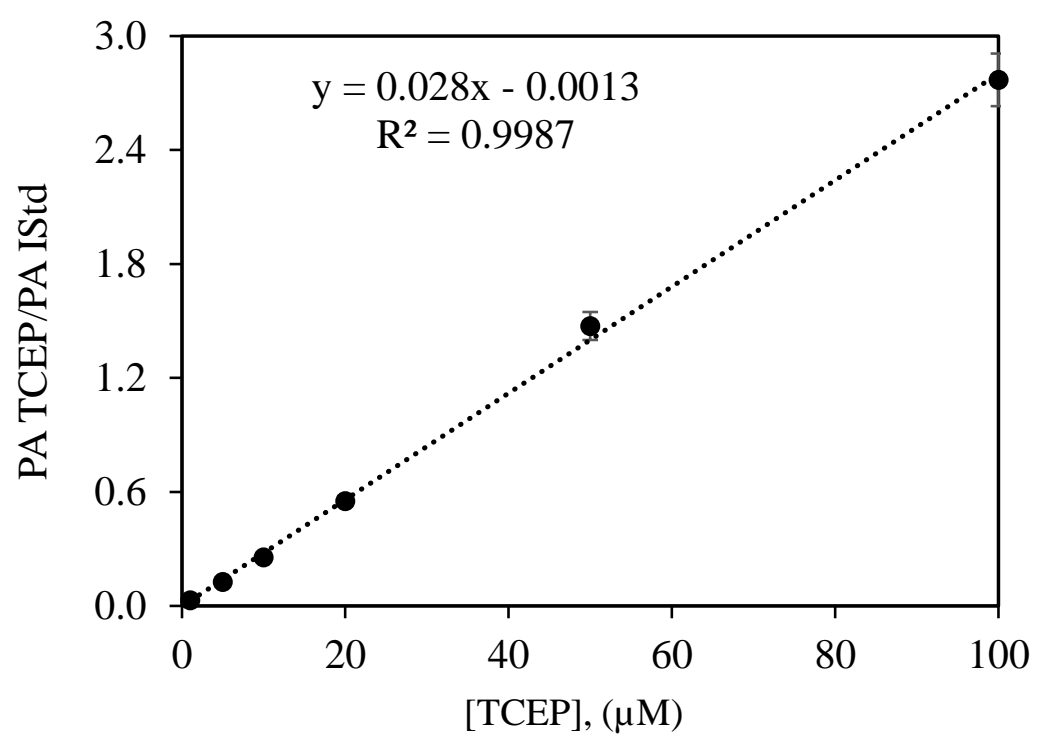

Figure 36. GC-NPD calibration curve for the determination of TCEP concentration in aqueous solution. TPhP was used as an internal standard.

\subsubsection{Analysis of phosphate and chloride by ion chromatography (IC)}

Phosphate $\left(\mathrm{PO}_{4}{ }^{3-}\right)$ and chloride $\left(\mathrm{Cl}^{-}\right)$released during ultrasonic treatment were determined by ion chromatography (761 Compact IC Metrohm) incorporated with a Metrosep A Supp 5 column and conductivity detector. The analyses were performed with a buffer composed of $3.2 \mathrm{mM}$ sodium carbonate and $1.0 \mathrm{mM}$ sodium hydrogen carbonate aqueous solution with a flow rate of $0.7 \mathrm{ml} \mathrm{min}^{-1}$. A solution of sulfuric acid $(0.125 \mathrm{M})$ with a flow rate of $2.0 \mathrm{~mL} \mathrm{~min}{ }^{-1}$ was used to regenerate the column. An IC-conductivity detector calibration curve, shown in Figure 37, was developed for the determination of chloride and phosphate ions against a series of carefully prepared standard solutions for both anions ranging from $0.01 \mathrm{mM}$ to $0.50 \mathrm{mM}$. The correlation coefficient of the calibration curve was $\geq 0.99$. 


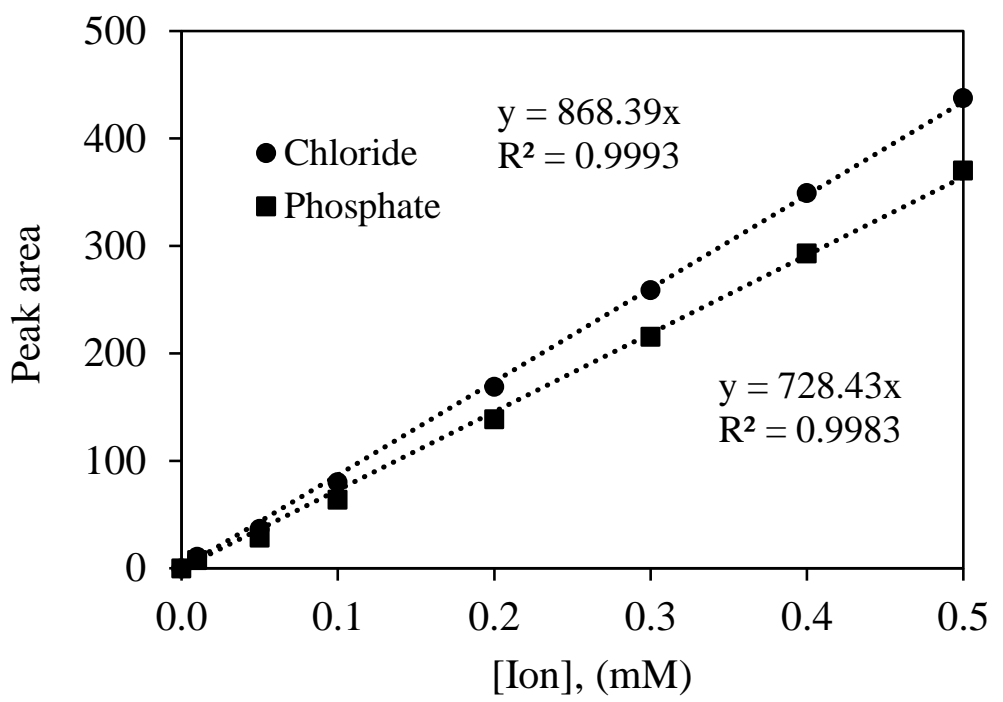

Figure 37. Ion chromatographic calibration curve for chloride and phosphate ions

\subsubsection{Analysis of intermediates and byproducts}

Identification of intermediates and/or transformation products of TCEP was carried out by ultra-high-performance liquid chromatography coupled with an Orbitrap highresolution mass spectrometry system (UHPLC-Orbitrap-HRMS) (Q Exactive). Chromatographic separation was performed employing a C-18 reverse phase column (Hypersil Gold, $50 \mathrm{~mm}$ x $2.1 \mathrm{~mm}, 1.9 \mu \mathrm{m}$ particle size, Thermo Scientific, USA) with a mobile phase consisting of methanol (solvent A) and water with $5 \mathrm{mM}$ ammonium formate (solvent B) with a flow rate of $0.4 \mathrm{~mL} \mathrm{~min}^{-1}$. A gradient elution program was set as follows: (0-1 $\min , 95 \%$ A) (1-12 min, 95 to $5 \%$ A). The column was maintained at room temperature. For mass analysis, an atmospheric pressure chemical ionization (APCI) source was used in positive ionization mode with a mass scan range of 100-500 mass/charge ratio, 140,000 resolution power, and 5 ppm mass tolerance. The MS system 
operated under the condition of discharge current $5.0 \mu \mathrm{A}$, capillary temperature $300{ }^{\circ} \mathrm{C}$, sheath gas flow rate $40 \mathrm{~L} \mathrm{~h}^{-1}$, Aux gas flow rate $10 \mathrm{~L} \mathrm{~h}^{-1}$. As ultrasonic irradiation can involve a variety of pyrolytic and radical-induced processes, degradation of TCEP can produce a range of transformation products. Therefore, we used the small molecule structure identification software, Compound Discoverer 3.0 (Thermo Scientific, USA), to assist in the identification of the intermediates and degradation products.

\subsection{Results and discussion}

\subsubsection{Ultrasound induced degradation kinetics of TCEP}

Tris (2-chloroethyl) phosphate (TCEP) is readily degraded upon ultrasonic irradiation at $640 \mathrm{kHz}$ in an $\mathrm{O}_{2}$-saturated aqueous solution. The degradation of TCEP as a function of treatment time is shown in Figure 38. More than $40 \%$ of TCEP was eliminated within the first 10 min of ultrasonic treatment. The rate of TCEP degradation decreases upon continuous treatment. The observed decrease in the degradation rate is assigned to the decrease of TCEP concentration and the presence of by-products that compete with TCEP for the degradation pathways. The degradation is likely the result of pyrolysis, and hydroxyl radical-mediated oxidation at the gas-liquid interface and the liquid bulk regions $[51,91,93]$. Ultrasonic cavitation also leads to the degradation of volatile compounds at the hot spot region and hydrophobic compounds in the interfacial regions. Given the relatively low vapor pressure of TCEP, it is not expected to partition into the gas phase of the cavitation site effectively. 


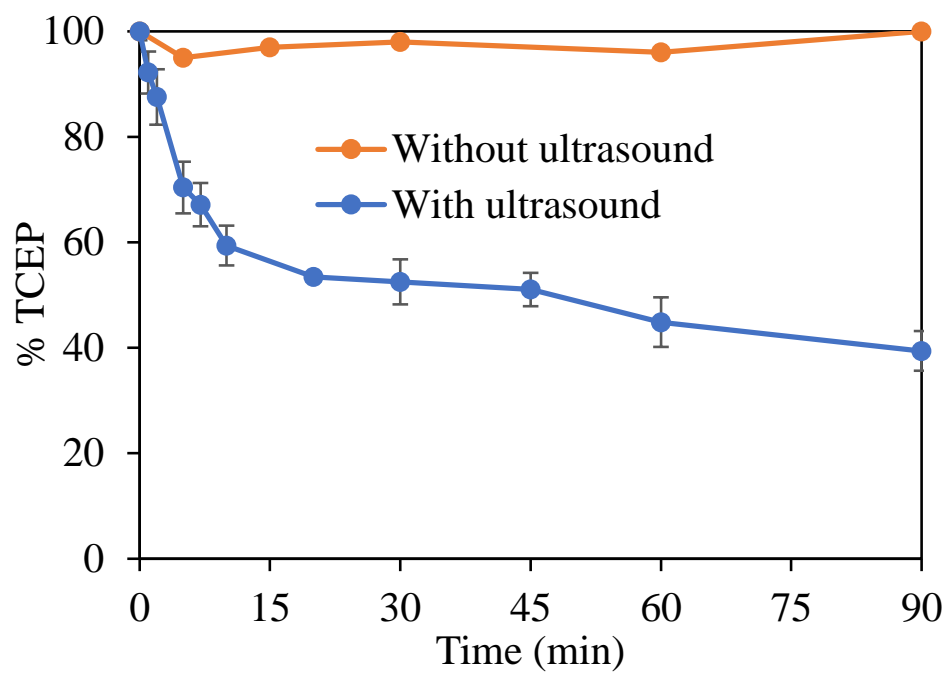

Figure 38. Ultrasonic induced degradation of TCEP at $640 \mathrm{kHz}$ in $\mathrm{O}_{2}$-saturated aqueous solution. $[\mathrm{TCEP}]_{0}=3.2 \mu \mathrm{M}, \mathrm{pH}=6.5$, and the reproducibility was within $5 \%$ on the basis of representative triplicate runs.

The degradation kinetics of TCEP was studied over a range of initial concentrations from 3.1 -84 $\mu \mathrm{M}$ (Figure 39). The initial degradation rates for the sonolysis of TCEP were determined at different concentrations and summarized in Table 8. The first $10-20 \%$ degradation was used to monitor the initial rates to minimize the effect of products on the initial kinetic parameters. Results suggest that the extent of degradation decreases with the increase of initial concentration. While concentration has been increased to around 25 times, the degradation rate only increases by six times. At low concentration, the ultrasonically induced degradation of organic compounds is reported to follow pseudofirst-order kinetics $[92,173,174]$. Pseudo-first-order kinetics is represented by the equation, $\left[\ln \left(C_{t} / C_{0}\right)=-k t\right]$, where $C_{t}$ and $C_{0}$ refer to the concentrations of TCEP at time $t$, and the start of the reaction, respectively and $\mathrm{k}$ represents rate constant. A linear relationship between $\ln \left(\mathrm{C}_{\mathrm{t}} / \mathrm{C}_{0}\right)$ vs. $\mathrm{t}$ is consistent with this kinetic model. The pseudo-first-order kinetic 
plots of the TCEP degradation over the range of concentrations of 3.1-84 $\mu \mathrm{M}$ are presented in Figure 40.

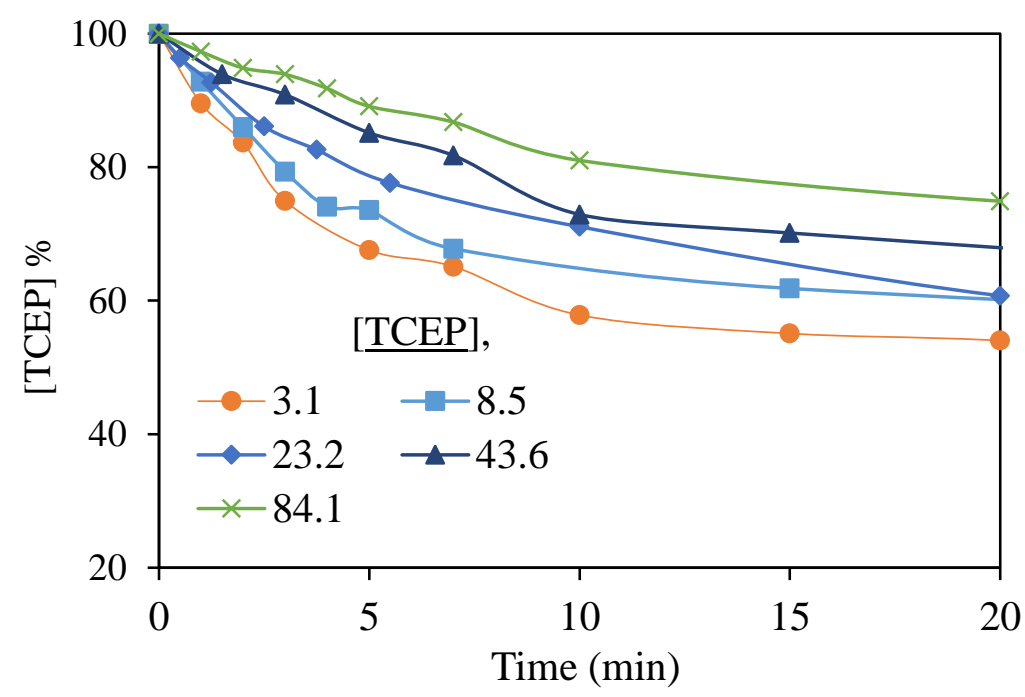

Figure 39. Degradation of TCEP as a function of treatment time over the initial concentrations of $3.1-84 \mu \mathrm{M}$ at $640 \mathrm{kHz}$ in the $\mathrm{O}_{2}$-saturated aqueous solution.

Results show that at each specific concentration, the degradation follows pseudo-first-order kinetics. The rate constants $(\mathrm{k})$ calculated from the slope of the straight line are also summarized in Table 8 . The observed first-order rate constant decreases by 5-fold when the substrate concentration increases by nearly 25 -fold. While the results for a given concentration of TCEP are consistent with pseudo-first-order kinetics, the change in the rate constant as a function of initial concentration suggests that the reaction kinetics is not truly consistent with a simple pseudo-first-order reaction. The above kinetic behavior has been observed for a variety of heterogeneous processes, where partition between reaction zones can play a critical role as well as the mass transfer limitations of the target molecule at the gas-liquid interface $[92,173]$. 


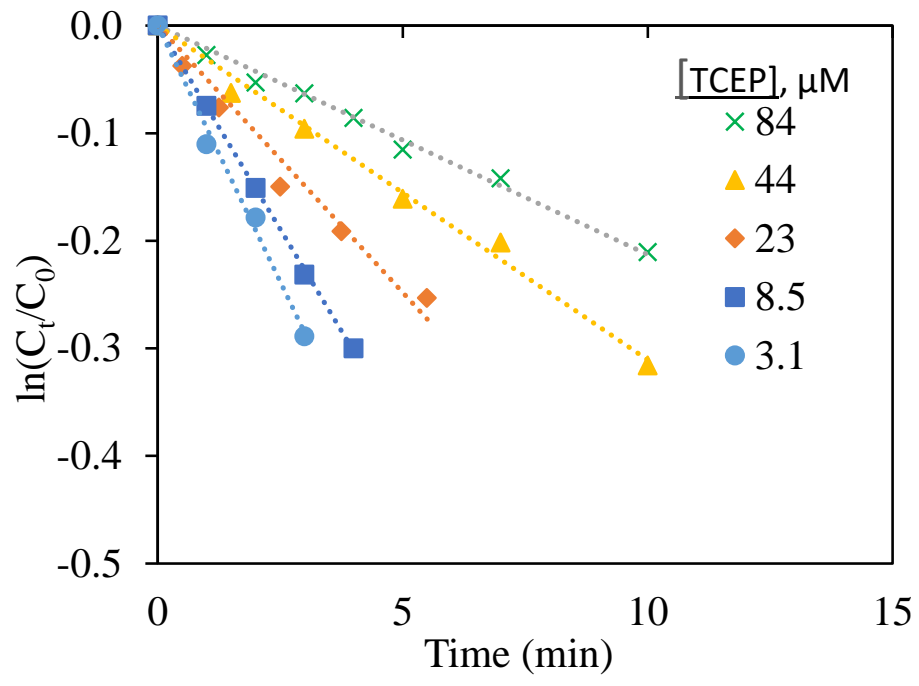

Figure 40. Pseudo-first-order kinetics plots of TCEP over a range of initial concentration $3.1-84 \mu \mathrm{M}$ upon ultrasonic treatment at $640 \mathrm{kHz}$ in $\mathrm{O}_{2}$-saturated aqueous solution.

Table 8. Kinetic parameters for the ultrasonic oxidation of TCEP at $640 \mathrm{kHz}$ in $\mathrm{O}_{2}$ saturated aqueous solution

\begin{tabular}{ccccc}
\hline $\begin{array}{c}\text { [TCEP] } \\
(\mu \mathrm{M})\end{array}$ & $\begin{array}{c}\text { Observed Initial } \\
\left.\text { rate } \mathrm{r}_{0}(\mu \mathrm{M} \mathrm{min})^{-1}\right)\end{array}$ & $\begin{array}{c}\mathrm{R}^{2} \text { value for } \\
\text { initial rate }\end{array}$ & $\begin{array}{c}\text { Pseudo-first-order rate } \\
\text { constant } \mathrm{k} \mathrm{x} 10^{2}\left(\mathrm{~min}^{-1}\right)\end{array}$ & $\begin{array}{c}\mathrm{R}^{2} \text { value for } \\
\text { rate constant }\end{array}$ \\
\hline 3.1 & 0.26 & 0.96 & 9.5 & 0.99 \\
8.5 & 0.57 & 0.99 & 7.6 & 0.99 \\
23 & 1.16 & 0.97 & 5.0 & 0.97 \\
44 & 1.33 & 0.98 & 3.1 & 0.99 \\
84 & 1.66 & 0.98 & 2.1 & 0.99 \\
\hline
\end{tabular}

\subsubsection{Heterogeneous kinetic modeling}

Ultrasonic mediated degradation can be viewed as a complex heterogeneous process (Figure 41) involving hot spot gas phase where volatile compounds can partition and undergo high-temperature pyrolysis, the gas-liquid interface where pyrolysis and 
hydroxyl radical-mediated transformation of hydrophobic type compounds can occur, and the bulk phase where hydroxyl radical can diffuse to degrade compounds in the bulk solution. While ultrasonic degradation of an organic compound is often ascribed to the hydroxyl radical-mediated process, direct pyrolysis of the target compound, however, can play a vital role in the degradation pathways. The extent and mechanism of the degradation pathways are dependent on the partitioning of the target compounds into the three phases.

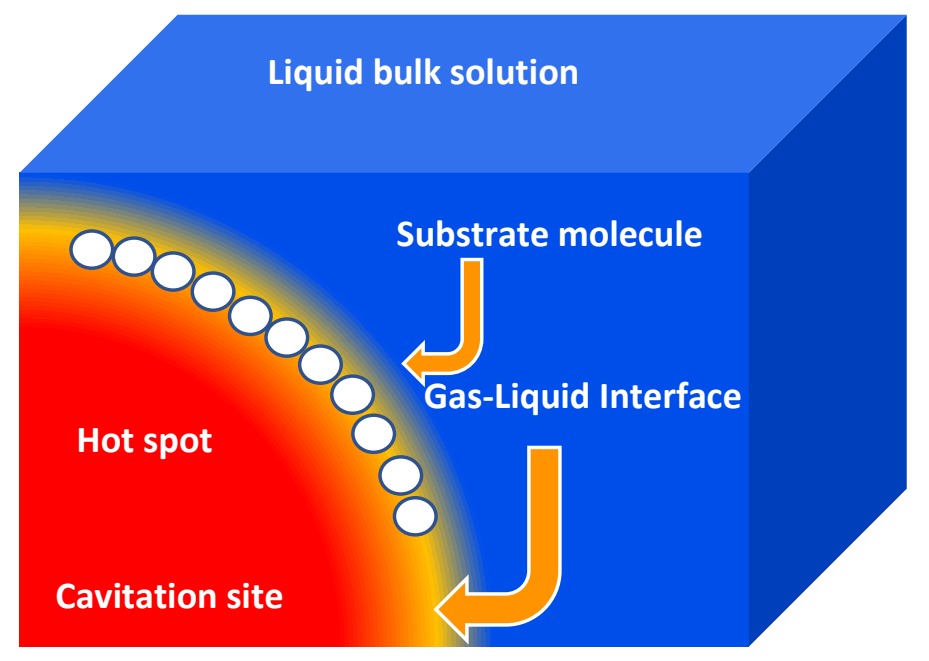

Figure 41. Partitioning of TCEP molecules in the hot spot, gas-liquid interface, and bulk liquid phase.

The TCEP has low vapor pressure, is non-ionic, and possesses hydrophobic character caused by its aliphatic chain. Therefore, TCEP is unlikely to partition into hot spots but likely to partition into the gas-phase interface and liquid bulk regions. The gasliquid interface at the cavitation site possesses high temperatures (>2000 K) and high pressures (>300 atm) well above the supercritical points $(680 \mathrm{~K}$ and $218 \mathrm{~atm})$ of water. Under such conditions, water exists as a supercritical state which exhibits hydrophobic 
rather than the typical hydrophilic properties associated with water under ambient circumstances. For the modeling of the degradation, the liquid-gas interface can be considered a reaction surface where TCEP can partition between the interface and bulk solution. To probe such partitioning and its effect on the degradation, we employed Langmuir-Hinshelwood (L-H) heterogeneous kinetic model which assumes (1) all interfacial sites are equivalent, (2) each molecule distributes uniformly and forms a monolayer, (3) there is no interaction between adjacent molecules, and (4) the adsorption and desorption processes are in equilibrium. The L-H model is represented in Equation 20, where $\mathrm{r}_{0}$ is the initial degradation rate, $\mathrm{C}_{0}$ is the initial concentration of substrate, $\mathrm{k}_{\mathrm{r}}$ is the reactivity constant, and $\mathrm{K}_{\mathrm{LH}}$ is the apparent partition equilibrium constant.

$$
\text { Langmuir-Hinshelwood equation: } \quad 1 / \mathrm{r}_{0}=1 / \mathrm{k}_{\mathrm{r}} \mathrm{K}_{\mathrm{LH}} \mathrm{C}_{0}+1 / \mathrm{k}_{\mathrm{r}}
$$

The L-H experiments were conducted over a range of initial concentrations of $3.1-84 \mu \mathrm{M}$ at uniform reaction conditions. The resulting plots, shown in Figure $42\left(\mathrm{R}^{2} \geq 0.98\right)$, suggested that the ultrasonic degradation kinetics of TCEP is in good agreement with the L-H type mechanism. The L-H kinetic parameters determined from the slope and intercept

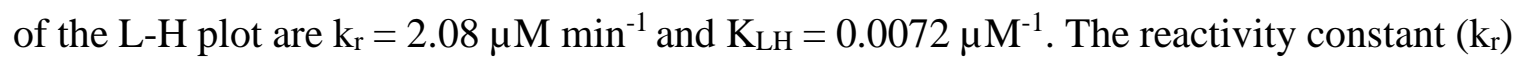
and the partitioning equilibrium constant $\left(\mathrm{K}_{\mathrm{LH}}\right)$ are empirical values describing the apparent reactivity and partitioning factor of target compounds into the gas-liquid interface. Cui et al. reported the ultrasonic degradation of diphenhydramine (DPH) with the reactivity constant of $1.96 \mu \mathrm{M} \mathrm{min}{ }^{-1}$ and partitioning equilibrium constant of $0.06 \mu \mathrm{M}^{-1}$ suggesting that TCEP, compared to DPH, may exhibit higher reactivity but lesser partitioning at the gas-liquid interface [173]. Enhanced reactivity and smaller partitioning values of TCEP in 
comparison with DPH could be attributed to its relatively lower hydrophobicity at the molecular structure and non-aromaticity of TCEP.

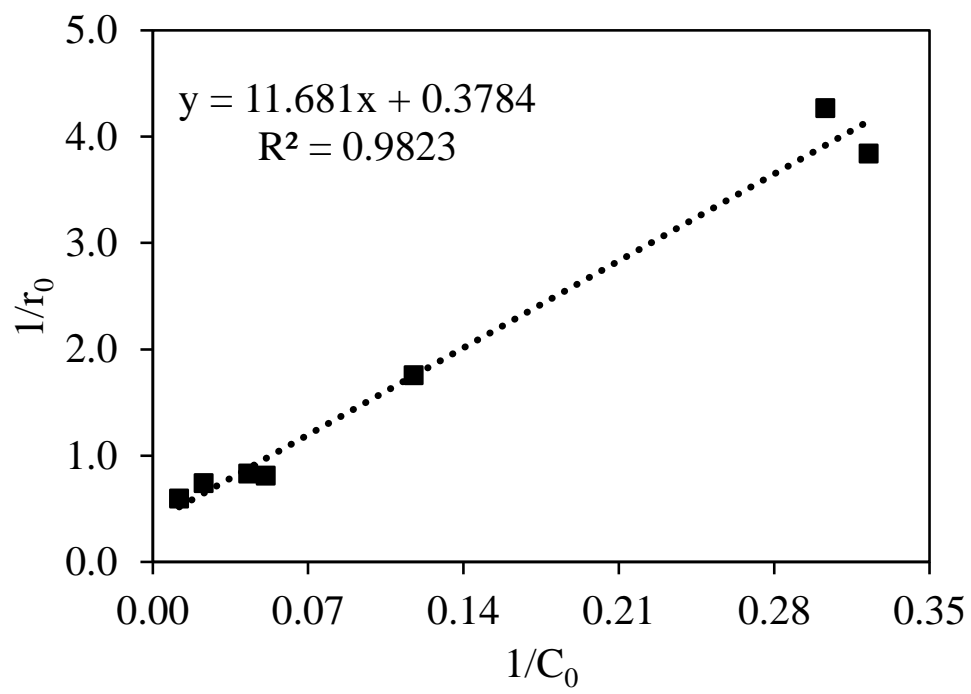

Figure 42. Langmuir-Hinshelwood kinetic plots for the ultrasonic degradation of TCEP at $640 \mathrm{kHz}$ in $\mathrm{O}_{2}$ saturated aqueous solution of TCEP $\left([\mathrm{TCEP}]_{0}=3.1 \mu \mathrm{M}-84 \mu \mathrm{M}\right)$.

\subsubsection{Hydroxyl radical competition study}

Ultrasonically induced degradation can occur by hydroxyl radical-mediated oxidation and direct pyrolysis. Upon cavitation, hydroxyl radicals, formed from the homolysis of water molecules, can partition among the hotspot gas phase $\left(\cdot \mathrm{OH}_{\mathrm{G}}\right)$, gasliquid interface $\left(\cdot \mathrm{OH}_{\mathrm{G}-\mathrm{L}}\right)$, and bulk liquid solution $\left(\bullet \mathrm{OH}_{\mathrm{L}}\right)$. Since TCEP has relatively low vapor pressure, it is unlikely to partition to the gas-phase hot spot. A series of competition experiments were conducted in the presence of specific hydroxyl radical scavengers for evaluating the partitioning and the roles of pyrolysis and hydroxyl radicals $\left(\cdot \mathrm{OH}_{\mathrm{G}-\mathrm{L}}\right.$, and $\left.\cdot \mathrm{OH}_{\mathrm{L}}\right)$ in the degradation process. Assessment of the individual contributions of hydroxyl 
radical and pyrolysis mediated degradation is important for understanding the partitioning of TCEP and $\mathrm{HO} \bullet$ within the cavitation regions. Selective quenching of hydroxyl radicals from each region will help understand its role in the degradation and, by difference, reveal the role of pyrolysis in the degradation process. The hydroxyl radical quencher, terephthalic acid (TPA), ${ }^{-} \mathrm{O}_{2} \mathrm{C}-\mathrm{Ph}-\mathrm{CO}_{2}{ }^{-}$, is ionic and will reside preferentially in bulk liquid solution. The addition of TPA will only quench the $\cdot \mathrm{OH}_{\mathrm{L}}$ reaction pathways. Alternatively, the $\mathrm{HO} \cdot$ quencher, coumarin $(\mathrm{COU})$, is a neutral organic compound that will reside predominantly within the gas-liquid interface and thus effectively scavenge $\bullet \mathrm{OH}_{\mathrm{G}-\mathrm{L}}$ at the interface and prevent $\mathrm{HO} \bullet$ from diffusing to the bulk liquid $\left(\bullet \mathrm{OH}_{\mathrm{L}}\right)$. With this in mind, if - $\mathrm{OH}_{\mathrm{G}-\mathrm{L}}$ radical is a major participant in the sonochemical degradation of TCEP, the reaction would be significantly suppressed by the addition of COU. Pseudo-first order kinetic plots obtained from scavenging experiments are shown in Figure 43. The rate constants and the likely mechanisms of ultrasonic degradation of TCEP in the presence of the individual hydroxyl radical scavengers are tabulated in Table 9. In the absence of $\bullet \mathrm{OH}$ scavengers, the rate constant for ultrasonically induced degradation of TCEP is $0.043 \mathrm{~min}^{-1}$. However, the rate constant decreased by $0.06 \mathrm{~min}^{-1}$ in the presence of excess TPA, a $\bullet \mathrm{OH}_{\mathrm{L}}$ scavenger, suggesting hydroxyl radical present in the bulk region plays a minor role, approximately $14 \%$, in the degradation of TCEP. 


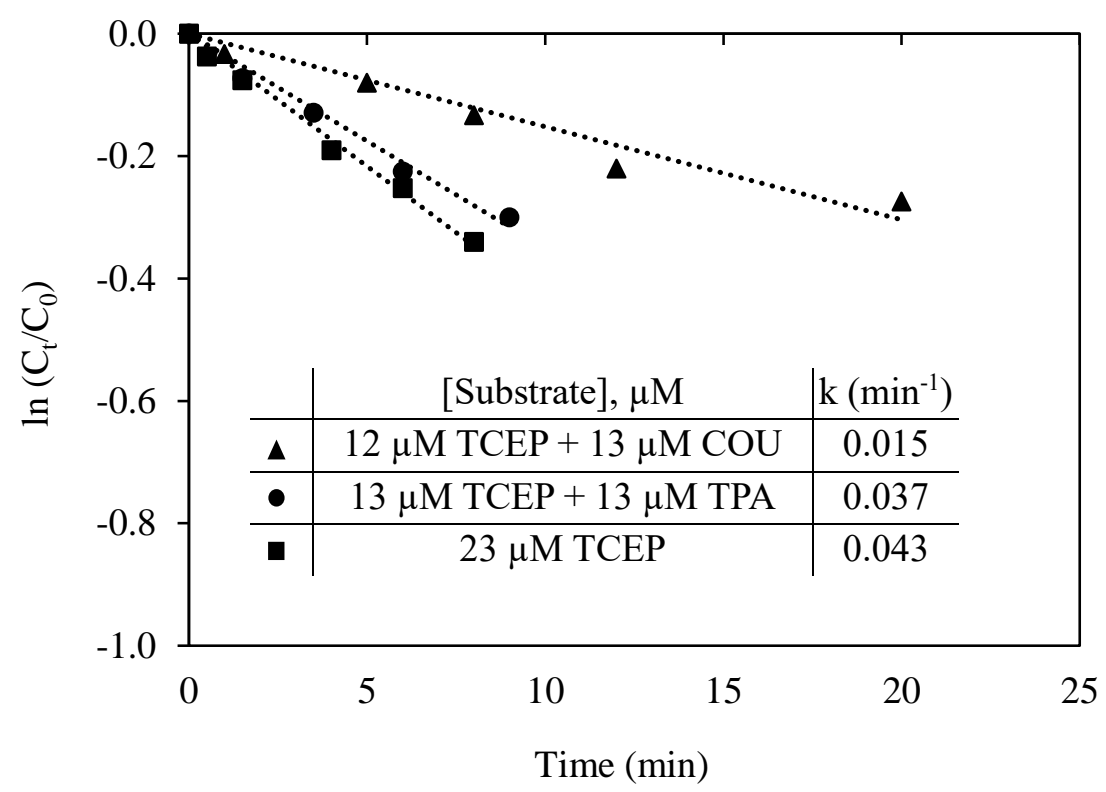

Figure 43. Effect of hydroxyl radical scavengers on the sonochemical degradation of TCEP at $640 \mathrm{kHz}$ in oxygenated aqueous solution. [COU $]_{0}=12 \mu \mathrm{M}$ and $[\mathrm{TPA}]_{0}=13 \mu \mathrm{M}$.

Table 9. Likely degradation pathways of ultrasonic treatment of TCEP in the presence of different hydroxyl radical scavengers

\begin{tabular}{|c|c|c|c|}
\hline & $\begin{array}{l}\text { Scavenged } \\
\text { radical }\end{array}$ & $\begin{array}{l}\text { Pseudo-first- } \\
\text { order k }\left(\min ^{-1}\right)\end{array}$ & Degradation pathways \\
\hline (TCEP + )))) & none & 0.043 & $\begin{array}{l}\text { Pyrolysis, } \cdot \mathrm{OH}_{\mathrm{G}-\mathrm{L}} \text { and } \cdot \mathrm{OH}_{\mathrm{L}} \\
\text { mediated degradation }\end{array}$ \\
\hline TCEP + TPA + )))) & $\cdot \mathrm{OH}_{\mathrm{L}}$ & 0.037 & $\begin{array}{l}86 \% \text { of degradation by pyrolysis } \\
\text { and } \cdot \mathrm{OH}_{\mathrm{G}-\mathrm{L}} \text { together; nearly } 14 \% \\
\text { of degradation by } \cdot \mathrm{OH}_{\mathrm{L}}\end{array}$ \\
\hline $\mathrm{TCEP}+\mathrm{COU}+())))$ & $\cdot \cdot \mathrm{OH}_{\mathrm{G}-\mathrm{L}}$ & 0.015 & $\begin{array}{l}30 \% \text { of degradation is led by } \\
\text { pyrolysis; } \\
56 \% \text { of degradation due } \cdot \mathrm{OH}_{\mathrm{G}-\mathrm{L}}\end{array}$ \\
\hline
\end{tabular}


The rate constant value, $0.015 \mathrm{~min}^{-1}$, observed for the degradation of TCEP in the presence of coumarin, a scavenger of $\bullet \mathrm{OH}_{\mathrm{G}-\mathrm{L}}$, and $\bullet \mathrm{OH}_{\mathrm{L}}$ indicates pyrolysis is significant and contributed to nearly $30 \%$ of TCEP degradation during ultrasonic treatment. The presence of coumarin decreases the degradation rate from 0.043 to $0.015 \mathrm{~min}^{-1}$ or by $0.028 \mathrm{~min}^{-1}$ indicating $\sim 56 \%$ of total degradation is a result of $\bullet \mathrm{OH}_{\mathrm{G}-\mathrm{L}}$ which is the major pathway in the degradation process. The result provides convincing evidence that ultrasonic degradation of TCEP is mediated by both interfacial hydroxyl radicals and pyrolysis.

\subsubsection{Mineralization of TCEP}

The sonochemical mineralization of TCEP was assessed by measuring the production of $\mathrm{PO}_{4}{ }^{3-}$ and $\mathrm{Cl}^{-}$, as a function of irradiation time. The monitoring of phosphate, chloride, and other small molecular ions was carried employing ion chromatography. Over six hours of ultrasonic treatment, chloride recovery was $48 \%$, and phosphate recovery was $32 \%$, as shown in Figure 44. Although we observed sonolysis of TCEP is rapid, partial phosphate and chloride mass balances observed upon extended irradiation indicate the involvement of intermediate byproducts [107,108], Antonopoulou et al. reported an almost complete mass balance of chloride ions, but $60 \%$ for phosphorus during the $\mathrm{TiO}_{2}$ photocatalytic degradation of TCPP [93]. In addition to the chloride and phosphate, we also identified a number of smaller molecular ions, including formate, and chloroacetate. 


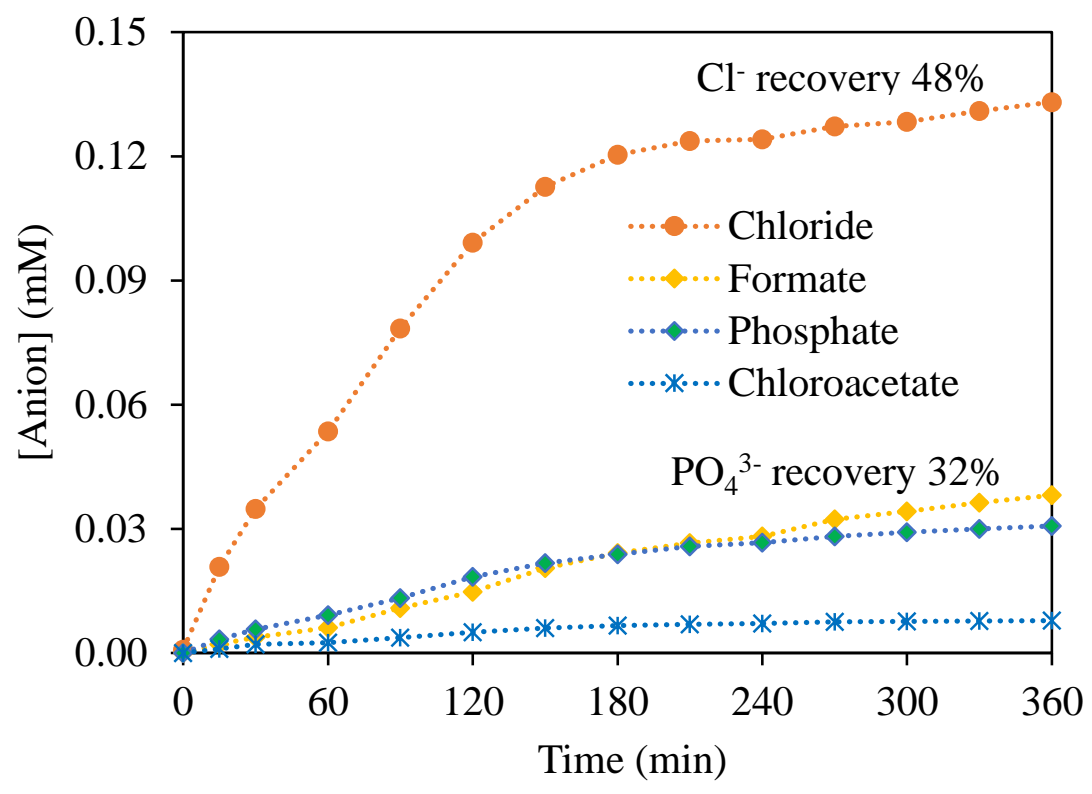

Figure 44. Evolution of $\mathrm{PO}_{4}{ }^{3-}$ and $\mathrm{Cl}^{-}$ion upon ultrasonic treatment at $640 \mathrm{kHz}$ in $\mathrm{O}_{2-}$ saturated aqueous solution of TCEP $\left([\mathrm{TCEP}]_{0}=93.5 \mu \mathrm{M}\right)$.

\subsubsection{Products studies}

The mineralization products of TCEP are $\mathrm{CO}_{2}, \mathrm{H}_{2} \mathrm{O}$, phosphate $\left(\mathrm{PO}_{4}{ }^{3-}\right)$, and chloride $\left(\mathrm{Cl}^{-}\right)$. We observed the ultrasonic degradation of TCEP yields $48 \%$ of chloride and $32 \%$ phosphate ions upon extended irradiation time, indicating incomplete mineralization. In an attempt to identify the intermediate products during ultrasonic treatment, analyses of the reaction solution were carried out by high-resolution mass spectrometry using an APCI source in full scan positive ion mode. After screening, three intermediates, shown in Table 10, were identified, including $\mathrm{C}_{6} \mathrm{H}_{11} \mathrm{Cl}_{2} \mathrm{O}_{6} \mathrm{P}$ (Product $\mathrm{A}, \mathrm{m} / \mathrm{z}$ 280.9753), $\mathrm{C}_{4} \mathrm{H}_{9} \mathrm{Cl}_{2} \mathrm{O}_{4} \mathrm{P}$ (product $\mathrm{B}, \mathrm{m} / \mathrm{z}$ 222.9689), $\mathrm{C}_{2} \mathrm{H}_{6} \mathrm{ClO}_{4} \mathrm{P}$ (Product $\mathrm{C}, \mathrm{m} / \mathrm{z}$ 160.9770). The relative abundance of these potential intermediates is also illustrated in

\section{Figure 45.}


Table 10. By-products/intermediates generated during the ultrasonic treatment of TCEP with their exact mass and mass/charge $(\mathrm{m} / \mathrm{z})$ ratio in positive ionization mode<smiles>O=P(OCCCl)(OCCCl)OCCCl</smiles>

Exact Mass: 283.9539

TCEP $\mathrm{m} / \mathrm{z} 284.9617$<smiles>O=C(O)COP(=O)(OCCCl)OCCCl</smiles>

Exact Mass: 279.9670

Product A $\mathrm{m} / \mathrm{z} 280.9753$<smiles>O=P(O)(OCCCl)OCCCl</smiles>

Exact Mass: 221.9616

Product B $\mathrm{m} / \mathrm{z} 222.9694$<smiles>O=P(O)(O)OCCCl</smiles>

Exact Mass: 159.9692

Product C $\mathrm{m} / \mathrm{z} 160.9770$

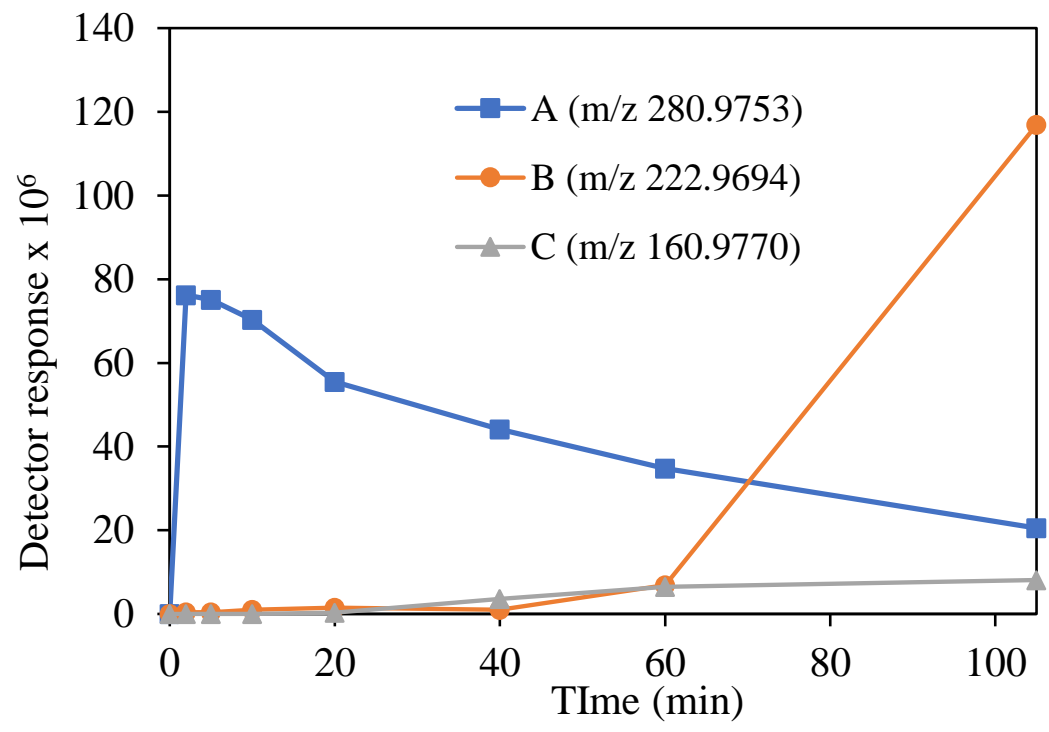

Figure 45. Relative abundance of intermediate products during ultrasonic treatment of TCEP $\left([\mathrm{TCEP}]_{0}=7.0 \mu \mathrm{M}\right)$ in oxygenated aqueous solution.

\subsubsection{Mechanistic consideration}

A number of reaction mechanisms can be proposed to explain the formation of the observed transformation products of TCEP. Hydroxyl radical $(\bullet \mathrm{OH})$ general reacts with organic molecules by the three different mechanisms: hydrogen atom abstraction, 
electrophilic addition to the double bond, and electron transfer from an organic molecule. Hydroxyl radical addition to the electron-rich system is typically faster than the proton abstraction, and electron transfer is unlikely except for very electron-rich systems. TCEP has two types of hydrogens, referred to as alpha $(\alpha)$ and beta $(\beta)$ in the alkyl chain. Hydroxyl radicals can abstract either hydrogen to make carbon-centered radicals, which can propagate through radical chain processes and ultimately lead to mineralization. Hydroxyl radical, although highly reactive, can exhibit some selective in the abstraction of hydrogens. Morozov et al. reported that hydroxyl radical abstracted the hydrogen atom $\alpha$ to oxygen preferentially over the hydrogen atom $\alpha$ to a halogen atom (analogous to $\beta$ hydrogen) in the halogenated-substituted ethanol [175]. On the basis of mechanistic studies of related organophosphates, and our product studies, we proposed two probable mechanisms involving hydroxyl radical abstraction of $\alpha$ and $\beta$-hydrogens of the alkyl chain in TCEP.

In Figure 46, a $\beta$-hydrogen atom is abstracted by a hydroxyl radical from an ethyl ester carbon leading to the formation of an alpha carbon-centered radical. Although the hydrogen alpha to the oxygen atom is more reactive than beta position, the $\beta-\mathrm{H}$ abstraction can also be a competing reaction pathway (minor). The $\beta$ carbon-centered radical can undergo further oxidation leading to the formation of alcohol, collapse to an aldehyde, and further oxidation to the carboxylic acid. The reaction pathways can lead to the diester of TCEP and acetic acid. In our study, the diester of TCEP and formate were observed, but not acetic acid, which, if the present was below the detection limit. 
a) $\beta$ - hydrogen abstraction mechanism<smiles>O=P(OCCCl)(OCCCl)OCC(Cl)CO</smiles><smiles>C[C@H](O)[C@H](C)O[N+](=O)[O-]</smiles><smiles>CC(O)COP(=O)(OCCCl)OCC(Cl)(Cl)CO</smiles><smiles>O=C([CH]Cl)COP(=O)(OCCCl)OCCCl</smiles>

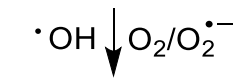

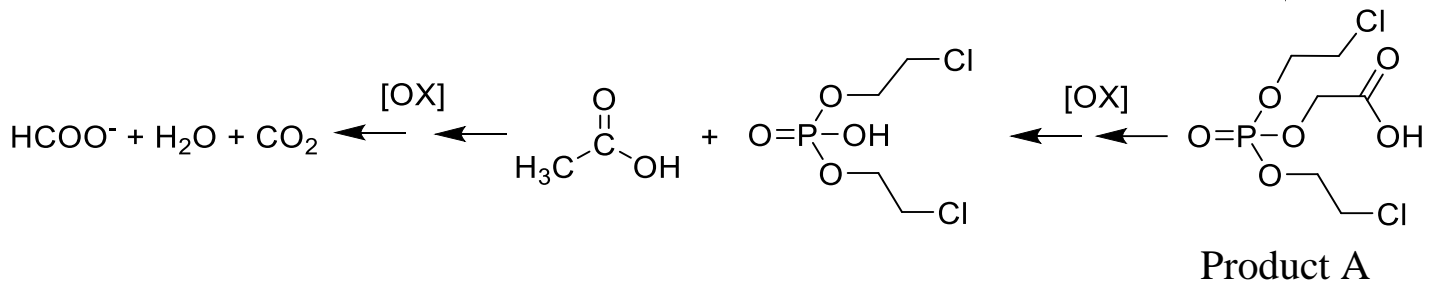

Figure 46. Proposed hydroxyl radical-mediated degradation of TCEP via $\beta-\mathrm{H}$ abstraction mechanism.

b) $\alpha$-hydrogen abstraction mechanism<smiles>O=P(CO)(OCCCl)OC(CCl)CCO</smiles><smiles>O=P(OCCCl)(OCCCl)OCCCl</smiles>

$\mathrm{Cl}$<smiles>O=CCCl</smiles>

Product B<smiles>[3H]OC(=O)OC</smiles>

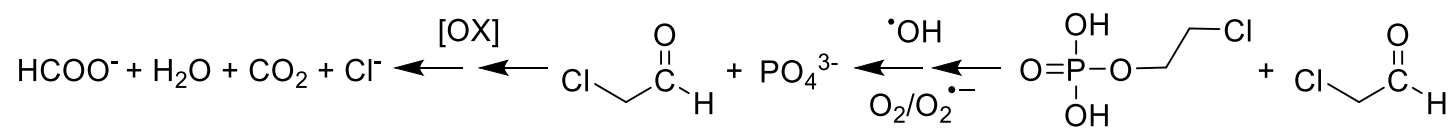

Figure 47. Proposed hydroxyl radical-mediated degradation of TCEP via $\alpha-\mathrm{H}$ abstraction mechanism. 
In Figure 47, hydroxyl radical abstracting $\alpha-\mathrm{H}$ forms a carbon-centered radical, which under further oxidation can result in the formation of an acetal, either by direct reaction with another hydroxyl radical or by the addition of oxygen to form a peroxyl radical. The dimerization of two peroxyl radicals, followed by extrusion of $\mathrm{O}_{2}$ via a Russell mechanism, can also be used to explain the observed products [11]. Oxidation of the remaining 2-chloroethoxy group yields 2-chloroethyl dihydrogen phosphate. Subsequent hydroxyl radical-mediated oxidation can convert the diester adduct to monoester adduct and, ultimately, to phosphate. The formation of di (2-chloroethyl) hydrogen phosphate,2chloroethyl dihydrogen phosphates, and chloroacetic acid are consistent with $\alpha-\mathrm{H}$ abstraction hydroxyl radical-mediated pathways [51].

\subsection{Conclusions}

We have shown the degradation kinetics of the tris (2-chloroethyl) phosphate (TCEP) upon the ultrasonic irradiation in oxygen-saturated aqueous solution. Our results indicate that ultrasonic irradiation leads to rapid degradation of TCEP at $640 \mathrm{kHz}$ in oxygenated aqueous solution. The degradation follows pseudo-first-order kinetics at a specifically given concentration. Varying rate constant depending on initial concentration indicated the partition of TCEP at the gas-liquid interface plays a prominent role in the degradation. The degradation of TCEP is consistent with Langmuir-Hinshelwood kinetic model, implying that degradation occurs at or near the gas-liquid interface during cavitation. Mineralization of TCEP over extended hours of ultrasonic treatment yields around $48 \%$ chloride and $32 \%$ of phosphate mass balance. Competition studies using 
hydroxyl radical scavengers reveal that the process is mediated by pyrolysis and hydroxyl radical-mediated process. The mono and diester of TCEP are the primary products identified by UPLC-Orbitrap-HRMS. These results suggest that ultrasonic oxidation will be useful for the decontamination of Naled from aqueous solution. 


\section{CHAPTER 5 HYDROLYSIS AND ULTRASONIC INDUCED DEGRADATION \\ OF THE NALED: KINETICS, PRODUCTS AND \\ MECHANISTIC INVESTIGATION}




\subsection{Abstract}

The extensive application of the pesticide Naled (1,2-dibromo-2,2-dichloroethyl dimethyl phosphate) for controlling mosquitoes harboring the Zika virus has increased the urgency to understand its stability and fate in aqueous environments. Herein, we report the hydrolysis and ultrasonic induced degradation of Naled in aqueous media. NMR spectroscopic studies established the slow hydrolysis of Naled in non-buffered aqueous solution at ambient temperature. The hydrolysis followed pseudo-first-order kinetics with a rate constant of $0.0012 \mathrm{~h}^{-1}$ and a half-life of approximately 24 days. The rate of hydrolysis of Naled increases at elevated temperature with half-life of 2.4 days to 1.4 hours at $80^{\circ} \mathrm{C}$. The activation energy of Naled, calculated from the Arrhenius plot over the range of temperatures $40-80{ }^{\circ} \mathrm{C}$, was $19.1 \mathrm{kcal} \mathrm{mole}^{-1}$. The hydrolysis was $\mathrm{pH}$ dependent and became exceedingly slow under acidic conditions and increased with $\mathrm{pH}$ in buffered solution. The partial hydrolysis of Naled leads to a pair of diester products, 1,2-dibromo2,2-dichloroethyl phosphate, and dimethyl hydrogen phosphate. Subsequent hydrolysis leads to the monoester, monomethyl phosphate. The product studies illustrate several competing and/or sequential pathways are involved in the hydrolysis of Naled.

We also demonstrated ultrasonic irradiation leads to the rapid degradation of Naled. in aqueous media. In general, ultrasonic irradiation leads to cavitation, producing elevated temperatures which can lead to radical initiated decomposition of the target compound. The ultrasonic induced degradation kinetics were monitored by GC-NPD demonstrating > $50 \%$ of Naled ([Naled $]_{0} \sim 30 \mu \mathrm{M}$ ) was degraded within half an hour upon ultrasonic irradiation in oxygen-saturated aqueous solution at $7( \pm 1)^{\circ} \mathrm{C}$ temperature. The degradation 
follows pseudo-first-order kinetics with rate constants varying from 0.05 to $0.01 \mathrm{~min}^{-1}$ depending on the initial concentrations over the range of $39-309 \mu \mathrm{M}$. The rate constant for the degradation decreases with increasing initial concentration of Naled implying that the process may be controlled by partitioning at the gas-liquid interface. This kinetic behavior is consistent with the Langmuir-Hinshelwood model, also suggesting oxidation occurs at the gas-liquid interface. Mineralization of Naled to chloride, bromide, and phosphate was monitored by IC under extended irradiation. Excellent mass balances were observed for bromide, chloride, and dimethyl phosphate anions. High-resolution mass spectrometry FT-ICR was used to identify the formation of 1,2-dibromo-2,2-dichloroethyl phosphate, dimethyl phosphate (DMP), and monomethyl phosphate (MMP) as primary intermediates during the ultrasonic treatment of Naled. These results suggest ultrasonic treatment has promise for the remediation of Naled contaminated of aqueous solutions.

\subsection{Introduction}

Recently, Naled (1,2-dibromo-2,2-dichloroethyl dimethyl phosphate) has been sprayed aerially for controlling adult mosquitoes harboring the Zika virus in the South Florida Bay area [176,177]. This widespread application of Naled has raised a severe concern over the potential impact of Naled on human health and the ecological environment. The application of Naled in response to the Zika scare has led to a renewed interest and public concerns about their stability and environmental fate. It is an active ingredient of Dibrom concentrate used to kill a wide variety of insects such as adult mosquitoes, black flies, and leaf-eating insects on a variety of fruits, vegetables, and nuts 
[178]. Approximately $70 \%$ of Naled is used for mosquito control, and $30 \%$ for agriculture, food, and feed crops. Occasionally, Naled was also used following natural disasters to control insect outbreaks, for example, in New Orleans after Hurricane Katrina, and in North Carolina after Hurricane Florence $[179,180]$. In Puerto Rico, Naled is employed in an attempt to control Dengue, a virus also carried by mosquitoes [178]. Naled is an organophosphate insecticide manufactured by the bromination of recently banned dichlorvos, an organophosphate pesticide [178]. Like other organophosphorus toxic substances such as sarin, chemical warfare agents, and parathion, Naled inhibits the release of cholinesterase, a key enzyme essential for the proper functioning of the nervous system $[178,181]$. Exposure to Naled at low dose causes nausea and dizziness, while high doses can affect the nervous system resulting in respiratory paralysis and even death. Naled is linked to congenital disabilities and is very non-selective [182]. The death of millions of honeybees in South Carolina because of the applications of Naled has been reported [183]. The broad spread applications of Naled has been banned in Europe since 2012 for safety and health concerns [184].

Interestingly, there are very few studies available on the chemistry and environmental fate of Naled [179,184]. In the aquatic environments, Naled is converted to dichlorvos $[179,184]$ with the half-life dependent on a number of environmental factors, including humidity, light, and $\mathrm{pH}$ [179]. Under highly alkaline conditions, the half-life of Naled is approximately 2 hours, and under mildly acidic condition, $\mathrm{pH} 5$, the half-life increases to 96 hours [181]. One study reported by Gan et al. claimed that Naled could be convert by sulfur species to the highly toxic substance dichlorvos in aqueous solution 
[184]. Although Naled undergoes transformation in water, detailed studies are lacking. Careful kinetic and product studies are crucial for the fundamental understanding required to accurately identify intermediate products and predict their fate in the aqueous systems. Given the strong influence of water quality on the rates of hydrolysis of Naled and the potential formation of toxic by-products, careful product and kinetic studies are critical to assess public health concerns. The primary purpose of this study is to evaluate the reactivity of Naled in water along with the detailed identification of the products and key intermediates formed during the hydrolysis. The kinetics of Naled hydrolysis at different temperature and $\mathrm{pH}$ conditions are reported herein.

Our results demonstrated that in aqueous solution, Naled hydrolyses into the diester adducts, 1,2-dibromo-2,2-dichloroethyl methyl phosphate (DDEMP), dimethyl phosphate (DMP), monomethyl phosphate (MMP), with highly halogenated aliphatic by-products [185]. The rate of Naled hydrolysis in non-buffered water can lead to extended residence times and a half-life of nearly three weeks due to acidification of the solution from the formation of acidic diester and monoester products. The hydrolysis of the phosphate diester is slow compared to the parent compound [186,187]. Product studies and mass balance measurements critical to ensure safe drinking water following contamination by Naled.

A number of water treatments can be considered to enhance the rate and overall conversion of Naled to non-toxic products. Ultrasound induced degradation, an advanced oxidation process (AOP), has been investigated for the treatment of a wide variety of organic pollutants and toxins, including organophosphorus compounds [57,59,60,97]. Unlike the other AOPs, ultrasonic treatment does not require any chemical additives and 
can be effective in turbid solutions and slurries. Although conversion efficiency from electrical to acoustic energy is relatively costly, proper optimization and dynamics of the reaction system, however, can improve the application efficiency $[57,69,70]$.

The chemical effect of ultrasound derives from a physical process called acoustic cavitation. When the ultrasonic wave travels through liquid medium (water), the formation, growth, and violet collapse of microbubbles are propagated. [71,72]. Extreme temperatures and pressures (about $5000 \mathrm{~K}$ and $500 \mathrm{~atm}$ ) during the violent bubble collapse at the cavitation site, leading to thermal homolysis of water vapor into $\mathrm{H} \bullet$ and $\bullet \mathrm{OH}$ radicals, which can subsequently transform pollutants and toxins in the solution[71]. The cavitation site is often broken into three distinct zones; the hot spot with around $5000 \mathrm{~K}$ and $500 \mathrm{~atm}$, an interfacial region reaching of $2000 \mathrm{~K}$ and $300 \mathrm{~atm}$, and a bulk solution that can be kept near ambient conditions $[71,73]$. Thus, ultrasound irradiation creates a unique chemical environment involving the extreme temperature and pressure that can lead the direct pyrolysis as well as hydroxyl radical based oxidation to degrade a variety of problematic organic compounds [59].

Therefore, we conducted kinetic and product studies for the ultrasonic induced degradation of Naled in aqueous media. Results showed ultrasonic irradiation leads to rapid degradation of Naled at $640 \mathrm{kHz}$ in oxygenated aqueous solution. Experiments involving hydroxyl radical scavengers suggested the degradation of Naled proceeds through both pyrolytic and hydroxyl radical-mediated processes. Detailed product studies carried out by ion chromatography and Fourier-Transform Ion Cyclotron Resonance mass spectrometry (FT-ICR-MS) identified a number of phosphorus-containing byproducts. 


\subsection{Hydrolysis of Naled: Products studies and mechanistic investigation}

\subsubsection{Experimental section}

\subsubsection{Materials}

Naled [CAS 300-76-5] [1,2-dibromo-2,2-dichloroethyl dimethyl phosphate], dimethyl phosphate, and triphenyl phosphate (TPhP) were purchased from Aldrich Chemical Company. A mixture of di- and mono-methyl phosphate was purchased from Tokyo Chemical Industry Co. Ltd. High purity GC grade dichloromethane (DCM) was obtained from Fisher Scientific. Citric acid, sodium citrate, sodium carbonate, and sodium hydrogen carbonate were purchased from Fisher Scientific. Millipore water $(18 \mathrm{M} \Omega \cdot \mathrm{cm})$ and volumetric glassware were used for the preparation of all of the aqueous solutions.

\subsubsection{Hydrolysis experiment}

Hydrolysis of Naled was investigated in distilled water (nominal solution $\mathrm{pH}=6.5$ ) over a wide range of temperatures. In a typical reaction, Naled $(2 \mu \mathrm{L})$ was dissolved into a mixture of $0.5 \mathrm{~mL}$ of distilled water and $0.4 \mathrm{~mL} \mathrm{D}_{2} \mathrm{O}$ to allow for monitoring by NMR. Then $0.1 \mathrm{~mL}$ of triphenyl phosphate was added to the resulting solution and mixed thoroughly using a magnetic stir bar of 1 hour. Finally, $0.7 \mathrm{~mL}$ of the reaction solution was transferred into an NMR tube for NMR characterization. The degradation kinetics were monitored by NMR at $25^{\circ} \mathrm{C}$ one hour after preparation of the Naled solution by recording ${ }^{1} \mathrm{H}$ NMR spectra at specific time intervals. Time points for each spectrum is considered the midpoint of $\sim 4$ min data acquisition time. To determine the effect of $\mathrm{pH}$, hydrolysis 
experiments were carried out in buffer solutions ranging from acidic $(\mathrm{pH}=3.1,5.0)$ to alkaline conditions $(\mathrm{pH}=8.5,9.7$, and 10.5). Solution $\mathrm{pH}$ measurements were conducted using the Mettler Toledo $\mathrm{pH}$ meter. Acidic hydrolysis was run in a citric acid/citrate buffer, and alkaline hydrolysis was in carbonate/bicarbonate buffer. The effect of temperature on the reaction of Naled hydrolysis was measured for $40-80{ }^{\circ} \mathrm{C}$ in non-buffered aqueous solutions.

\subsubsection{NMR spectroscopic analysis of Naled hydrolysis}

Proton and phosphorus NMR (Bruker-Spectrospin 400 Ultrashield) was used to monitor the concentration of Naled and for the identification of intermediate and final products of hydrolysis. For kinetic measurements, ${ }^{1} \mathrm{H}$ decoupled ${ }^{31} \mathrm{P}-\mathrm{NMR}$ spectra [abbreviated as ${ }^{31} \mathrm{P}\{\mathrm{H}\}$-NMR] were recorded at specific time intervals, and for screening and structural identification, ${ }^{1} \mathrm{H}$ coupled ${ }^{31} \mathrm{P}-\mathrm{NMR}$ spectra $\left[{ }^{31} \mathrm{P}-\mathrm{NMR}\right]$ were obtained. Comparison of NMR spectra of authentic samples was used to confirm the structure of the reaction intermediates and final products [100]. The chemical shifts of ${ }^{31} \mathrm{P}\{\mathrm{H}\}-\mathrm{NMR}$ spectra are reported in ppm with respect to the peak of $85 \% \mathrm{H}_{3} \mathrm{PO}_{4}$ as the chemical shift reference. The concentrations of all compounds detected in the reaction mixture were determined from the integration of the respective ${ }^{31} \mathrm{P}\{\mathrm{H}\}-\mathrm{NMR}$ relative to the area of the internal standard triphenyl phosphate. 


\subsubsection{Results and discussion}

\subsubsection{Product studies of the Naled hydrolysis}

The stacked plot of ${ }^{31} \mathrm{P}\{\mathrm{H}\}$-NMR spectra for the hydrolysis of Naled recorded over 170 hours is shown in Figure 48. Results indicate that only $18 \%$ of Naled is converted to the corresponding products in the non-buffered aqueous solution. ${ }^{31} \mathrm{P}\{\mathrm{H}\}-\mathrm{NMR}$ spectrum (Figure 48) after 1 hour of hydrolysis shows Naled as a major component with two minor components, while the ${ }^{31} \mathrm{P}\{\mathrm{H}\}-\mathrm{NMR}$ spectrum taken at 170 hours shows three peaks in addition to Naled, indicating the formation of three different phosphorus-containing products. The ${ }^{1} \mathrm{H}$ coupled ${ }^{31} \mathrm{P}-\mathrm{NMR}$ spectra (Figure 49) and ${ }^{1} \mathrm{H}$ spectra (Figure 50) were also recorded for the identification of the products. A summary of the ${ }^{31} \mathrm{P}-\mathrm{NMR}$ and ${ }^{1} \mathrm{H}-$ NMR data for the hydrolysis reaction mixture are given in Table 11. The phosphoruscontaining products are identified as 1,2-dibromo-2,2-dichloroethyl methyl phosphate (DDEMP), dimethyl phosphate (DMP), and monomethyl phosphate (MMP). While dichlorvos has been reported as a degradation product of Naled was not detected under our reaction conditions by NMR. If formed during our experiments, the concentration of dichlorvos was below the instrument detection limit. The relative abundance of generated products during the hydrolysis reaction is shown in Figure 51. Two carbon-containing compounds, 1,2-dibromo-2,2-dichloro ethanol, and methanol were also identified during Naled hydrolysis. 


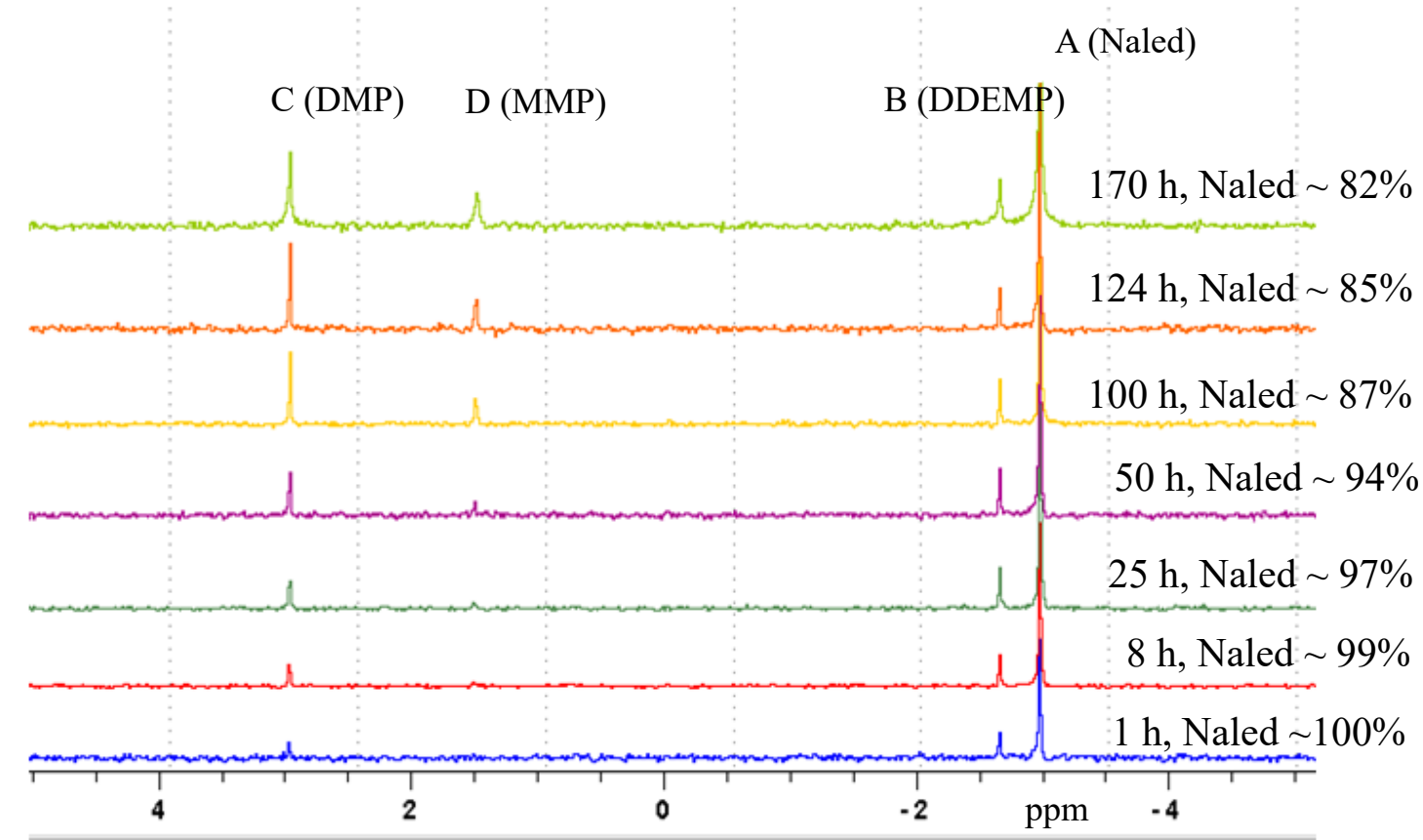

Figure 48. ${ }^{31} \mathrm{P}\{\mathrm{H}\}$-NMR spectra during the degradation reaction mixture of Naled in $\mathrm{H}_{2} \mathrm{O} / \mathrm{D}_{2} \mathrm{O}$ solution with starting $\mathrm{pH} 6.4$ and concentration of Naled $3.2 \mu \mathrm{M}$.

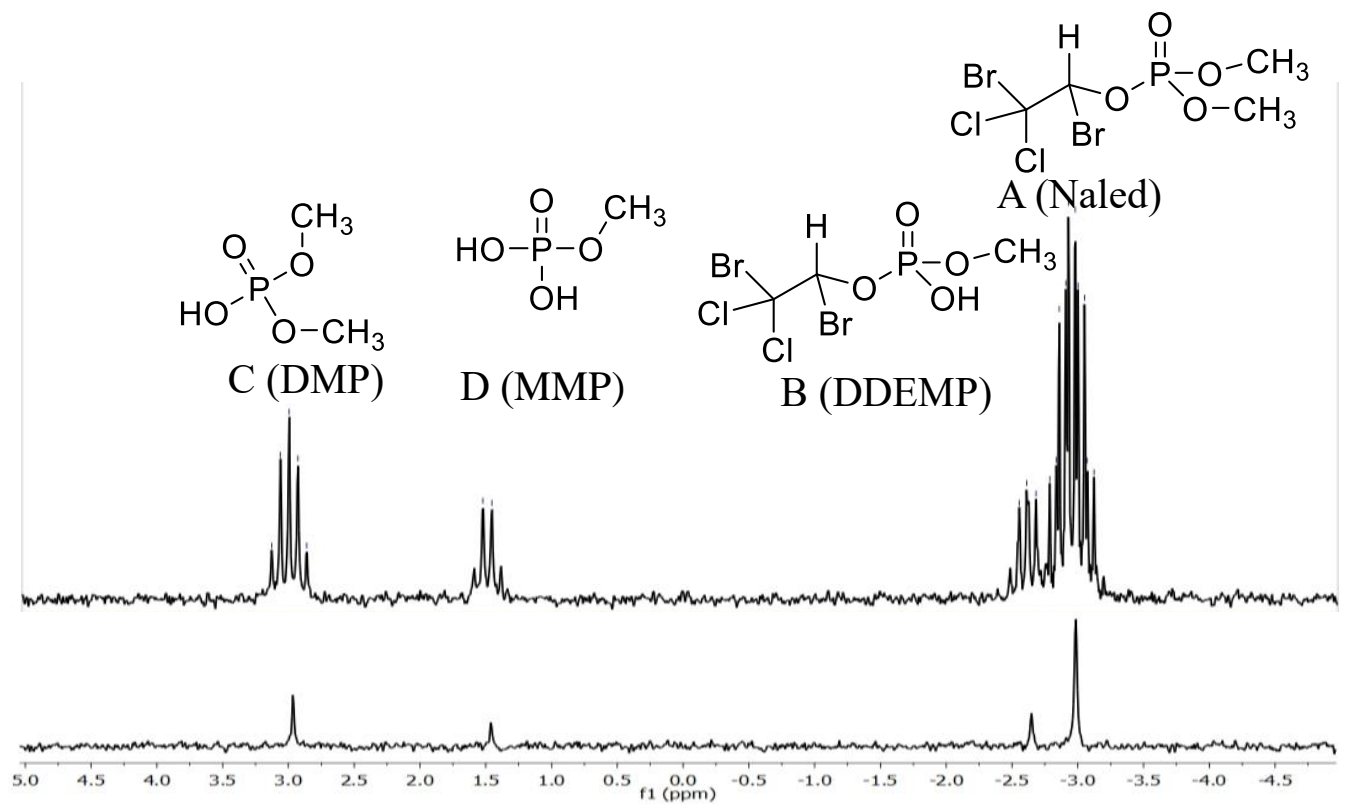

Figure 49. ${ }^{31} \mathrm{P}-\mathrm{NMR}$ and $31 \mathrm{P}\{\mathrm{H}\}-\mathrm{NMR}$ spectra of the Naled hydrolysis in $\mathrm{H}_{2} \mathrm{O} / \mathrm{D}_{2} \mathrm{O}$ solution after 170 hours. 

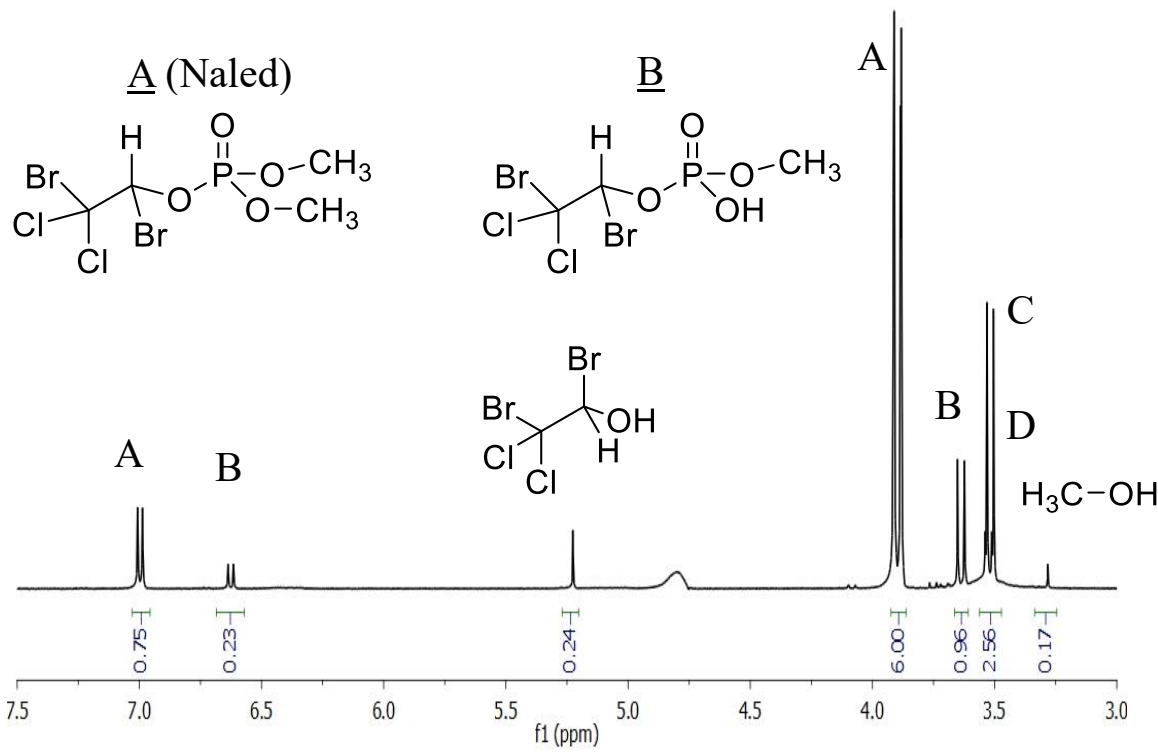

Figure 50. Water suppressed ${ }^{1} \mathrm{H}$ NMR spectrum of Naled hydrolysis in $\mathrm{H}_{2} \mathrm{O} / \mathrm{D}_{2} \mathrm{O}$ solution.

Table 11. Summary table of NMR data for the products generated during the hydrolysis of Naled

\begin{tabular}{lll}
\hline Compound & \multicolumn{1}{c}{${ }^{31} \mathrm{P}-\mathrm{NMR}$ spectrum } & \multicolumn{1}{c}{${ }^{1} \mathrm{H}-\mathrm{NMR}$ spectrum } \\
& \multicolumn{1}{c}{$\left(\mathrm{D}_{2} \mathrm{O}, 126 \mathrm{MHz}\right), \delta$ in ppm } & $\left(\mathrm{D}_{2} \mathrm{O}, 400 \mathrm{MHz}\right), \delta$ in ppm \\
\hline A (Naled) & $-3.0\left(1 \mathrm{P}\right.$, doublet of septate, ${ }^{3} \mathrm{~J}_{\mathrm{P}-\mathrm{He}}$ & $3.9\left(6 \mathrm{H}, \mathrm{d},{ }^{3} \mathrm{~J}_{\mathrm{P}-\mathrm{Hm}} 6.8 \mathrm{~Hz}\right) ;$ \\
& $\left.6.9 \mathrm{~Hz},{ }^{3} \mathrm{~J}_{\mathrm{P}-\mathrm{Hm}} 6.5 \mathrm{~Hz}\right)$ & $7.0\left(1 \mathrm{H}, \mathrm{d},{ }^{3} \mathrm{~J}_{\mathrm{P}-\mathrm{He}} 6.5 \mathrm{~Hz}\right)$ \\
B (DDEMP) & $-2.7\left(1 \mathrm{P}, \mathrm{dq},{ }^{3} \mathrm{~J}_{\mathrm{P}-\mathrm{He}} 6.9 \mathrm{~Hz},{ }^{3} \mathrm{~J}_{\mathrm{P}-\mathrm{Hm}}\right.$ & $3.6\left(3 \mathrm{H}, \mathrm{d},{ }^{3} \mathrm{~J}_{\mathrm{P}-\mathrm{Hm}} 6.8 \mathrm{~Hz}\right) ;$ \\
& $6.5 \mathrm{~Hz})$ & $6.7\left(1 \mathrm{H}, \mathrm{d}{ }^{3} \mathrm{~J}_{\mathrm{P}-\mathrm{He}} 6.5 \mathrm{~Hz}\right)$ \\
$\mathrm{C}(\mathrm{DMP})$ & $2.9\left(1 \mathrm{P}\right.$, septate,$\left.{ }^{3} \mathrm{~J}_{\mathrm{P}-\mathrm{Hm}} 6.5 \mathrm{~Hz}\right)$ & $3.5\left(6 \mathrm{H}, \mathrm{d},{ }^{3} \mathrm{~J}_{\mathrm{P}-\mathrm{Hm}} 6.8 \mathrm{~Hz}\right)$ \\
D (MMP) & $1.4\left(1 \mathrm{P}, \mathrm{q},{ }^{3} \mathrm{~J}_{\mathrm{P}-\mathrm{Hm}} 6.5 \mathrm{~Hz}\right)$ & $3.5\left(3 \mathrm{H}, \mathrm{d},{ }^{3} \mathrm{~J}_{\mathrm{P}-\mathrm{Hm}} 6.8 \mathrm{~Hz}\right)$ \\
\hline
\end{tabular}




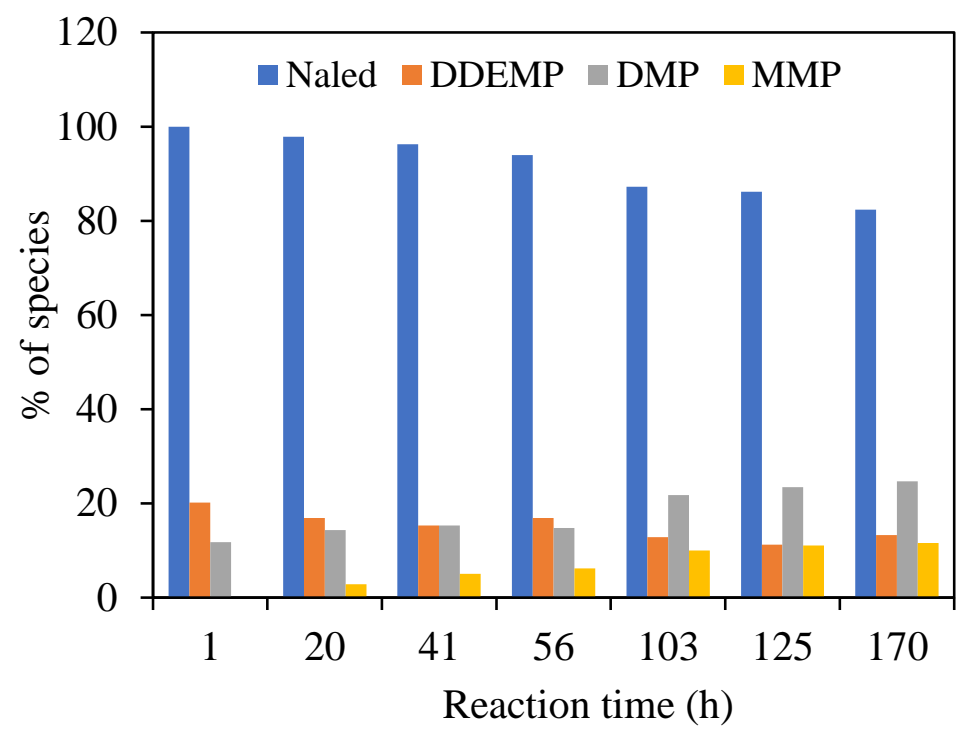

Figure 51. Reaction profile of starting material and products for the hydrolysis of Naled in $\mathrm{H}_{2} \mathrm{O} / \mathrm{D}_{2} \mathrm{O}$ solution at ambient temperature.

\subsubsection{Kinetics of the Naled hydrolysis}

Hydrolysis of Naled follows pseudo-first-order kinetics presented by the equation, $\left[\ln \left(\mathrm{C}_{\mathrm{t}} / \mathrm{C}_{0}\right)=-\mathrm{kt}\right]$, where $\mathrm{C}_{0}$ is the concentration of the target compound at the start of the reaction and $\mathrm{C}_{\mathrm{t}}$ is the concentration at time $\mathrm{t}$. $\mathrm{k}$ represents the rate constant of the reaction. The linear relationship between $\ln \left(\mathrm{C}_{\mathrm{t}} / \mathrm{C}_{0}\right)$ vs. time illustrated in Figure 52 demonstrates the hydrolysis of Naled follows pseudo-first-order kinetics. The values of the half-life of the Naled in aqueous solution were calculated from the following equation $t_{1 / 2}=\ln 2 / k$, where $\mathrm{t}_{1 / 2}$ refers to half-life, and $\mathrm{k}$ is the pseudo-first-order rate constant. The rate constant $(\mathrm{k})$ calculated from the slope of the plot is $1.2 \times 10^{-3} \mathrm{~h}^{-1}$ with a half-life of Naled is approximately 24 days. 


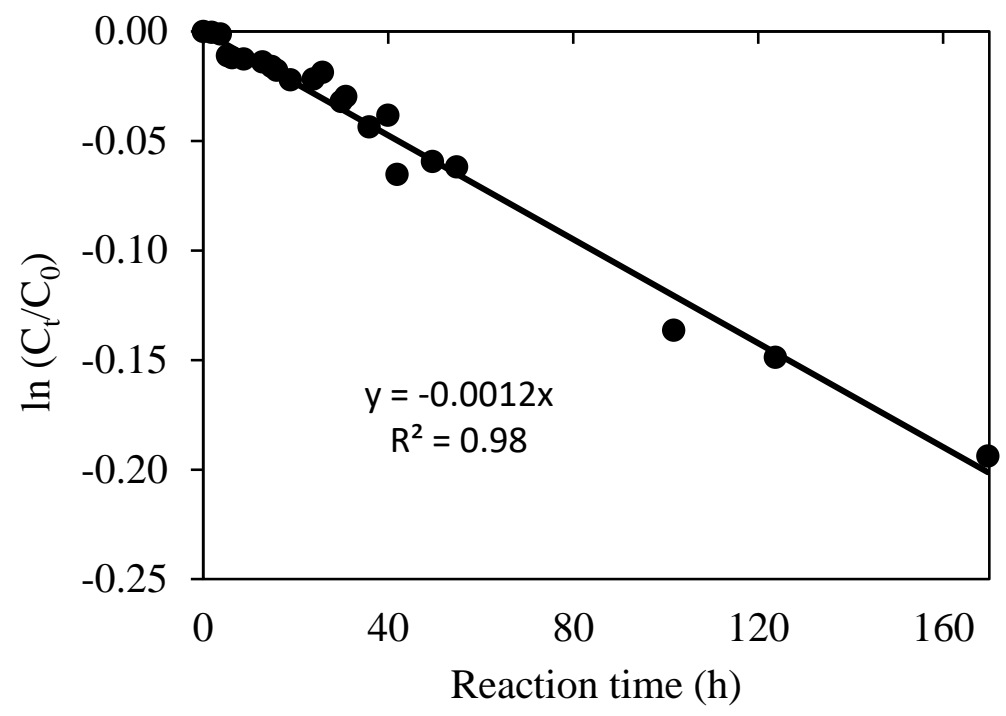

Figure 52. Pseudo-first-order kinetic plot of the hydrolysis of Naled in $\mathrm{H}_{2} \mathrm{O} / \mathrm{D}_{2} \mathrm{O}$ solution at ambient temperature. [Naled $]_{0}=3.2 \mu \mathrm{M}$ and starting $\mathrm{pH}$ was 6.5 .

The hydrolysis kinetics of Naled was studied over a range of temperatures from $40{ }^{\circ} \mathrm{C}$ to $80{ }^{\circ} \mathrm{C}$ to understand the effect of temperature to determine the activation $\left(\mathrm{E}_{\mathrm{a}}\right)$ on the reactivity of Naled in water. The temperature-dependent pseudo-first-order kinetic plots are presented in Figure 53. The half-life of Naled hydrolysis at a specific temperature was calculated, and a summary included within the inset of Figure 53. The hydrolysis rate increases with temperature. At $40{ }^{\circ} \mathrm{C}$, the calculated half-life of Naled hydrolysis was 54 hours. At $80{ }^{\circ} \mathrm{C}$, the half-life decreases to 1.4 hours. The Arrhenius equation shows the reaction rate constant as a function of temperature. Arrhenius equation can be represented by $\ln \mathrm{k}=\left(-\mathrm{E}_{\mathrm{a}} / \mathrm{RT}\right)+\ln \mathrm{A}$ where $\mathrm{k}$ is the reaction rate constant, and $\mathrm{E}_{\mathrm{a}}$ is the activation energy, $\mathrm{R}$ is gas constant, $\mathrm{T}$ is the temperature in Kelvin, $\mathrm{A}$ is a pre-exponential factor. The activation energy $\left(E_{a}\right)$ calculated from the slope of the linear plot of lnk vs. 1/T (Figure 54) was $19.1 \mathrm{kcal} \mathrm{mole}^{-1}$, indicating Naled may be stable in the environment depending on 
the condition such as $\mathrm{pH}$ of the solution. The reported activation energy of parathion is $21.5 \mathrm{kcal} \mathrm{mole}^{-1}$, quite similar to the activation energy of Naled [172].

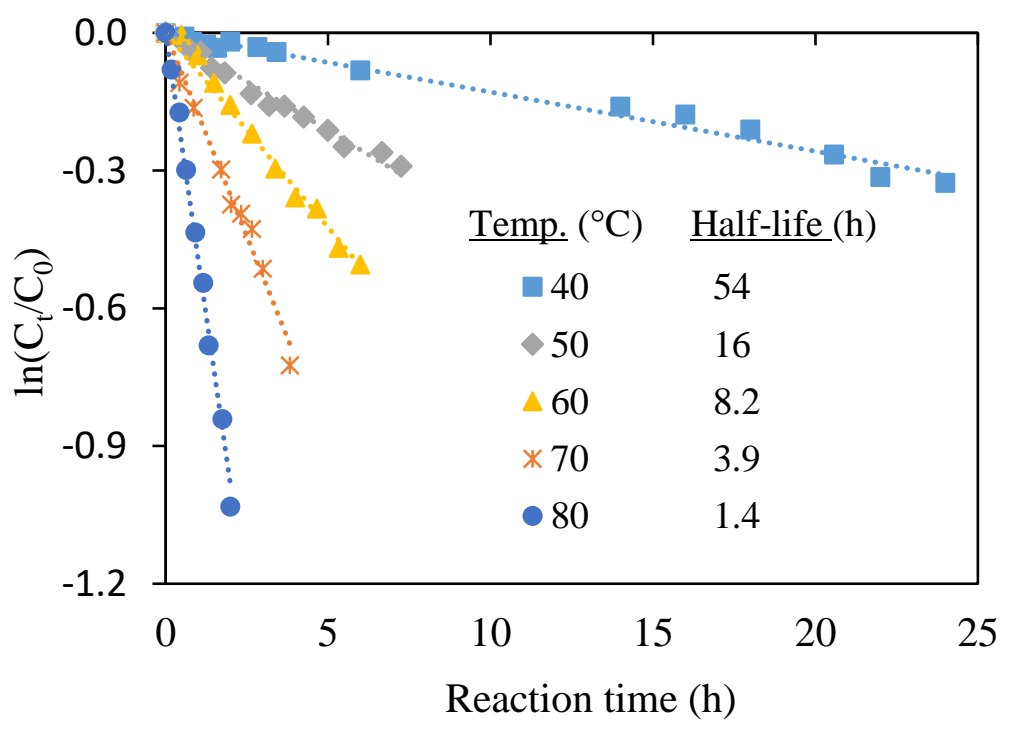

Figure 53. Hydrolysis of Naled as a function of temperature in non-buffered $\mathrm{H}_{2} \mathrm{O} / \mathrm{D}_{2} \mathrm{O}$ solution.

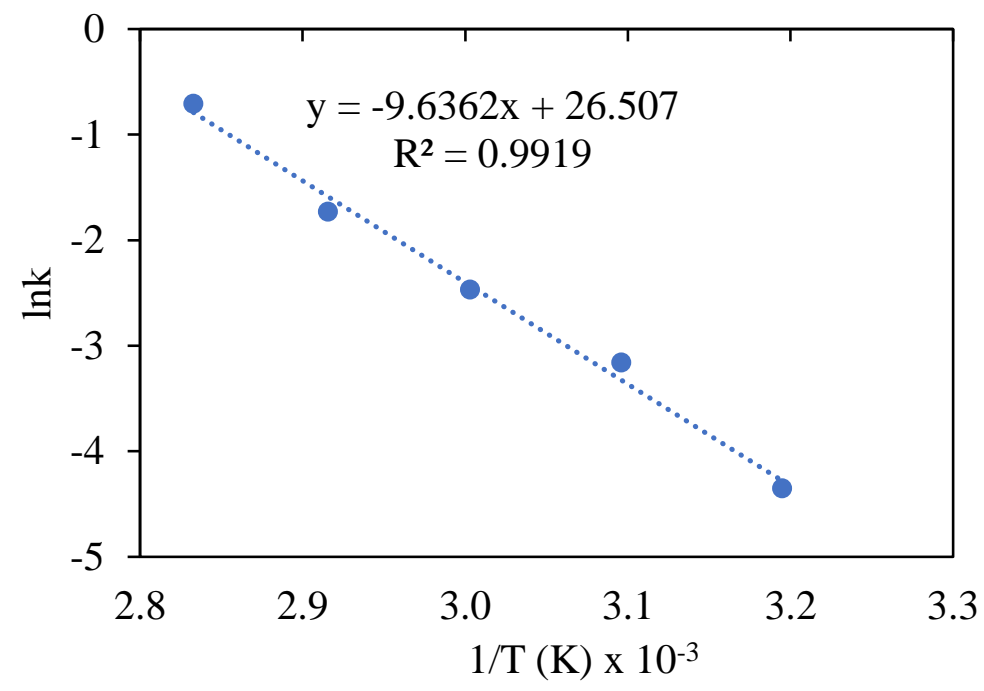

Figure 54. Arrhenius plot of the hydrolysis of Naled over a range of the temperature 40 $80{ }^{\circ} \mathrm{C}$ at $\mathrm{D}_{2} \mathrm{O} / \mathrm{H}_{2} \mathrm{O}$ solution. Standard deviation was \pm 8 on the basis of representative triplicate runs. 


\subsubsection{Effect of solution $\mathrm{pH}$ on the Naled hydrolysis}

The hydrolysis of organophosphate compounds is dependent on the initial solution $\mathrm{pH}$ [188]. The effect of solution $\mathrm{pH}$ on Naled hydrolysis was evaluated over a wide range of buffer solutions from highly acidic ( $\mathrm{pH} 3.0)$ to highly alkaline (pH 10.5) conditions. Citric acid/citrate buffer was used to make the solution $\mathrm{pH} 3.1$ and 5.0. For adjusting the $\mathrm{pH}$ to $8.5,9.7$, and 10.4 for hydrolysis reaction, carbonate/bicarbonate buffer was employed. Hydrolysis of Naled increases with $\mathrm{pH}$, illustrated in Figure 55.

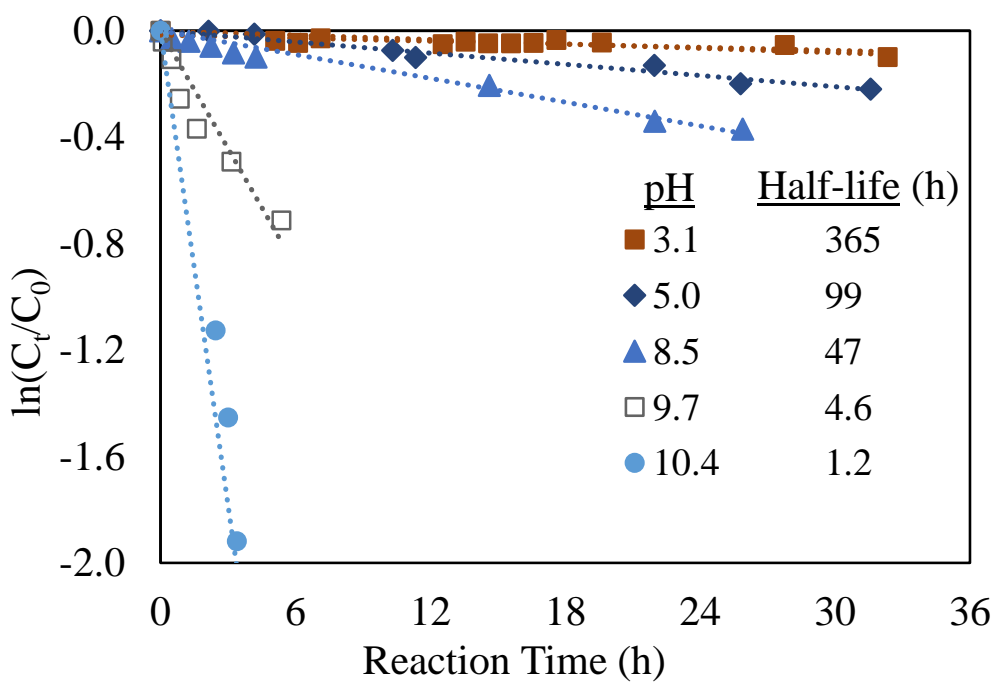

Figure 55. Effect of initial solution $\mathrm{pH}$ on the hydrolysis of Naled in buffered $\mathrm{H}_{2} \mathrm{O} / \mathrm{D}_{2} \mathrm{O}$ aqueous solution.

Under modest acidic conditions $(\mathrm{pH} 3-5)$, the rate of degradation is relatively slow. However, under highly basic $\mathrm{pH}$, the hydrolysis rate of Naled increases significantly. Maybe the different reaction mechanisms can contribute to the reduction of Naled hydrolysis at acidic conditions. The hydrolysis of Naled is a bimolecular reaction [Naled + $\mathrm{HO}^{-}=>$hydrolysis products], and the rate of reaction depends on the concentration of $\mathrm{OH}^{-}$ 
. Therefore, the raising of solution $\mathrm{pH}$ increases the concentration of $\mathrm{OH}^{-}$in reaction media and hence increases the rate of the hydrolysis of Naled. The calculated half-life of Naled at different $\mathrm{pH}$ levels presented in Figure 56 shows that while at high alkaline $\mathrm{pH}$ 10.4, the half-life of Naled is 1.2 hours, at moderately acidic $\mathrm{pH} 3.1$, it increases to 15 days.

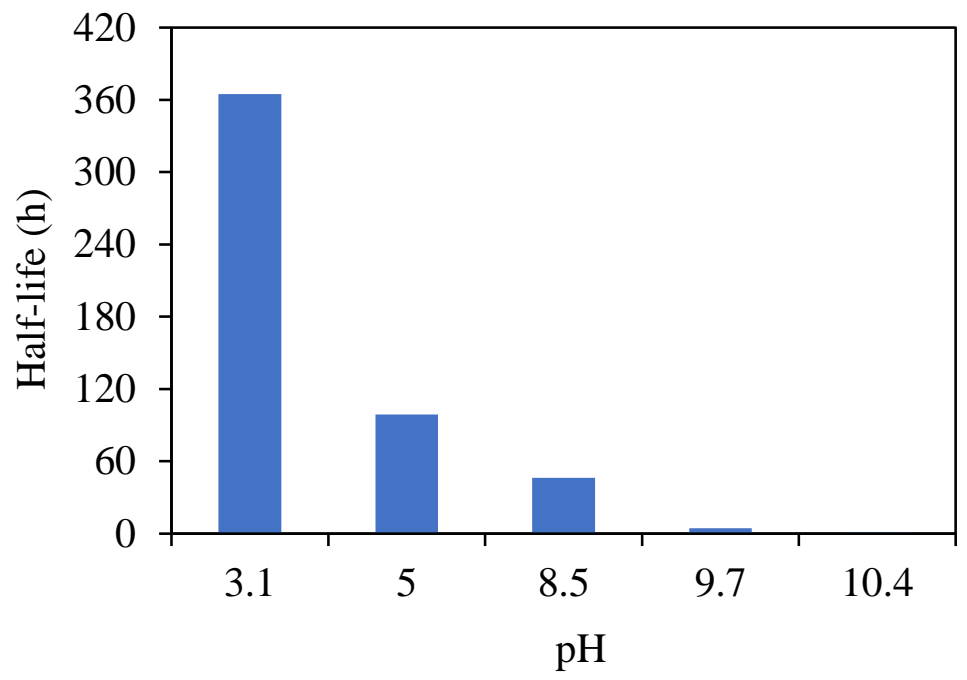

Figure 56. Effect of initial solution $\mathrm{pH}$ on the half-lives of Naled in buffered $\mathrm{H}_{2} \mathrm{O} / \mathrm{D}_{2} \mathrm{O}$ solution. [Naled $]_{0}=3.2 \mu \mathrm{M}$ and standard deviation was $\pm 8 \%$ on the basis on representative triplicate runs.

\subsubsection{Mechanistic consideration}

Hydrolysis may occur at a number of reactive centers in the triester of an organophosphate molecule, depending on the nature of nucleophilic reagents and reaction conditions. Barnard et al. [98] demonstrated that in neutral or acidic solution $\left(\mathrm{H}_{2} \mathrm{O}\right.$ nucleophile), the hydrolysis of trimethyl phosphate (TMP) is slow and undergoes carbonoxygen bond cleavage, whereas in alkaline solution $\left(\mathrm{OH}^{-}\right)$the reaction is relatively faster and proceeds via phosphorus-oxygen bond cleavage as shown in Figure 57. However, both cases, the product was diester, meaning that the subsequent hydrolysis of TMP did not 
proceed to monoester. Recently Su et al. reported the base-catalyzed hydrolysis of a number of organophosphorus flame retardants and identified diesters phosphate as the end products with no detection of monoester phosphates and suggested that hydrolysis proceeds via a direct nucleophilic attack on the phosphorus atom resulting in the cleavage of the phosphorus-oxygen bond [188]. Although our reaction conditions may not induce reduction, a different mechanistic pathway reported by Gan et al. relevant to real aquatic systems demonstrated that Naled is broken down into diester adducts dichlorvos in an aquatic environment following a debromination mechanism in the presence of reduced sulfur species, shown in Figure 58 [184,189].

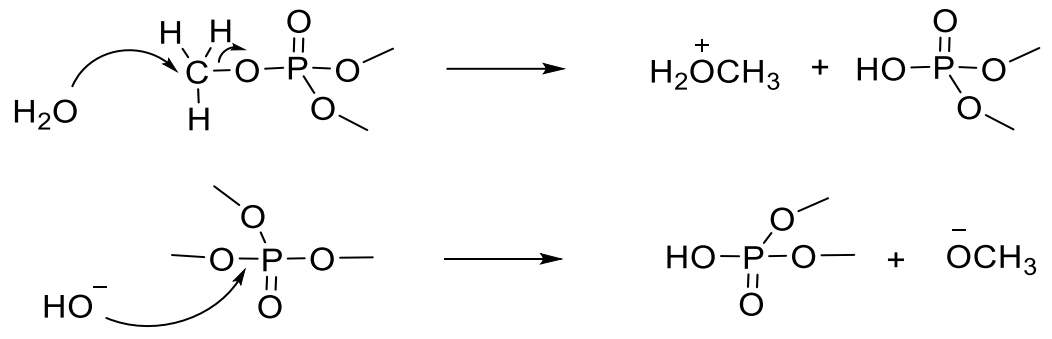

Figure 57. Hydrolysis of trimethyl phosphate.

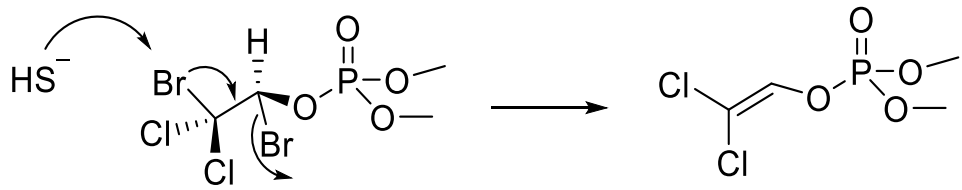

Figure 58. Debromination of Naled by nucleophilic debromination mechanism.

However, our exploration of product studies by NMR analysis showed the hydrolysis of Naled resulted in the monoester MMP, in addition to the production of a variety of diester phosphates such as DDEMP, and DMP. We also observed that hydrolysis of Naled is $\mathrm{pH}$ 
sensitive, and alkaline hydrolysis is much faster than the hydrolysis under neutral or acidic conditions. On the basis of product studies as well as the kinetic observations, a number of hydrolytic pathways for the Naled are proposed. Hydrolysis of Naled can occur via a number of competing processes; nucleophilic addition/elimination reaction, $\mathrm{SN}_{2}$ reaction, and elimination mechanism. Naled could be attacked by the nucleophile $\mathrm{HO}-$ at $\mathrm{P}$ atom in an additional step, followed by the elimination of alkoxide group resulting in the generation of diesters, as shown in Figure 59. Dimethyl phosphate (DMP) was the dominant product in the case of the halogenated ethoxy leaving group (1,2-dibromo-2,2-dichloro ethoxide), and 1,2-dibromo-2,2-dichloro ethyl methyl phosphate (DDEMP) is the hydrolysis product then methoxy group is eliminated. Although DMP can be produced by an $\mathrm{SN}_{2}$ reaction mechanism of Naled by reaction at the carbon center of the halogenated ethoxy group, the pathway is expected to be inhibited by steric congestion Figure $\mathbf{6 0}$.

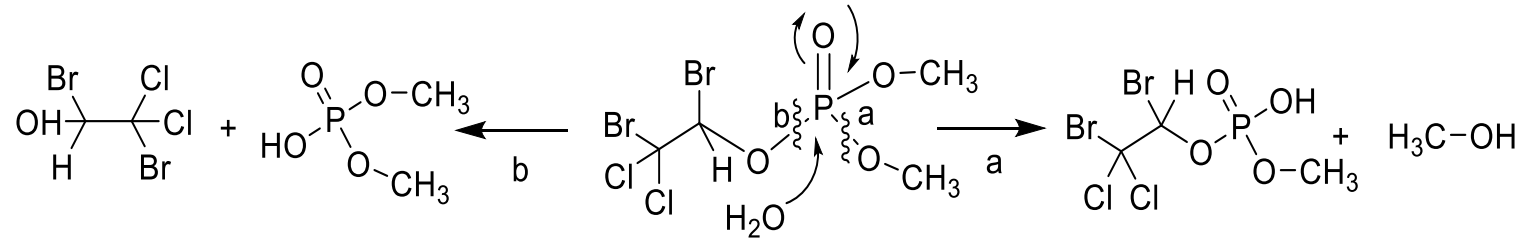

Figure 59. Proposed nucleophilic addition-elimination reaction during the hydrolysis of Naled.<smiles>CCC(COP(=O)(OC)OC)(OP(=O)(OC)OC)OP(=O)(OC)OC</smiles>

Figure 60. Nucleophilic substitution at ethyl carbon center of Naled leading to dimethyl phosphate. 
Trimethyl phosphate or organophosphate flame retardants hydrolyzed into the diester phosphate as end products, which tend to very unreactive toward further nucleophilic attack [98,188,190]. Alkaline hydrolysis of tris (2-chloroethyl) phosphate (TCEP) also leads to the formation of the corresponding diester adduct, bis (2-chloroethyl) phosphate [51]. Further attack addition-elimination can be inhibited by the presence of a negative charge on nucleophile and the substrate molecule. Kirby et al. [186,191,192] showed that depending on the nature of leaving groups and nucleophiles, diester can proceed to the formation of monoester phosphate by one cleaving another $\mathrm{P}$ - alkoxy bond, showing in

\section{Figure 61.}

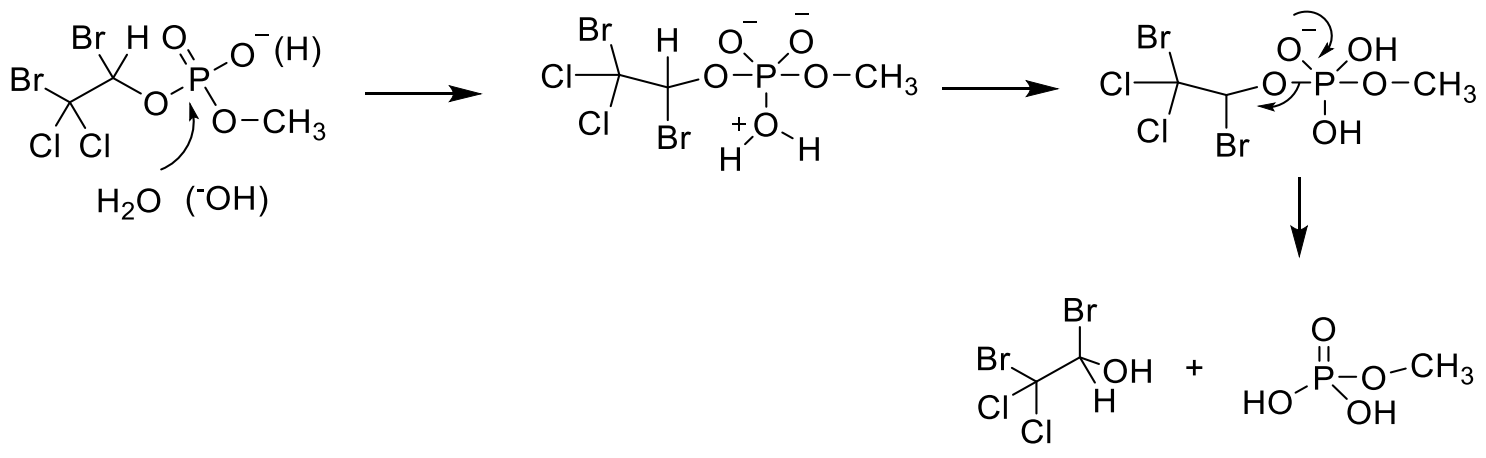

Figure 61. Proposed secondary nucleophilic addition/elimination pathways at the $\mathrm{P}$ atom of the Naled diester product.

\subsubsection{Conclusions}

We have investigated the reactivity of Naled in aqueous solutions at a wide range of temperatures and $\mathrm{pH}$. The hydrolysis of Naled is fast at an alkaline solution, while it turns into a slow process at an acidic solution. It follows pseudo-first-order kinetics with a half-life ranging from few hours to a couple of weeks, depending on reaction condition. 
The temperature has a significant influence on the hydrolysis of Naled. Product studies show that Naled dissipates into 1,2-dibromo-2,2-dichloroethyl phosphate, dimethyl phosphate, and monomethyl phosphate via a number of reaction mechanisms, including nucleophilic addition/elimination, and $\mathrm{SN}_{2}$ pathways.

\subsection{Ultrasonic induced degradation of Naled: Kinetics and mechanistic investigation}

\subsubsection{Experimental section}

\subsubsection{Sonolytic experiment}

The Ultrasonic treatment of Naled was carried out in an ultrasonic reactor, UES 1.5 - 660 Pulsar (Ultrasonic Energy Systems Inc. Panama City, Florida) with pulse mode at the frequency of $640 \mathrm{kHz}$ and power amplitude of $650 \mathrm{~W}$. The schematic diagram of reactor equipped with an ultrasound generator, a transducer, and a $550 \mathrm{~mL}$ cylinder-shaped glass vessel is illustrated in Figure 62. The Naled was treated as an aqueous solution and exposed to ultrasonic irradiation at 1 hour later of the creation of the solution. The power density of the sonication was $10.2 \mathrm{~W} / \mathrm{cm}^{2}$ with a horn diameter of $9 \mathrm{~cm}$. The reaction vessel was placed $5 \mathrm{~cm}$ away from the face of the attached horn. Typically, $500 \mathrm{~mL}$ of Naled aqueous solution was taken in a reaction container and was submerged in ice-bath maintained at 7 $( \pm 1)^{\circ} \mathrm{C}$ temperature. The reaction solutions were purged with oxygen gas for $15 \mathrm{~min}$ before exposure to ultrasonic irradiation. An aliquot of $5 \mathrm{~mL}$ of treated solution was transferred at specific time intervals for monitoring the concentration of Naled by GC-NPD. 


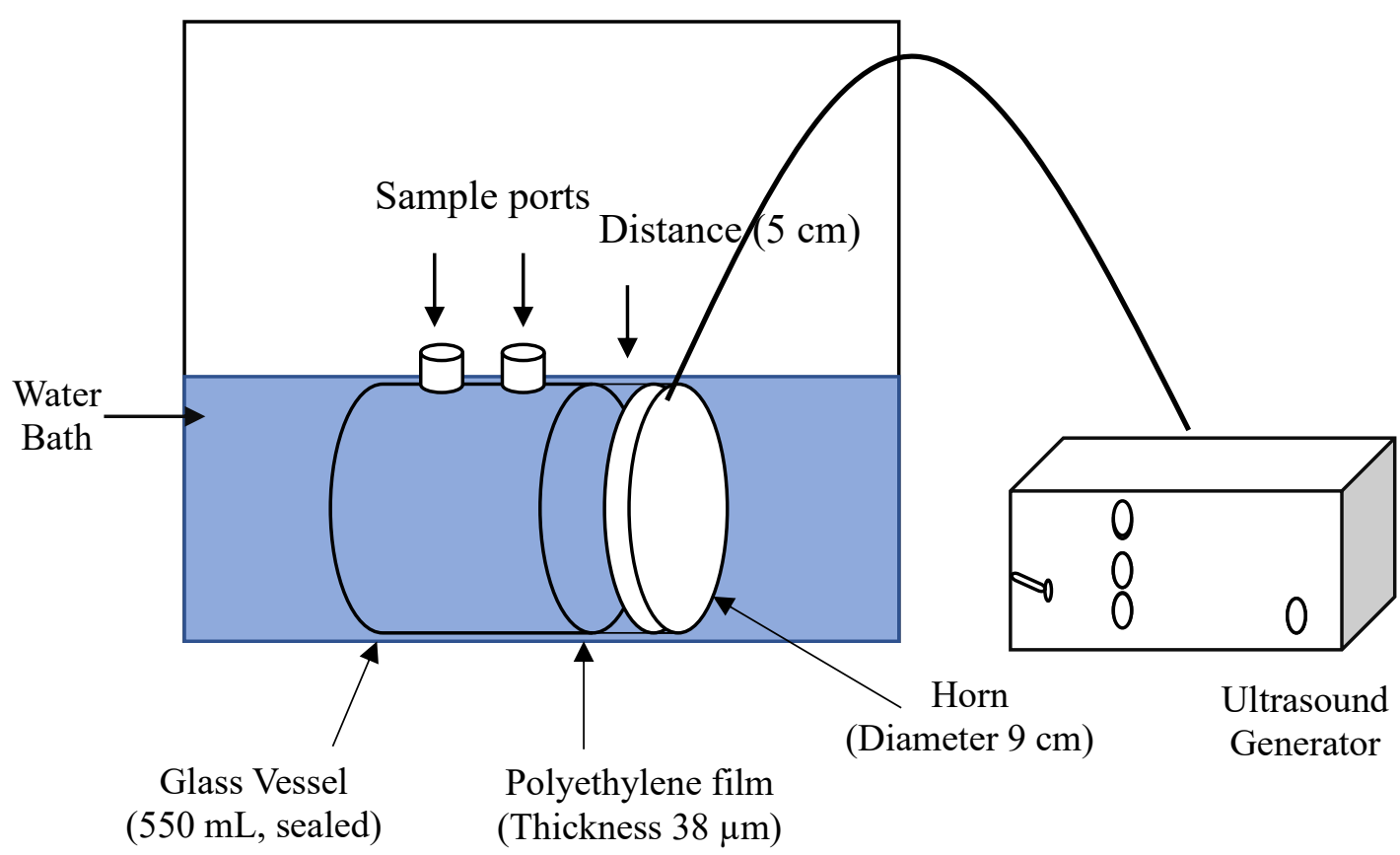

Figure 62. Schematic diagram of the experimental ultrasound setup. The diameter of the sound horn $9 \mathrm{~cm}$, frequency $640 \mathrm{kHz}$, power density $10.2 \mathrm{~W} / \mathrm{cm}^{2}$, Volume of the reaction glass vessel $550 \mathrm{~mL}$

\subsubsection{Analytical methods for the monitoring of Naled}

Naled was extracted from ultrasonic irradiated aqueous solution using liquid-liquid extraction and then analyzed by an established gas chromatographic method [82]. Extraction was carried out with dichloromethane (DCM) in a $40 \mathrm{~mL}$ extraction vial using tris (2-chloroethyl) phosphate as an internal standard. Analysis of Naled was performed on a Hewlett-Packard 6890 gas chromatograph equipped with a nitrogen-phosphorus detector (NPD). The same extraction procedure was followed in the preparation of calibration standards for the GC-NPD detector. Samples were injected manually into the GC inlet in splitless mode and an injector temperature of $200{ }^{\circ} \mathrm{C}$. Chromatographic separation was carried out on a DB-5 fused silica capillary column [ (5\% phenyl) methyl polysiloxane, 0.32 
$\mathrm{mm} \times 30 \mathrm{~m} \times 25 \mu \mathrm{m}]$. The initial GC temperature was held at $40{ }^{\circ} \mathrm{C}$ for $4 \mathrm{~min}$ and increased to $250{ }^{\circ} \mathrm{C}$ at $15{ }^{\circ} \mathrm{C} \mathrm{min}^{-1}$ and held at $250{ }^{\circ} \mathrm{C}$ for $4 \mathrm{~min}$. Helium was used as a carrier gas. The detector response was calibrated against a series of standard Naled dichloromethane solution ranging from $1-200 \mu \mathrm{M}$ with the TCEP internal standard yielding a correlation coefficient $\left(R^{2}\right) \geq 0.99$, shown in Figure 63. Standards were run periodically to ensure accurate calibration of GC.

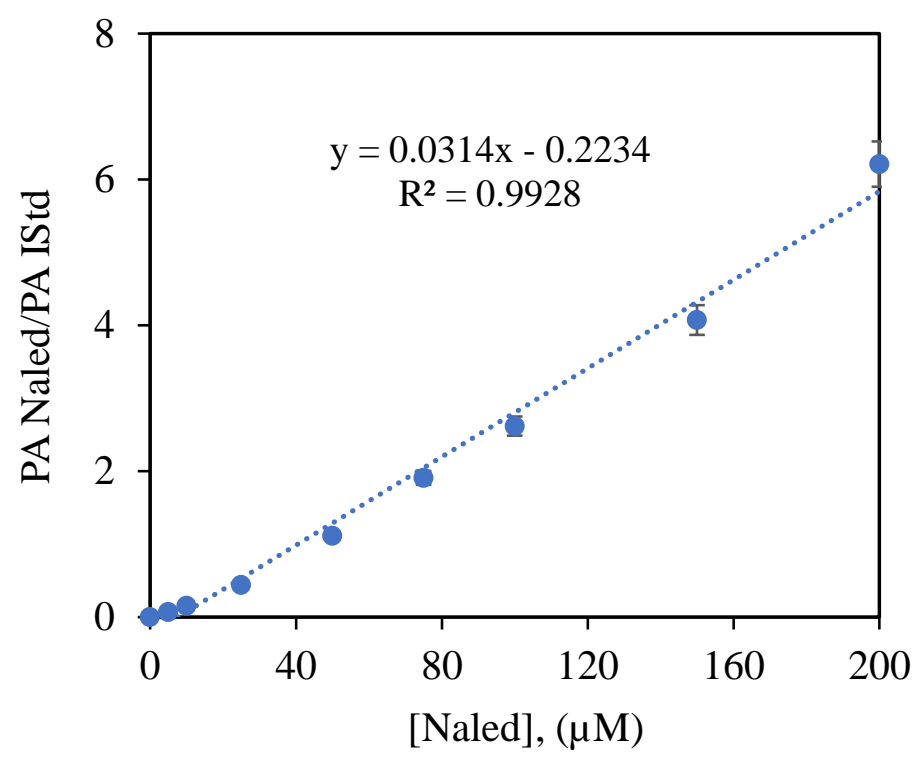

Figure 63. GC-NPD calibration curve for the determination of Naled using TCEP as an internal standard. Data were reproducible within $\pm 5 \%$ of the standard deviation.

\subsubsection{Ion chromatographic (IC) product analysis}

An ion chromatograph, 761 Compact IC Metrohm, equipped with a Metrosep A Supp 5 column and conductivity detector was used to monitor the ions including bromide $\left(\mathrm{Br}^{-}\right)$, chloride $\left(\mathrm{Cl}^{-}\right)$, dimethyl phosphate (DMP) and phosphate $\left(\mathrm{PO}_{4}{ }^{3-}\right)$ released during ultrasonic treatment of Naled. A buffer solution composed of $3.2 \mathrm{mM}$ sodium carbonate 
and $1.0 \mathrm{mM}$ sodium hydrogen carbonate aqueous solution with a flow rate of $0.7 \mathrm{~mL} \mathrm{\text {min } ^ { - }}$

${ }^{1}$ was used for the analyses. The column was regenerated using a sulfuric acid solution $(0.125 \mathrm{M})$. The calibration curves (Figure 64) for the determination of bromide, chloride, phosphate, and dimethyl phosphate ions were established using carefully prepared standard solutions ranging from 0.01 to $0.58 \mathrm{mM}$. The correlation coefficient for the calibration curve was $\geq 0.99$.

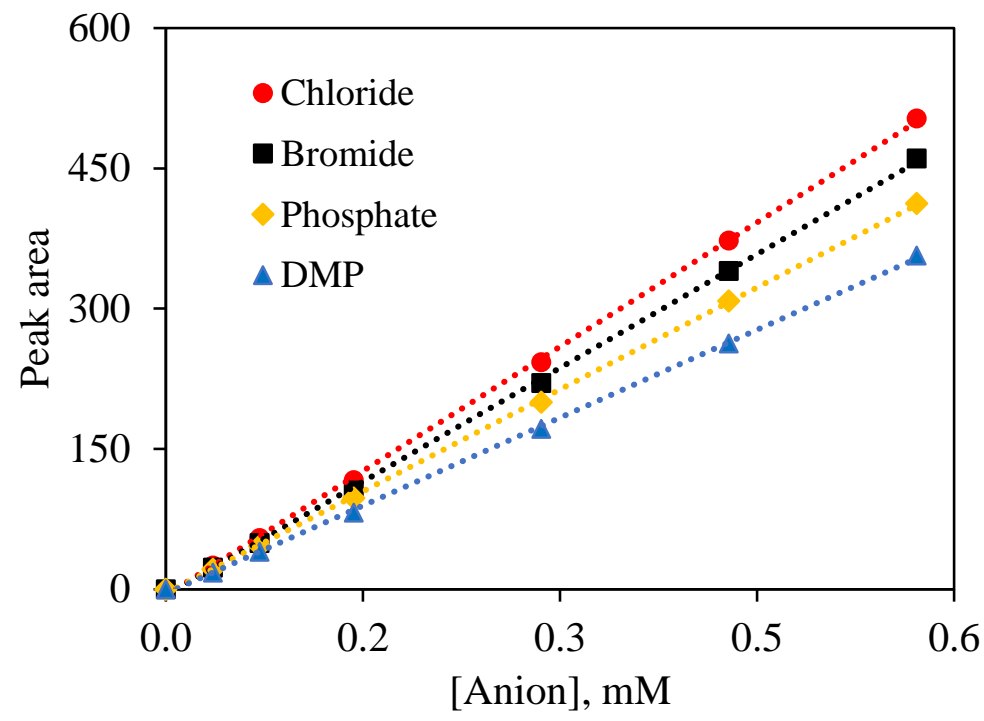

Figure 64. Ion chromatographic calibration curve for the determination of bromide, chloride, dimethyl phosphate, and phosphate ions in aqueous solution.

\subsubsection{Analysis of intermediates and byproducts}

Identification of intermediates and byproducts yielded during the ultrasonic treatment of Naled was carried out in using ultra-high-resolution mass spectrometry conducted on a Bruker Solarix FT-ICR-MS instrument equipped with an electrospray source operated under negative (-) ion mode. Samples were infused at $7 \mu \mathrm{L} / \mathrm{min}$. Spectra 
were internally calibrated, allowing a mass error of $<1 \mathrm{ppm}$. The instrument was operated under 4 MW mode with 20 co-added scans, with a mass range of m/z 53 - 700. Resolving power was $140000 @ 400$ m/z. Data were explored by interrogating common possible pseudo-molecular ions of Naled as well as the anticipated degradation products, as suggested by previous studies.

\subsubsection{Results and discussion}

\subsubsection{Degradation kinetics of Naled by ultrasonic irradiation}

The ultrasonic degradation of Naled was conducted at $640 \mathrm{kHz}$ in an $\mathrm{O}_{2}$-saturated aqueous solution maintained at $(7 \pm 1){ }^{\circ} \mathrm{C}$ temperature. The concentration of Naled at the specific treatment time was monitored by GC-NPD. Control experiments run in the absence

of ultrasound showed no significant removal of Naled through the experimental process. Ultrasonic irradiation leads to rapid degradation of Naled at $640 \mathrm{kHz}$ in the $\mathrm{O}_{2}$-saturated aqueous solution shown in Figure 65. Upon ultrasonic treatment, more than $50 \%$ of Naled was degraded within 20 min of treatment. The decrease of the rate of Naled degradation at extended treatment is attributed to the decrease of Naled concentration and the increase of by-product concentrations competing with Naled for the degradation pathways. 


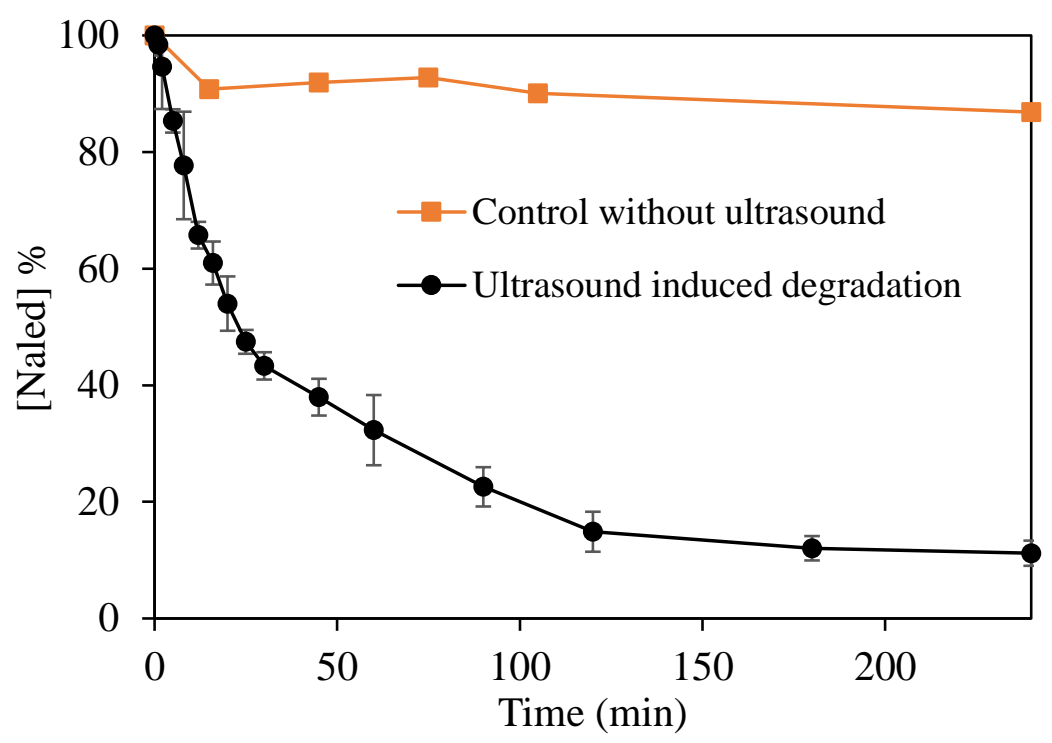

Figure 65. Ultrasonic induced degradation of Naled at $640 \mathrm{kHz}$ in $\mathrm{O}_{2}$-saturated aqueous solution. $[\mathrm{Naled}]_{0}=30 \mu \mathrm{M}$, and $\mathrm{pH}=6.5$, and the reproducibility was within $\pm 9 \%$ on the basis of representative triplicate runs.

To probe the kinetics of ultrasonic induced degradation of Naled, a range of initial concentrations of Naled from $39-309 \mu \mathrm{M}$ were subjected to treatment. The degradation as a function of initial concentrations and treatment times are illustrated in Figure 66. The observed initial degradation rates determined using the first $10-20 \%$ of Naled degradation at different concentrations are summarized in Table 12. Only the first 10-20\% conversions were used to minimize the competition from products on the initial kinetic parameters. The results demonstrate the extent of degradation does not increase proportionally with concentration, i.e., the degradation increases by only three times with a tenfold increase in initial concentration. 


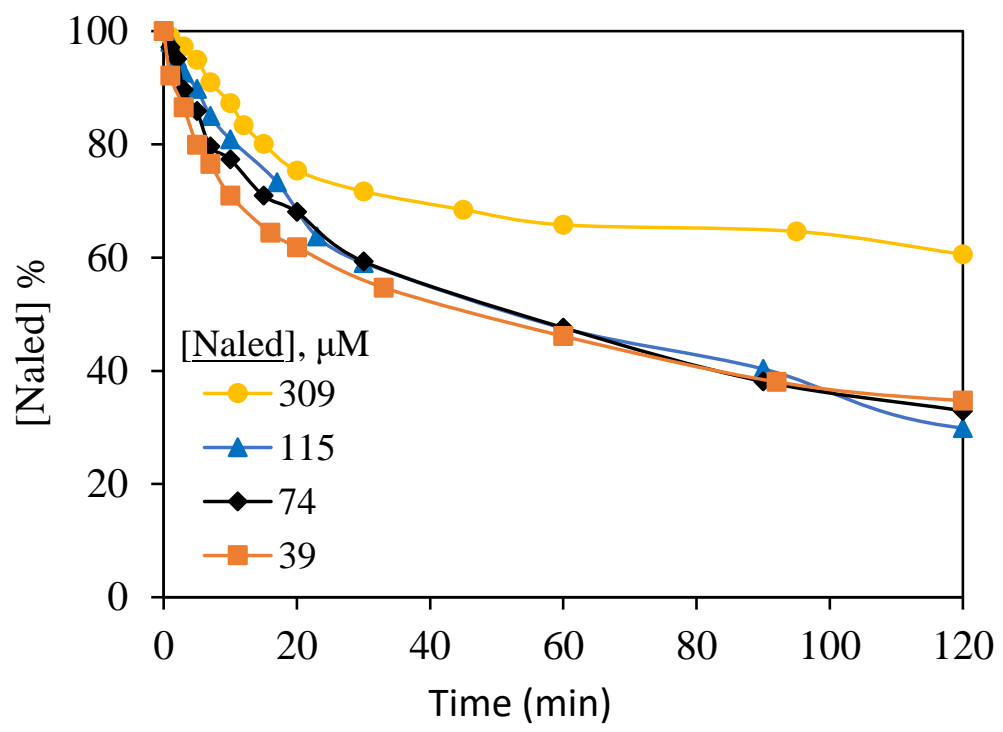

Figure 66. Degradation of Naled as a function of treatment time over the initial concentration of $39-309 \mu \mathrm{M}$ at $640 \mathrm{kHz}$ in the $\mathrm{O}_{2}$-saturated aqueous solution.

Table 12. Kinetic parameters for the ultrasonic degradation of Naled at $640 \mathrm{kHz}$ in $\mathrm{O}_{2-}$ saturated aqueous solution

\begin{tabular}{ccccc}
\hline $\begin{array}{c}\text { Naled }] \\
(\mu \mathrm{M})\end{array}$ & $\begin{array}{c}\text { Initial rate } \mathrm{r}_{0} \\
\left.(\mu \mathrm{M} \mathrm{min})^{-1}\right)\end{array}$ & $\begin{array}{c}\mathrm{R}^{2} \text { value } \\
\text { for } \mathrm{r}_{0}\end{array}$ & $\begin{array}{c}\text { Pseudo-first-order rate } \\
\text { constant } \mathrm{k} \mathrm{x} 10^{2}\left(\mathrm{~min}^{-1}\right)\end{array}$ & $\begin{array}{c}\mathrm{R}^{2} \text { value for } \\
\text { rate constant }\end{array}$ \\
\hline 39 & 1.5 & 0.91 & 4.7 & 0.92 \\
74 & 1.9 & 0.95 & 2.8 & 0.95 \\
115 & 2.3 & 0.98 & 2.2 & 0.99 \\
309 & 4.1 & 0.99 & 1.4 & 0.98 \\
\hline
\end{tabular}

Ultrasonic induced degradation of organics in aqueous media often consistent with the pseudo-first-order kinetic model as described by $\left.\ln \left(\mathrm{C}_{t} / \mathrm{C}_{0}\right)=-\mathrm{kt}\right]$ where $\mathrm{C}_{\mathrm{t}}$ and $\mathrm{C}_{0}$ are the concentrations of Naled at time $\mathrm{t}$ and at the start of the reaction, respectively and $\mathrm{k}$ represents rate constant $[92,173,174]$. However, the adherence of ultrasonically induced 
degradation to the pseudo-first-order kinetic model is observed at a given concentration the rate constant changes with concentration, thus indicated a more complicated process. The plots of $\ln \left(\mathrm{C}_{t} / \mathrm{C}_{0}\right)$ versus time (t) over the range of initial concentrations of $39-309 \mu \mathrm{M}$ are presented in Figure 67, and the rate constants (k) calculated from their slope are summarized in Table 12.

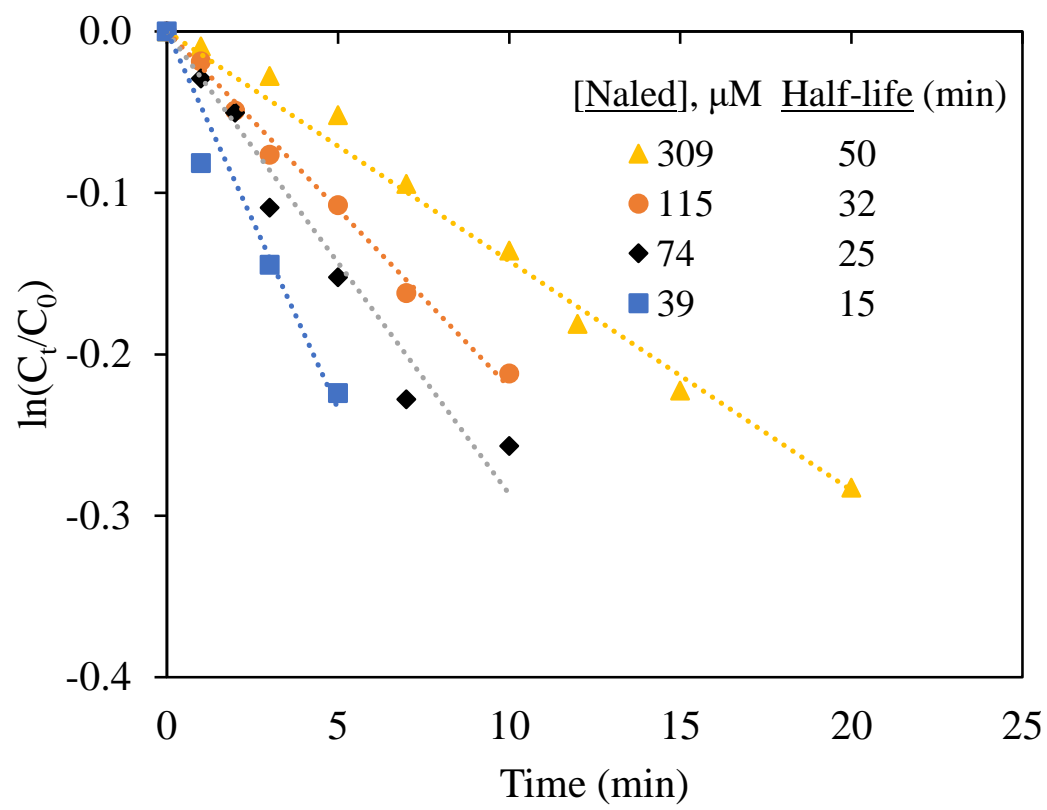

Figure 67. Pseudo-first-order kinetic plots of Naled over a range of initial concentration of $39-309 \mu \mathrm{M}$ upon ultrasonic treatment at $640 \mathrm{kHz}$ in $\mathrm{O}_{2}$-saturated aqueous solution.

Although the observed degradation is consistent with pseudo-first-order kinetics at each specific concentration, the observed first-order rate constants change with concentration. While the results establish that ultrasonic irradiation can lead to the rapid degradation of Naled following the pseudo-first-order kinetics at each specific concertation, the variation of rate constants over initial concentrations suggested more complex reaction kinetics than 
a simple first-order reaction. A number of studies reported a similar kind of kinetic behavior and attributed the results with a variety of heterogeneous processes, where partition between reaction zones plays a very prominent role as well as the limitation of mass transfer of the target molecule at the gas-liquid interface $[92,173]$.

\subsubsection{Heterogeneous kinetic modeling}

The ultrasonic induced degradation of organic compounds is a complex process, and the chemical effect of ultrasound arises from acoustic cavitation. Cavitation, illustrated in Figure 68, involves hot spot possessing extreme temperatures where volatile compounds can partition and undergo high-temperature pyrolysis, the gas-liquid interface where pyrolysis and hydroxyl radical-mediated transformation of hydrophobic type compounds can occur, and the bulk solution maintained at near ambient conditions where hydroxyl radical can diffuse to polar compounds. While ultrasonic treatment of organic compounds can proceed through direct pyrolysis and hydroxyl radical-mediated oxidation, the degree of the partition of target compounds among these phases are critical for the extent and mechanism of the degradation. Naled is a non-ionic polar compound with relatively low vapor pressure and possesses hydrophobic character because of its aliphatic chain. Thus, Naled is likely to partition into the gas-phase interface and liquid bulk regions. Moreover, water near the interface between the hot spot and bulk solution exists as a supercritical state due to the high temperature and pressure of the interface and exhibits hydrophobic rather than the hydrophilic properties associated with water under typical ambient circumstances. 


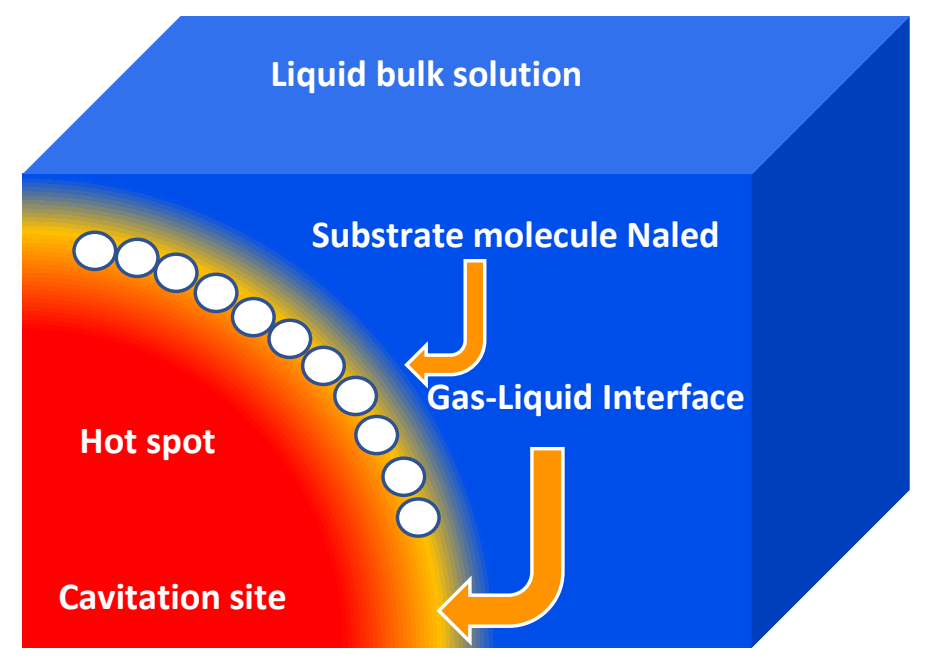

Figure 68. Partitioning of Naled molecules in the hot spot, gas-liquid interface, and bulk liquid phase.

For understanding the partitioning of Naled and its effect on the degradation, we employed the Langmuir-Hinshelwood (L-H) heterogeneous kinetic model. Although the L-H model was developed for the gas-solid heterogeneous system, it is has been effectively applied for the determination of apparent kinetic parameters in a variety of heterogeneous systems [91,97] Ultrasonic induced degradation of Naled can be initiated by thermal processes and/or involve hydroxyl radical at or near the gas-liquid interface; thus the degradation of Naled as a function of concentration was fit to the L-H model. The liquidgas interface can be considered the reaction surface where Naled can partition between the interface and bulk solution. The application of $\mathrm{L}-\mathrm{H}$ model to such systems assumes a homogenous reaction surface where (1) all sites are equivalent, (2) each site can accommodate only one molecule, (3) interaction between adjacent molecules is insignificant, and (4) the adsorption and desorption process is in pure equilibrium. Equation 21 represents the L-H kinetic model where $\mathrm{r}_{0}$ is the initial degradation rate, $\mathrm{C}_{0}$ 
is the initial concentration of substrate, $\mathrm{k}_{\mathrm{r}}$ is the reactivity constant, and $\mathrm{K}_{\mathrm{LH}}$ is the apparent partition equilibrium constant.

$$
1 / \mathrm{r}_{0}=1 / \mathrm{K}_{\mathrm{LH}} \mathrm{k}_{\mathrm{r}} \mathrm{C}_{0}+1 / \mathrm{k}_{\mathrm{r}}
$$

The L-H plots of $1 / \mathrm{r}_{0}$ versus $1 / \mathrm{C}_{0}$ for a range of initial concentrations of $39-309 \mu \mathrm{M}$ at uniform reaction conditions (Figure 69, $\mathrm{R}^{2}$ value $\geq 0.98$ ) suggested that the ultrasonic degradation kinetics of Naled is in good agreement with the L-H kinetic model.

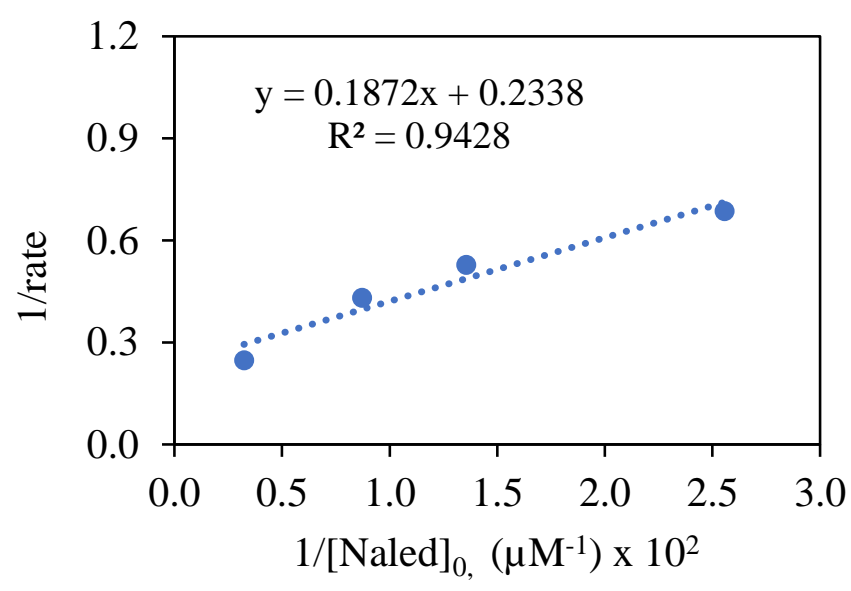

Figure 69. Langmuir-Hinshelwood kinetic plots of the ultrasound-assisted degradation of Naled at $640 \mathrm{kHz}$ over a range of the initial concentration of $39 \mu \mathrm{M}-309 \mu \mathrm{M}$.

The partitioning equilibrium constant $\left(\mathrm{K}_{\mathrm{LH}}\right)$ and the reactivity constant $\left(\mathrm{k}_{\mathrm{r}}\right)$ determined from the slope and intercept of the L-H plot are $0.004 \mu \mathrm{M}^{-1}$ and $\mathrm{k}_{\mathrm{r}}=4.28 \mu \mathrm{M} \mathrm{min}{ }^{-1}$, respectively. $\mathrm{K}_{\mathrm{LH}}$ and $\mathrm{k}_{\mathrm{r}}$ are the empirical values indicating the apparent reactivity and partitioning factor of target compounds into the gas-liquid interface according to the $\mathrm{L}-\mathrm{H}$ model. Our recent report on the ultrasonic degradation of tris (2-chloroethyl) phosphate (TCEP) with partitioning equilibrium constant $0.007 \mu \mathrm{M}^{-1}$ and reactivity constant $2.08 \mu \mathrm{M}$ 
$\min ^{-1}$ suggests that Naled has more potential to show high reactivity but lower partitioning to the gas-liquid interface when compared with TCEP. Literal interpretation of these kinetic parameters suggests enhanced reactivity, but less partitioning into the interface are may be to the relatively highly polar properties of Naled.

\subsubsection{Scavenger study to assess the role of hydroxyl radicals}

The ultrasonic degradation of organophosphate ester proceeds through both pyrolytic induced processes and hydroxyl radical-mediated oxidation [193]. To further explore the ultrasonically induced degradation pathways of Naled, different hydroxyl radical scavengers were added into the reaction system before ultrasonic irradiation. Hydroxyl radical formed from the homolysis of water molecules during cavitation can partition among the hotspot gas phase $\left(\cdot \mathrm{OH}_{\mathrm{G}}\right)$, gas-liquid interface $\left(\cdot \mathrm{OH}_{\mathrm{G}-\mathrm{L}}\right)$, and bulk liquid solution $\left(\cdot \mathrm{OH}_{\mathrm{L}}\right)$. Assessment of their roles is very critical for elucidating the degradation pathways. Since Naled is a nonvolatile polar compound, it is unlikely to partition at the gas-phase hot spot, but given its aliphatic side groups, Naled could partition to the hydrophobic gas-liquid interface. A competition experiment was run in the presence of hydroxyl radical scavengers, non-polar coumarin (COU) for evaluating the roles of $\cdot \mathrm{OH}_{\mathrm{G}-\mathrm{L}}$, and $\bullet \mathrm{OH}_{\mathrm{L}}$ hydroxyl radicals in the degradation process. Quenching the $\bullet \mathrm{OH}$ from reaction media not only will help understand its role in the degradation but by deduction also reveal the role of pyrolysis in the degradation process. COU is a neutral organic compound, will reside predominantly within the gas-liquid interface and can scavenge - $\mathrm{OH}_{\mathrm{G}-\mathrm{L}}$ at the interface and also prevent the accumulation of hydroxyl radical near the 
interface $\left(\cdot \mathrm{OH}_{\mathrm{L}}\right)$. If $\bullet \mathrm{OH}_{\mathrm{G}-\mathrm{L}}$ radical is a major participant in the ultrasonically induced degradation of Naled, the reaction would be significantly suppressed by the addition of COU. Pseudo-first-order kinetic plots obtained from scavenging experiments are shown in Figure 70. The rate constants in the presence of the individual hydroxyl radical scavengers, along with their respective likely degradation pathways are summarized in Table $\mathbf{1 3 .}$

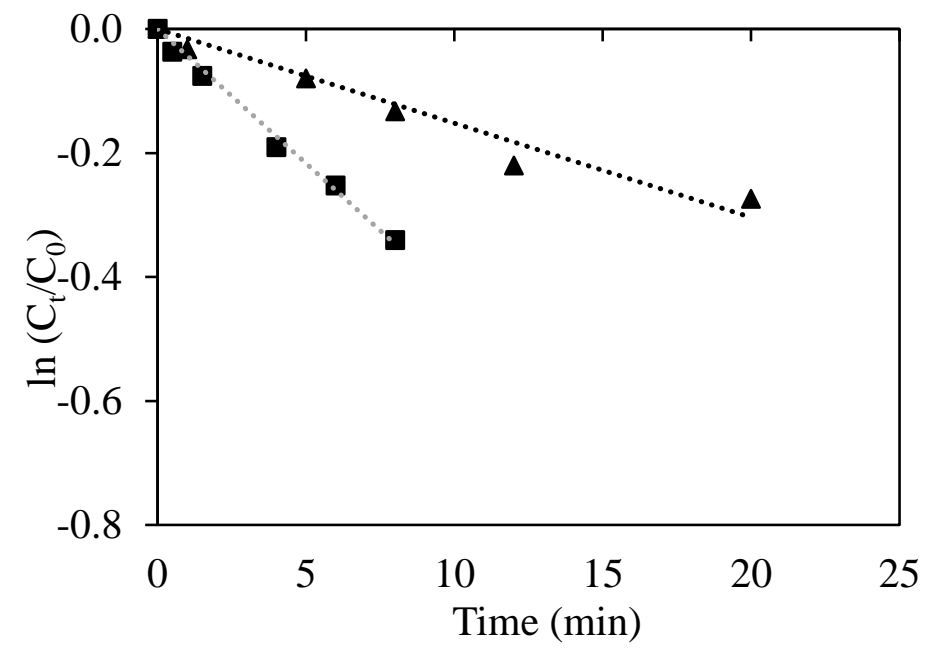

Figure 70. Effect of hydroxyl radical scavengers on the sonochemical degradation of Naled at $640 \mathrm{kHz}$ in oxygenated aqueous solution.

Table 13. Likely degradation pathways of ultrasonic treatment of Naled in the presence of different hydroxyl radical scavengers

\begin{tabular}{cccc}
\hline Reaction type & $\begin{array}{c}\text { Scavenged } \\
\text { radical }\end{array}$ & $\mathrm{k}\left(\mathrm{min}^{-1}\right)$ & $\begin{array}{c}\text { Likely degradation } \\
\text { pathways }\end{array}$ \\
\hline $100 \mu \mathrm{M}$ Naled +$))))$ & - & 0.031 & $\begin{array}{c}\text { Pyrolysis, } \cdot \mathrm{OH}_{\mathrm{G}-\mathrm{L}} \text { and } \bullet \mathrm{OH}_{\mathrm{L}} \\
\text { mediated degradation }\end{array}$ \\
$\begin{array}{c}50 \mu \mathrm{M} \mathrm{Naled}+50 \mu \mathrm{M} \\
\mathrm{COU}+))))\end{array}$ & $\cdot \mathrm{OH}_{\mathrm{G}-\mathrm{L},} \cdot \mathrm{OH}_{\mathrm{L}}$ & 0.009 & Pyrolysis \\
\hline
\end{tabular}


While the rate constant for ultrasonically induced degradation of Naled was 0.031 $\min ^{-1}$, the addition of excess coumarin in the solution before the ultrasonic irradiation decreased the rate constant by $0.022 \mathrm{~min}^{-1}$ suggesting that hydroxyl radical plays a predominant role in the degradation. The rate constant $0.009 \mathrm{~min}^{-1}$ observed for the degradation of Naled in the presence of coumarin indicates that pyrolysis also plays a significant role, $\sim 27 \%$, in the degradation process. The result provides convincing evidence that ultrasonic degradation of Naled proceeds via both interfacial hydroxyl radical-mediated oxidation as well as pyrolytic pathways.

\subsubsection{Ion chromatographic product studies}

The production of small organic molecules and mineralized products, including bromide, chloride, and phosphate during the sonochemical treatment of Naled, was monitored by ion chromatography. Figure 71 shows a typical ion chromatogram of sonolytically treated solution taken at extended 4 hours of irradiation time. Results suggested ultrasonic treatment transforms Naled into a number of phosphorus-containing compounds dimethyl phosphate (DMP), monomethyl phosphate (MMP), as well as bromide $\left(\mathrm{Br}^{-}\right)$, chloride $\left(\mathrm{Cl}^{-}\right)$, and phosphate $\left(\mathrm{PO}_{4}{ }^{3-}\right)$ and formate ions. Ion chromatographic product identification is performed by comparing the retention time of standard compounds during the chromatographic run in the same condition. The recovery of ions as a function of irradiation time was demonstrated in Figure 72. Over the six hours of extended ultrasonic treatment, although the recovery of chloride and bromide, was closer to $100 \%$, the recovery of phosphate, however, was around $20 \%$. 


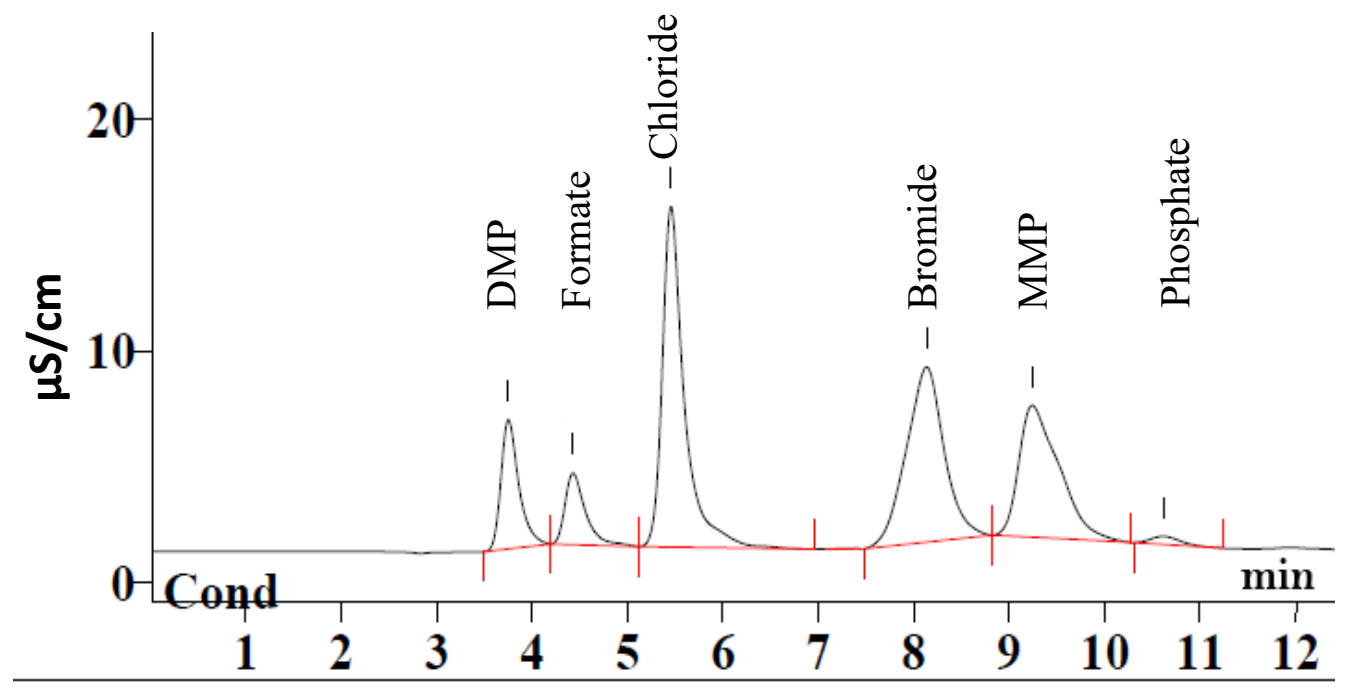

Figure 71. Ion chromatogram of the ultrasonic treated solution of Naled at $240 \mathrm{~min}$.

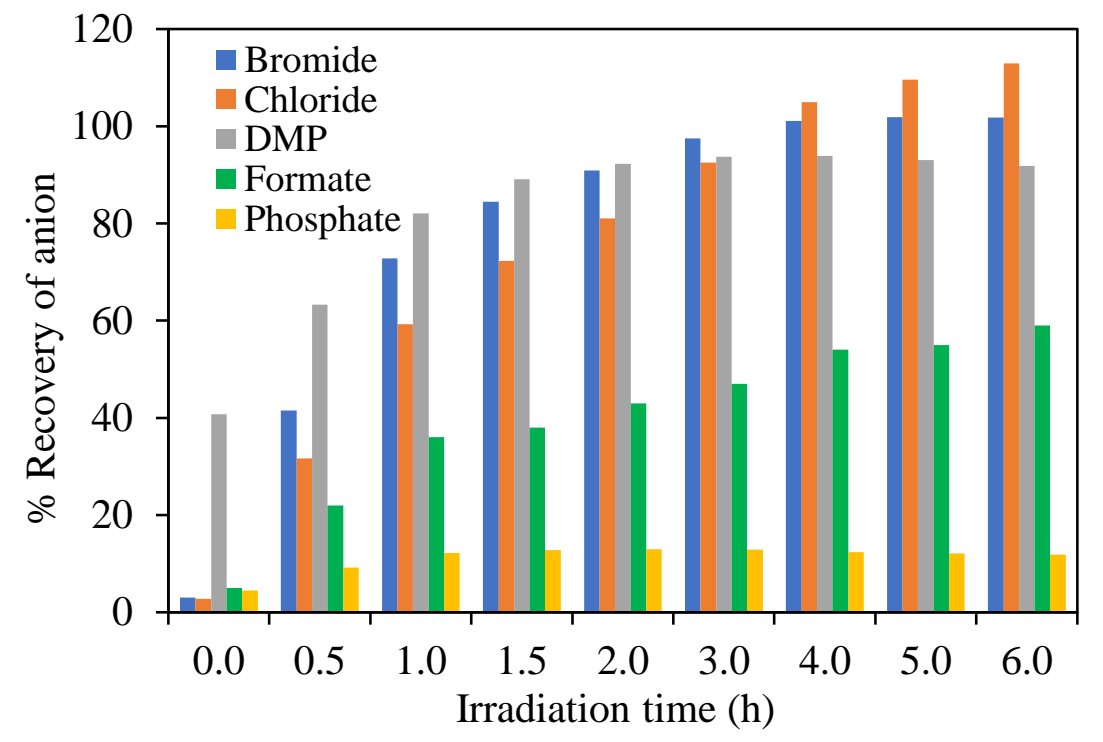

Figure 72. Evolution of $\mathrm{Br}^{-}, \mathrm{Cl}^{-}, \mathrm{DMP}$, Formate, and $\mathrm{PO}_{4}{ }^{3-}$ as a function of treatment time during the ultrasonic irradiation of Naled at $640 \mathrm{kHz}$ in $\mathrm{O}_{2}$-saturated aqueous solution. $[\text { Naled }]_{0}=0.098 \mathrm{mM}$. 
Although we observed the sonolysis of Naled is rapid, partial phosphate recovery observed upon extended irradiation indicates the presence of phosphorus-containing byproducts $[107,108]$. The mass balance on the basis of the recovery of dimethyl phosphate was nearly $90 \%$, with a significant portion of DMP observed at the beginning of the reaction, confirming the hydrolysis of Naled reported above. Accumulation of formate ions during the treatment time demonstrates incomplete mineralization. Antonopoulou et al. reported an almost complete mass balance of chloride ions, a phosphorus mass balance of only $60 \%$ was reported during the $\mathrm{TiO}_{2}$ photocatalytic degradation of TCPP [93]. Because of the unavailability of pure monomethyl phosphate, we did not quantify the recovery of monomethyl phosphate.

\subsubsection{Mass spectrometric products studies}

Although the mass balance for chloride and bromide in the ultrasonic degradation of Naled is nearly $100 \%$, the recovery of only $\sim 20 \%$ of phosphate ions upon extended irradiation suggested incomplete mineralization. To identify the potential intermediates or byproducts during ultrasonic treatment, we employed Fourier-Transform Ion Cyclotron Resonance mass spectrometry (FT-ICR-MS) with electrospray ionization negative ion mode. After screening with mass spectrometric data, three intermediates were identified, including 1,2-dibromo-2,2-dichloroethyl methyl phosphate (DDEMP) with m/z 362.7596, dimethyl phosphate (DMP) with m/z 125.0009, and monomethyl phosphate (MMP) with $\mathrm{m} / \mathrm{z}$ 110.9853, shown in Table 14. However, the hydrolysis of Naled reported above also demonstrated that Naled decomposes to DDEMP, DMP, and MMP in water [185]. 
Table 14. Identified by-products/intermediates generated during the ultrasonic treatment of Naled with their exact mass and mass/charge $(\mathrm{m} / \mathrm{z})$ ratio in negative ionization mode

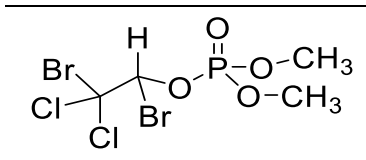

Exact Mass: 377.7826

Naled

$\mathrm{m} / \mathrm{z} 376.7819$

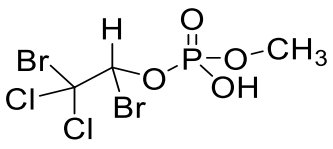

Exact Mass: 363.7669

DDEMP

$\mathrm{m} / \mathrm{z} 362.7596$

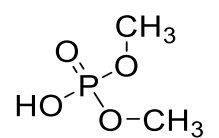

Exact Mass: 126.0082

DMP $\mathrm{m} / \mathrm{z} 125.0009$

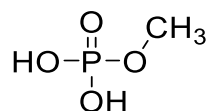

Exact Mass: 111.9925

MMP

\subsubsection{Mechanistic consideration}

Scavenger experiments established that hydroxyl radical $(\bullet \mathrm{OH})$ is the predominant species responsible for the ultrasonically induced degradation of Naled. $\bullet \mathrm{OH}$ reacts with an organic molecule via one of the three different reaction pathways: hydrogen atom abstraction, electrophilic addition to a double bond, and electron transfer $[56,171]$. We outlined two degradation pathways to explain the products observed during the treatment of Naled. Naled has two types of hydrogen, specifically methyl hydrogens $\left(1^{\circ}\right)$ and ethyl hydrogen $\left(3^{\circ}\right.$ type). Hydroxyl radicals can abstract either hydrogen to make carbon center free radical, while the $3^{\circ}$ type is generally more reactive than the $1^{\circ}$ hydrogen, the $1: 1$ ratio statistically favors the methyl hydrogen abstraction pathway. In the presence of molecular oxygen, these carbon-centered radicals can participate in radical chain oxidation processes, which can ultimately lead the fragmentation and mineralization. Following previous mechanistic studies of related organophosphates [51], we proposed two mechanisms on the basis of the hydroxyl radical abstraction of hydrogen of the alkyl chain of Naled to explain the formation of the observed products. 
In pathway A (Figure 73), hydroxyl radical abstraction of the $3{ }^{\circ}$ hydrogen atom of the ethyl group yields a carbon-centered free radical which can undergo further transformation leading to the formation of an acetal, either by direct reaction with another hydroxyl radical or by the addition of oxygen to form a peroxyl radical and subsequent collapse. The dimerization of two peroxyl radicals, followed by extrusion of $\mathrm{O}_{2}$ via a Russell mechanism, can also be used to explain the observed products dimethyl phosphate and monomethyl phosphate [11].

A) Abstraction of hydrogen from ethyl group of Naled<smiles>COP(=O)(OC)OC(Br)(Br)C(Cl)(Br)Br</smiles>

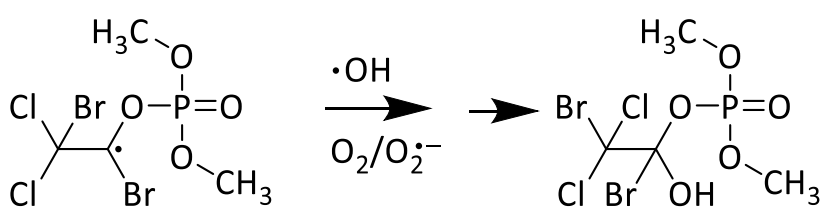
[Hydrolysis]

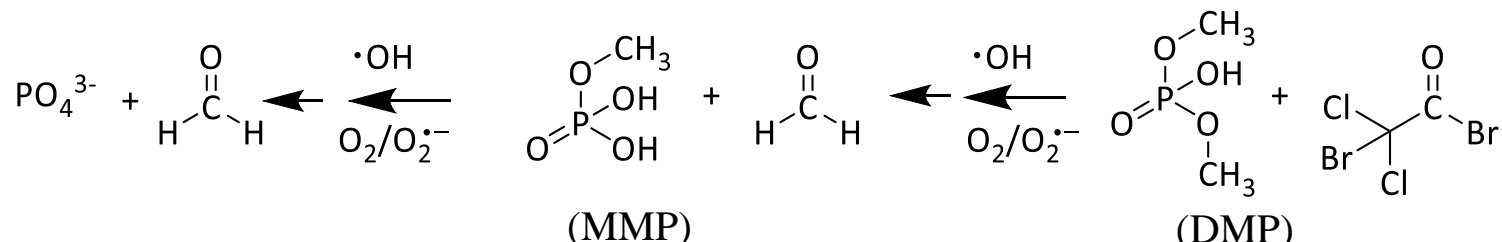
B) Abstraction of hydrogen from the methyl group of Naled

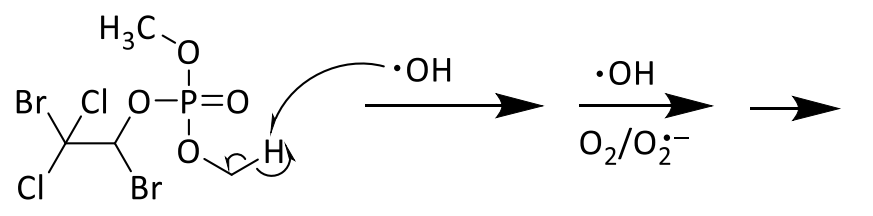<smiles>COP(=O)(O)OC(Br)C(Cl)(Cl)Br</smiles>

(DDEMP) 
C) Secondary oxidation of byproducts

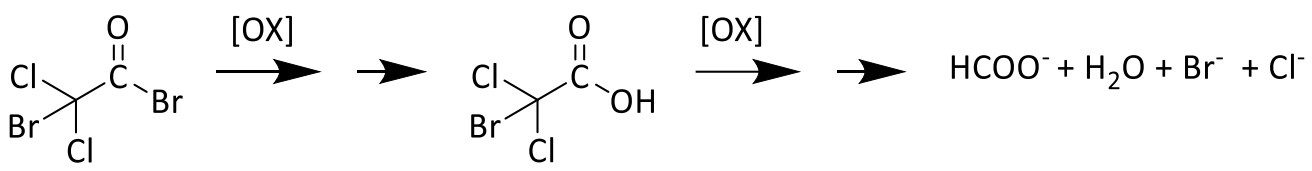

Figure 73. Proposed hydroxyl radical-mediated degradation via hydrogen abstraction mechanism.

In pathway B (Figure 73), a hydrogen atom is abstracted by a hydroxyl radical from the methyl group leading to the formation of a carbon-centered radical. The resulting carbon-centered radical can undergo further oxidation leading to the formation of a compound by a substitution reaction with another hydroxyl radical. Then rearrangement leads to the formation of the carbonyl compound. The resulting carbonyl compound can be further oxidized to the carboxylic acid and ultimately lead to DDEMP, a diester of Naled. Subsequent hydroxyl radical-mediated oxidation of highly halogenated carboxylic compounds leads to the formation of formate, bromide, and chloride ions, shown in pathway C (Figure 73).

\subsubsection{Conclusions}

We demonstrated the detailed kinetics and mechanistic studies of ultrasonic induced treatment of Naled in an oxygen-saturated aqueous solution. The results indicate that ultrasonic irradiation leads to rapid degradation of Naled at $640 \mathrm{kHz}$ in oxygenated aqueous solution. The degradation follows pseudo-first-order kinetics at a specifically given concentration. Variation of rate constants depending on initial concentration 
indicated the partition of Naled at the gas-liquid interface plays a prominent role in the degradation. The degradation of Naled is consistent with Langmuir-Hinshelwood kinetic model, implying that degradation occurs at or near the gas-liquid interface during cavitation. While the mass balance for chloride and bromides was nearly $100 \%$, the recovery of $20 \%$ phosphate suggested incomplete mineralization of Naled upon extended hours of ultrasonic treatment. Competition studies using hydroxyl radical scavengers reveal that the process is mediated by pyrolysis and hydroxyl radical-mediated process. The mono and diester of Naled are the primary products identified by ion chromatography and FT-ICR-HRMS. These results suggest that ultrasonic oxidation will be useful for the decontamination of Naled from aqueous solution. 


\section{CHAPTER 6 ULTRASONIC REMEDIATION OF EMERGING \\ PERFLUOROALKYL SUBSTANCES (PFAS)}




\subsection{Abstract}

The presence of poly- and perfluoroalkyl substances (PFASs) in drinking water sources is a serious threat to the environment and human health. These compounds are incredibly persistent and have severe negative biological impacts. The remediations of PFASs by conventional methods are mostly ineffective because of the extreme stability of PFASs. The removal of PFASs by adsorption is also difficult because of their design with anti-stick properties. We have demonstrated that a variety of legacy and emerging PFASs can be readily degraded by ultrasonic irradiation at $640 \mathrm{kHz}$. Perfluorobutanoic acid (PFBA), perfluoropentanoic acid (PFPA), perfluoroheptanoic acid (PFHpA), perfluorooctanoic acid (PFOA), perfluoro-2-propoxypropanoic acid (GenX), and perfluoro-4-methoxybutanoic acid (PFMeoBA) are transformed to fluoride ions in fairly good yields under treatment by ultrasonic irradiation. The fluoride mass balance from PFBA after three hours of treatment was $50 \%$, while nearly $75 \%$ mineralization to fluoride was achieved for GenX, PFMeoBA, PFPA, PFHpA, and PFOA. Ion chromatographic analysis of treated GenX revealed the production of formate ion. Detailed product studies of GenX were performed using an UHPLC-Orbitrap-HRMS followed by the Compound Discoverer (CD) software. Product studies suggest minor intermediate products, specifically 2H,2-perfluoropropoxypropanoic acid, and 2,3-dihydroxyperfluoropropanoic acid, are formed during the sonolysis of GenX. While ultrasonic induced degradation is initiated through a cavitation process and often dependent on hydroxyl radical production, the addition of hydroxyl radical scavengers, coumarin, terephthalic acid, and t-butyl alcohol showed no significant effect on the rates of GenX degradation. Our results clearly 
demonstrate that the ultrasonically induced degradation of GenX proceeds through pyrolysis and oxidation plays an insignificant role in the degradation. Scavenger experiments also confirmed that the production of fluoride ions does not depend on $\mathrm{OH}$ radicals. We propose that the PFAS compounds partition to the gas-liquid interfacial region and undergo extensive pyrolysis leading to conversion to fluoride ion. The obtained results suggest that sonolytic induced degradation is a promising method for the remediation of PFASs from water.

\subsection{Introduction}

Poly- and Perfluoroalkyl substances (PFASs) refer to wide variety of anthropogenic chemicals with highly fluorinated alkyl backbones $[22,23]$. A number of select PFASs studied in this work are given in Table 15. These compounds are used for a wide range of applications, and incredibly persistent. Given their widespread use, PFASs get into the environment through a variety of ways, including the application of firefighting foam at airport and military sites and improper disposal of manufacturing waste. [23]. PFASs generally contain poly- or perfluorinated alkyl chain and a polar head group, thus making them both hydrophobic and hydrophilic $[7,22]$. PFASs are used in a variety of applications, including in the nonstick surface, water-, grease-, and stain-repellants and aqueous filmforming firefighting foam for military bases and airport facilities [7,23]. By design, these compounds have incredible stability due to the strong carbon-fluorine single bonds. PFASs

are resistant to environmental and biological degradation and have recently been referred to as forever chemicals [24,67]. 
Table 15. Name and structure of a number of select perfluoroalkyl substances (PFASs)

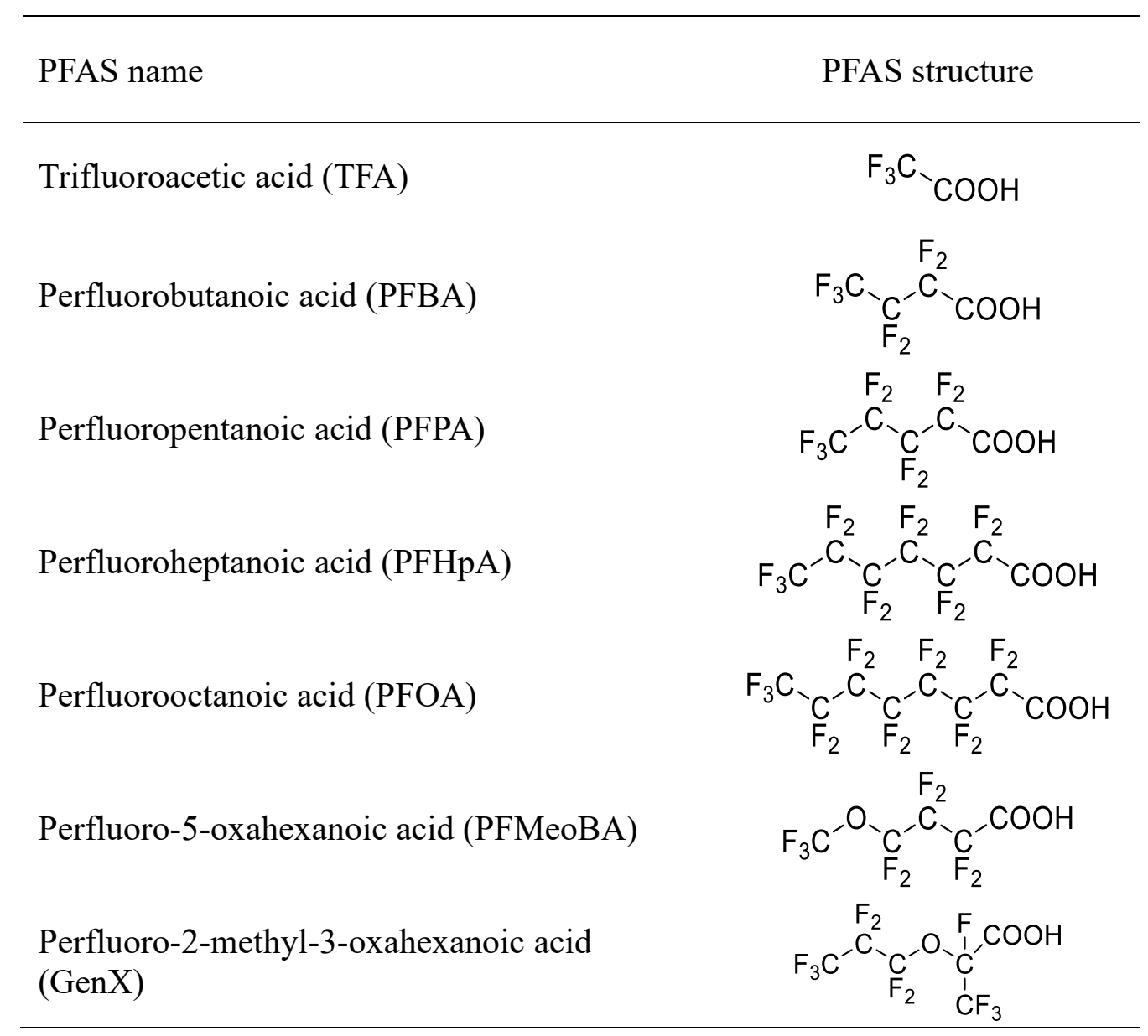

The presence of PFAS in drinking water sources, humans, wildlife, and the environment is well documented [7,26,28,29,194]. Exposure to these chemicals is linked to a broad spectrum of serious health effects, including liver, kidney, and bladder cancer, thyroid disease, infertility, and developmental delays [30,32-35]. In response to their extreme persistence and adverse health effects, the US-EPA restricted the production of legacy Perfluorooctanesulfonic acid (PFOS) and perfluorooctanoic acid (PFOA) with the adoption of a maximum health advisory limit for PFOA and PFOS in drinking water of 70 ng/L [7]. As a replacement for legacy PFASs, DuPont introduced perfluoro 2- 
propoxypropionic acid, known as GenX, in 2009 for the manufacture of fluoropolymer coatings for stain-resistant carpeting and waterproof clothing [7]. Given the ether functionality and decrease the hydrophobic character of GenX, it was forecasted to less toxic and less persistent than the legacy PFASs. However, GenX has been recently detected in drinking water, raising concerns about the impact on the environment and human health $[27,37]$. The presence of GenX in drinking water sources in North Carolina has resulted in a state-wide health advisory level for GenX [38].

Conventional adsorption methods are employed for the removal of a wide variety of pollutants from the drinking water sources. Traditional physical separation techniques, including granular activated carbon (GAC), anion exchange resin, and high-pressure filtration, have been reported for removal of PFASs from drinking water [61-67]. However, these methods are only effective for a small number of PFASs, limited in their capacity, often require long contact times, and ultimately result in a contaminated solid or concentrated liquid, eventually requiring additional treatment. GAC and ion-exchange resin can also require frequent maintenance and/or replacement [67]. Moreover, these physical methods are, in general, not suitable for the removal of perfluoroether carboxylic acids (PFECAs) [27,195]. Sedimentation, ozonation, biofiltration, and disinfection processes show insignificant removal of 7 PFECAs from drinking water sources [27]. GenX, the most notorious of the PFECAs, exhibits weak absorption compared to PFOA on powder activated carbon [27].

Advanced oxidation technologies (AOTs), which rely on hydroxyl radicalmediated oxidation processes, are among the most applicable water treatment methods for 
the degradation of toxins/pollutants [6]. $\mathrm{TiO}_{2}$ photocatalysis, an AOT, was been reported effective for the destruction of a large number of organic compounds [49,51,196]. However, PFASs appear to be highly resistant to $\mathrm{TiO}_{2}$ photocatalysis [197]. While activated sulfate has been applied for in situ remediations of PFAS from groundwater, it is typically slow and ineffective for PFOS and other perfluoroalkyl sulphonic acids [27,198]. Although there are remarkably few proven remediation methods for PFASs, Bentel et al. recently demonstrated effective defluorination for a significant number of perfluorocarboxylates (PFCAs) and polyfluorodicarboxylates (PFDCAs) by $254 \mathrm{~nm}$ photochemical generation of the hydrated electron from sulfite [199]. They reported stepwise de-fluorination via a reductive elimination by the addition of the hydrated electron, followed by the elimination of fluoride ion. While PFCAs, PFDCAs, and perfluorosulfonate lead to reductive defluorination by the hydrated electron, however, perfluorosulfonate and perfluorotelomer are resistant to this process. Bao et al. reported the degradation of GenX by hydrated electron generated in the UV/sulfite system and identified perfluoropropanoic acid and trifluoroacetic acid as stable intermediates [200].

Ultrasonic induced degradation of a wide variety of pollutants and toxins has been demonstrated over the past couple of decades [59,71]. While the conversion factor of electrical to acoustic energy is relatively low [70], proper optimization for energy efficiency or dynamics of reaction systems, however, can be used to improve the economic feasibility $[69,201]$. Unlike the photocatalysis and UV/peroxide, the ultrasonic process requires no chemical additives and can be effectively utilized in turbid solutions and sludge. Ultrasonic irradiation can be used for both disinfection and remediation of chemical toxins in treating drinking water. Unique to ultrasonic treatment is the initiation of both 
pyrolytic and hydroxyl radical initiated oxidation pathways [68,71]. The transmission of ultrasonic waves through a liquid can induce acoustic cavitation and create resonating gas bubbles. At specific frequencies, a significant pressure differential is created between the inside and outside of the bubbles. Ultimately this pressure differential leads to a violent bubble collapse producing extreme temperatures and pressures. The cavitation process is often broken into three distinct reaction zones; a hot spot with temperatures to $5000 \mathrm{~K}$ and pressures to $500 \mathrm{~atm}$, an interfacial region reaching $2000 \mathrm{~K}$ and $300 \mathrm{~atm}$, and a bulk solution which can be kept near ambient conditions $[71,78]$. The hot-spot is dominated by pyrolysis of the solvent and volatile target compounds. In aqueous media, thermal pyrolysis of water vapor yields $\mathrm{H} \bullet$ and $\bullet \mathrm{OH}$ radicals, keys to degradation by advanced oxidation processes. There are only a few studies reported the ultrasonic treatment of PFAS [77,79,202]. Moriwaki et al. reported that ultrasonic treatment PFOS and PFOA could lead to the formation of lower PFCAs [79]. However, their study was limited to PFOA and PFOS without discussion or investigation of degradation pathways. Vecitis et al. successfully demonstrated the complete mineralization of PFOS and PFOA compounds into inorganic ions and identified a number intermediates en route to mineralization to fluoride ions $[78,202]$.

In this study, we showed for the first-time effective degradation of low molecular weight and ether-based emerging PFASs. The compounds include perfluorobutanoic acid (PFBA), perfluoropentanoic acid (PFPA), perfluoroheptanoic acid (PFHA), perfluorooctanoic acid (PFOA), perfluoro-2-propoxypropanoic acid (GenX), and perfluoro-4-methoxybutanoic acid (PFMeoBA). Our studies demonstrate ultrasonic irradiation at $640 \mathrm{kHz}$ can effectively degrade legacy, low molecular weight, and 
representative ether-based PFASs, including PFBA, PFPA, PFHpA, PFOA, GenX, and PFMeoBA. Detailed kinetic and product studies of the sonolytic degradation of GenX were carried out to better understand the reaction pathways and degradation mechanisms. Assessment of the degradation kinetics in the presence of carefully chosen hydroxyl radical scavenger demonstrated pyrolysis is the predominant or exclusive degradation process during the ultrasonic treatment of GenX. Using the experimental results, we proposed thermal-induced $\mathrm{C}-\mathrm{C}$ bond homolysis, followed by $\beta$-secession and hydrolysis reaction pathways leading to the effective conversion of GenX to fluoride. Our results demonstrate that ultrasonic induced degradation is a promising technique for the remediation of PFASs from aqueous media.

\subsection{Experimental section}

\subsubsection{Materials}

Perfluorobutanoic acid (PFBA), perfluoropentanoic acid (PFPA), perfluoroheptanoic acid (PFHpA), perfluorooctanoic acid (PFOA) were purchased from Sigma-Aldrich. Perfluoro-2-propoxypropanoic acid (GenX) was purchased from AlfaAesar and perfluoro-4-methoxybutanoic acid (PFMeoBA) from Synquest Labs. Methanol (LC-MS grade) and ammonium acetate were obtained from Fisher Scientific. The argon gas was from Trigas of the highest purity available. Millipore water $(18 \mathrm{M} \Omega \cdot \mathrm{cm})$ and volumetric glassware were used for the preparation of all of the aqueous solutions. Glasswares were baked and rinsed with solvents before use to avoid contamination. 


\subsubsection{Sonolytic experiment}

All the sonolytic reactions were carried out in an Ultrasonic Energy Systems 15660 sonolytic reactor equipped with an ultrasound generator, a horn, and a $550 \mathrm{~mL}$ cylinder glass reaction vessel. The detailed sonolytic experiment has been described elsewhere [203]. In a typical reaction, $500 \mathrm{~mL}$ of PFAS solution was transferred to the reaction vessel. The reaction vessel and attached horn were submerged within in a 10-gallon ice-water bath. Throughout the experiments, the temperature was maintained at $7 \pm 1{ }^{\circ} \mathrm{C}$. The solution was gas purged with appropriate gas for 15 min before exposure of the ultrasonic irradiation. The amplitude and frequency were set at $700 \mathrm{~W}$ and $640 \mathrm{kHz}$, respectively. Samples of 20 $\mathrm{mL}$ of treated solution were withdrawn at specific time intervals for analyses.

\subsubsection{UHPLC-Orbitrap-HRMS analysis of PFAS}

The concentration of PFASs was monitored by the ultra-high-performance liquid chromatography Orbitrap high-resolution mass spectrometry (UHPLC-Orbitrap-HRMS) (Q Exactive, Thermo Fisher Scientific). Chromatographic separation was carried out in a Hypersil Gold PFP column (100 mm x $2.1 \mathrm{~mm}, 1.9 \mu \mathrm{m}$, Thermo Scientific, USA) with a mobile phase of methanol (A) and $2 \mathrm{mM}$ ammonium acetate (B). The linear gradient was as follows: $40 \%$ A for $0-1 \mathrm{~min}, 40-90 \%$ A for $1-4 \mathrm{~min}, 90 \% \mathrm{~A}$ for $4-8 \mathrm{~min}$, and $90-40 \%$ A for 8-9 min and $40 \%$ A for 9-12 min. Heated electrospray ionization (HESI) was used for ionization. Data acquisition and analyses were carried out by Xcalibur software. The transformation products were detected in full scan negative ionization mode with a resolution of 140,000, a scan range of 100-550 mass/charge ratio, and mass tolerance of 5 ppm. The concentration of PFAS was determined using the characteristic retention time, 
reference standard, and careful calibration of the MS detector. A calibration curve of each PFAS was made by a series of standard PFAS solutions ranging from $50-2000 \mu \mathrm{g} / \mathrm{L}$ using PFOA as an internal standard. The calibration curves are shown in Figure $74-77$. As ultrasonic irradiation can involve a variety of pyrolytic and radical-induced processes, degradation of PFAS can produce a complex reaction mixture. Therefore, we have used the small molecule structure identification software, Compound Discoverer 3.0 (Thermo Scientific, USA), to assist with the identification of intermediates and degradation products evolved over the course of degradation.

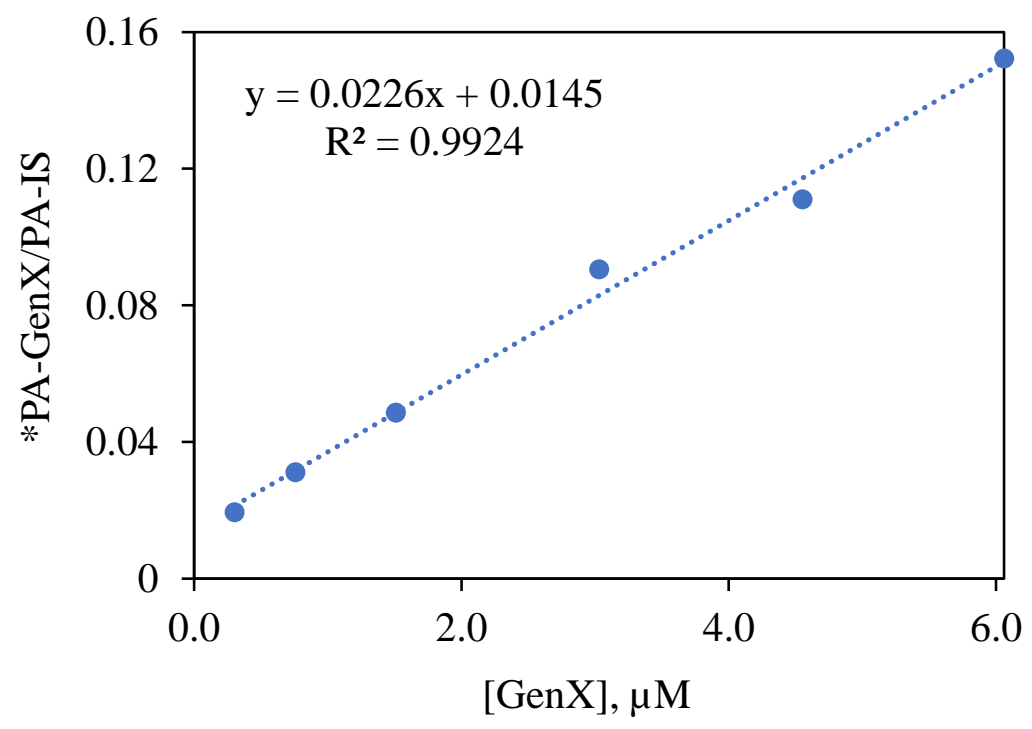

Figure 74. LC-MS calibration curve for the determination of GenX in aqueous solution. PFOA was used as an internal standard and *PA stands for peak area. 


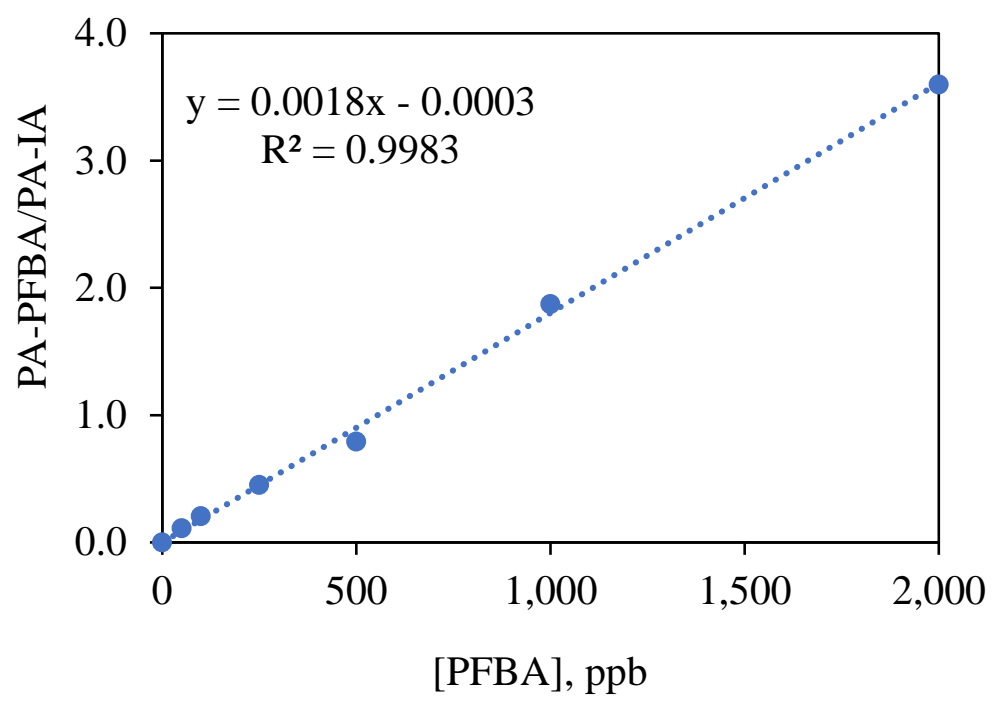

Figure 75. LC-MS calibration curve for the determination of PFBA concentration in aqueous solution. PFOA was used as an internal standard.

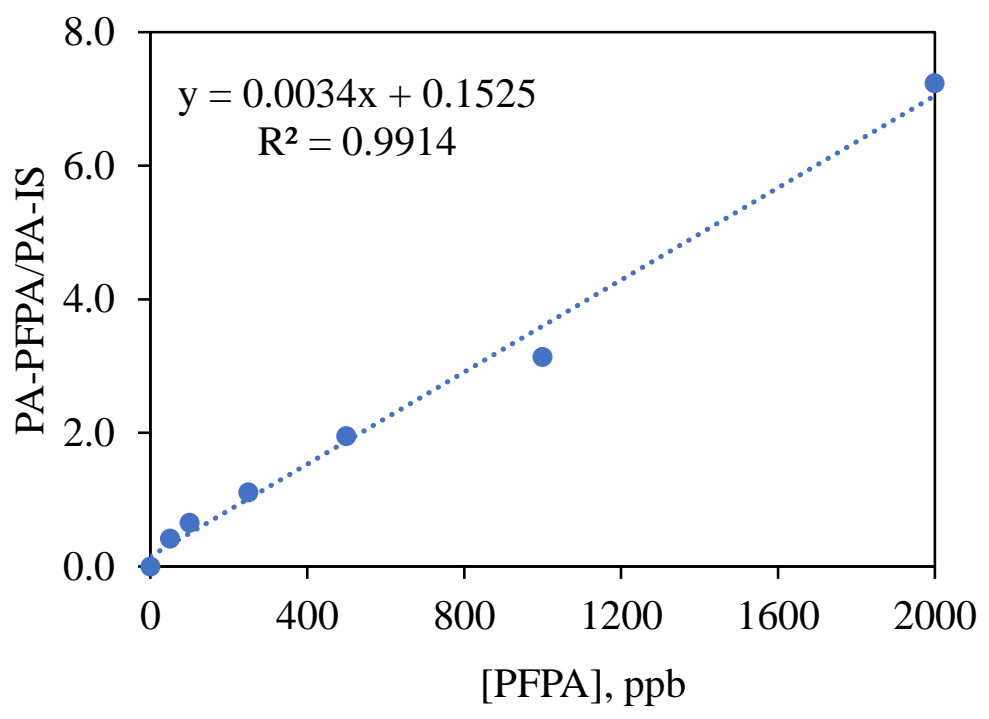

Figure 76. LC-MS calibration curve for the quantification of PFPA concentration in aqueous solution. PFOA was used as an internal standard. 


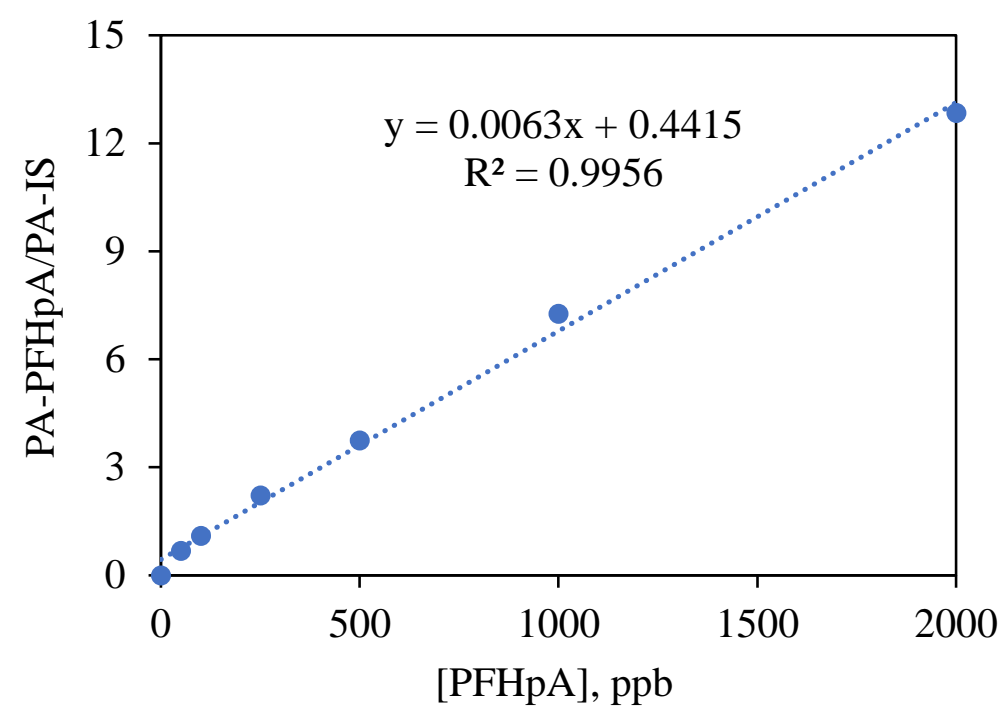

Figure 77. LC-MS Calibration curve for the quantification of PFHpA in aqueous solution. PFOA was used as an internal standard.

\subsubsection{Fluoride ion-selective electrode analysis}

The fluoride ions released from the PFAS compounds were determined potentiometrically using a Thermo Scientific Orion fluoride ion-selective electrode connected to a Mettler Toledo ISE meter through a BNC connection. A total ionic strengthadjusting buffer (TISAB) made from glacial acetic acid and sodium chloride was added to provide a constant background of ionic strength. A potentiometric calibration curve was made using a range of fluoride ion concentrations from 1.3-263 $\mu \mathrm{M}$ ( $25 \mathrm{ppb}$ to $5000 \mathrm{ppb})$ using the Nernst equation, $\mathrm{E}=\mathrm{E}_{0}+2.03 \mathrm{~S} \log \mathrm{C}$, where $\mathrm{E}$ and $\mathrm{E}_{0}$ refer to experimental and standard electrode cell potential, S represents electrode slope, a constant value specific to cell arrangement, and $\mathrm{C}$ indicates the fluoride ion concentration. The correlation coefficient 
of the calibration curve was 0.99 , and data were reproducible within around $2 \%$ standard deviation, shown in Figure 78.

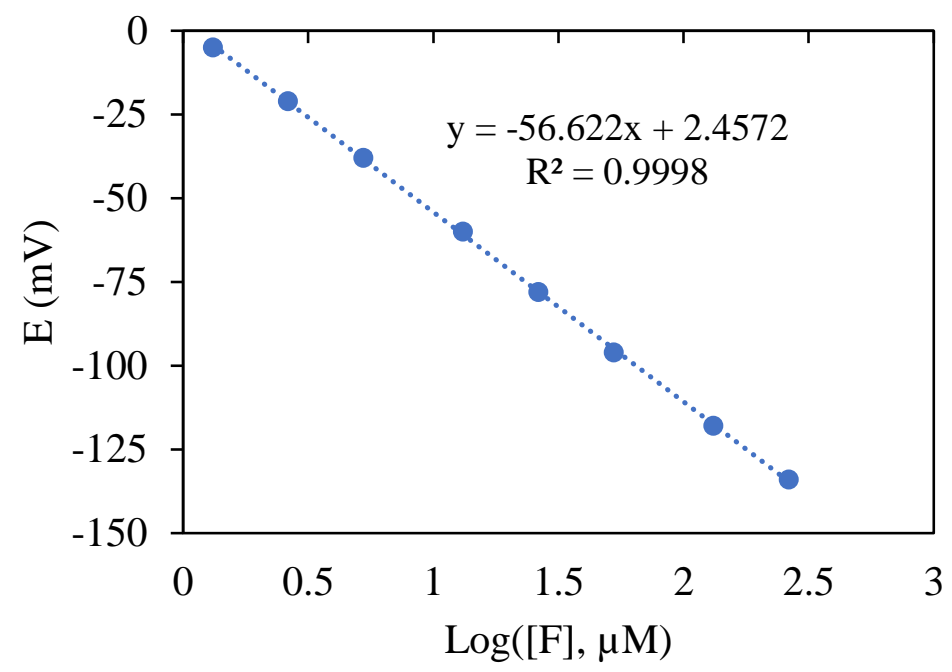

Figure 78. Potentiometric calibration curve for the determination fluoride ion PFAS aqueous solutions treated with ultrasonic irradiation.

\subsubsection{Ion chromatographic analysis of mineralization fluoride ions}

Ion chromatography (IC) was also used to monitor fluoride $\left(\mathrm{F}^{-}\right)$and other smaller molecular ions as a mineralized product of PFAS. A 761 Compact IC Metrohm equipped with a Metrosep A Supp 5 column and conductivity detector was employed using the manufacturer's protocol. A mixture of $3.2 \mathrm{mM}$ sodium carbonate and $1.0 \mathrm{mM}$ sodium hydrogen carbonate aqueous solution was used as a buffer with a flow rate of $0.7 \mathrm{~mL} / \mathrm{min}$. The column was regenerated using a $0.125 \mathrm{M}$ solution of sulfuric acid with a flow rate of $2.0 \mathrm{~mL} / \mathrm{min}$. The detector response was calibrated, and a standardization curve developed using carefully prepared fluoride from 0.03 to $1.0 \mathrm{mM}$ standard solutions yielding correlation coefficients $\geq 0.99$ (Figure 79). 


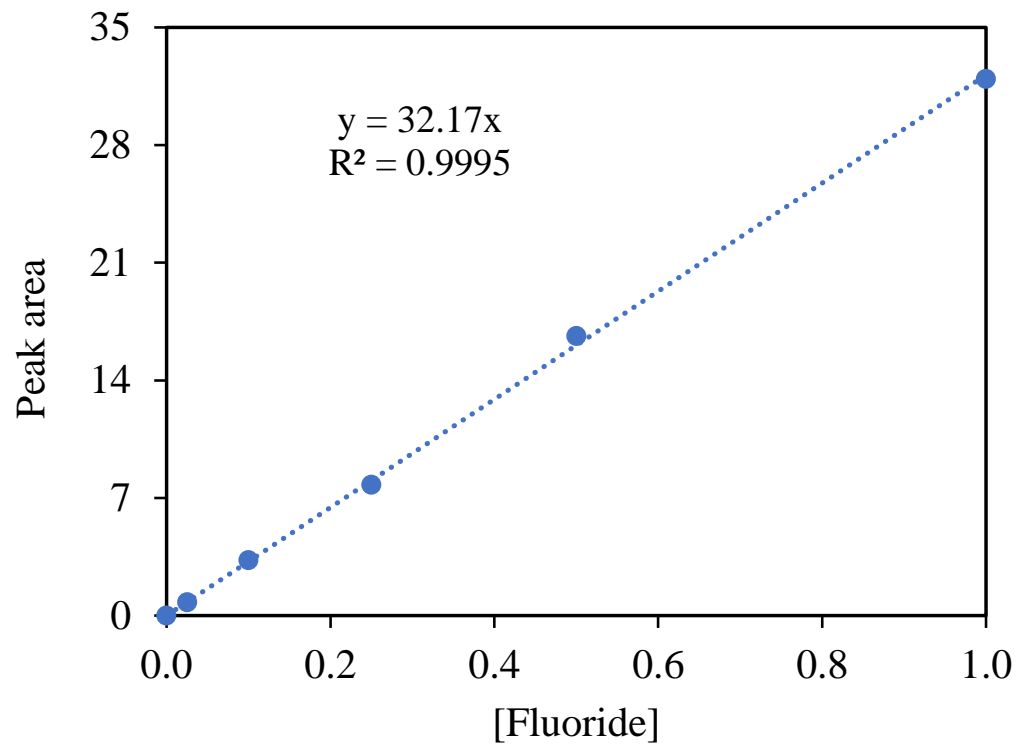

Figure 79. Ion chromatographic calibration curve for the determination of fluoride ions in ultrasonically treated PFAS solutions.

\subsection{Results and discussion}

\subsubsection{Ultrasound induced Degradation of PFAS}

In a typical experiment, the PFAS contaminated aqueous solution was irradiated at $640 \mathrm{kHz}$, and the concentration of PFAS monitored as a function of treatment time. The reaction solution was purged with argon, and a temperature of $7 \pm 1{ }^{\circ} \mathrm{C}$ was maintained throughout the treatment process. Control experiments establish no loss of target PFAS due to evaporation or adsorption to glassware and reaction vessels. Under ultrasonic treatment, specific emerging PFASs, PFBA, PFPA, PFHpA, GenX are effectively degraded, as illustrated in Figure 80. Results showed that more than $50 \%$ of low molecular weight PFASs and GenX are eliminated within nearly one hour of treatment time. While all 
compounds exhibit similar degradation rates, a marked decrease in the degradation rate was observed at extended treatment times. Such trends are common for bimolecular rate processes as the concentration of reactant, PFAS, in this case, decreases the overall observed degradation rate decreases proportionately. In the case of hydroxyl mediated conversions, the rate will decrease markedly during treatment due to a decreasing concentration of target compound as well as competition for hydroxyl radical by the increasing concentration of reaction by-products. Complete degradation of GenX was observed at an extended degradation of 3 hours.

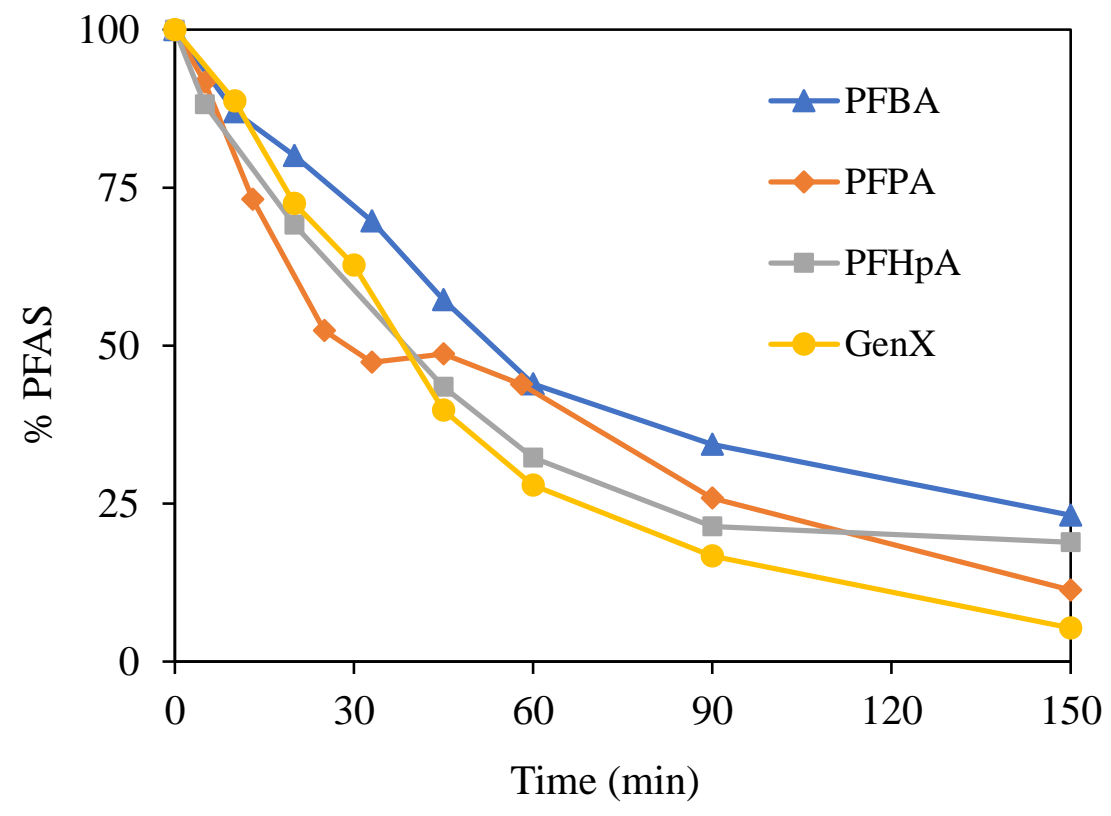

Figure 80. Ultrasonic treatment of emerging PFASs at $640 \mathrm{kHz}$ in argon saturated aqueous solution. $[\mathrm{PFAS}]_{0}=2000 \mathrm{ppb}$ and the reproducibility was within $\pm 10 \%$ on the basis of the representative triplicate run on GenX. 


\subsubsection{Degradation kinetics of GenX}

To probe the degradation process, the initial concentration of Gen $\mathrm{X}$ was varied from 3 to $60 \mu \mathrm{M}$, and the degradation was studied as a function of treatment time. GenX is selected because it has been used as a new generation replacement of PFOA and detected extensively in drinking water sources [27]. The degradation of GenX at different initial concentrations is illustrated in Figure 81. The observed degradation decreases significantly with increasing initial concentration. The initial degradation rates were calculated from the disappearance of the GenX at each initial concentration. Care was taken not to include extended conversion to minimize the potential competitive effects of by-products to the degradation processes. The initial rate of degradation of GenX as a function of initial concentration are summarized in Table $\mathbf{1 6 .}$

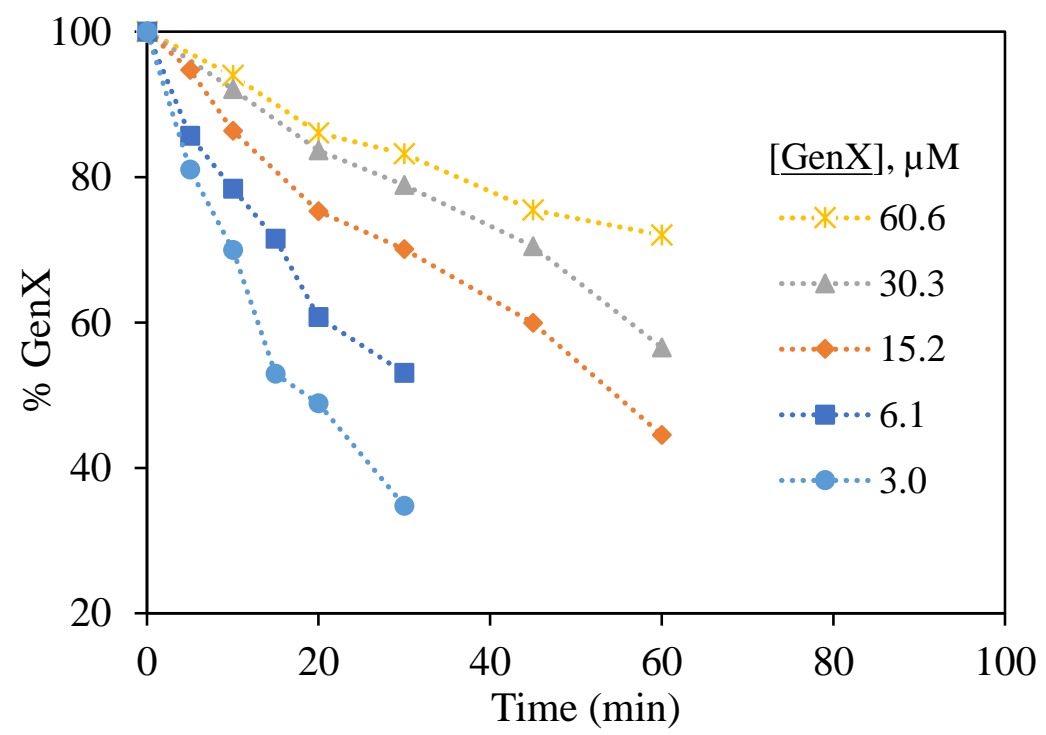

Figure 81. Degradation kinetics of GenX $\left([\mathrm{GenX}]_{0}=3-60 \mu \mathrm{M}\right)$ upon ultrasonic irradiation at $640 \mathrm{kHz}$ in $\mathrm{Ar}$-saturated aqueous solution. 
Table 16. Initial degradation rates of GenX as a function of GenX concentration in argonsaturated solution

\begin{tabular}{ccc}
\hline GenX], $(\mu \mathrm{M})$ & $\begin{array}{c}\text { Initial rate } \\
\left(\mu \mathrm{M} \mathrm{min}^{-1}\right)\end{array}$ & $\begin{array}{c}\mathrm{R}^{2} \text { value for } \\
\text { initial rate }\end{array}$ \\
\hline 3.0 & 0.08 & 0.95 \\
6.1 & $0.11^{*}$ & 0.99 \\
15.2 & 0.14 & 0.97 \\
30.3 & 0.21 & 0.98 \\
60.6 & 0.31 & 0.98 \\
\hline
\end{tabular}

*data were reproducible around $90 \%$ on the basis of representative triplicate runs

The observed rate of degradation decreases with an increase in the initial concentration. Although ultrasonic mediated degradation processes are considered a complex heterogeneous process, numerous examples have shown the ultrasonic mediated degradation of a variety of organic compounds follows pseudo-first-order kinetics at a given initial concentration. Pseudo-first-order kinetics is represented by the equation $\left[\ln C_{t} / C_{0}=-k t\right]$ where $C_{t}$ and $C_{0}$ are the concentrations of GenX at time $t$ and the start of the reaction, and $\mathrm{k}$ refers to the rate constants. A linear relationship between $\ln \left(\mathrm{C}_{\mathrm{t}} / \mathrm{C}_{0}\right)$ and time (t) is consistent with this kinetic model. Plots of pseudo-first-order kinetics for the sonolytic degradation of GenX are presented in Figure 82. The rate constants (k) were calculated from the slope of the linear pseudo-first-order equation, and the results are summarized in the inset of Figure 82. 


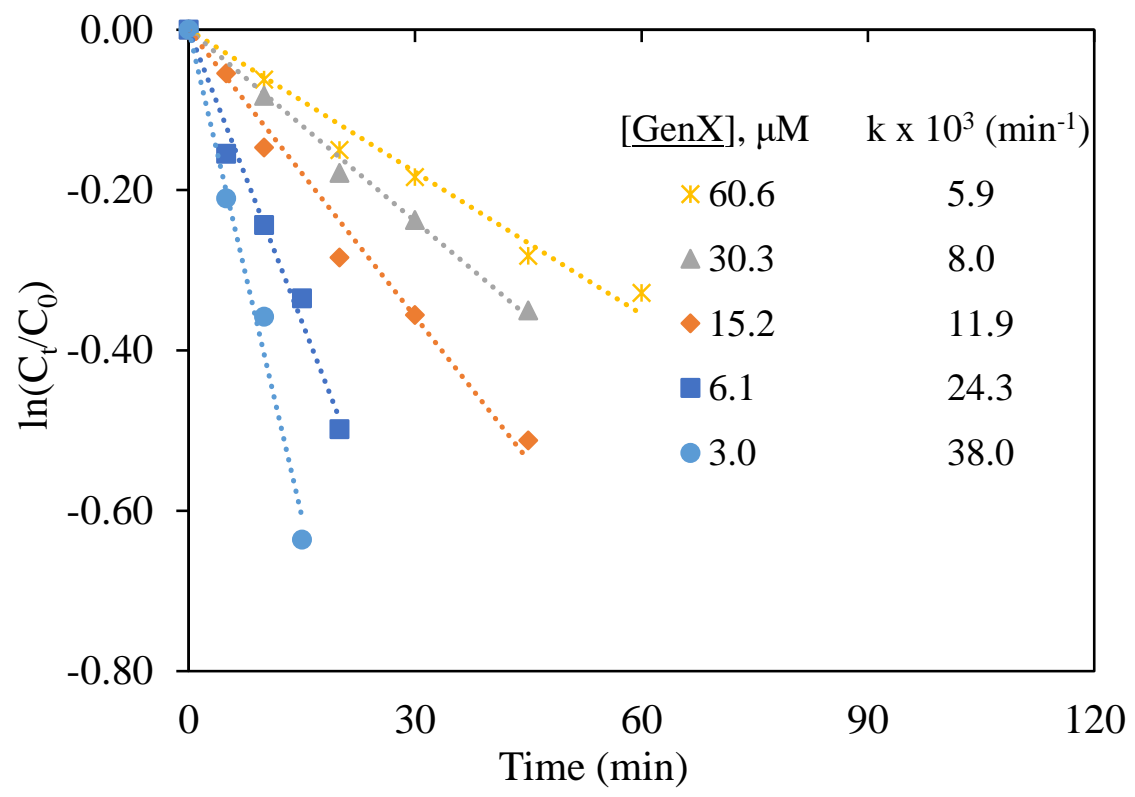

Figure 82. Pseudo-first-order kinetics plots of ultrasonic degradation of GenX over a range of initial concentration of 3-60 $\mu \mathrm{M}$ at $640 \mathrm{kHz}$ in Ar-saturated aqueous solution. Data were reproducible within $\pm 10 \%$.

While the results for a given concentration of GenX are consistent with pseudo-first-order kinetics, the change in the rate constant as a function of initial concentration suggests that the reaction kinetics are more complex than a simple pseudo-first-order reaction. The observed rate constant decreased by approximately 6-fold as the initial concentration of GenX increased by about 20 -fold. For a true pseudo-first-order reaction, the rate constant is independent with initial concentration. However, variation in the reaction rate constant as a function of initial concentration has been previously reported for heterogeneous processes $[173,174]$. This anomaly has been rationalized to mass transfer limitations and saturation effects for the heterogeneous process occurring at the gas-liquid interface. 


\subsubsection{Heterogeneous kinetic modeling for ultrasound-assisted degradation of GenX}

Ultrasonic cavitation is a complex process involving gas, gas-liquid interface, and bulk liquid regions, as shown in Figure 83. Ultrasonic mediated degradation of organic compounds in aqueous media is often correlated to hydroxyl radical-mediated processes. However, degradation mechanisms involving direct pyrolysis of target compounds can also play a key role in the degradation. The extent and mechanism of the degradation pathways are dependent on the partitioning of the target compounds at the gas, gas-liquid interface, and liquid bulk regions during cavitation. GenX is acidic and exists as the negatively charged carboxylate ion under solution $\mathrm{pH}$ above $\mathrm{pH} \sim 3$ (pKa of GenX 2.8). In the ionic state, the vapor pressure is low, and thus, it is less likely that GenX will partition into the gas phase of the hot spot region. The GenX carboxylate anion functional group is polar and most effectively solvated in the bulk solution, while the aliphatic fluorinated chain possesses hydrophobic character. The gas-liquid interface at the cavitation site possesses high temperatures (>2000 K) and high pressures (>300 atm) well above the supercritical points (680 K and $218 \mathrm{~atm})$ of water. Therefore, water exists as a supercritical state which exhibits hydrophobic rather than the normal hydrophilic properties associated with water under ambient conditions. Ultrasonic mediated degradation can be broken into the hot spot region where volatile compounds can partition and undergo high-temperature pyrolysis, at the gas-liquid interfacial area where pyrolysis and hydroxyl radical-mediated transformation of hydrophobic type compounds can occur, and in the bulk solution where hydroxyl radical can diffuse to polar compounds. In the case of legacy and emerging PFAS studied here, the compounds are ionic (non-volatile) possess both hydrophobic and 
hydrophilic character, which can lead to partitioning between the liquid-gas and liquid bulk regions. To probe the partitioning and its effect on the degradation, Langmuir-Hinshelwood (L-H) heterogeneous kinetic model was employed to the degradation process [204]. For the modeling of the cavitation site, the liquid-gas interface is considered the reaction surface where GenX can partition between the interface and bulk solution. The L-H model assumes (1) all sites on the surface (interface) are equivalent (2) each molecule occupies one site and forms a monolayer (uniform partitioning) (3) the adjacent molecules have no interactions (4) the adsorption and desorption process is in equilibrium.

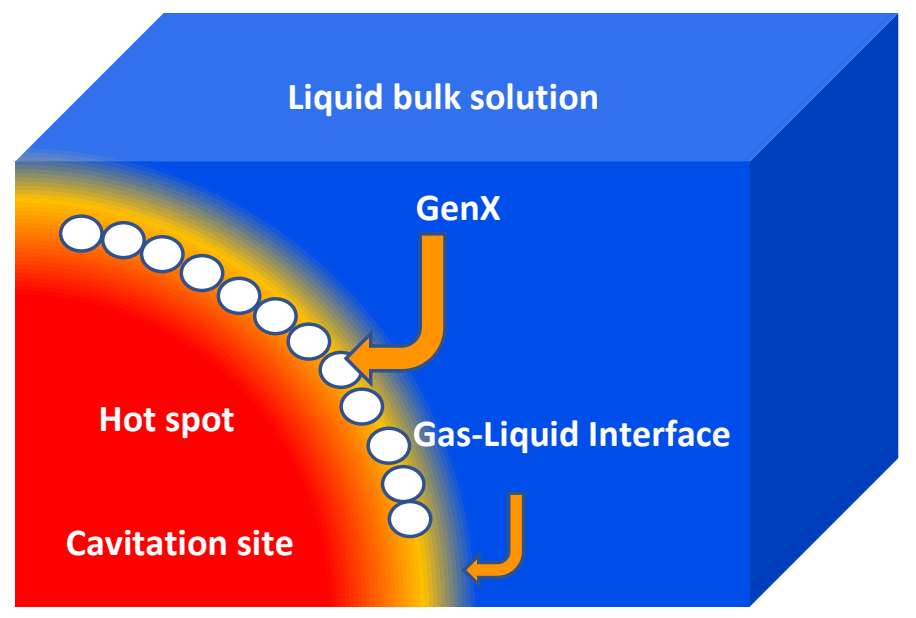

Figure 83. Partitioning of GenX molecules in the hot spot, gas-liquid interface, and bulk liquid phase.

The L-H model is represented in Equation 22, where $\mathrm{r}_{0}$ is the initial degradation rate of target materials, $\mathrm{C}_{0}$ is the initial concentration of substrate, $\mathrm{k}_{\mathrm{r}}$ is the reactivity constant, and $\mathrm{K}_{\mathrm{LH}}$ is the apparent equilibrium constant. The $\mathrm{L}-\mathrm{H}$ experiment was conducted over a range of initial concentrations of $3-60.6 \mu \mathrm{M}$ at uniform reaction conditions. $\mathrm{R}^{2}$ value $(\geq 0.94)$, 
calculated in Figure 84, and suggested that the ultrasonic degradation kinetics of GenX is in good agreement with the L-H mechanism.

$$
\text { Langmuir-Hinshelwood equation: } \quad 1 / \mathrm{r}_{0}=1 / \mathrm{k}_{\mathrm{r}} K_{L H} \mathrm{C}_{0}+1 / \mathrm{k}_{\mathrm{r}}
$$

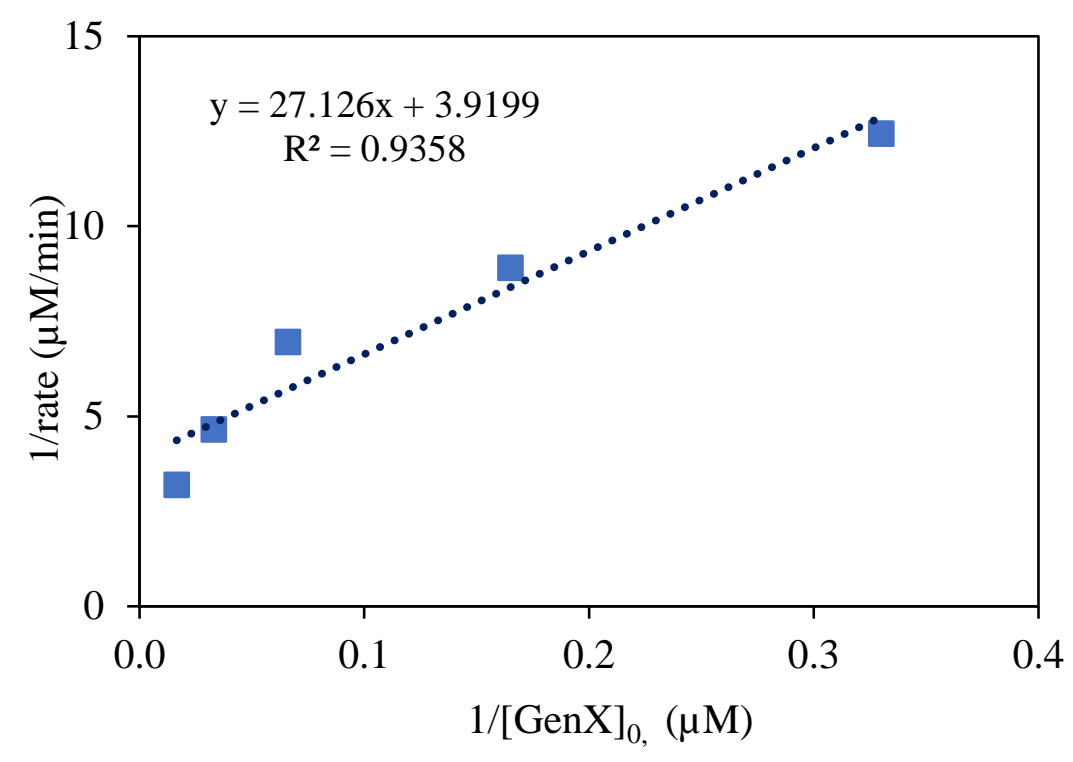

Figure 84. Langmuir-Hinshelwood kinetic plot of the ultrasound-assisted degradation of GenX over a range of initial concentration.

The L-H kinetic parameters determined from the slope and intercept of the L-H plot are $\mathrm{K}_{\mathrm{LH}}=0.14 \mu \mathrm{M}^{-1}$ and $\mathrm{k}_{\mathrm{r}}=0.26 \mu \mathrm{M} \mathrm{min}^{-1}$. Vecitis et al. reported the ultrasonic degradation of PFOA and PFOS over a range of initial concentrations of $20 \mathrm{nM}$ to $200 \mu \mathrm{M}$. Their results suggested that at a low initial concentration $(<20 \mu \mathrm{M})$ PFOA degraded with pseudo-firstorder kinetics and changed to zero-order when concentration is $>40 \mu \mathrm{M}$ due to the saturation of bubble interface sites [205]. 


\subsubsection{Hydroxyl radical competition study}

To assess the roles and partitioning of hydroxyl radicals in the degradation process, a series of competition experiments were conducted through the addition of specific hydroxyl radical scavengers. Hydroxyl radicals can be formed and/or partition among the hot-spot, gas-liquid interface, and bulk liquid regions. For this paper, the hydroxyl radicals residing in the different regions are defined as follows; in the hot spot region $\left(\cdot \mathrm{OH}_{\mathrm{G}}\right)$, within the gas-liquid interface region $\left(\cdot \mathrm{OH}_{\mathrm{G}-\mathrm{L}}\right)$, and in the bulk liquid area $\left(\cdot \mathrm{OH}_{\mathrm{L}}\right)$. Determination of individual contribution of $\bullet \mathrm{OH}$ is crucial for assessing the degradation processes and pathways. Selective quenching of hydroxyl radicals from each region will help understand its role in the degradation and reveal the role of pyrolysis in the degradation process under conditions of complete $\bullet \mathrm{OH}$ quenching. To quench the $\bullet \mathrm{OH}_{\mathrm{L}}$, terephthalic acid (TA), which exists in the ionized form (as non-volatile dianion), will have a strong preference to reside in the bulk solution and not at hydrophobic G-L interface or in the hot-spot. Thus, the addition of TA during treatment will quench the $\bullet \mathrm{OH}_{\mathrm{L}}$ reaction pathways. The hydroxyl radical quencher, coumarin (COU), a neutral organic compound, will reside predominantly within the gas-liquid interface and quench $\bullet \mathrm{OH}_{\mathrm{G}-\mathrm{L}}$. t-Butanol partition to all the regions and can scavenge the hydroxyl radical in the gas, interface, and bulk solution $\left(\cdot \mathrm{OH}_{\mathrm{G}}, \cdot \mathrm{OH} \mathrm{G}_{\mathrm{L}}\right.$, and $\bullet \mathrm{OH}_{\mathrm{L}}$ ). The rate constant of ultrasonic induced degradation of GenX in the presence of the individual hydroxyl radical scavengers is summarized in Table 17. In the absence of hydroxyl radical scavengers, the rate constant for ultrasonically induced degradation of GenX is $0.025 \mathrm{~min}^{-1}$. The degradation of GenX in the presence of excess $\bullet O H$ scavengers is unchanged. The result provides convincing evidence that hydroxyl radical plays an 
insignificant role in the ultrasonically induced degradation of PFASs and that direct pyrolysis is the predominant degradation mechanism.

Table 17. Pseudo-first-order rate constant (k) of the sonolytic degradation of GenX in the presence of hydroxyl radical scavengers

\begin{tabular}{|c|c|c|c|c|}
\hline $\begin{array}{c}\text { Scavenger } \\
\text { name }\end{array}$ & $\begin{array}{c}\text { Scavenged } \\
\cdot \mathrm{OH}\end{array}$ & $\begin{array}{c}\text { [Scavenger] } \\
\mu \mathrm{M} \times 10^{2}\end{array}$ & $\begin{array}{c}\text { [GenX], } \\
\mu \mathrm{M}\end{array}$ & $\begin{array}{c}\mathrm{k} \\
\left(\min ^{-1}\right)\end{array}$ \\
\hline No scavenger & - & 0 & 6.1 & 0.025 \\
\hline Terephthalic acid & $\cdot \mathrm{OH}_{\mathrm{L}}$ & 2.0 & 6.7 & 0.024 \\
\hline Coumarin & $\cdot \mathrm{OH}_{\mathrm{G}}$, and $\cdot \mathrm{OH}_{\mathrm{G}-\mathrm{L}}$ & 2.0 & 5.9 & 0.025 \\
\hline t-Butanol & $\cdot \mathrm{OH}_{\mathrm{G}}, \cdot \mathrm{OH}_{\mathrm{G}-\mathrm{L}}$, and $\bullet \mathrm{OH}_{\mathrm{L}}$ & 2.0 & 5.6 & 0.023 \\
\hline
\end{tabular}

Therefore, the rate constant $0.025 \mathrm{~min}^{-1}$ observed for the degradation of GenX in the presence of coumarin indicates hydroxyl radical portioned in the interface was unlikely to participate in the degradation process. Terephthalic acid is an ionic compound and more likely to scavenge the hydroxyl radical partitioned in bulk solution. Since the GenX degraded in ultrasound in presence of terephthalic acid with a rate constant $0.024 \mathrm{~min}^{-1}$, it could be concluded that hydroxyl radical partitioned in bulk solution has a small role in the degradation of GenX. From the competitional studies, it is found that reactive species are less likely to participate in the degradation process. So, direct pyrolysis is likely the primary process for the degradation of GenX. 


\subsubsection{Mineralization of PFASs to fluorides}

In general, oxidative, reductive, and photochemical treatment processes include the formation of potentially toxic reaction by-product mixtures. Although mineralization is ideal for the remediation of toxic compounds, it is rarely practical. Recent reports have shown the reductive conversion of PFAS to fluoride ion, a highly attractive process $[199,200]$. Our results indicate the ultrasonically mediated degradation of PFAS is primarily the result of pyrolysis, leading to the formation of fluoride ion. PFAS employed in our study were subjected to ultrasonic treatment, and the production of fluoride ion monitored as a function of treatment time, as illustrated in Figure 85. The percentile conversion of PFAS to fluoride ion was calculated using Equation 23 and summarized in

\section{Table 18.}

$$
\% \text { recovery of } \mathrm{F}^{-}=\left[\text {Mineralization to } \mathrm{F}^{-}\right] * 100 /\left[\text { Theoretical yield of } \mathrm{F}^{-}\right]
$$

The recovery of fluoride ion ranges from 15 to $80 \%$ under extended ultrasonic treatment. The rate of fluoride production is fastest initially and decreases with treatment time. Among the PFASs with carboxylate functionality, the higher molecular weight PFASs are more readily degraded than the lower molecular weight PFASs. The emerging GenX is more likely to degrade over the legacy PFOA. The highest percentile recovery of fluoride ion is observed for perfluoroheptanoic acid PFHpA, and the slowest is for trifluoroacetic acid. The higher rates of degradation observed for higher molecular and more hydrophobic PFASs may be due to the greater partition of the alkyl chain at the hydrophobic gas-liquid interface. TFA is ionic, shorter alkyl chain, and its charge density are much higher than its corresponding homolog, and thus, it is more likely to partition in bulk solution than the 
interface. Consequently, only $15 \%$ of degradation was observed for three hours of treatment time.

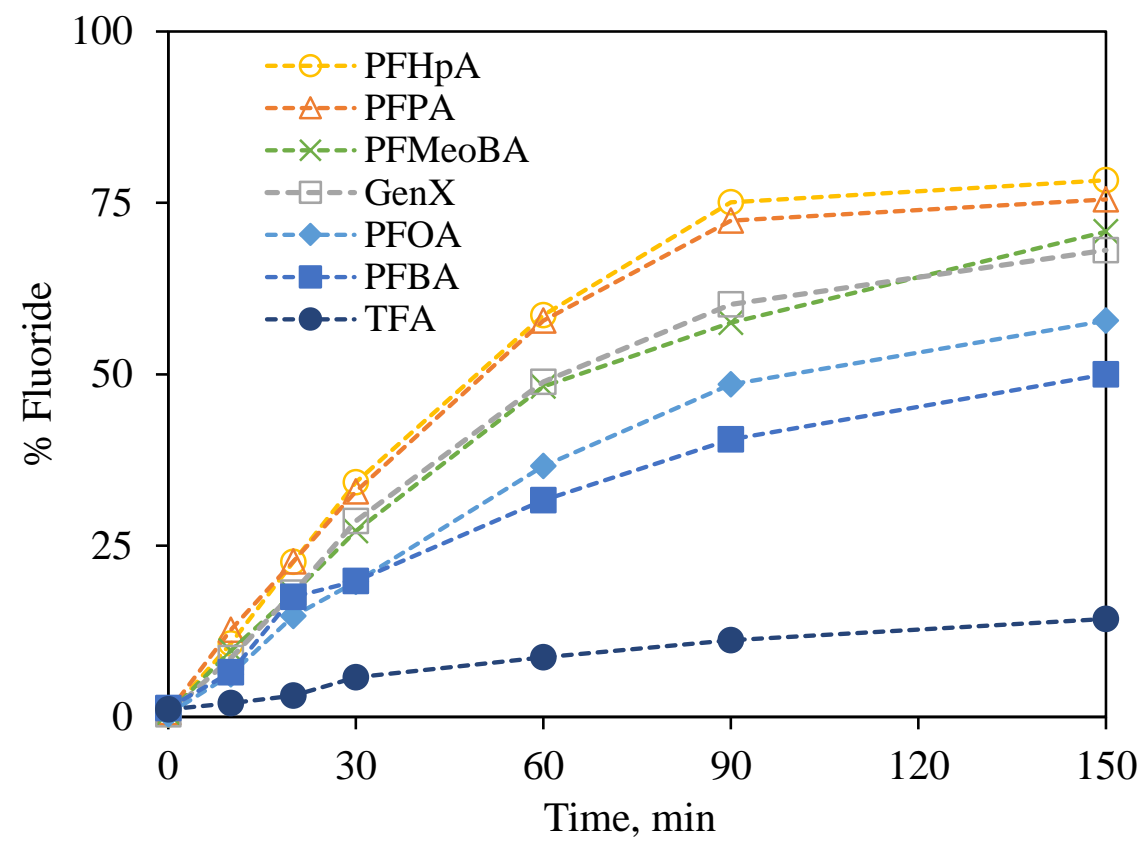

Figure 85. Evolution of fluoride ions upon ultrasonic treatment of a variety of emerging PFASs $\left([\mathrm{PFAS}]_{0}=2000 \mathrm{ppb}\right)$ at $640 \mathrm{kHz}$ in Ar-saturated aqueous solution.

The production of fluoride ions and degradation of GenX were simultaneously measured to assess the presence of intermediates and the extent of defluorination (Figure 86). Upon extended treatment time, $80 \%$ of GenX is converted to fluoride ion. The remaining $20 \%$ of fluorine atoms are likely associated with low molecular weight/volatile products, following previous reports of the ultrasonic conversion of PFOA to fluoride ions [78]. 
Table 18. Defluorination of select PFASs upon ultrasonic treatment

\begin{tabular}{|c|c|c|c|c|}
\hline $\begin{array}{l}\text { PFAS } \\
\text { name }\end{array}$ & PFAS structure & $\begin{array}{c}{[\mathrm{PFAS}]} \\
(\mu \mathrm{M})\end{array}$ & $\begin{array}{l}\text { Defluorination } \\
\text { yield }\left[\mathrm{F}^{-}\right](\mu \mathrm{M})\end{array}$ & $\begin{array}{l}\%[\mathrm{~F}] \\
\text { recovery }\end{array}$ \\
\hline TFA & $\mathrm{F}_{3} \mathrm{C}_{-\mathrm{COOH}}$ & 8.8 & 26 & 15 \\
\hline PFBA & $\mathrm{F}_{3} \mathrm{C}_{-\mathrm{C}^{\prime}} \mathrm{C}_{2}$ & 9.3 & 65 & 50 \\
\hline PFPA & & 7.6 & 68 & 76 \\
\hline PFHpA & & 5.5 & 71 & 78 \\
\hline PFOA & & 4.8 & 73 & 58 \\
\hline PFMeoBA & & 7.1 & 64 & 72 \\
\hline GenX & $\mathrm{F}_{3} \mathrm{C}^{-\mathrm{C}}$ & 6.1 & 68 & 70 \\
\hline
\end{tabular}

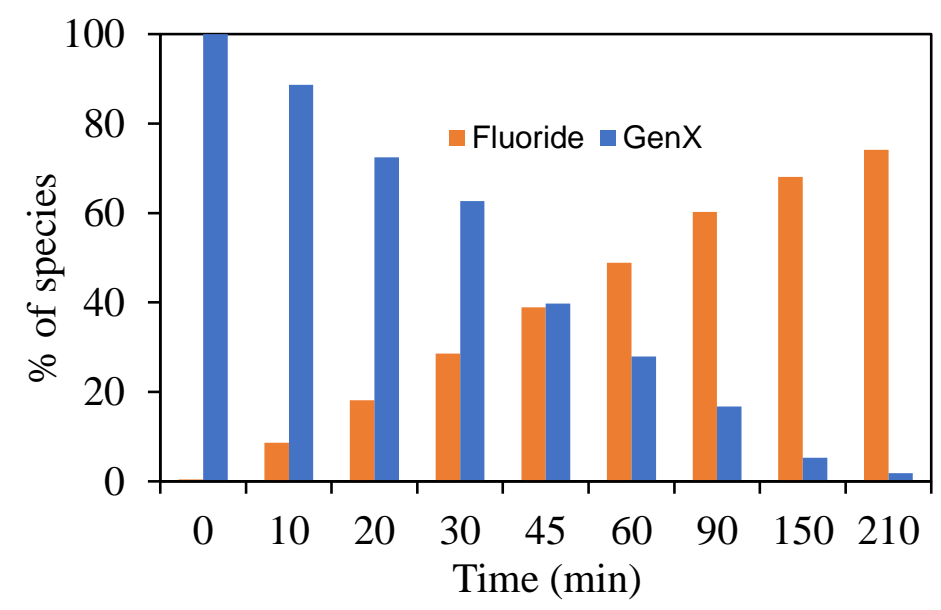

Figure 86. Ultrasonic degradation of GenX $\left([\mathrm{GenX}]_{0}=6.1 \mu \mathrm{M}\right)$ and evolution of fluoride at $640 \mathrm{kHz}$ in Ar-saturated aqueous solution. 
To identify the role of hydroxyl radical and pyrolysis on the generation of fluoride ions, the formation rate of fluoride ions was monitored in the presence of scavengers, including terephthalic acid, coumarin, and t-butanol. The bar diagram illustrated in Figure 87 shows the effect of scavengers on the production of fluoride ions.

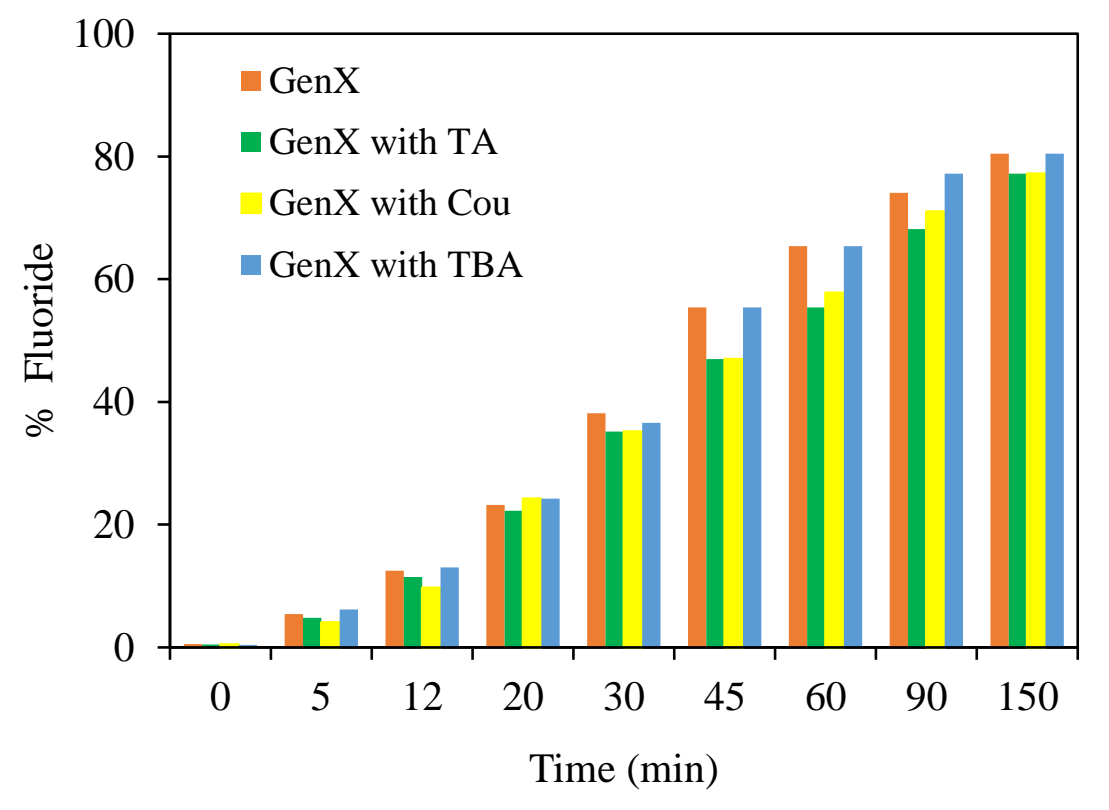

Figure 87. Evolution of fluoride ions in sonolytic degradation of GenX in the presence of $\cdot \mathrm{OH}$ scavengers.

Recovery of fluoride ions in the presence of TA, COU, and TBA was nearly constant around $75 \%$ at extended treatment time, meaning that hydroxyl radical-mediated oxidation does not play a significant role on fluoride production and pyrolysis is the main contributor to sonolytic degradation of GenX and the output of fluorides ions. 


\subsubsection{Intermediate products during the ultrasonic degradation of GenX}

The fluoride mass balance for GenX illustrated in Figure 86 demonstrates the incomplete conversion of PFAS to fluoride ions. This observation implies the production of other fluorine-containing intermediates (volatile/nonvolatile) during the sonolytic treatment. Ultrasonic treatment is a complex process involving reactive species and pyrolytic reaction pathways. Due to the variety and a number of possible degradation pathways, complex product mixtures are often produced during ultrasonic treatment. Although our $\bullet \mathrm{OH}$ scavenging experiments described earlier indicate pyrolysis is the predominated pathways for ultrasonic degradation of PFASs, the pyrolysis induced degradation will involve a number of competing for degradation pathways. The likely products are shorter chain compounds with carboxylates functionality in ionized forms under our conditions. With this in mind, initial ion chromatographic product studies were conducted and exhibited several well-resolved peaks indicative of degradation products/ions. Fluoride and formate ions were assigned in ion chromatography by comparing their retention time with standard fluoride and formate ions. The time profile ion chromatographic estimation of fluoride and formate ions is given in Figure 88. Moriwaki et al. reported sequential dissociation of $\mathrm{COO}^{-}$group leading to a number of shorter chain PFCAs, including $\mathrm{C} 2-\mathrm{C} 7$ perfluorocarboxylate such as $\mathrm{CF}_{3} \mathrm{COO}^{-}, \mathrm{C}_{2} \mathrm{~F}_{5} \mathrm{COO}^{-}$, $\mathrm{C}_{3} \mathrm{~F}_{7} \mathrm{COO}^{-}, \mathrm{C}_{4} \mathrm{~F}_{9} \mathrm{COO}^{-}, \mathrm{C}_{5} \mathrm{~F}_{11} \mathrm{COO}^{-}$, and $\mathrm{C}_{6} \mathrm{~F}_{13} \mathrm{COO}^{-}$, during the ultrasonic treatment of PFOA and PFOS [79]. However, Vecitis et al. did not report shorter chain perfluorocarboxylates during ultrasonic treatment of PFOA and PFOS; instead, they reported a wide variety of volatile intermediates including $1 \mathrm{H}-$ fluoroalkane or perfluoro- 
olefins yielding $\mathrm{C} 1$ fluororadicals en route to mineralization to $\mathrm{CO}, \mathrm{CO}_{2}$ and fluoride ions [202]. A recent study reported by Bao et al. showed UV/sulfite treatment of GenX also yielded shorter perfluorocarboxylates such as TFA and PFA by reductive defluorination [200].

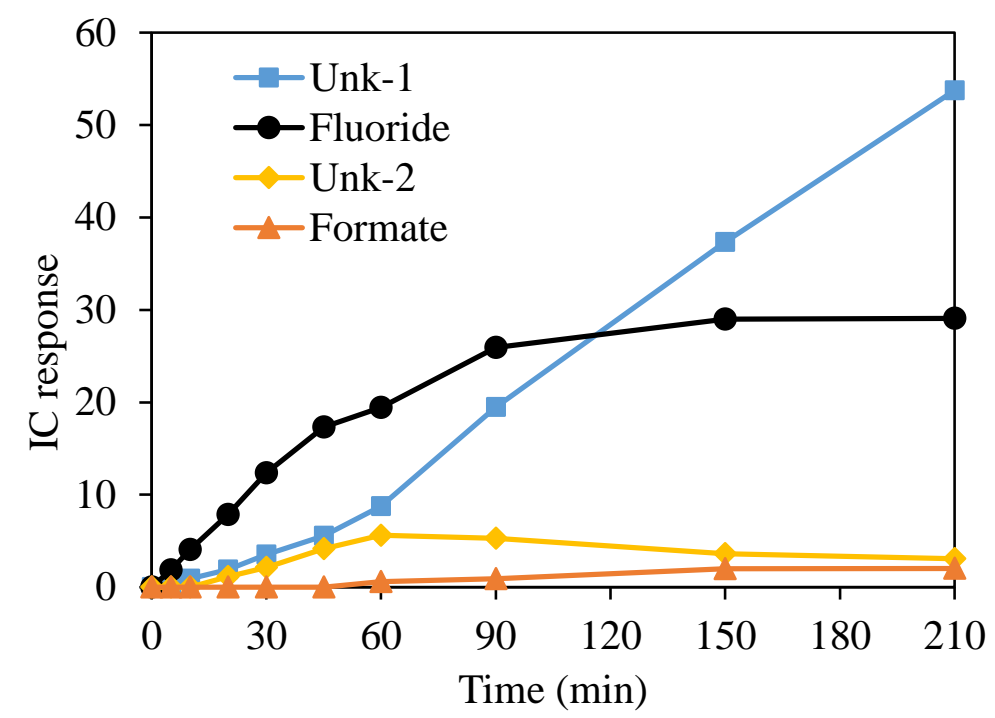

Figure 88. Ion chromatographic analysis of small molecular ions during the ultrasonic treatment of GenX $\left([\mathrm{GenX}]_{0}=60.6 \mu \mathrm{M}\right)$ at $640 \mathrm{kHz}$ in Ar-saturated aqueous solution.

For a detailed identification of degradation products in ultrasonically treated GenX solution, LC-Orbitrap-HRMS was used with negative electrospray ionization mode. Screening of unknown products was carried out by Compound Discoverer software. LCMS raw data represents the exact mass of the deprotonated values, $\mathrm{m} / \mathrm{z}=\mathrm{M}-1$ values; therefore, for this manuscript, we will refer the exact mass instead of molecular weight. The time profile of the UHPLC-Orbitrap-HRMS chromatogram of treated GenX solution is given in Figure 89. Among the observed products are two resolved peaks with an identified molecular weight of 325.9837 at retention time $1.87 \mathrm{~min}$ and molecular weight 
of 311.9844 at 4.82 retention time. Products with MW of 311.9844 corresponds to $2 \mathrm{H}-2-$ perfluoropropoxypropanoic acid, and MW of 325.9837 indicated 2,3-dihydroxyperfluoropropanoic acid. No shorter chain perfluorocarboxylates, including TFA, was not identified in our study. The time profile evolution of two intermediates, given in Figure 90, implies that intermediate with molecular weight 311.9844 reaches its maximum concentration at one hour of treatment time.

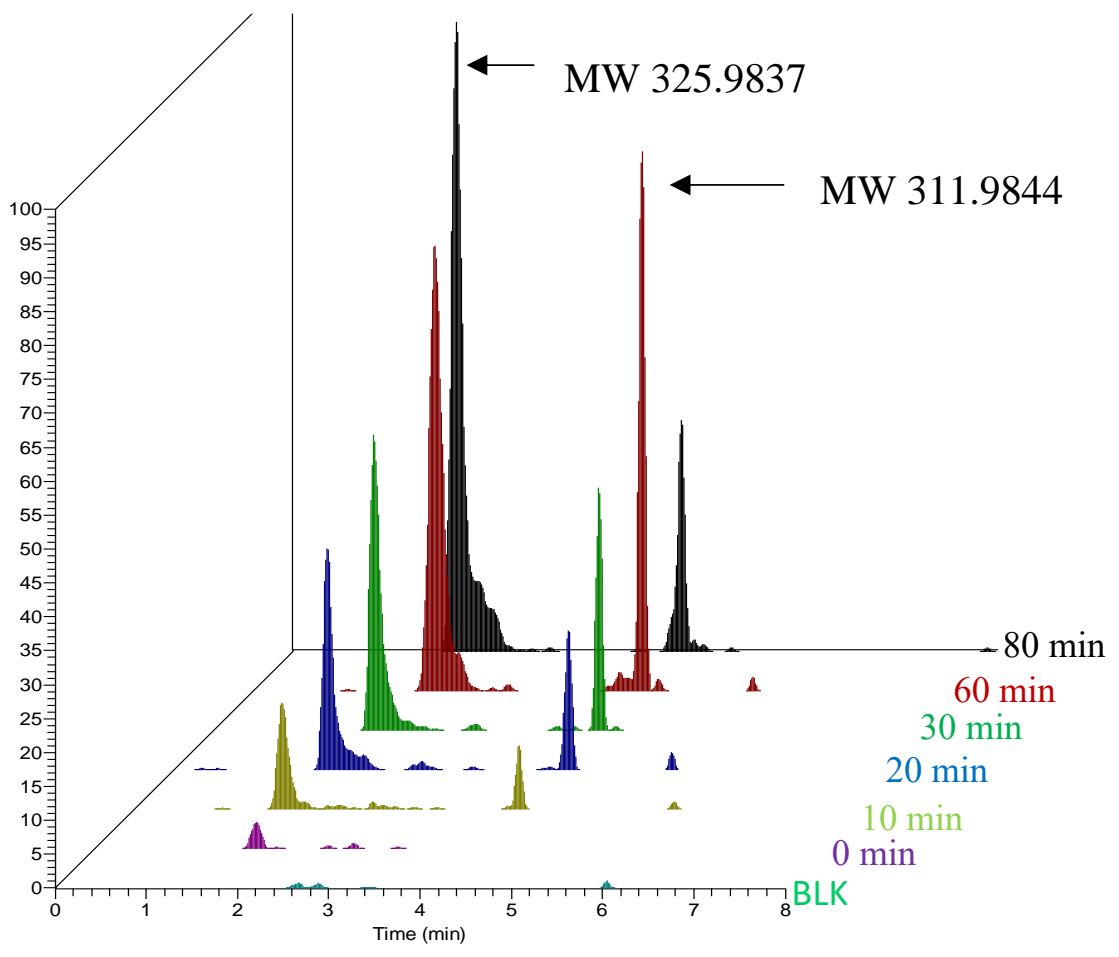

Figure 89. UHPLC-Orbitrap-HRMS chromatogram of the identified ultrasonic degradation products of GenX $\left([\mathrm{GenX}]_{0}=60.6 \mu \mathrm{M}\right)$ over treatment time. 


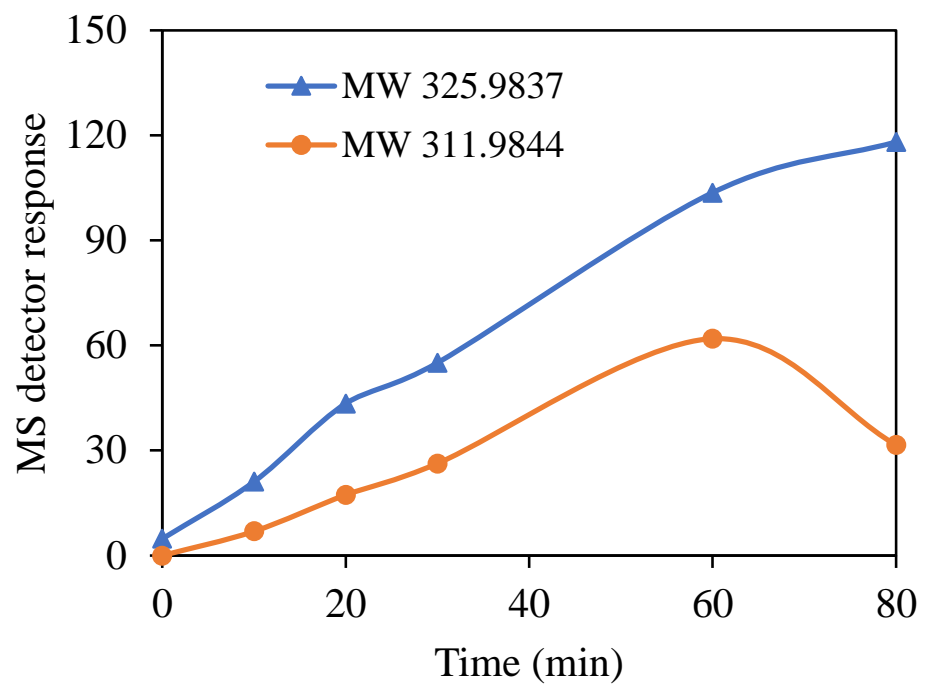

Figure 90. Time profile relative abundance of intermediate products during ultrasonic treatment of $\mathrm{GenX}\left([\mathrm{GenX}]_{0}=60.6 \mu \mathrm{M}\right)$ at $640 \mathrm{kHz}$ in Ar-saturated aqueous solution.

\subsubsection{The mechanistic study on the degradation of GenX}

A sequential dissociation of $\mathrm{COO}^{-}$from $\mathrm{PFOA}$ molecule was proposed by Moriwaki et al. on the basis of the detection of shorter-chain perfluoroalkyl acids during ultrasonic treatment [79]. However, their study did not detect any shorter chain perfluoroalkyl carboxylic acid at the experimental conditions. The direct pyrolytic reaction occurs in the high-temperature gas phase (hot spot) and G-L interface [59]. Because of the ionic nature of GenX at experimental condition, the direct partition of GenX into the hot spot is unlikely, even though these compounds may reside primarily in the G-L interface because of their hydrophobic tail and a hydrophilic head. Vecitis et al. proposed the degradation of PFOA and PFOS is initiated by the interfacial pyrolytic reaction followed by immediate mineralization involving both gas phase and bulk solution [202]. The initial pyrolytic degradation occurred at the G-L interface forms a variety of fluorochemical 
intermediates through a homolytic cleavage of polar head group and alkyl moiety. The neutral fluorochemical intermediates rapidly partition to the high-temperature gas-phase leading to the fluoro-radicals that eventually converted to $\mathrm{CO}, \mathrm{CO}_{2}$, and fluoride ions upon hydrolysis in water. The hydroxyl radical scavenger competitional study provides some insights into the mechanism of GenX degradation. Of particular interest is the almost no hydroxyl radical scavenger has any significant impact on the degradation of GenX, indicative of pyrolytic reaction could be at the interface and vapor phase. The experiments over a wide range of concentrations of GenX show pyrolytic reaction is G-L interfacial phenomenon. Computational studies performed to understand the initiation of pyrolytic cleavage indicates that e (C-F) bond in GenX, shown in Figure 91, is the least energy C-F bond. Therefore, the most likely homolytic cleavage of C-F occurs at e (C-F) bond during $\beta$ pyrolysis.

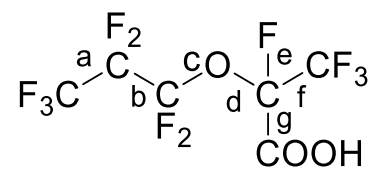

Figure 91. Molecular structure of GenX

Given the high-temperature condition available together with the addition of hydrogen atoms, a reductive defluorination mechanism will be a likely pathway to yield 2H-2-perfluoropropoxypropanoic acid, shown in Figure 92. In the reductive defluorination mechanism, reactive hydrogen atom attacks the carbon-centered free radical and leads to the formation of 2H-2-perfluoropropoxypropanoic acid. A likely secondary transformation called oxidative defluorination might proceed by the addition of hydroxyl radical to $2 \mathrm{H}-2$ - 
perfluoropropoxypropanoic acid that ultimately leads to the hydroxylated product 2,3dihydroxy-perfluoropropanoic acid, shown in Figure 93.

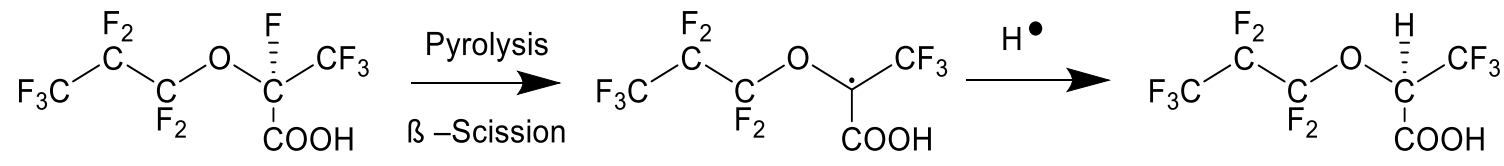

MW 311. 9844

Figure 92. Reductive defluorination mechanism of GenX.

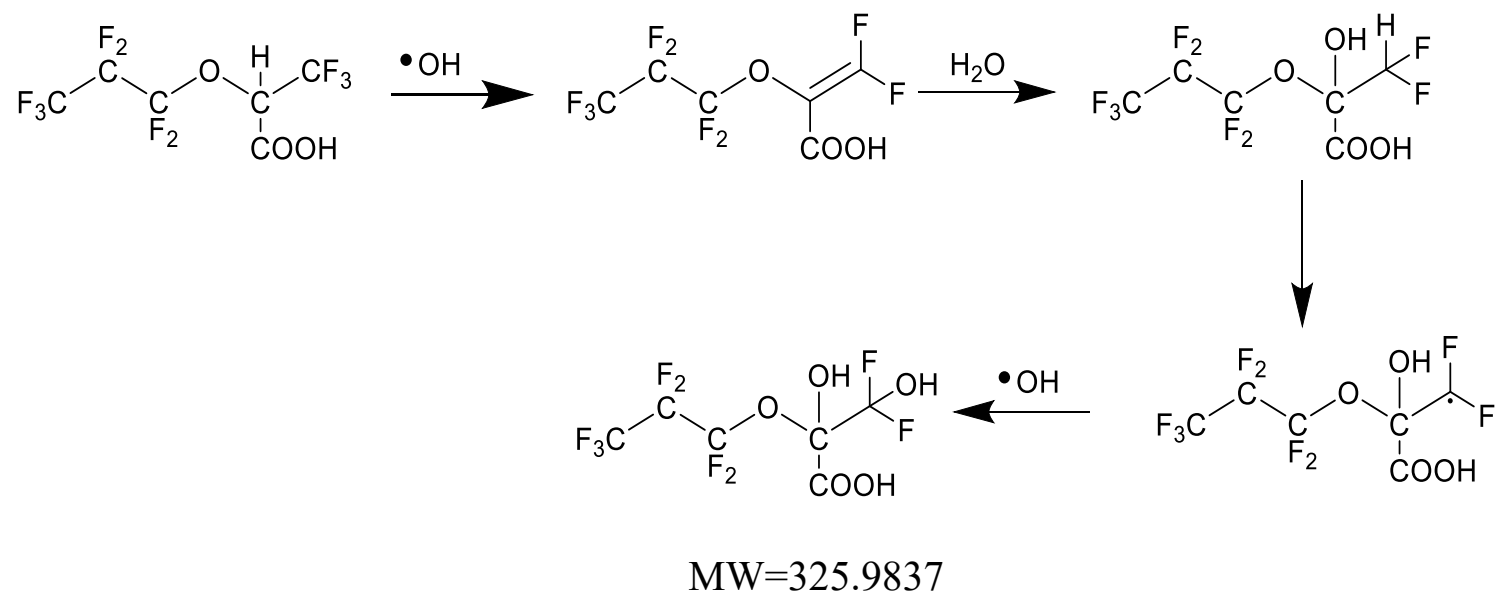

Figure 93. A secondary transformation via oxidative defluorination of GenX products.

The rapid mineralization of GenX can be explained by the initial interfacial pyrolysis reaction [202]. Pyrolysis occurred at the interface may lead to the formation of a number of neutral molecules along with production fluoro-radicals, shown in Figure 94. These neutral intermediates may rapidly partition again to the hot spot and interface and lead directly to mineralization into fluoride in the presence of water, shown in Figure95. 


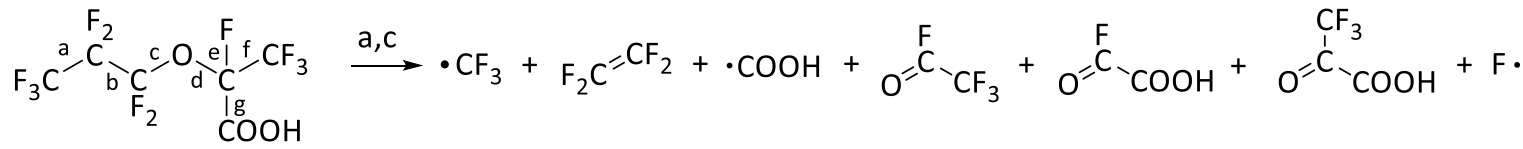

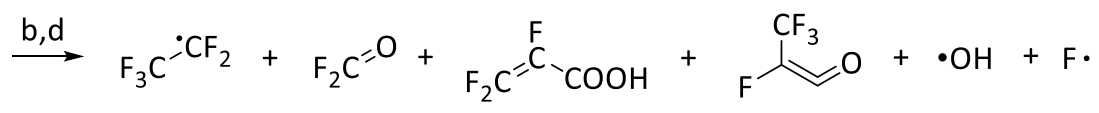

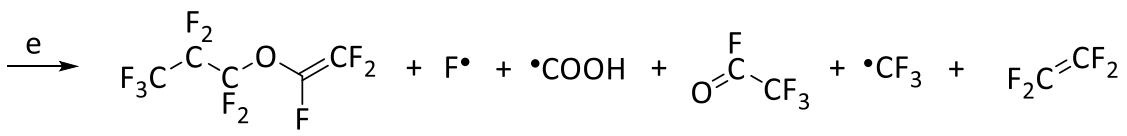

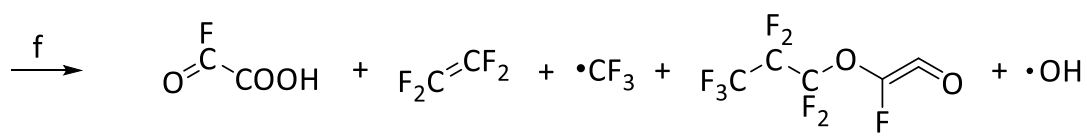

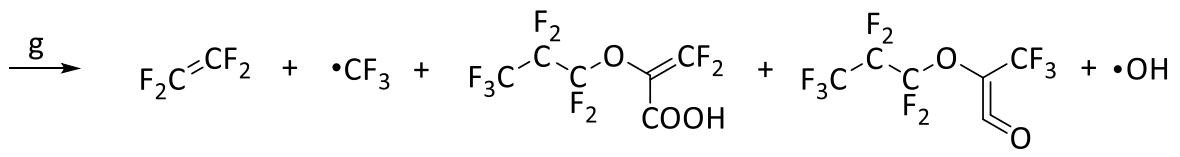

Figure 94. $\beta$-pyrolysis mechanism of GenX.

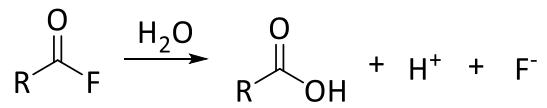

$$
\begin{aligned}
& \mathrm{F}_{3} \mathrm{C} \stackrel{\mathrm{O}}{\stackrel{\mathrm{H}_{2} \mathrm{O}}{\longrightarrow}} \mathrm{F}_{3} \mathrm{C} \stackrel{\stackrel{\mathrm{O}}{\mathrm{N}}}{\mathrm{OH}}+\mathrm{F}^{-} \\
& \mathrm{F}_{\mathrm{F}}^{\stackrel{\mathrm{O}}{\mathrm{H}_{2} \mathrm{O}}} \underset{\mathrm{HO}}{\stackrel{\mathrm{O}}{\mathrm{N}}} \mathrm{OH}+2 \mathrm{~F}^{-} \\
& \mathrm{HOOC}_{\mathrm{F}}^{\stackrel{\mathrm{O}}{\mathrm{H}_{2} \mathrm{O}} \longrightarrow \mathrm{HO}_{\mathrm{O}}^{\mathrm{H}}} \stackrel{\mathrm{OH}}{\longrightarrow}+\mathrm{F}^{-}
\end{aligned}
$$

Figure 95. Hydrolysis of acetyl chloride to the formation of fluoride ions. 


\subsection{Conclusions}

We have shown that PFAS compounds are readily degraded upon ultrasound irradiation at an Ar-saturated aqueous solution. On the basis of defluorination experiments, nearly $75 \%$ mineralization to fluoride was observed for GenX, PFMeoBA, PFPA, and PFHpA, while PFBA and TFA mineralized to fluoride only to 50 and $15 \%$. The detailed kinetic studies of GenX revealed that the degradation follows pseudo-first-order kinetics with varying rate constant depending on the initial concentration. The rate constant for the degradation decreases with increasing initial GenX concentration indicating the process may be controlled by the interface between gas-liquid. Hydroxyl radical scavengers showed no significant effect on the rate of PFAS GenX degradation, indicating the likely degradation proceeds through pyrolysis and not oxidation. The hydroxylated adducts of GenX are the primary degradation products identified by LC-HRMS. Ultrasound is a promising technique to mineralize a number of emerging perfluoroalkyl substances. Our findings will provide an insight for designing future water treatment design for the remediation of organic pollutants. 


\section{CHAPTER 7 GENERAL CONCLUSIONS}


Organophosphorus esters (OPEs), used as flame-retardants in furniture, plastics, automobiles, electronic equipment, and cable, have caused widespread contamination of drinking water sources. These compounds are often highly toxic, potential carcinogens, and can exhibit acute to chronic neurological disorders. Perfluorinated alkyl substances (PFASs) are another class of problematic water pollutant. These anthropogenic chemicals are incredibly persistent, highly toxic, and difficult to remove from water, too. Therefore, the detection of both kind of persistent organic pollutants in drinking water sources pose a serious threat to the environment and human health. Since current water purification methods do not effectively remove these pollutants, identification of a safe, sustainable and effective treatment process, therefore, is very critical for the safe drinking water providers. The focus of this dissertation is to explore fundamental understandings on advanced oxidation processes (AOPs), specifically $\mathrm{TiO}_{2}$ photocatalysis and sonolysis to degrade a number of targeted highly toxic organophosphate esters (OPEs) and forever chemicals perfluoroalkyl substances (PFASs) in water. We demonstrated that $\mathrm{TiO}_{2}$ photocatalysis can mineralize tris (2-chloroethyl) phosphate (TCEP), a model OPE, into innocuous materials. One of the major drawbacks of $\mathrm{TiO}_{2}$ photocatalysis is the costly UV radiation required for $\mathrm{TiO}_{2}$ activation. We synthesized visible light-activated (VLA) $\mathrm{TiO}_{2}$ photocatalyst and showed that visible and solar light activation can yield hydroxyl radicals, keys to the remediation of organic toxins. VLA photocatalysts have a major economic advantage for industrial applications. Naled is a highly toxic OPE pesticide that was extensively sprayed aerially for controlling mosquitos harboring the Zika virus without assessing their environmental fate. We first demonstrated that by-products of Naled persist in the water longer than initially reported, and then we showed their enhanced degradation by ultrasonic 
irradiation. Finally, we, for the first time, demonstrated the effective mineralization of emerging PFASs. Their devastating health effects has led to a number of massive case action lawsuits. We revealed the thermal processes associated with sonolysis can completely degrade these compounds. Our findings, hopefully, will provide an insight into designing future water treatment processes for the remediation of organic pollutants. 


\section{REFERENCES}

[1] UNESCO-WWAP, The United Nations World Development Report 2019. Leaving no one behind. Executive Summary, 2019. doi:.1037//0033-2909.I26.1.78.

[2] H. Dormido, These countries are the most at risk from a water crisis, Bloomberg. (2019). https://www.bloomberg.com/graphics/2019-countries-facing-water-crisis/ (accessed September 23, 2019).

[3] UNICEF, Children dying daily because of unsafe water supplies and poor sanitation and hygiene, 2013. https://www.unicef.org/media/media_68359.html (accessed September 23, 2019).

[4] G. De Gooijer, W. Rast, H. Tropp, V. Aimard, G. Allaerts, M. Black, R. Boelens, S. Burchi, H. Engel, J. Harlin, M. Hellmuth, S. Hendry, A. Hudson, A. Jägerskog, H. Larsen, P. Moriarty, E. van Beek, P. van der Zaag, J. Winpenny, H. Tropp, G. de Gooijer, The United Nations World Water Development Report, UNESCO, 2012. doi:10.4324/9781849773355.

[5] R. Andreozzi, V. Caprio, A. Insola, R. Marotta, Advanced oxidation processes (AOP) for water purification and recovery, Catal. Today. 53 (1999) 51-59. doi:10.1016/S0920-5861(99)00102-9.

[6] K.E. O'Shea, D.D. Dionysiou, Advanced oxidation processes for water treatment, J. Phys. Chem. Lett. 3 (2012) 2112-2113. doi:10.1021/jz300929x.

[7] S.D. Richardson, T.A. Ternes, Water analysis: Emerging contaminants and current Issues, Anal. Chem. 90 (2018) 398-428. doi:10.1021/acs.analchem.7b04577.

[8] Y.C. Yang, J.A. Baker, J.R. Ward, Decontamination of chemical warfare agents, Chem. Rev. 92 (1992) 1729-1743. doi:10.1021/cr00016a003.

[9] I. van der Veen, J. de Boer, Phosphorus flame retardants: properties, production, environmental occurrence, toxicity and analysis, Chemosphere. 88 (2012) 11191153. doi:10.1016/j.chemosphere.2012.03.067.

[10] G.L. Wei, D.Q. Li, M.N. Zhuo, Y.S. Liao, Z.Y. Xie, T.L. Guo, J.J. Li, S.Y. Zhang, Z.Q. Liang, Organophosphorus flame retardants and plasticizers: Sources, occurrence, toxicity and human exposure, Environ. Pollut. 196 (2015) 29-46. doi:10.1016/j.envpol.2014.09.012.

[11] K.E. O'Shea, Titanium dioxide-photocatalyzed reactions of organophosphorus compounds in aqueous media, in: Semicond. Photochem. Photophysics, 2003: pp. 231-247. doi:10.1201/9780203912294. 
[12] A. Araki, I. Saito, A. Kanazawa, K. Morimoto, K. Nakayama, E. Shibata, M. Tanaka, T. Takigawa, T. Yoshimura, H. Chikara, Y. Saijo, R. Kishi, Phosphorus flame retardants in indoor dust and their relation to asthma and allergies of inhabitants, Indoor Air. 24 (2014) 3-15. doi:10.1111/ina.12054.

[13] J. Cristale, D.D. Ramos, R.F. Dantas, A. Machulek Junior, S. Lacorte, C. Sans, S. Esplugas, Can activated sludge treatments and advanced oxidation processes remove organophosphorus flame retardants?, Environ. Res. 144 (2016) 11-18. doi:10.1016/j.envres.2015.10.008.

[14] A.M. Sundkvist, U. Olofsson, P. Haglund, Organophosphorus flame retardants and plasticizers in marine and fresh water biota and in human milk, J. Environ. Monit. 12 (2010) 943-951. doi:10.1039/b921910b.

[15] E. Martínez-Carballo, C. González-Barreiro, A. Sitka, S. Scharf, O. Gans, Determination of selected organophosphate esters in the aquatic environment of Austria, Sci. Total Environ. 388 (2007) 290-299. doi:10.1016/j.scitotenv.2007.08.005.

[16] V.D. Ahrens, G.A. Maylin, J.D. Henion, L.E.S. John, D.J. Lisk, Fabric release, fish toxicity and water stability of the flame retardant, fyrol FR-2, Bull. Environ. Contam. Toxicol. 21 (1979) 409-412. doi:10.1007/BF01685445.

[17] C.A. Bunton, D.R. Llewellyn, K.G. Oldham, C.A. Vernon, The reactions of organic phosphates. Part I. The hydrolysis of methyl dihydrogen phosphate, J. Chem. Soc. (1958) 3574-3587. doi:10.1039/JR9580003574.

[18] D. Crump, S. Chiu, S.W. Kennedy, Effects of tris(1,3-dichloro-2-propyl) phosphate and tris(1-chloropropyl) phosphate on cytotoxicity and mRNA expression in primary cultures of avian hepatocytes and neuronal cells, Toxicol. Sci. 126 (2012) 140-148. doi:10.1093/toxsci/kfs015.

[19] J.D. Meeker, E.M. Cooper, H.M. Stapleton, R. Hauser, Urinary metabolites of organophosphate flame retardants: Temporal variability and correlations with house dust concentrations, Environ. Health Perspect. 121 (2013) 580-585. doi:10.1289/ehp.1205907.

[20] P.J. Morris, D. Medina-Cleghorn, A. Heslin, S.M. King, J. Orr, M.M. Mulvihill, R.M. Krauss, D.K. Nomura, Organophosphorus flame retardants inhibit specific liver carboxylesterases and cause serum hypertriglyceridemia, ACS Chem. Biol. 9 (2014) 1097-1103. doi:10.1021/cb500014r.

[21] J. Li, J.P. Giesy, L. Yu, G. Li, C. Liu, Effects of tris(1,3-dichloro-2-propyl) phosphate (TDCPP) in tetrahymena thermophila: Targeting the ribosome, Sci. Rep. 5 (2015) 1-9. doi:10.1038/srep10562. 
[22] Z. Wang, J.C. Dewitt, C.P. Higgins, I.T. Cousins, A never-ending story of per- and polyfluoroalkyl substances (PFASs)?, Environ. Sci. Technol. 51 (2017) 2508-2518. doi:10.1021/acs.est.6b04806.

[23] F. Xiao, Emerging poly- and perfluoroalkyl substances in the aquatic environment: A review of current literature, Water Res. 124 (2017) 482-495. doi:10.1016/j.watres.2017.07.024.

[24] K. Jansen, 'Forever chemicals' no more?, C\&EN Glob. Enterp. 97 (2019) 28-32. doi:10.1021/cen-09712-cover.

[25] N. Quinete, Q. Wu, T. Zhang, S.H. Yun, I. Moreira, K. Kannan, Specific profiles of perfluorinated compounds in surface and drinking waters and accumulation in mussels, fish, and dolphins from southeastern Brazil, Chemosphere. 77 (2009) 863869. doi:10.1016/j.chemosphere.2009.07.079.

[26] X.C. Hu, D.Q. Andrews, A.B. Lindstrom, T.A. Bruton, L.A. Schaider, P. Grandjean, R. Lohmann, C.C. Carignan, A. Blum, S.A. Balan, C.P. Higgins, E.M. Sunderland, Detection of poly- and perfluoroalkyl substances (PFASs) in U.S. drinking Water linked to industrial sites, military fire training areas, and wastewater treatment plants, Environ. Sci. Technol. Lett. 3 (2016) 344-350. doi:10.1021/acs.estlett.6b00260.

[27] M. Sun, E. Arevalo, M. Strynar, A. Lindstrom, M. Richardson, B. Kearns, A. Pickett, C. Smith, D.R.U. Knappe, Legacy and emerging perfluoroalkyl substances are important drinking water contaminants in the Cape Fear river watershed of North Carolina, Environ. Sci. Technol. Lett. 3 (2016) 415-419. doi:10.1021/acs.estlett.6b00398.

[28] N. Yamashita, K. Kannan, S. Taniyasu, Y. Horii, G. Petrick, T. Gamo, A global survey of perfluorinated acids in oceans, Mar. Pollut. Bull. 51 (2005) 658-668. doi:10.1016/j.marpolbul.2005.04.026.

[29] X. Ju, Y. Jin, K. Sasaki, N. Saito, Perfluorinated surfactants in surface, subsurface water and microlayer from Dalian coastal waters in China, Environ. Sci. Technol. 42 (2008) 3538-3542. doi:10.1021/es703006d.

[30] A.M. Calafat, L.Y. Wong, Z. Kuklenyik, J.A. Reidy, L.L. Needham, Polyfluoroalkyl chemicals in the U.S. population: Data from the national health and nutrition examination survey (NHANES) 2003-2004 and comparisons with NHANES 19992000, Environ. Health Perspect. 115 (2007) 1596-1602. doi:10.1289/ehp.10598.

[31] Congress report, Protecting americans at risk of PFAS contamination \& exposure, 2019 (accessed January 07, 2020). 
[32] É. Caron-Beaudoin, P. Ayotte, E.A. Laouan Sidi, N. Gros-Louis McHugh, M. Lemire, Exposure to perfluoroalkyl substances (PFAS) and associations with thyroid parameters in First Nation children and youth from Quebec, Environ. Int. 128 (2019) 13-23. doi:10.1016/j.envint.2019.04.029.

[33] E. Gorrochategui, S. Lacorte, R. Tauler, F.L. Martin, Perfluoroalkylated substance effects in xenopus laevis A6 kidney epithelial cells determined by ATR-FTIR spectroscopy and chemometric analysis, Chem. Res. Toxicol. 29 (2016) 924-932. doi:10.1021/acs.chemrestox.6b00076.

[34] V.M. Vieira, K. Hoffman, H.M. Shin, J.M. Weinberg, T.F. Webster, T. Fletcher, Perfluorooctanoic acid exposure and cancer outcomes in a contaminated community: A geographic analysis, Environ. Health Perspect. 121 (2013) 318-323. doi:10.1289/ehp.1205829.

[35] A.A. Rand, J.P. Rooney, C.M. Butt, J.N. Meyer, S.A. Mabury, Cellular toxicity associated with exposure to perfluorinated carboxylates (PFCAs) and their metabolic precursors, Chem. Res. Toxicol. 27 (2014) 42-50. doi: $10.1021 / \mathrm{tx} 400317 \mathrm{p}$.

[36] DuPont ${ }^{\mathrm{TM}}$, DuPont ${ }^{\mathrm{TM}}$ GenX processing aid for making fluoropolymer resins; setting a new industry standard for sustainable replacement technology, 2010. https://bladenonline.com/wp/content/uploads/2017/06/Chemours_GenX_Brochure _Final_07July2010.pdf (accessed May 18, 2019).

[37] M.I. Gomis, R. Vestergren, D. Borg, I.T. Cousins, Comparing the toxic potency in vivo of long-chain perfluoroalkyl acids and fluorinated alternatives, Environ. Int. 113 (2018) 1-9. doi:10.1016/j.envint.2018.01.011.

[38] NCDEQ, NCDHHS, Secretaries' Science Advisory Board Review of the North Carolina Drinking Water Provisional Health Goal for GenX, 2018. https://files.nc.gov/ncdeq/GenX/SAB/SAB-GenX-Report-DRAFT-082018.pdf (accessed May 18, 2019).

[39] R. Dewil, D. Mantzavinos, I. Poulios, M.A. Rodrigo, New perspectives for advanced oxidation processes, J. Environ. Manage. 195 (2017) 93-99. doi:10.1016/j.jenvman.2017.04.010.

[40] Y. Deng, R. Zhao, Advanced oxidation processes (AOPs) in wastewater treatment, Curr. Pollut. Reports. 1 (2015) 167-176. doi:10.1007/s40726-015-0015-z.

[41] K.G. Linden, M. Mohseni, Advanced oxidation processes: Applications in drinking water treatment, in: Compr. Water Qual. Purif., 2014: pp. 148-172. doi:10.1016/B978-0-12-382182-9.00031-1. 
[42] R. Andreozzi, V. Caprio, A. Insola, R. Marotta, Advanced oxidation processes (AOP) for water purification and recovery, Catal. Today. 53 (1999) 51-59. doi:10.1016/S0920-5861(99)00102-9.

[43] A. Hong, M.E. Zappi, C.H. Kuo, D. Hill, Modeling kinetics of illuminated and dark advanced oxidation processes, J. Environ. Eng. 122 (1996) 58-62. doi:10.1061/(ASCE)0733-9372(1996)122:1(58).

[44] W.H. Glaze, J.W. Kang, D.H. Chapin, The chemistry of water treatment processes involving ozone, hydrogen peroxide and ultraviolet radiation, Ozone Sci. Eng. 9 (1987) 335-352. doi:10.1080/01919518708552148.

[45] M.R. Hoffmann, S. Martin, W. Choi, D.W. Bahnemann, Environmental applications of semiconductor photocatalysis, Chem. Rev. 95 (1995) 69-96. doi:10.1021/cr00033a004.

[46] M. Pelaez, N.T. Nolan, S.C. Pillai, M.K. Seery, P. Falaras, A.G. Kontos, P.S.M. Dunlop, J.W.J. Hamilton, J.A. Byrne, K. O'Shea, M.H. Entezari, D.D. Dionysiou, A review on the visible light active titanium dioxide photocatalysts for environmental applications, Appl. Catal. B Environ. 125 (2012) 331-349. doi:10.1016/j.apcatb.2012.05.036.

[47] H. Al-Ekabi, N. Serpone, E. Pelizzetti, C. Minero, M.A. Fox, R.B. Draper, Kinetic studies in heterogeneous photocatalysis. 2. $\mathrm{TiO}_{2}$-mediated degradation of 4chlorophenol alone and in a three-component mixture of 4-chlorophenol, 2,4dichlorophenol, and 2,4,5-trichlorophenol in air-equilibrated aqueous media, Langmuir. 5 (1989) 250-255. doi:10.1021/la00085a048.

[48] H. Al-Ekabi, N. Serpone, Kinetics studies in heterogeneous photocatalysis. I. Photocatalytic degradation of chlorinated phenols in aerated aqueous solutions over titania supported on a glass matrix, J. Phys. Chem. 92 (1988) 5726-5731. doi:10.1021/j100331a036.

[49] D.F. Ollis, E. Pelizzetti, N. Serpone, Photocatalyzed destruction of water contaminants, Environ. Sci. Technol. 25 (1991) 1522-1529. doi:10.1021/es00021a001.

[50] D. Chatterjee, S. Dasgupta, Visible light induced photocatalytic degradation of organic pollutants, J. Photochem. Photobiol. C Photochem. Rev. 6 (2005) 186-205. doi:10.1016/j.jphotochemrev.2005.09.001.

[51] A.M. Abdullah, K.E. O'Shea, $\mathrm{TiO}_{2}$ photocatalytic degradation of the flame retardant tris (2-chloroethyl) phosphate (TCEP) in aqueous solution: A detailed kinetic and mechanistic study, J. Photochem. Photobiol. A Chem. 377 (2019) 130-137. doi:10.1016/j.jphotochem.2019.03.026. 
[52] 4,920 Search Results - $\operatorname{Keywords}\left(\mathrm{TiO}_{2}\right)$ - ScienceDirect, (n.d.). https://www.sciencedirect.com/search/advanced?qs $=\mathrm{TiO}_{2} \&$ years=2019\&lastSelect edFacet=years (accessed January 19, 2020).

[53] C. Minero, F. Catozzo, E. Pelizzetti, Role of adsorption in photocatalyzed reactions of organic molecules in aqueous titania suspensions, Langmuir. 8 (1992) 481-486. doi:10.1021/la00038a029.

[54] A. Fujishima, T.N. Rao, D.A. Tryk, Titanium dioxide photocatalysis, J. Photochem. Photobiol. C Photochem. Rev. 1 (2000) 1-21. doi:10.1016/S1389-556700002-2.

[55] M.A. Oturan, J.J. Aaron, Advanced oxidation processes in water/wastewater treatment: Principles and applications. A review, Crit. Rev. Environ. Sci. Technol. 44 (2014) 2577-2641. doi:10.1080/10643389.2013.829765.

[56] H. Harada, K. Okitsu, Application of ultrasound in environmental technologies, in: Sonochemistry Acoust. Bubble, Elsevier, 2015: pp. 231-250. doi:10.1016/B978-012-801530-8.00010-4.

[57] N.N. Mahamuni, Y.G. Adewuyi, Advanced oxidation processes (AOPs) involving ultrasound for waste water treatment: A review with emphasis on cost estimation, Ultrason. Sonochem. 17 (2010) 990-1003. doi:10.1016/j.ultsonch.2009.09.005.

[58] N. Serpone, R. Terzian, H. Hidaka, E. Pelizzetti, Ultrasonic induced dehalogenation and oxidation of 2-, 3-, and 4-chlorophenol in air-equilibrated aqueous media. Similarities with irradiated semiconductor particulates, J. Phys. Chem. 98 (1994) 2634-2640. doi:10.1021/j100061a021.

[59] M.R. Hoffmann, I. Hua, R. Höchemer, Application of ultrasonic irradiation for the degradation of chemical contaminants in water, Ultrason. Sonochem. 3 (1996) S163-S172. doi:10.1016/S1350-4177(96)00022-3.

[60] J. González-García, V. Sáez, I. Tudela, M.I. Díez-Garcia, M.D. Esclapez, O. Louisnard, Sonochemical treatment of water polluted by chlorinated organocompounds. A review, Water (Switzerland). 2 (2010) 28-74. doi:10.3390/w2010028.

[61] C. Boo, Y. Wang, I. Zucker, Y. Choo, C.O. Osuji, M. Elimelech, High performance nanofiltration membrane for effective removal of perfluoroalkyl substances at high water recovery, Environ. Sci. Technol. 52 (2018) 7279-7288. doi:10.1021/acs.est.8b01040.

[62] Y. Tsai, A.Y. Lin, Treatment of perfluorinated chemicals by electro-microfiltration, Environ. Sci. Technol. 44 (2010) 7914-7920. doi:10.1021/es101964y. 
[63] X. Xiao, B.A. Ulrich, B. Chen, C.P. Higgins, Sorption of poly- and perfluoroalkyl substances (PFASs) relevant to aqueous film-forming foam (AFFF)-impacted groundwater by biochars and activated carbon, Environ. Sci. Technol. 51 (2017) 6342-6351. doi:10.1021/acs.est.7b00970.

[64] M.J. Weiss-Errico, I. Ghiviriga, K.E. O'Shea, 19F NMR characterization of the encapsulation of emerging perfluoroethercarboxylic acids by cyclodextrins, J. Phys. Chem. B. 121 (2017) 8359-8366. doi:10.1021/acs.jpcb.7b05901.

[65] M. Ateia, M.F. Attia, A. Maroli, N. Tharayil, F. Alexis, D.C. Whitehead, T. Karanfil, Rapid removal of poly- and perfluorinated alkyl substances by poly(ethylenimine)functionalized cellulose microcrystals at environmentally relevant conditions, Environ. Sci. Technol. Lett. 5 (2018) 764-769. doi:10.1021/acs.estlett.8b00556.

[66] W. Ji, L. Xiao, Y. Ling, C. Ching, M. Matsumoto, R.P. Bisbey, D.E. Helbling, W.R. Dichtel, Removal of GenX and perfluorinated alkyl substances from water by amine-functionalized covalent organic frameworks, J. Am. Chem. Soc. 140 (2018) 12677-12681. doi:10.1021/jacs.8b06958.

[67] I. Ross, J. McDonough, J. Miles, P. Storch, P. Thelakkat Kochunarayanan, E. Kalve, J. Hurst, S. S. Dasgupta, J. Burdick, A review of emerging technologies for remediation of PFASs, Remediation. 28 (2018) 101-126. doi:10.1002/rem.21553.

[68] Y.G. Adewu-Yi, Sonochemistry in environmental remediation. 2. Heterogeneous sonophotocatalytic oxidation processes for the treatment of pollutants in water, Environ. Sci. Technol. 39 (2005) 8557-8570. doi:10.1021/es0509127.

[69] H. Kyllönen, P. Pirkonen, M. Nyström, J. Nuortila-Jokinen, A. Grönroos, Experimental aspects of ultrasonically enhanced cross-flow membrane filtration of industrial wastewater, Ultrason. Sonochem. 13 (2006) 295-302. doi:10.1016/j.ultsonch.2005.04.006.

[70] J.M. Löning, C. Horst, U. Hoffmann, Investigations on the energy conversion in sonochemical processes, Ultrason. Sonochem. 9 (2002) 169-179. doi:10.1016/S1350-4177(01)00113-4.

[71] K.S. Suslick, D.A. Hammerton, R.E. Cline, The Sonochemical Hot Spot, J. Am. Chem. Soc. 108 (1986) 5641-5642. doi:10.1021/ja00278a055.

[72] T.J. Mason, Sonochemistry: Current uses and future prospects in the chemical and processing industries, Philos. Trans. R. Soc. A Math. Phys. Eng. Sci. 357 (1999) 355-369. doi:10.1098/rsta.1999.0331.

[73] E.B. Flint, K.S. Suslick, The temperature of cavitation, Science 253 (1991) 13971399. doi:10.1126/science.253.5026.1397. 
[74] R. Xiao, Z. Wei, D. Chen, L.K. Weavers, Kinetics and mechanism of sonochemical degradation of pharmaceuticals in municipal wastewater, Environ. Sci. Technol. 48 (2014) 9675-9683. doi:10.1021/es5016197.

[75] D.K. Kim, K.E. O'Shea, W.J. Cooper, Mechanistic considerations for the degradation of methyl tert-butyl ether (MTBE) by sonolysis: Effect of argon vs. oxygen saturated solutions, Ultrason. Sonochem. 19 (2012) 959-968. doi:10.1016/j.ultsonch.2011.12.003.

[76] A. Hudder, W. Song, K.E. O'Shea, P.J. Walsh, Toxicogenomic evaluation of microcystin-LR treated with ultrasonic irradiation, Toxicol. Appl. Pharmacol. 220 (2007) 357-364. doi:10.1016/j.taap.2007.02.004.

[77] J. Cheng, C.D. Vecitis, H. Park, B.T. Mader, M.R. Hoffmann, Sonochemical degradation of perfluorooctane sulfonate (PFOS) and perfluorooctanoate (PFOA) in groundwater: Kinetic effects of matrix inorganics, Environ. Sci. Technol. 44 (2010) 445-450. doi:10.1021/es902651g.

[78] C.D. Vecitis, Y. Wang, J. Cheng, H. Park, B.T. Mader, M.R. Hoffmann, Sonochemical degradation of perfluorooctanesulfonate in aqueous film-forming foams, Environ. Sci. Technol. 44 (2010) 432-438. doi:10.1021/es902444r.

[79] H. Moriwaki, Y. Takagi, M. Tanaka, K. Tsuruho, K. Okitsu, Y. Maeda, Sonochemical decomposition of perfluorooctane sulfonate and perfluorooctanoic acid, Environ. Sci. Technol. 39 (2005) 3388-3392. doi:10.1021/es040342v.

[80] A.M. Abdullah, K.O'Shea, Ultrasonic degradation of the naled in aqueous solution: Kinetics and mechanistic study, in: 255th ACS Conf. New Orleans, LA, 2018.

[81] E.D. Schreder, M.J. La Guardia, Flame retardant transfers from U.S. households (dust and laundry wastewater) to the aquatic environment, Environ. Sci. Technol. 48 (2014) 11575-11583. doi:10.1021/es502227h.

[82] A. Marklund, B. Andersson, P. Haglund, Organophosphorus flame retardants and plasticizers in Swedish sewage treatment plants, Environ. Sci. Technol. 39 (2005) 7423-7429. doi:10.1021/es0510131.

[83] J. Cristale, A. García Vázquez, C. Barata, S. Lacorte, Priority and emerging flame retardants in rivers: Occurrence in water and sediment, Daphnia magna toxicity and risk assessment, Environ. Int. 59 (2013) 232-243. doi:10.1016/j.envint.2013.06.011.

[84] M. Garcia-Lopez, I. Rodriguez, R. Cela, Development of a dispersive liquid-liquid microextraction method for organophosphorus flame retardants and plasticizers determination in water samples, J. Chromatogr. A. 1166 (2007) 9-15. doi:10.1016/j.chroma.2007.08.006. 
[85] S.D. Kim, J. Cho, I.S. Kim, B.J. Vanderford, S.A. Snyder, Occurrence and removal of pharmaceuticals and endocrine disruptors in South Korean surface, drinking, and waste waters, Water Res. 41 (2007) 1013-1021. doi:10.1016/j.watres.2006.06.034.

[86] P.E. Stackelberg, J. Gibs, E.T. Furlong, M.T. Meyer, S.D. Zaugg, R.L. Lippincott, Efficiency of conventional drinking-water-treatment processes in removal of pharmaceuticals and other organic compounds, Sci. Total Environ. 377 (2007) 255272. doi:10.1016/j.scitotenv.2007.01.095.

[87] N. Serpone, Brief introductory remarks on heterogeneous photocatalysis, Sol. Energy Mater. Sol. Cells. 38 (1995) 369-379. doi:10.1016/0927-0248(94)00230-4.

[88] K. Ishibashi, A. Fujishima, T. Watanabe, K. Hashimoto, Quantum yields of active oxidative species formed on $\mathrm{TiO}_{2}$ photocatalyst, J. Photochem. Photobiol. A Chem. 134 (2000) 139-142.

[89] W.J. Cooper, C.J. Cramer, N.H. Martin, S.P. Mezyk, K.E. O'Shea, C. Von Sonntag, Free radical mechanisms for the treatment of methyl tert-butyl ether (MTBE) via advanced oxidation/reductive processes in aqueous solutions, Chem. Rev. 109 (2009) 1302-1345. doi:10.1021/cr078024c.

[90] K.E. O'Shea, I. Garcia, M. Aguilar, $\mathrm{TiO}_{2}$ photocatalytic degradation of dimethyland diethyl- methylphosphonate, effects of catalyst and environmental factors, Res. Chem. Intermed. 23 (1997) 325-339. doi:10.1163/156856797X00556.

[91] K.E. O’Shea, S. Beightol, I. Garcia, M. Aguilar, D. V. Kalen, W.J. Cooper, Photocatalytic decomposition of organophosphonates in irradiated $\mathrm{TiO}_{2}$ suspensions, J. Photochem. Photobiol. A Chem. 107 (1997) 221-226. doi:10.1016/S1010-6030(96)04420-6.

[92] K.E. O'Shea, Ailette Aguila, K. Vinodgopal, Prashant V. Kamat, Reaction pathways and kinetics parameters of sonolytically induced oxidation of dimethyl methylphosphonate in air-saturated aqueous solutions, Res. Chem. Intermed. 24 (1998) 695-705. doi:10.1163/156856798X00591.

[93] M. Antonopoulou, P. Karagianni, I.K. Konstantinou, Kinetic and mechanistic study of photocatalytic degradation of flame retardant tris (1-chloro-2-propyl) phosphate, Appl. Catal. B Environ. 192 (2016) 152-160. doi:10.1016/j.apcatb.2016.03.039.

[94] X.C. Ruan, R. Ai, X. Jin, Q.F. Zeng, Z.Y. Yang, Photodegradation of tris (2chloroethyl) phosphate in aqueous solution by $\mathrm{UV} / \mathrm{H}_{2} \mathrm{O}_{2}$, Water. Air. Soil Pollut. 225 (2014) 1405-1414. doi:10.1007/s11270-014-2085-8.

[95] M.J. Watts, K.G. Linden, Advanced oxidation kinetics of aqueous trialkyl phosphate flame retardants and plasticizers, Environ. Sci. Technol. 43 (2009) 2937-2942. doi:10.1021/es8031659. 
[96] X. Yuan, S. Lacorte, J. Cristale, R.F. Dantas, C. Sans, S. Esplugas, Z. Qiang, Removal of organophosphate esters from municipal secondary effluent by ozone and $\mathrm{UV} / \mathrm{H}_{2} \mathrm{O}_{2}$ treatments, Sep. Purif. Technol. 156 (2015) 1028-1034. doi:10.1016/j.seppur.2015.09.052.

[97] A. Aguila, K.E. O'Shea, T. Tobien, K.D. Asmus, Reactions of hydroxyl radical with dimethyl methylphosphonate and diethyl methylphosphonate. A fundamental mechanistic study, J. Phys. Chem. A. 105 (2001) 7834-7839. doi:10.1021/jp002367w.

[98] P.W.C. Barnard, C.A. Bunton, D.R. Llewellyn, C.A. Vernon, V.A. Welch, The reactions of organic phosphates. Part V. The hydrolysis of triphenyl and trimethyl phosphates, J. Chem. Soc. (1961) 2670. doi:10.1039/jr9610002670.

[99] F.S. Via, S.Y. Liu, Synthesis of mono-alkyl acid phosphates with high monocontent, US Pat. 4126650. (1978).

[100] F. Benoit-Marquié, C. de Montety, V. Gilard, R. Martino, M.T. Maurette, M. MaletMartino, Dichlorvos degradation studied by 31P-NMR, Environ. Chem. Lett. 2 (2004) 93-97. doi:10.1007/s10311-004-0076-5.

[101] F. Sabin, T. Türk, A. Vogler, Photo-oxidation of organic compound in the presence of titanium dioxide: determination of the efficiency, J. Photochem. Photobiol. A Chem. 63 (1992) 99-106. doi:10.1016/1010-6030(92)85157-P.

[102] E. Pelizzetti, Concluding remarks on heterogeneous solar photocatalysis, Sol. Energy Mater. Sol. Cells. 38 (1995) 453-457. doi:10.1016/0927-0248(94)00237-1.

[103] C. Minero, F. Catozzo, E. Pelizzetti, Role of adsorption in photocatalyzed reactions of organic-molecules in aqueous $\mathrm{TiO}_{2}$ suspensions, Langmuir. 8 (1992) 481-486. doi:10.1021/la00038a029.

[104] W. Adamson, P. Gast, Physical chemistry of surfaces Sixth Edition, 1997. doi:10.1149/1.2133374.

[105] S. Azizian, S. Eris, L.D. Wilson, Re-evaluation of the century-old Langmuir isotherm for modeling adsorption phenomena in solution, Chem. Phys. 513 (2018) 99-104. doi:10.1016/j.chemphys.2018.06.022.

[106] K.E. O'Shea, C. Cardona, Hammett study on the $\mathrm{TiO}_{2}$-catalyzed photooxidation of para-substituted phenols. A kinetic and mechanistic analysis, J. Org. Chem. 59 (1994) 5005-5009. doi:10.1021/jo00096a052.

[107] T. Oncescu, M.I. Stefan, P. Oancea, Photocatalytic degradation of dichlorvos in aqueous $\mathrm{TiO}_{2}$ suspensions, Environ. Sci. Pollut. Res. 17 (2010) 1158-1166. doi:10.1007/s11356-009-0292-4. 
[108] E. Evgenidou, I. Konstantinou, K. Fytianos, T. Albanis, Study of the removal of dichlorvos and dimethoate in a titanium dioxide mediated photocatalytic process through the examination of intermediates and the reaction mechanism, J. Hazard. Mater. 137 (2006) 1056-1064. doi:10.1016/j.jhazmat.2006.03.042.

[109] Y. Ding, K.M. Cawley, C.N. da Cunha, R. Jaffé, Environmental dynamics of dissolved black carbon in wetlands, Biogeochemistry. 119 (2014) 259-273. doi:10.1007/s10533-014-9964-3.

[110] U.I. Gaya, A.H. Abdullah, Heterogeneous photocatalytic degradation of organic contaminants over titanium dioxide: A review of fundamentals, progress and problems, J. Photochem. Photobiol. C Photochem. Rev. 9 (2008) 1-12. doi:10.1016/j.jphotochemrev.2007.12.003.

[111] K.E. O'Shea, E. Pernas, J. Saiers, Influence of mineralization products on the coagulation of $\mathrm{TiO}_{2}$ photocatalyst, Langmuir. 15 (1999) 2071-2076. doi:10.1021/la9806808.

[112] G.A. Poskrebyshev, P. Neta, R.E. Huie, Temperature dependence of the acid dissociation constant of the hydroxyl radical, J. Phys. Chem. A. 106 (2002) 11488 11491. doi:10.1021/jp020239x.

[113] G. V. Buxton, C.L. Greenstock, W.P. Helman, A.B. Ross, Critical review of rate constants for reactions of hydrated electrons, hydrogen atoms and hydroxyl radicals in aqueous solution, J. Phys. Chem. 17 (1988) 513-886. doi:10.1063/1.555805.

[114] S. Schnell, C. Mendoza, The condition for pseudo-first-order kinetics in enzymatic reactions is independent of the initial enzyme concentration, Biophys. Chem. 107 (2004) 165-174. doi:10.1016/j.bpc.2003.09.003.

[115] H. Czili, A. Horváth, Applicability of coumarin for detecting and measuring hydroxyl radicals generated by photoexcitation of $\mathrm{TiO}_{2}$ nanoparticles, Appl. Catal. B Environ. 81 (2008) 295-302. doi:10.1016/j.apcatb.2008.01.001.

[116] R. Daghrir, P. Drogui, D. Robert, Modified $\mathrm{TiO}_{2}$ for environmental photocatalytic applications: A review, Ind. Eng. Chem. Res. 52 (2013) 3581-3599. doi:10.1021/ie303468t.

[117] R. Fagan, D.E. McCormack, D.D. Dionysiou, S.C. Pillai, A review of solar and visible light active $\mathrm{TiO}_{2}$ photocatalysis for treating bacteria, cyanotoxins and contaminants of emerging concern, Mater. Sci. Semicond. Process. 42 (2016) 2-14. doi:10.1016/j.mssp.2015.07.052.

[118] J. Zhang, Y. Nosaka, Mechanism of the $\mathrm{OH}$ radical generation in photocatalysis with $\mathrm{TiO}_{2}$ of different crystalline types, J. Phys. Chem. C. 118 (2014) 10824-10832. doi:10.1021/jp501214m. 
[119] D. Dvoranová, Z. Barbieriková, V. Brezová, Radical intermediates in photoinduced reactions on $\mathrm{TiO}_{2}$ (An EPR spin trapping study), Molecules. 19 (2014) 1727917304. doi:10.3390/molecules191117279.

[120] C. Byrne, G. Subramanian, S.C. Pillai, Recent advances in photocatalysis for environmental applications, J. Environ. Chem. Eng. 6 (2018) 3531-3555. doi:10.1016/j.jece.2017.07.080.

[121] K.I. Ishibashi, A. Fujishima, T. Watanabe, K. Hashimoto, Detection of active oxidative species in $\mathrm{TiO}_{2}$ photocatalysis using the fluorescence technique, Electrochem. Commun. 2 (2000) 207-210. doi:10.1016/S1388-2481(00)00006-0.

[122] R. Fagan, D.E. McCormack, S. Hinder, S.C. Pillai, Improved high temperature stability of anatase $\mathrm{TiO}_{2}$ photocatalysts by N, F, P co-doping, Mater. Des. 96 (2016) 44-53. doi:10.1016/j.matdes.2016.01.142.

[123] C. Zhao, M. Pelaez, D.D. Dionysiou, S.C. Pillai, J.A. Byrne, K.E. O'Shea, UV and visible light activated $\mathrm{TiO}_{2}$ photocatalysis of 6-hydroxymethyl uracil, a model compound for the potent cyanotoxin cylindrospermopsin, Catal. Today. 224 (2014) 70-76. doi:10.1016/j.cattod.2013.09.042.

[124] C. Han, M. Pelaez, V. Likodimos, A. Kontos, P. Falaras, K. O’Shea, D. Dionysiou, Innovative visible light-activated sulfur doped $\mathrm{TiO}_{2}$ films for water treatment, Appl. Catal. B Environ. 107 (2011) 77-87. doi:10.1016/j.apcatb.2011.06.039.

[125] M. Pelaez, P. Falaras, A.G. Kontos, A.A. De la Cruz, K. O'shea, P.S.M. Dunlop, J.A. Byrne, D.D. Dionysiou, A comparative study on the removal of cylindrospermopsin and microcystins from water with $\mathrm{NF}_{-} \mathrm{TiO}_{2}-\mathrm{P} 25$ composite films with visible and UV-vis light photocatalytic activity, Appl. Catal. B Environ. 121-122 (2012) 30-39. doi:10.1016/j.apcatb.2012.03.010.

[126] J.A. Byrne, P.S.M. Dunlop, J.W.J. Hamilton, P. Fernández-Ibáñez, I. Polo-López, P.K. Sharma, A.S.M. Vennard, A review of heterogeneous photocatalysis for water and surface disinfection, Molecules. $20 \quad$ (2015) 5574-5615. doi:10.3390/molecules20045574.

[127] M. Ghosh, J. Liu, S.S.C. Chuang, S.C. Jana, Fabrication of hierarchical $\mathrm{V}_{2} \mathrm{O}_{5}$ nanorods on $\mathrm{TiO}_{2}$ nanofibers and their enhanced photocatalytic activity under visible light, ChemCatChem. 10 (2018) 3305-3318. doi:10.1002/cctc.201800172.

[128] M. Ghosh, M. Lohrasbi, S.S.C. Chuang, S.C. Jana, Mesoporous titanium dioxide nanofibers with a significantly enhanced photocatalytic activity, ChemCatChem. 8 (2016) 2525-2535. doi:10.1002/cctc.201600387.

[129] N.T. Nolan, M.K. Seery, S.J. Hinder, L.F. Healy, S.C. Pillai, A systematic study of the effect of silver on the chelation of formic acid to a titanium precursor and the 
resulting effect on the anatase to rutile transformation of $\mathrm{TiO}_{2}$, J. Phys. Chem. C. 114 (2010) 13026-13034. doi:10.1021/jp1016054.

[130] S. Rajesh Kumar, S.C. Pillai, U.S. Hareesh, P. Mukundan, K.G.K. Warrier, Synthesis of thermally stable, high surface area anatase-alumina mixed oxides, Mater. Lett. 43 (2000) 286-290. doi:10.1016/S0167-577X(99)00275-X.

[131] M.K. Seery, R. George, P. Floris, S.C. Pillai, Silver doped titanium dioxide nanomaterials for enhanced visible light photocatalysis, J. Photochem. Photobiol. A Chem. 189 (2007) 258-263. doi:10.1016/j.jphotochem.2007.02.010.

[132] M.R. Shakil, A.M. El-Sawy, H. Tasnim, A.G. Meguerdichian, J. Jin, J.P. Dubrosky, S.L. Suib, Single-doped and multidoped transition-metal (Mn, Fe, Co, and Ni) ZnO and their electrocatalytic activities for oxygen reduction reaction, Inorg. Chem. 57 (2018) 9977-9987. doi:10.1021/acs.inorgchem.8b01153.

[133] C. McManamon, J. O’Connell, P. Delaney, S. Rasappa, J.D. Holmes, M.A. Morris, A facile route to synthesis of $\mathrm{S}$-doped $\mathrm{TiO}_{2}$ nanoparticles for photocatalytic activity, J. Mol. Catal. A Chem. 406 (2015) 51-57. doi:10.1016/j.molcata.2015.05.002.

[134] X. Hong, Z. Luo, J.D. Batteas, Enhanced visible-light absorption and dopant distribution of iodine- $\mathrm{TiO}_{2}$ nanoparticles synthesized by a new facile two-step hydrothermal method, J. Solid State Chem. 184 (2011) 2244-2249. doi:10.1016/J.JSSC.2011.06.012.

[135] A.E. Giannakas, M. Antonopoulou, Y. Deligiannakis, I. Konstantinou, Preparation, characterization of $\mathrm{N}-\mathrm{I}$ co-doped $\mathrm{TiO}_{2}$ and catalytic performance toward simultaneous $\mathrm{Cr}(\mathrm{VI})$ reduction and benzoic acid oxidation, Appl. Catal. B Environ. 140-141 (2013) 636-645. doi:10.1016/J.APCATB.2013.04.052.

[136] G. Zhang, Y.C. Zhang, M. Nadagouda, C. Han, K. O’Shea, S.M. El-Sheikh, A.A. Ismail, D.D. Dionysiou, Visible light-sensitized S, N, and C co-doped polymorphic $\mathrm{TiO}_{2}$ for photocatalytic destruction of microcystin-LR, Appl. Catal. B Environ. 144 (2014) 614-621. doi:10.1016/j.apcatb.2013.07.058.

[137] F. Wei, L. Ni, P. Cui, Preparation and characterization of N-S-codoped $\mathrm{TiO}_{2}$ photocatalyst and its photocatalytic activity, J. Hazard. Mater. 156 (2008) 135-140. doi:10.1016/J.JHAZMAT.2007.12.018.

[138] J. Yu, M. Zhou, B. Cheng, X. Zhao, Preparation, characterization and photocatalytic activity of in situ N,S-codoped $\mathrm{TiO}_{2}$ powders, J. Mol. Catal. A Chem. 246 (2006) 176-184. doi:10.1016/j.molcata.2005.10.034.

[139] M.V. Dozzi, E. Selli, Doping $\mathrm{TiO}_{2}$ with p-block elements: Effects on photocatalytic activity, J. Photochem. Photobiol. C Photochem. Rev. 14 (2013) 13-28. doi:10.1016/j.jphotochemrev.2012.09.002. 
[140] A.M. Abdullah, T. Debnath, C.H. Rüscher, A. Hussain, Synthesis and Characterization of Vanadium Substituted Potassium Tungsten Bronzes, $\mathrm{K}_{\mathrm{x}} \mathrm{V}_{\mathrm{y}} \mathrm{W}_{1}$ y $\mathrm{O}_{3}$, J. Sci. Res. 4 (2012) 507-514. doi:10.3329/jsr.v4i2.9349.

[141] Z. Yi, J. Ye, N. Kikugawa, T. Kako, S. Ouyang, H. Stuart-Williams, H. Yang, J. Cao, W. Luo, Z. Li, Y. Liu, R.L. Withers, An orthophosphate semiconductor with photooxidation properties under visible-light irradiation, Nat. Mater. 9 (2010) 559564. doi:10.1038/nmat2780.

[142] J.H. Park, S. Kim, A.J. Bard, Novel carbon-doped $\mathrm{TiO}_{2}$ nanotube arrays with high aspect ratios for efficient solar water splitting, Nano Lett. 6 (2006) 24-28. doi:10.1021/n1051807y.

[143] S. Livraghi, M.C. Paganini, E. Giamello, A. Selloni, C. Di Valentin, G. Pacchioni, Origin of photoactivity of nitrogen-doped titanium dioxide under visible light, J. Am. Chem. Soc. 128 (2006) 15666-15671. doi:10.1021/ja064164c.

[144] X. Chen, L. Liu, P.Y. Yu, S.S. Mao, Increasing solar absorption for photocatalysis with black hydrogenated titanium dioxide nanocrystals, Science 331 (2011) 746750. doi:10.1126/science. 1200448 .

[145] Z. Zheng, B. Huang, J. Lu, Z. Wang, X. Qin, X. Zhang, Y. Dai, M.-H. Whangbo, Hydrogenated titania: synergy of surface modification and morphology improvement for enhanced photocatalytic activity, Chem. Commun. 48 (2012) 5733-5735. doi:10.1039/c2cc32220j.

[146] A. Naldoni, M. Allieta, S. Santangelo, M. Marelli, F. Fabbri, S. Cappelli, C.L. Bianchi, R. Psaro, V. Dal Santo, Effect of nature and location of defects on bandgap narrowing in black $\mathrm{TiO}_{2}$ nanoparticles, J. Am. Chem. Soc. 134 (2012) 7600-7603. doi:10.1021/ja3012676.

[147] A. Sinhamahapatra, J.-P. Jeon, J.-S. Yu, A new approach to prepare highly active and stable black titania for visible light-assisted hydrogen production, Energy Environ. Sci. 8 (2015) 3539-3544. doi:10.1039/c5ee02443a.

[148] Z. Wang, C. Yang, T. Lin, H. Yin, P. Chen, D. Wan, F. Xu, F. Huang, J. Lin, X. Xie, M. Jiang, Visible-light photocatalytic, solar thermal and photoelectrochemical properties of aluminium-reduced black titania, Energy Environ. Sci. 6 (2013) 3007 3014. doi:10.1039/c3ee41817k.

[149] H. Tan, Z. Zhao, M. Niu, C. Mao, D. Cao, D. Cheng, P. Feng, Z. Sun, A facile and versatile method for preparation of colored $\mathrm{TiO}_{2}$ with enhanced solar-driven photocatalytic activity, Nanoscale. 6 (2014) 10216-23. doi:10.1039/c4nr02677b.

[150] N. Serpone, G. Sauvé, R. Koch, H. Tahiri, P. Pichat, P. Piccinini, E. Pelizzetti, H. Hidaka, Standardization protocol of process efficiencies and activation parameters 
in heterogeneous photocatalysis: Relative photonic efficiencies $\zeta \mathrm{r}$, J. Photochem. Photobiol. A Chem. 94 (1996) 191-203. doi:10.1016/1010-6030(95)04223-7.

[151] N. Serpone, Relative photonic efficiencies and quantum yields in heterogeneous photocatalysis, J. Photochem. Photobiol. A Chem. 104 (1997) 1-12. doi:10.1016/S1010-6030(96)04538-8.

[152] J.R. Bolton, K.G. Bircher, W. Tumas, C.A. Tolman, Figures-of-merit for the technical development and application of advanced oxidation technologies for both electric- and solar-driven system (IUPAC technical report), Pure Appl. Chem. 73 (2001) 1998-1999. https://www.degruyter.com/downloadpdf/j/pac.2001.73.issue4/pac200173040627/pac200173040627.pdf (accessed May 10, 2019).

[153] A. Mills, S. Morris, Photomineralization of 4-chlorophenol sensitized by $\mathrm{TiO}_{2}$ : a study of the initial kinetics of carbon dioxide photogeneration, J. Photochem. Photobiol. A Chem. 71 (1993) 75-83. doi:10.1016/1010-6030(93)87012-C.

[154] S. Nagarajan, N.C. Skillen, F. Fina, G. Zhang, C. Randorn, L.A. Lawton, J.T.S. Irvine, P.K.J. Robertson, Comparative assessment of visible light and UV active photocatalysts by hydroxyl radical quantification, J. Photochem. Photobiol. A Chem. 334 (2017) 13-19. doi:10.1016/J.JPHOTOCHEM.2016.10.034.

[155] Q. Xiang, J. Yu, P.K. Wong, Quantitative characterization of hydroxyl radicals produced by various photocatalysts, J. Colloid Interface Sci. 357 (2011) 163-167. doi:10.1016/j.jcis.2011.01.093.

[156] The Southern New England Ultraviolet Company, Rayonet - Reactors, 2019. (n.d.). https://rayonet.org/reactors.php?part=RPR-100 (accessed June 5, 2019).

[157] J. Zhang, Y. Nosaka, Quantitative detection of $\mathrm{OH}$ radicals for investigating the reaction mechanism of various visible-light $\mathrm{TiO}_{2}$ photocatalysts in aqueous suspension, J. Phys. Chem. C. 117 (2013) 1383-1391. doi:10.1021/jp3105166.

[158] G.L. Newton, J.R. Milligan, Fluorescence detection of hydroxyl radicals, Radiat. Phys. Chem. 75 (2006) 473-478. doi:10.1016/j.radphyschem.2005.10.011.

[159] C. Byrne, R. Fagan, S. Hinder, D.E. McCormack, S.C. Pillai, New approach of modifying the anatase to rutile transition temperature in $\mathrm{TiO}_{2}$ photocatalysts, $\mathrm{RSC}$ Adv. 6 (2016) 95232-95238. doi:10.1039/c6ra19759k.

[160] N.T. Nolan, M.K. Seery, S.C. Pillai, Spectroscopic investigation of the anatase-torutile transformation of sol-gel-synthesized $\mathrm{TiO}_{2}$ photocatalysts, J. Phys. Chem. C. 113 (2009) 16151-16157. doi:10.1021/jp904358g.

[161] S.C. Pillai, P. Periyat, R. George, D.E. McCormack, M.K. Seery, H. Hayden, J. Colreavy, D. Corr, S.J. Hinder, Synthesis of high-temperature stable anatase $\mathrm{TiO}_{2}$ photocatalyst, J. Phys. Chem. C. 111 (2007) 1605-1611. doi:10.1021/jp065933h. 
[162] P. Periyat, D.E. McCormack, S.J. Hinder, S.C. Pillai, One-pot synthesis of anionic (nitrogen) and cationic (sulfur) codoped high-temperature stable, visible light active, anatase photocatalysts, J. Phys. Chem. C. 113 (2009) 3246-3253. doi:10.1021/jp808444y.

[163] S. Banerjee, S.C. Pillai, P. Falaras, K.E. O'shea, J.A. Byrne, D.D. Dionysiou, New insights into the mechanism of visible light photocatalysis, J. Phys. Chem. Lett. 5 (2014) 2543-2554. doi:10.1021/jz501030x.

[164] N.T. Nolan, D.W. Synnott, M.K. Seery, S.J. Hinder, A. Van Wassenhoven, S.C. Pillai, Effect of N-doping on the photocatalytic activity of sol-gel $\mathrm{TiO}_{2}$, J. Hazard. Mater. 211-212 (2012) 88-94. doi:10.1016/j.jhazmat.2011.08.074.

[165] A.E. Giannakas, E. Seristatidou, Y. Deligiannakis, I. Konstantinou, Photocatalytic activity of $\mathrm{N}$-doped and $\mathrm{N}-\mathrm{F}$ co-doped $\mathrm{TiO}_{2}$ and reduction of chromium(VI) in aqueous solution: An EPR study, Appl. Catal. B Environ. 132-133 (2013) 460-468. doi:10.1016/J.APCATB.2012.12.017.

[166] J. Cai, Z. Huang, K. Lv, J. Sun, K. Deng, Ti powder-assisted synthesis of Ti ${ }^{3+}$ selfdoped $\mathrm{TiO}_{2}$ nanosheets with enhanced visible light photoactivity, RSC Adv. 4 (2014) 19588-19593. doi:10.1039/c4ra01496k.

[167] A. Salamova, Y. Ma, M. Venier, R.A. Hites, High levels of organophosphate flame retardants in the Great Lakes atmosphere, Environ. Sci. Technol. Lett. 1 (2014) 814. doi:10.1021/ez400034n.

[168] R.W. Matthews, S.R. McEvoy, A comparison of $254 \mathrm{~nm}$ and $350 \mathrm{~nm}$ excitation of $\mathrm{TiO}_{2}$ in simple photocatalytic reactors, J. Photochem. Photobiol. A Chem. 66 (1992) 355-366. doi:10.1016/1010-6030(92)80008-J.

[169] S.A. Grieco, B. V. Ramarao, Removal of TCEP from aqueous solutions by adsorption with zeolites, Colloids Surfaces A Physicochem. Eng. Asp. 434 (2013) 329-338. doi:10.1016/j.colsurfa.2013.04.042.

[170] W. Wang, S. Deng, D. Li, L. Ren, D. Shan, B. Wang, J. Huang, Y. Wang, G. Yu, Sorption behavior and mechanism of organophosphate flame retardants on activated carbons, Chem. Eng. J. 332 (2018) 286-292. doi:10.1016/j.cej.2017.09.085.

[171] J.D. Schramm, I. Hua, Ultrasonic irradiation of dichlorvos: Decomposition mechanism, Water Res. 35 (2001) 665-674. doi:10.1016/S0043-1354(00)00304-3.

[172] J.J. Yao, N.Y. Gao, C. Li, L. Li, B. Xu, Mechanism and kinetics of parathion degradation under ultrasonic irradiation, J. Hazard. Mater. 175 (2010) 138-145. doi:10.1016/j.jhazmat.2009.09.140.

[173] D. Cui, A.M. Mebel, L.E. Arroyo-Mora, C. Zhao, A. De Caprio, K. O’Shea, Fundamental study of the ultrasonic induced degradation of the popular 
antihistamine, diphenhydramine (DPH), Water Res. 144 (2018) 265-273. doi:10.1016/j.watres.2018.07.032.

[174] D.K. Kim, Y. He, J. Jeon, K.E. O'Shea, Irradiation of ultrasound to 5methylbenzotriazole in aqueous phase: Degradation kinetics and mechanisms, Ultrason. Sonochem. 31 (2016) 227-236. doi:10.1016/j.ultsonch.2016.01.006.

[175] I. Morozov, S. Gligorovski, P. Barzaghi, D. Hoffmann, Y.G. Lazarou, E. Vasiliev, H. Herrmann, Hydroxyl radical reactions with halogenated ethanols in aqueous solution: Kinetics and thermochemistry, Int. J. Chem. Kinet. (2008). doi:10.1002/kin.20301.

[176] F. Karimi, S. Visser, Zika aerial spraying completed in Miami despite protests CNN, (2016). https://www.cnn.com/2016/09/09/health/florida-zika-sprayingstarts/index.html (accessed February 4, 2019).

[177] E. Bauer, Naled spraying to begin Monday in parts of Miami-Dade | Miami Herald, (2017).https://www.miamiherald.com/news/local/environment/article159166724.ht $\mathrm{ml}$ (accessed September 26, 2019).

[178] US Environmental Protection Agency, Naled for Mosquito Control FAQs, 2016. https://www.epa.gov/sites/production/files/2016/08/documents/naled_web_page_e dits-final_for_pdf.pdf (accessed February 4, 2019).

[179] N.S. Tietze, K.R. Shaffer, P.G. Hester, Half-life of naled under three test scenarios, J. Am. Mosq. Control Assoc. 12 (1996) 251-254.

[180] J.W. Harris, S.L. Richards, A. Anderson, Emergency Mosquito Control on a Selected Area in Eastern North Carolina after Hurricane Irene, Environ. Health Insights. 8 (2014) 29-33. doi:10.4137/ehi.s16001.

[181] Cornell University, Naled, (n.d.).http://pmep.cce.cornell.edu/profiles/extoxnet/ metiram-propoxur/naled-ext.html (accessed September 26, 2019).

[182] M. Mergel, Naled, 2010. http://toxipedia.org/display/toxipedia/Naled (accessed September 27, 2019).

[183] B. Guarino, 'Like it's been nuked': Millions of bees dead after South Carolina sprays for Zika mosquitoes, Washington Post. (2016). https://www.washingtonpost.com/news/morning-mix/wp/2016/09/01/like-its-beennuked-millions-of-bees-dead-after-south-carolina-sprays-for-zika-mosquitoes/ (accessed January 22, 2020).

[184] Q. Gan, R.M. Singh, U. Jans, Degradation of Naled and Dichlorvos promoted by reduced sulfur species in well-defined anoxic aqueous solutions, Environ. Sci. Technol. 40 (2006) 778-783. doi:10.1021/es051482n. 
[185] A.M. Abdullah, K.E. O'Shea, Hydrolysis of the Zika pesticide naled: Kinetics and mechanistic investigation, in: 255th ACS Conf. New Orleans, LA, 2018.

[186] A.J. Kirby, M. Younas, The reactivity of phosphate esters. Diester hydrolysis, J. Chem. Soc. (1970) 510-514. doi:10.1007/s10311-004-0076-5.

[187] A.J. Kirby, A.G. Varvoglis, The reactivity of phosphate esters. Monoester Hydrolysis, J. Am. Chem. Soc. 89 (1967) 415-423. doi:10.1021/ja00978a044.

[188] G. Su, R.J. Letcher, H. Yu, Organophosphate flame retardants and plasticizers in aqueous solution: PH-dependent hydrolysis, kinetics, and pathways, Environ. Sci. Technol. 50 (2016) 8103-8111. doi:10.1021/acs.est.6b02187.

[189] T. Wu, Q. Gan, U. Jans, Nucleophilic substitution of phosphorothionate ester pesticides with bisulfide (HS-) and polysulfides (Sn2-), Environ. Sci. Technol. 40 (2006) 5428-5434. doi:10.1021/es060711i.

[190] P.W.C. Barnard, C.A. Bunton, D. Kellerman, M.M. Mhala, B. Silver, C.A. Vernon, V.A. Welch, Reactions of organic phosphates. Part VI. The hydrolysis of aryl phosphates, J. Chem. Soc. B Phys. Org. (1966) 227-235. doi:10.1039/J29660000227.

[191] A.J. Kirby, M. Younas, The reactivity of phosphate esters. Reactions of diesters with nucleophiles, J. Chem. Soc. B Phys. Org. (1970) 1165. doi:10.1039/j29700001165.

[192] A.J. Kirby, A.G. Varvoglis, The Reactivity of phosphate esters. Monoester hydrolysis, J. Am. Chem. Soc. 89 (1967) 415-423. doi:10.1021/ja00978a044.

[193] A.M. Abdullah, K.E. O'Shea, Ultrasonic degradation of the flame retardant tris (2chloroethyl) phosphate (TCEP) in aqueous solution: Kinetics and mechanistic investigation, in: 257th ACS Conf. Orlando, FL, 2019.

[194] N. Quinete, Q. Wu, T. Zhang, S.H. Yun, I. Moreira, K. Kannan, Specific profiles of perfluorinated compounds in surface and drinking waters and accumulation in mussels, fish, and dolphins from southeastern Brazil, Chemosphere. 77 (2009) 863869. doi:10.1016/j.chemosphere.2009.07.079.

[195] T.D. Appleman, C.P. Higgins, O. Quiñones, B.J. Vanderford, C. Kolstad, J.C. Zeigler-Holady, E.R.V. Dickenson, Treatment of poly- and perfluoroalkyl substances in U.S. full-scale water treatment systems, Water Res. 51 (2014) 246255. doi:10.1016/j.watres.2013.10.067.

[196] J. Byrne, P. Dunlop, J. Hamilton, P. Fernández-Ibáñez, I. Polo-López, P. Sharma, A. Vennard, A review of heterogeneous photocatalysis for water and surface disinfection, Molecules. 20 (2015) 5574-5615. doi:10.3390/molecules20045574. 
[197] D. Cui, A.M. Abdullah, J. Peller, S.P. Mezyk, P. V. Kamat, K.E. O’Shea, A comparison of radiolysis, $\mathrm{TiO}_{2}$ photocatalysis and sonolysis of GenX, in: 257th ACS Conf. Orlando, FL, 2019.

[198] T.A. Bruton, D.L. Sedlak, Treatment of aqueous film-forming foam by heatactivated persulfate under conditions representative of in situ chemical oxidation, Environ. Sci. Technol. 51 (2017) 13878-13885. doi:10.1021/acs.est.7b03969.

[199] M.J. Bentel, Y. Yu, L. Xu, Z. Li, B.M. Wong, Y. Men, J. Liu, Defluorination of perand polyfluoroalkyl substances (PFASs) with hydrated electrons: Structural dependence and implications to PFAS remediation and management, Environ. Sci. Technol. 53 (2019) 3718-3728. doi:10.1021/acs.est.8b06648.

[200] Y. Bao, S. Deng, X. Jiang, Y. Qu, Y. He, L. Liu, Q. Chai, M. Mumtaz, J. Huang, G. Cagnetta, G. Yu, Degradation of PFOA substitute: GenX (HFPO-DA ammonium salt): oxidation with UV/persulfate or reduction with UV/sulfite?, Environ. Sci. Technol. 52 (2018) 11728-11734. doi:10.1021/acs.est.8b02172.

[201] N.N. Mahamuni, Y.G. Adewuyi, Advanced oxidation processes (AOPs) involving ultrasound for wastewater treatment: A review with emphasis on cost estimation, Ultrason. Sonochem. 17 (2010) 990-1003. doi:10.1016/j.ultsonch.2009.09.005.

[202] C.D. Vecitis, H. Park, J. Cheng, B.T. Mader, M.R. Hoffmann, Kinetics and mechanism of the sonolytic conversion of the aqueous perfluorinated surfactants, perfiuorooctanoate (PFOA), and perfluorooctane sulfonate (PFOS) into inorganic Products, J. Phys. Chem. A. 112 (2008) 4261-4270. doi:10.1021/jp801081y.

[203] D. Cui, A.M. Mebel, L.E. Arroyo-Mora, H. Holness, K.G. Furton, K. O’Shea, Kinetic, product, and computational studies of the ultrasonic induced degradation of 4-methylcyclohexanemethanol (MCHM), Water Res. 126 (2017) 164-171. doi:10.1016/j.watres.2017.09.005.

[204] K. Okitsu, K. Iwasaki, Y. Yobiko, H. Bandow, R. Nishimura, Y. Maeda, Sonochemical degradation of azo dyes in aqueous solution: a new heterogeneous kinetics model taking into account the local concentration of $\mathrm{OH}$ radicals and azo dyes, Ultrason. $\quad$ Sonochem. $12 \quad$ (2005) 255-262. doi:10.1016/J.ULTSONCH.2004.01.038.

[205] C.D. Vecitis, H. Park, J. Cheng, B.T. Mader, M.R. Hoffmann, Enhancement of perfluorooctanoate and perfluorooctanesulfonate activity at acoustic cavitation bubble interfaces, J. Phys. Chem. C. 112 (2008) 16850-16857. doi:10.1021/jp804050p. 
VITA

\section{A. M. ABDULLAH}

July 01, 1982

2000-2006

2007-2008

2008-2014

$2014-2020$

2014-2019

2018-2019

2018-2019

2019-2020

2019-2020
Born, Kishoreganj, Bangladesh

B.Sc., Chemistry

University of Dhaka, Dhaka, Bangladesh

MS, Analytical and Inorganic Chemistry

University of Dhaka, Dhaka, Bangladesh

Senior Scientific Officer and Scientific Officer

Bangladesh Council of Scientific and Industrial Research

Dhaka, Bangladesh

Doctorate in Chemistry

Florida International University, Miami, Florida

Teaching and Research Assistant

Florida International University, Miami, Florida

Exemplary Service Award

CASE, Florida International University, Miami, Florida

Ph.D. Graduate Student Award

Environmental Chemistry, American Chemical Society

Best Poster Award

$15^{\text {th }}$ annual LC-MS/MS workshop, Miami, Florida

Dissertation Year Fellowship

Florida International University, Miami, Florida

\section{PUBLICATIONS AND PRESENTATIONS}

1. A.M. Abdullah, Kevin $\mathrm{O}^{\prime}$ Shea, $\mathrm{TiO}_{2}$ photocatalytic degradation of the flame retardant tris (2-chloroethyl) phosphate (TCEP) in aqueous solution: A detailed kinetic \& mechanistic study, J Photochem. Photobiol. C: Chem. 2019, 377, 130-137

2. A.M. Abdullah, Miguel Gracia-Pinilla, Suresh Pillai, Kevin O'Shea, UV and visiblelight-driven production of hydroxyl radicals by reduced forms of N, F, and F codoped titanium dioxide, Molecules 2019, 24(11), 2147-2162 
3. A.M. Abdullah, Natalia S. Quinete, Piero Gardinali, Kevin O'Shea, Kinetic and mechanistic investigation on ultrasonic degradation of the flame retardant (TCEP) in aqueous solution. 15th Annual LC-MS/MS Workshop, Miami, FL, May 29- 31, 2019

4. A.M. Abdullah, Natalia S. Quinete, Piero Gardinali, Kevin O'Shea, Remediation of perfluoroalkyl substances (PFAS) in water by ultrasonic irradiation. 15th Annual LCMS/MS Workshop, Miami, FL, May 29-May 31, 2019

5. A.M. Abdullah, Natalia S. Quinete, Kevin O'Shea, Degradation of perfluoroalkyl substances (PFAS) in water by ultrasonic irradiation. 257th ACS National Meeting \& Exposition, Orlando, FL, Mar 31-Apr 4, 2019

6. A.M. Abdullah, Kevin O'Shea, Ultrasonic degradation of the flame retardant tris (2chloroethyl) phosphate (TCEP) in aqueous solution: Kinetics and mechanistic investigation. ACS National Meeting \& Exposition, Orlando, FL, Mar 31-Apr 4, 2019

7. Danni Cui, A.M. Abdullah, Julie Peller, Stephen P. Mezyk, Prashant Kamat, Kevin O'Shea, A comparison of radiolysis, $\mathrm{TiO}_{2}$ photocatalysis, and sonolysis of GenX. 257th ACS National Meeting \& Exposition, Orlando, FL, Mar 31-Apr 4, 2019

8. A.M. Abdullah, Kevin. O'Shea, Hydrolysis of Zika pesticide Naled: Kinetics and mechanistic investigation, 255th ACS National Meeting \& Exposition, New Orleans, LA, Mar 18-22, 2018

9. A.M. Abdullah, Kevin O'Shea, Ultrasonic degradation of Zika pesticide Naled in aqueous solution: Kinetics and mechanistic investigation. 255th ACS National Meeting \& Exposition, New Orleans, LA, Mar 18-22, 2018

10. A.M. Abdullah, Kevin O'Shea; Kinetic and mechanistic investigation on $\mathrm{TiO}_{2}$ photocatalytic degradation of the flame retardant tris (2-chloroethyl) phosphate in aqueous solution. 23th Int. Conf. on AOTs for Treatment of Water, Air and Soil, Clearwater Beach, FL, Nov 13-16, 2017

11. A.M. Abdullah, Miguel A. Gracia-Pinilla, Kevin O'Shea, UV and visible light photocatalytic production of hydroxyl radical by reduced forms of titanium oxide. 22th Int. Conf. on Semiconductor Photocatalysis \& Solar Energy Conversion (SPASEC), Clearwater Beach, FL, Nov 13-16, 2017

12. A.M. Abdullah, Kevin O'Shea; Kinetic and mechanistic investigation on $\mathrm{TiO}_{2}$ photocatalytic degradation of the flame retardant tris (2-chloroethyl) phosphate in aqueous solution. 93rd FAME Meeting, Tampa, FL, May 4-6, 2017

13. A.M. Abdullah, Kevin $\mathrm{O}^{\prime}$ Shea, $\mathrm{TiO}_{2}$ photocatalytic degradation of the flame retardant tris (2-chloroethyl) phosphate: Kinetic and mechanistic studies. 253rd ACS National Meeting \& Exposition, San Francisco, CA, Apr 2-6, 2017 